\title{
ipen
}

AUTARQUIA ASSOCIADA Á UNIVERSIDADE DE SÃO PAULO

DETERMINAÇÃO DA CONCENTRAÇÃO DE ENTRADA DOS GASES DE EFEITO ESTUFA NA COSTA NORTE/NORDESTE BRASILEIRA

VIVIANE FRANCISCA BORGES

Dissertação apresentada como parte dos requisitos para a obtenção do Grau de Mestre em Ciências na Área de Tecnologia Nuclear - Materiais

Orientadora:

Profa. Dra. Luciana Vanni Gatti 
INSTITUTO DE PESQUISAS ENERGÉTICAS E NUCLEARES

Autarquia Associada à Universidade De São Paulo

\section{DETERMINAÇÃO DA CONCENTRAÇÃO DE ENTRADA DOS GASES DE EFEITO ESTUFA NA COSTA NORTE/NORDESTE BRASILEIRA}

VIVIANE FRANCISCA BORGES

Dissertação apresentada como parte dos requisitos para a obtenção do Grau de Mestre em Ciências na Área de Tecnologia Nuclear - Materiais

Orientadora:

Profa. Dra. Luciana Vanni Gatti

Versão Corrigida

Versão Original disponível no IPEN

São Paulo

2013 
Dedico este trabalho aos meus pais, Eulanda e Jorge...

Que me deram o dom da vida... E assim, através da longa jornada pude chegar até aqui... 


\section{AGRADECIMENTOS}

Primeiramente, gostaria de agradecer a Deus por toda proteção em minha vida, permitindo que eu pudesse obter mais uma conquista acadêmica.

Agradeço a minha mãe, Eulanda e ao meu pai, Jorge, que me deram muito além do dom da vida, eles me educaram e me ensinaram que sempre é necessário em todos os momentos da vida o respeito, a sinceridade e a responsabilidade por nossas escolhas. À minha irmã Bianca mesmo com a distância que sempre torceu por mim.

Ao meu amor, amigo, companheiro e marido, Mauro, pela compreensão, carinho, amor e dedicação, sempre me apoiando e ajudando quando possível para que eu pudesse realizar este trabalho.

À minha orientadora Dra. Luciana Vanni Gatti, pela oportunidade de realização deste trabalho, pela orientação, apoio, compreensão e amizade.

Às agências, NERC/AMAZÔNICA pelo apoio financeiro na realização dos estudos na Bacia Amazônica e Costa Brasileira e à FAPESP, pela bolsa concedida durante todo o período do mestrado.

Agradeço a valorosa colaboração da Marinha do Brasil, 4ํ Distrito Naval do Rádio Farol de Salinópolis e da equipe local pela realização das coletas e apoio. Agradeço também a valorosa colaboração de Francisco, Tércio e equipe do INPE/CRN pela disponibilidade, apoio e realização das coletas.

Ao IPEN e ao CQMA pela infraestrutura para a realização do projeto.

Aos amigos e colegas do LQA, pelo apoio e colaboração na realização deste trabalho, Alexandre, Ana Maria, Angélica, Caio, Carlos, Débora, Juan, Juliana, Karen, Luana, Lucas e Maria Helena.

A todos os colegas e as amizades construídas ao longo de minha vida, pela torcida para atingir este objetivo de aprimoramento acadêmico. 


\title{
DETERMINAÇÃO DA CONCENTRAÇÃO DE ENTRADA DOS GASES DE EFEITO ESTUFA NA BACIA AMAZÔNICA
}

\author{
Viviane Francisca Borges
}

\section{RESUMO}

Este estudo teve como objetivo a determinação da concentração de entrada dos Gases de Efeito Estufa (GEE) no ar proveniente do Oceano Atlântico na região norte/nordeste da costa brasileira e o entendimento da origem destas massas de ar e o padrão circulatório e sua sazonalidade. Esta parte do litoral corresponde à área em que as massas de ar adentram no continente, antes de chegar à Bacia Amazônica. Em 2010 foram iniciados estudos em dois locais na costa, Salinópolis, no estado do Pará e Natal, no Rio Grande do Norte. Amostras de ar foram coletadas em superfície semanalmente e foram analisadas no Laboratório de Química Atmosférica do IPEN, quantificando-se os gases: dióxido de carbono $\left(\mathrm{CO}_{2}\right)$, metano $\left(\mathrm{CH}_{4}\right)$, óxido nitroso $\left(\mathrm{N}_{2} \mathrm{O}\right)$, hexafluoreto de enxofre $\left(\mathrm{SF}_{6}\right)$ e monóxido de carbono (CO). Os resultados obtidos mostraram que Salinópolis (SAL) apresenta maior sazonalidade, entre as estações climáticas, quando comparada a Natal (NAT), sendo essa observação confirmada pelas trajetórias retrocedentes das massas de ar, para cada local de estudo. Observou-se que SAL recebe massas de ar, tanto do Oceano Atlântico Norte, como do Sul (dependendo da época do ano), e em NAT, as massas de ar são originárias apenas do Oceano Atlântico Sul. Este comportamento está relacionado com a zona de convergência intertropical. Os resultados de uma maneira geral mostram a ocorrência de um crescimento nas concentrações médias obtidas em SAL e NAT com o passar dos anos, acompanhando o crescimento mundial. A concentração média para o principal GEE, $\mathrm{CO}_{2}$, em SAL nos anos de 2010, 2011 e 2012 foi de 388,01, 390,39 e 392,14 ppm, respectivamente, e em NAT foi de $388,59,389,65$ e 392,59 ppm respectivamente. 


\title{
DETERMINATION OF THE BACKGROUND GREENHOUSE GASES CONCENTRATIONS IN AMAZON BASIN
}

\author{
Viviane Francisca Borges
}

\begin{abstract}
This study had the objective to determinate the background concentrations of Greenhouse Gases in the air from Atlantic Ocean in the north/northeast region of the Brazilian coast and understanding the origin of these air masses and circulatory pattern and seasonality. This region of the coast corresponds to the zone where the air masses pass through before to arrive in Amazon Basin. Studies were started in 2010, in two sites of the coast, Salinópolis in Pará state and Natal in Rio Grande do Norte state. The air samplings were performed on the surface weekly and analysed in the Atmospheric Chemistry Laboratory of IPEN, quantifying concentrations of the gases: Carbon dioxide $\left(\mathrm{CO}_{2}\right)$, Methane $\left(\mathrm{CH}_{4}\right)$, Nitrous oxide $\left(\mathrm{N}_{2} \mathrm{O}\right)$, Sulfur hexafluoride $\left(\mathrm{SF}_{6}\right)$ and Carbon monoxide (CO). The obtained results showed that Salinópolis (SAL) have higher seasonality, among climatic seasons, in comparison to Natal (NAT), being this observation confirmed by backward trajectories of air masses to each studied site. SAL received air masses from the North and South Atlantic Ocean, and NAT the air masses arrived only from the South Atlantic Ocean. This behavior, is related with the intertropical convergence zone position. The results, in general, showed an increase of mean GHG concentrations in SAL and NAT along the years, following global growth. The mean concentration of the main $\mathrm{GHG}, \mathrm{CO}_{2}$, in $\mathrm{SAL}$ to 2010, 2011 and 2012 was $388.01,390.39$ and 392.14 ppm, respectively, and in NAT it was $388.59,389.65$ e 392.59 ppm, respectively.
\end{abstract}




\section{SUMÁRIO}

\section{Página}

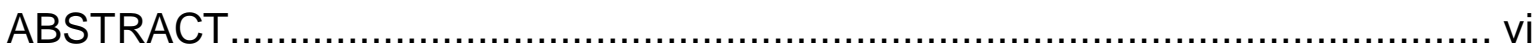

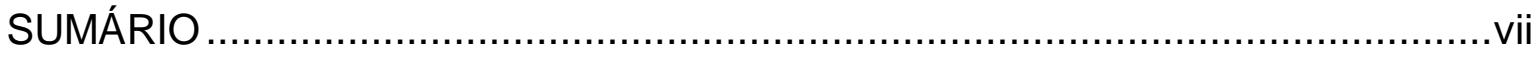

LISTA DE TABELAS ......................................................................... ix

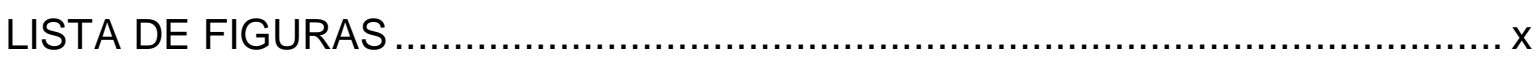

LISTA DE ABREVIATURAS E/OU SIGLAS .......................................... xV

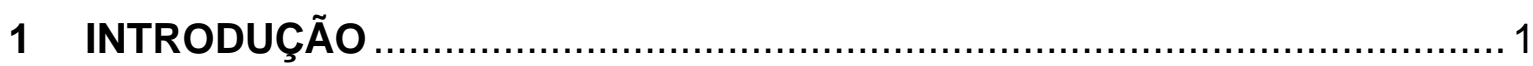

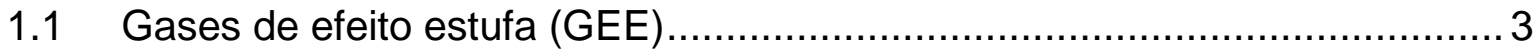

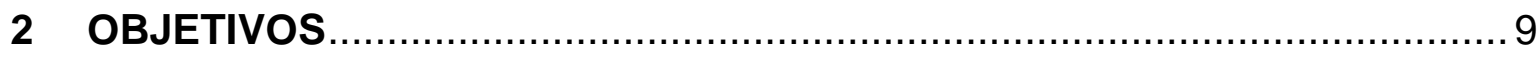

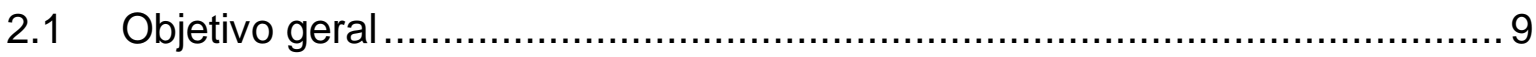

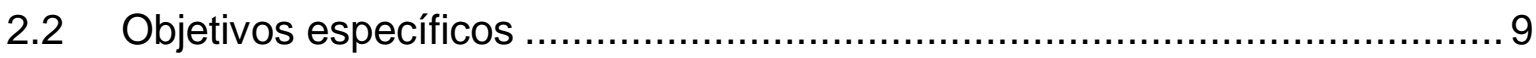

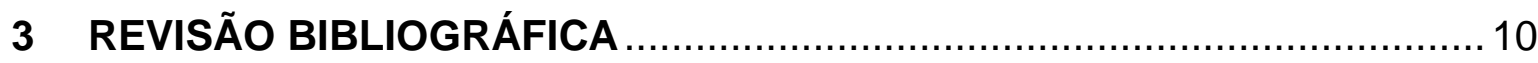

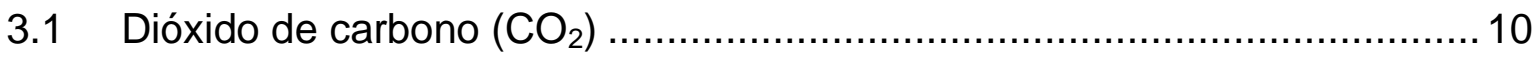

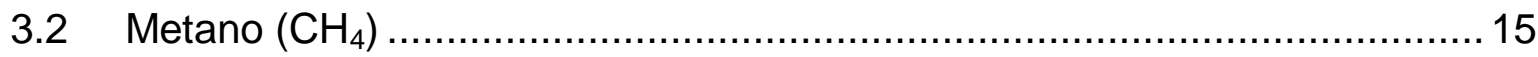

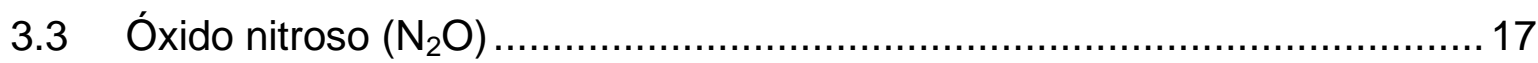

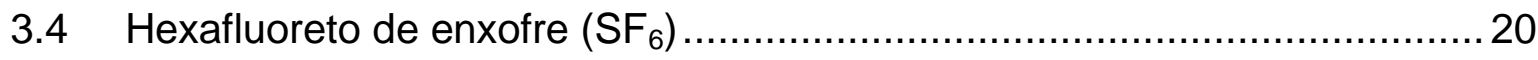

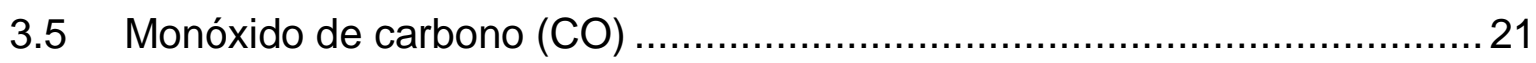

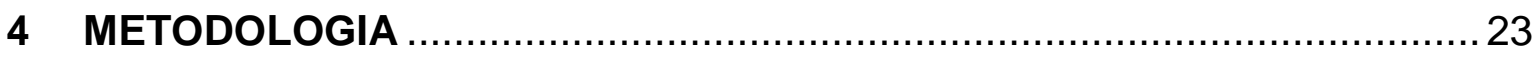

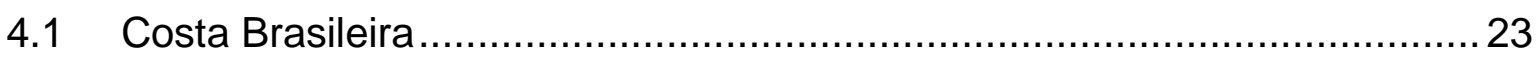

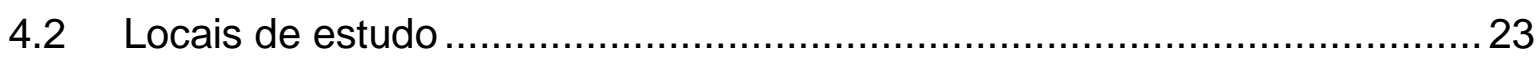

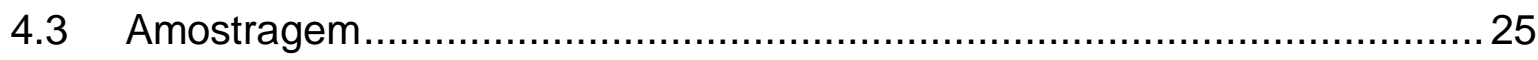

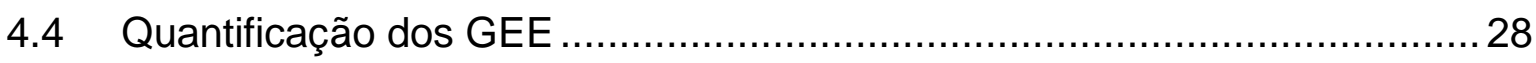

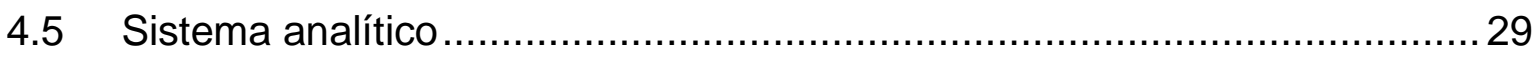

4.6 Precisão e Acurácia dos resultados ....................................................... 34 


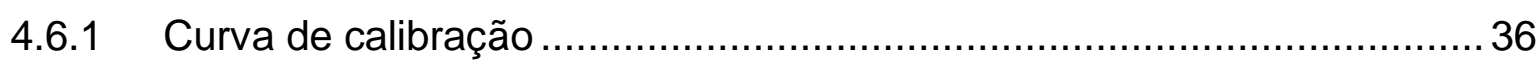

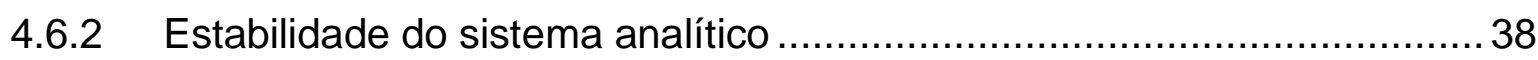

4.7 Simulação das trajetórias das massas de ar ...............................................39

4.8 Formas de análise de dados ................................................................. 40

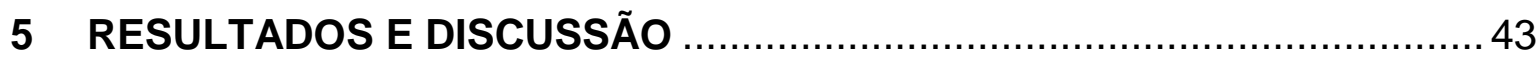

5.1 Análise da qualidade das amostragens de ar em SAL e NAT ....................43

5.2 Avaliação dos resultados dos GEE medidos em SAL ................................45

5.2.1 Análise das trajetórias das massas de ar que chegaram a SAL ............... 45

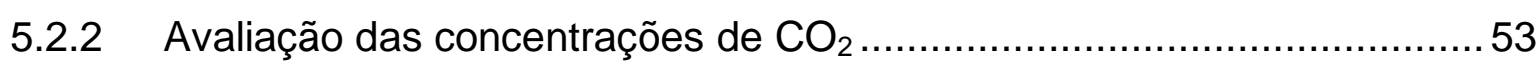

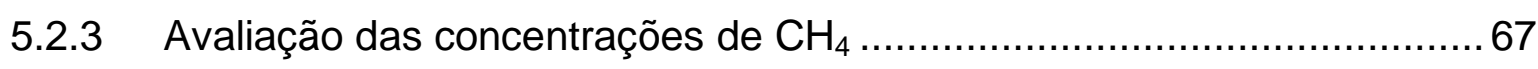

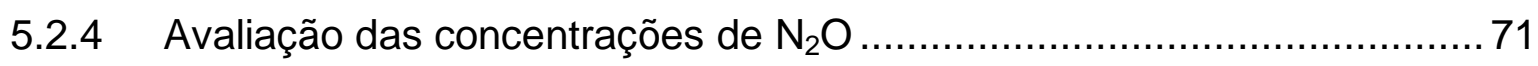

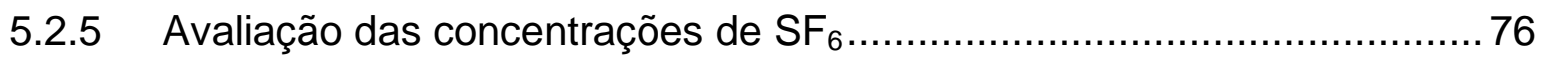

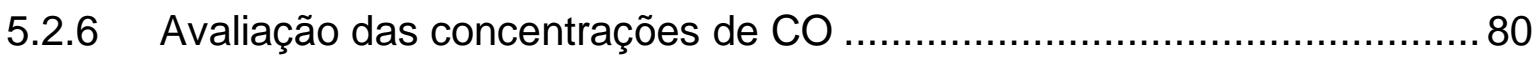

5.3 Avaliação dos resultados dos GEE medidos em NAT ............................... 85

5.3.1 Análise das trajetórias das massas de ar que chegaram a NAT ..............85

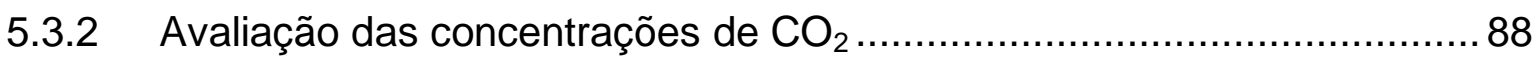

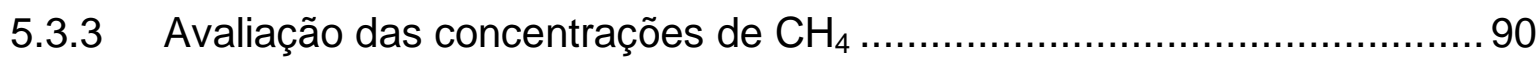

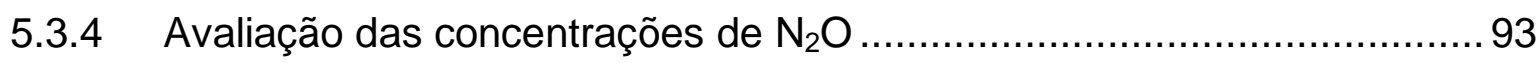

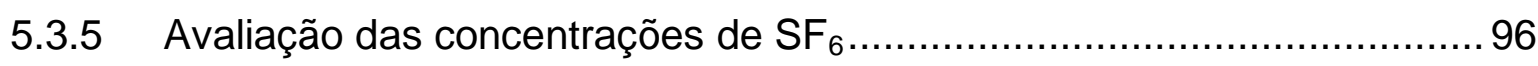

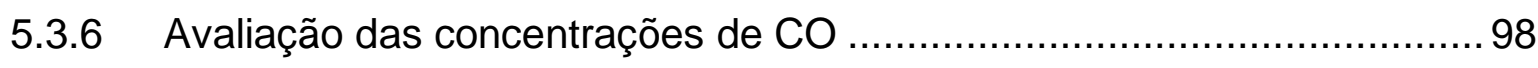

5.3.7 Intercomparação das concentrações entre NAT/IPEN e NAT/NOAA .... 101

5.4 Comparação das concentrações dos GEE entre SAL e NAT .................... 103

5.5 Comparação das concentrações de SAL e NAT com a concentração de

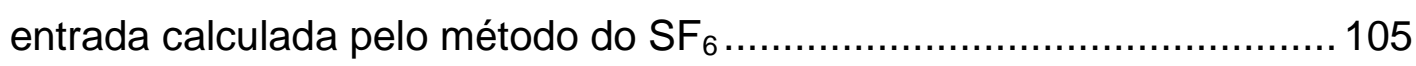

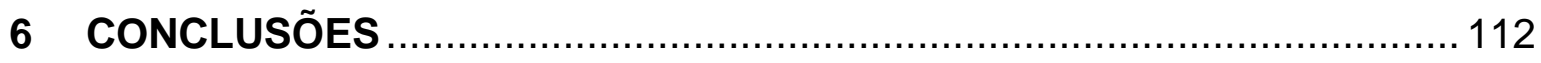

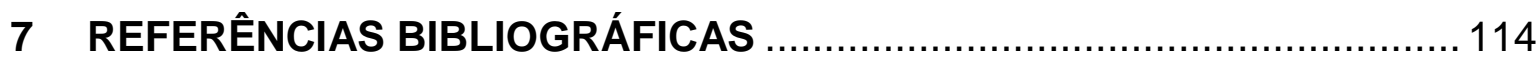




\section{LISTA DE TABELAS}

\section{Página}

Tabela 1: PAG e tempo de vida na atmosfera dos principais GEE 6

Tabela 2: Concentrações dos principais GEE, observações da WMO ....................6

Tabela 3: Coordenadas dos locais de estudo e das estações globais da NOAA..24

Tabela 4: Concentrações dos padrões das curvas de calibração de $\mathrm{CO}$ e $\mathrm{N}_{2} \mathrm{O}$...37

Tabela 5: Concentrações dos padrões para a curva de calibração do $\mathrm{CO}_{2} \ldots \ldots . . .37$

Tabela 6: Precisão dos gases analisados no laboratório de GEE da GMD / ESRL

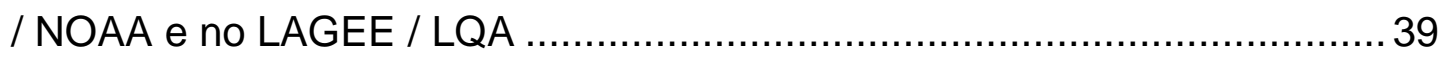

Tabela 7: Quantidade de amostras coletadas em cada local de estudo 43

Tabela 8: Frequência observada entre os pares de frascos de SAL e NAT para

todos os anos de estudos .44

Tabela 9: Concentração média anual de $\mathrm{CO}_{2}$ em SAL .......................................54

Tabela 10: Concentração média de $\mathrm{CO}_{2}$ por período em SAL ..............................65

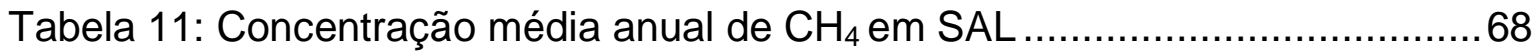

Tabela 12: Concentração média de $\mathrm{CH}_{4}$ por período em SAL..............................70

Tabela 13: Concentração média anual de $\mathrm{N}_{2} \mathrm{O}$ em SAL...................................... 72

Tabela 14: Concentração média de $\mathrm{N}_{2} \mathrm{O}$ por período em $\mathrm{SAL}$..............................75

Tabela 15: Concentração média anual de $\mathrm{SF}_{6}$ em SAL.....................................77

Tabela 16: Concentração média de $\mathrm{SF}_{6}$ por período em $\mathrm{SAL}$..............................79

Tabela 17: Concentração média anual de CO em SAL ..................................... 82

Tabela 18: Concentração média anual de $\mathrm{CO}_{2}$ em NAT ..................................... 89

Tabela 19: Concentração média anual de $\mathrm{CH}_{4}$ em NAT ......................................91

Tabela 20: Concentração média de $\mathrm{CH}_{4}$ por período em NAT .............................93

Tabela 21: Concentração média anual de $\mathrm{N}_{2} \mathrm{O}$ em NAT ......................................94

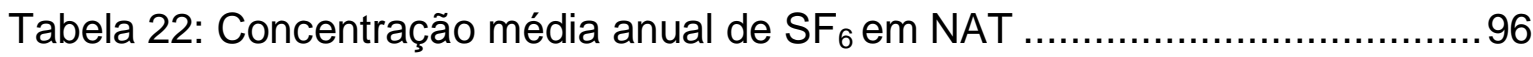

Tabela 23: Concentração média anual de CO em NAT .........................................99

Tabela 24: Concentração média de CO por período em NAT ............................101

Tabela 25: Frequência observada entre a diferença das concentrações médias entre NAT / IPEN e NAT / NOAA, para todos os anos de estudos.............. 102

Tabela 26: Concentrações médias dos GEE em SAL e NAT ..............................104 


\section{LISTA DE FIGURAS}

\section{Página}

Figura 1: Balanço radiativo sem o efeito estufa e com o efeito estufa ....................2

Figura 2: Média anual global do balanço de energia da Terra (2000-2010) ........... 3

Figura 3: Variações de deutério e concentrações de $\mathrm{CO}_{2}, \mathrm{CH}_{4}$ e $\mathrm{N}_{2} \mathrm{O} \ldots \ldots \ldots \ldots \ldots \ldots . . . . .4$

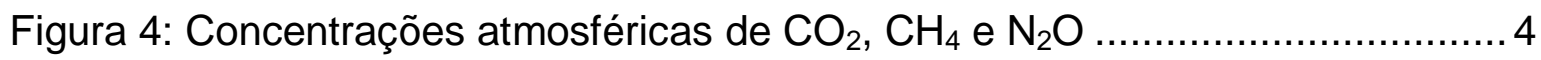

Figura 5: Principais componentes da forçante radiativa ..................................... 5

Figura 6: Rede de monitoramento das estações da WMO .................................

Figura 7: Locais de estudos na Bacia Amazônica e costa brasileira...................... 8

Figura 8: Trajetórias das massas de ar em: (a) TAB, (b) SAN, (c) RBA e (d) ALF . 8

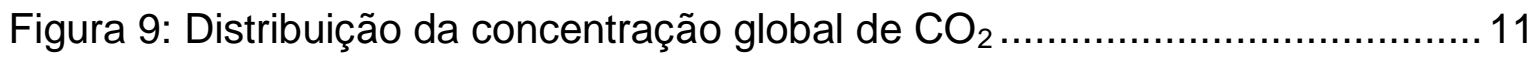

Figura 10: Média mensal das concentrações de $\mathrm{CO}_{2}$ e a sua tendência ................11

Figura 11: Contribuição das emissões globais dos GEE por setor ....................... 12

Figura 12: Média mensal global da concentração de $\mathrm{CO}_{2}$ e taxa de crescimento

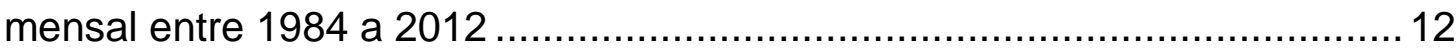

Figura 13: (a) Emissões globais de $\mathrm{CO}_{2}$ por tipo de combustível, (b) emissão global de $\mathrm{CO}_{2}$ a partir de combustível fóssil e cimento e (c) pela mudança

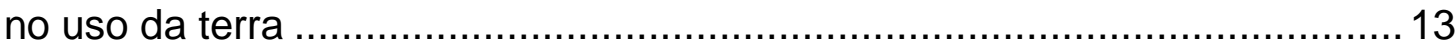

Figura 14: População mundial e estimativa entre 1914 a 2050 ........................... 13

Figura 15: Emissões de $\mathrm{CO}_{2}$ por setor no ano de 2005 e $2010 \ldots \ldots \ldots \ldots \ldots \ldots \ldots \ldots . . . .14$

Figura 16: Taxa de desmatamento anual na Amazônia legal entre 1988 a 2012.14

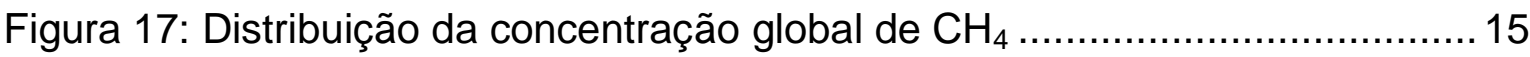

Figura 18: Média mensal das concentrações de $\mathrm{CH}_{4}$ e a sua tendência............... 16

Figura 19: Média mensal global da concentração de $\mathrm{CH}_{4}$ e taxa de crescimento

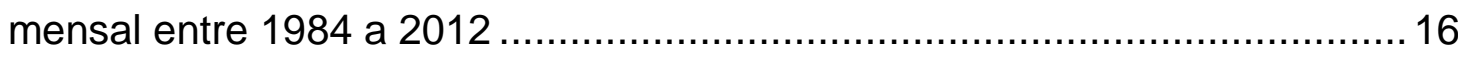

Figura 20: Emissões de $\mathrm{CH}_{4}$ por setor no ano de 2005 e 2010 .......................... 17

Figura 21: Distribuição da concentração global de $\mathrm{N}_{2} \mathrm{O}$..................................... 18

Figura 22: (a) Média mensal das concentrações de $\mathrm{N}_{2} \mathrm{O}$ e (b) a taxa de crescimento anual, sobre a média dos Hemisférios Norte e Sul .................... 18

Figura 23: Média mensal global da concentração de $\mathrm{N}_{2} \mathrm{O}$ e taxa de crescimento

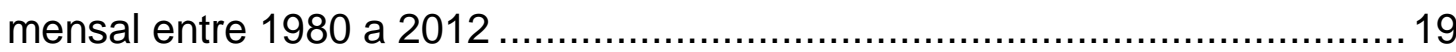

Figura 24: Emissões de $\mathrm{N}_{2} \mathrm{O}$ por setor no ano de 2005 e 2010 .......................... 20

Figura 25: Média da concentração mensal de $\mathrm{SF}_{6}$ de 1995 a 2012 .......................21

Figura 26: Distribuição da concentração global de CO ......................................21

Figura 27: Média mensal das concentrações de $\mathrm{CO}$ e a sua tendência................22

Figura 28: Emissões de CO por setor no ano de 2005.......................................22 
Figura 29: Locais de coleta na costa brasileira 24

Figura 30: (a) Sistema de secagem de ar e (b) limpeza de frascos com ar

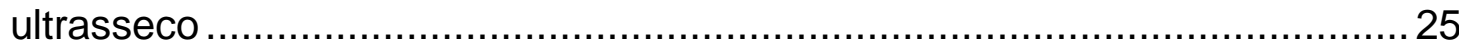

Figura 31: Amostrador portátil utilizado nas coletas .......................................... 26

Figura 32: Praia Corvina - SAL: (a) e (b) local na costa; (c) praia Corvina; (d) foto panorâmica do ponto de coleta; (e) amostrador e tubo coletor; (f) amostragem

Figura 33: Maxaranguape - NAT: (a) e (b) local na costa; (c) praia em Maxaranguape; (d) ponto de coleta; (e) e (f) estação de Maxaranguape; (g) instalação do tubo coletor

Figura 34: LAGEE: (1) monitor $\mathrm{CO}_{2}$; (2) cromatógrafo $\mathrm{CO}$; (3) cromatógrafo $\mathrm{N}_{2} \mathrm{O} / \mathrm{SF}_{6} / \mathrm{CH}_{4}$; (4) controlador de fluxo; (5) válvula de seleção; (6) amostra/CO referência; (7) medidor de vácuo e receptor de amostras; (8) interface do cromatógrafo; (9) banho resfriador; (10) microcomputador; (11) painel de gases; (12) interface monitor $\mathrm{CO}_{2}$; (13) interfaces das válvulas e cromatógrafo $\mathrm{CO}$.

Figura 35: Esquema de funcionamento do Sistema LAGEE-Brasil ...................... 30

Figura 36: (a) Esquema de entrada e saída dos gases de referência e amostra nas células do monitor de $\mathrm{CO}_{2} \mathrm{e}$ (b) esquema detalhado de uma célula ........31

Figura 37: Esquema de funcionamento do cromatógrafo na análise do $\mathrm{CH}_{4}$ (a) posição de espera e (b) posição de injeção da amostra no equipamento .......32

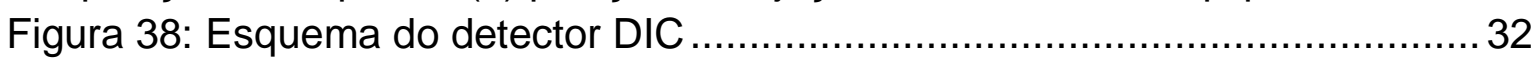

Figura 39: Esquema de funcionamento do detector DCE .................................. 33

Figura 40: Esquema de funcionamento do cromatógrafo de $\mathrm{CO}$............................34

Figura 41: Esquema do detector do cromatógrafo de $\mathrm{CO}$.....................................3 34

Figura 42: (a) Curva do tanque de calibração e (b) curva de calibração do $\mathrm{N}_{2} \mathrm{O} . .35$

Figura 43: Intercomparação entre o LQA (BRA-IPEN) com outros laboratórios

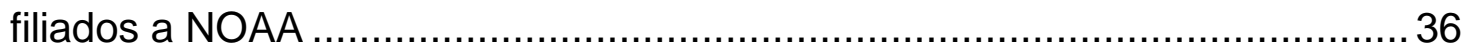

Figura 44: Análise de $\mathrm{CO}_{2}$ mostrando a sequência das referências e as

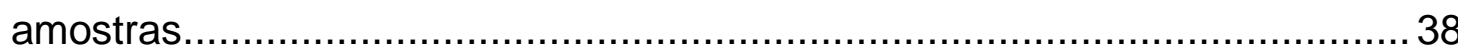

Figura 45: Tanque de calibração do cilindro $\mathrm{CA04533}$, para $\mathrm{CO}_{2}$ e $\mathrm{CH}_{4} \ldots \ldots \ldots \ldots . . . .39$

Figura 46: Trajetória da massa de ar para: (a) NAT e (b) SAL ........................... 40

Figura 47: Concentrações medidas para os GEE em ASC e RPB e as curvas ajustadas dessas concentrações realizadas pela NOAA

Figura 48: Trajetórias retrocedentes das massas de ar que chegaram a SAL, simuladas pelo modelo HYSPLIT para cada coleta realizada em todos os anos de estudo (2010, 2011, 2012 e 2013)

Figura 49: Trajetórias retrocedentes das massas de ar que chegaram a SAL, separadas para cada mês referentes a todos os anos de estudos

Figura 50: Variabilidade sazonal da posição da ZCIT observada e simulada para a região do Atlântico Tropical, próximo à costa sul-americana.

Figura 51: Médias climatológicas mensais de Radiação Onda Longa e

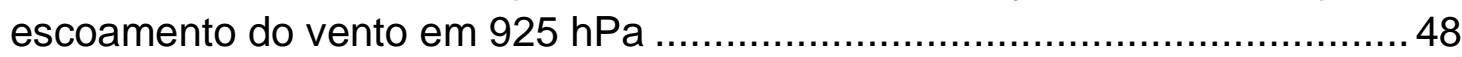

Figura 52: Posições sazonais da Zona de Convergência Intertropical costeira. ... 48 
Figura 53: Mapas da fração média mensal de nuvens para o ano de 2010 .........50

Figura 54: Mapas da fração média mensal de nuvens para o ano de 2011 .........51

Figura 55: Mapas da fração média mensal de nuvens para o ano de 2012 ..........52

Figura 56: Direção e velocidade do vento às 12 horas em SAL utilizando a base

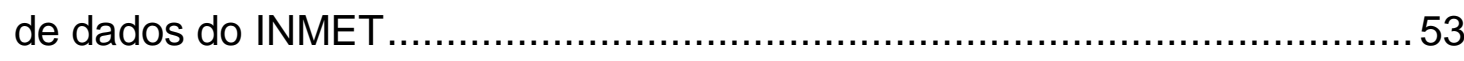

Figura 57: Comparação da série temporal de $\mathrm{CO}_{2}$ em SAL com os resultados medidos em ASC e RPB realizados pela NOAA

Figura 58: Comparação da concentração média anual do $\mathrm{CO}_{2}$ em SAL com a concentração média anual global por latitude

Figura 59: Concentração de "Clorofila a" no Oceano Atlântico em 2010 ..............57

Figura 60: Concentração de "Clorofila a" no Oceano Atlântico em 2011 ...............58

Figura 61: Concentração de "Clorofila a" no Oceano Atlântico em 2012 ..............59

Figura 62: Matéria orgânica dissolvida no Oceano Atlântico em 2010. ................. 60

Figura 63: Matéria orgânica dissolvida no Oceano Atlântico em 2011..................61

Figura 64: Matéria orgânica dissolvida no Oceano Atlântico em 2012. ................. 62

Figura 65: Concentrações de $\mathrm{CO}_{2}$ medidas em perfis verticais de avião em $\mathrm{SAH}$.

Figura 66: Concentrações de $\mathrm{CO}_{2}$ mensais e polinomiais para cada ano de estudo em SAL.

Figura 67: Diagrama de dispersão entre as concentrações de $\mathrm{CO}_{2}$ em SAL com as estações de ASC e RPB, onde: (a) representa todo o período, (b) período de janeiro-abril e (c) período de maio-dezembro

Figura 68: Diferença entre as concentrações de $\mathrm{CO}_{2}$ das estações globais com as concentrações obtidas em SAL para todos os anos de estudo 66

Figura 69: Comparação da série temporal de $\mathrm{CH}_{4}$ em SAL com os resultados medidos em ASC e RPB realizados pela NOAA

Figura 70: Comparação da concentração média anual do $\mathrm{CH}_{4}$ em SAL com a concentração média anual global por latitude

Figura 71: Concentrações de $\mathrm{CH}_{4}$ medidas em perfis verticais de avião em $\mathrm{SAH}$.

Figura 72: Concentrações de $\mathrm{CH}_{4}$ mensais e polinomiais para cada ano de estudo em SAL

Figura 73: Diagrama de dispersão entre as concentrações de $\mathrm{CH}_{4}$ em SAL com as estações de ASC e RPB, onde: (a) representa todo o período, (b) período de janeiro-abril e (c) período de maio-dezembro

Figura 74: Diferença entre as concentrações de $\mathrm{CH}_{4}$ das estações globais com as concentrações obtidas em SAL para todos os anos de estudo .................. 71

Figura 75: Comparação da série temporal de $\mathrm{N}_{2} \mathrm{O}$ em SAL com os resultados medidos em ASC e RPB realizados pela NOAA

Figura 76: Comparação da concentração média anual do $\mathrm{N}_{2} \mathrm{O}$ em SAL com a concentração média anual global por latitude

Figura 77: Concentrações de $\mathrm{N}_{2} \mathrm{O}$ medidas em perfis verticais de avião em $\mathrm{SAH}$.. 
Figura 78: Concentrações de $\mathrm{N}_{2} \mathrm{O}$ mensais e polinomiais para cada ano de estudo em SAL

Figura 79: Diagrama de dispersão entre as concentrações de $\mathrm{N}_{2} \mathrm{O}$ em SAL com as estações de ASC e RPB, onde: (a) representa todo o período, (b) período de janeiro-abril e (c) período de maio-dezembro

Figura 80: Diferença entre as concentrações de $\mathrm{N}_{2} \mathrm{O}$ das estações globais com as concentrações obtidas em SAL para todos os anos de estudo 76

Figura 81: Comparação da série temporal de $\mathrm{SF}_{6}$ em $\mathrm{SAL}$ com os resultados medidos em ASC e RPB realizados pela NOAA

Figura 82: Comparação da concentração média anual do $\mathrm{SF}_{6}$ em SAL com a concentração média anual global por latitude ........................................... 78

Figura 83: Concentrações de $\mathrm{SF}_{6}$ medidas em perfis verticais de avião em SAH 78 Figura 84: Concentrações de $\mathrm{SF}_{6}$ mensais para cada ano de estudo em SAL .... 79 Figura 85: Diagrama de dispersão entre as concentrações de $\mathrm{SF}_{6}$ em SAL com as estações de ASC e RPB, onde: (a) representa todo o período, (b) período de janeiro-abril e (c) período de maio-dezembro

Figura 86: Diferença entre as concentrações de $\mathrm{SF}_{6}$ das estações globais com as concentrações obtidas em SAL para todos os anos de estudo .................. 80

Figura 87: Comparação da série temporal de CO em SAL com os resultados medidos em ASC e RPB realizados pela NOAA

Figura 88: Trajetória retrocedente de 240 horas para o dia 18/09/12 e focos de queimadas entre o período de 17/09 a 26/09/12.

Figura 89: Comparação da concentração média anual do CO em SAL com a concentração média anual global por latitude

Figura 90: Concentrações de $\mathrm{CO}$ medidas em perfis verticais de avião em SAH 83

Figura 91: Concentrações de CO mensais e polinomiais para cada ano de estudo em SAL

Figura 92: Diferença entre as concentrações de CO das estações globais com as concentrações obtidas em SAL para todos os anos de estudo 84

Figura 93: Trajetórias retrocedentes das massas de ar que chegaram a NAT, simuladas pelo modelo HYSPLIT para cada coleta realizada em todos os anos de estudo $(2010,2011,2012$ e 2013)

Figura 94: Trajetórias retrocedentes das massas de ar que chegaram a NAT, separadas para cada mês referentes a todos os anos de estudos

Figura 95: Direção e velocidade do vento em NAT, com base nas observações do dia da coleta na estação de Maxaranguape - RN

Figura 96: Direção e velocidade do vento às 12 horas em Natal, utilizando a base de dados do INMET.

Figura 97: Série temporal de $\mathrm{CO}_{2}$ em NAT, estação de Maxaranguape - RN .......88

Figura 98: Comparação da concentração média anual do $\mathrm{CO}_{2}$ em NAT com a concentração média anual global por latitude

Figura 99: Concentrações de $\mathrm{CO}_{2}$ mensais e polinomiais para cada ano de estudo em NAT 
Figura 100: Diagrama de dispersão entre as concentrações de $\mathrm{CO}_{2}$ em NAT com as estações de ASC e RPB para todo o período

Figura 101: Série temporal de $\mathrm{CH}_{4}$ em NAT, estação de Maxaranguape - RN ....91

Figura 102: Comparação da concentração média anual do $\mathrm{CH}_{4}$ em NAT com a concentração média anual global por latitude.

Figura 103: Concentrações de $\mathrm{CH}_{4}$ mensais e polinomiais para cada ano de estudo em NAT

Figura 104: Diagrama de dispersão entre as concentrações de $\mathrm{CH}_{4}$ em NAT com as estações de ASC e RPB para todo o período

Figura 105: Série temporal de $\mathrm{N}_{2} \mathrm{O}$ em NAT, estação de Maxaranguape - RN ....99

Figura 106: Comparação da concentração média anual do $\mathrm{N}_{2} \mathrm{O}$ em NAT com a concentração média anual global por latitude.

Figura 107: Concentrações de $\mathrm{N}_{2} \mathrm{O}$ mensais e polinomiais para cada ano de estudo em NAT

Figura 108: Diagrama de dispersão entre as concentrações de $\mathrm{N}_{2} \mathrm{O}$ em NAT com as estações de ASC e RPB para todo o período

Figura 109: Série temporal de $\mathrm{SF}_{6}$ em NAT, estação de Maxaranguape - RN ..... 96

Figura 110: Comparação da concentração média anual do $\mathrm{SF}_{6}$ em NAT com a concentração média anual global por latitude

Figura 111: Concentrações de $\mathrm{SF}_{6}$ mensais e polinomiais para cada ano de estudo em NAT

Figura 112: Diagrama de dispersão entre as concentrações de $\mathrm{SF}_{6}$ em NAT com as estações de ASC e RPB para todo o período

Figura 113: Série temporal de CO em NAT, estação de Maxaranguape - RN ..... 99

Figura 114: Trajetória retrocedente de 240 horas para o dia 21/09/12 e focos de queimadas entre o período de 17/09 a 26/09/12

Figura 115: Comparação da concentração média anual do CO em NAT com a concentração média anual global por latitude

Figura 116: Concentrações de CO mensais e polinomiais para cada ano de estudo em NAT

Figura 117: Diagrama de dispersão entre as concentrações de CO em NAT com as estações de ASC e RPB para todo o período

Figura 118: Diagrama de dispersão entre as concentrações médias obtidas em NAT realizadas pelo $L Q A$ e pela NOAA para $\mathrm{CO}_{2}, \mathrm{CH}_{4}, \mathrm{~N}_{2} \mathrm{O}, \mathrm{SF}_{6}$ e $\mathrm{CO} \ldots . .103$

Figura 119: Comparação das concentrações de $\mathrm{CO}_{2}$ em SAL e NAT, com as concentrações de entrada no continente, para ALF, RBA, SAN e TAB ....... 107

Figura 120: Comparação das concentrações de $\mathrm{CH}_{4}$ em SAL e NAT, com as concentrações de entrada no continente, para ALF, RBA, SAN e TAB ....... 108

Figura 121: Comparação das concentrações de $\mathrm{N}_{2} \mathrm{O}$ em SAL e NAT, com as concentrações de entrada no continente, para ALF, RBA, SAN e TAB ....... 109

Figura 122: Comparação das concentrações de CO em SAL e NAT, com as concentrações de entrada no continente, para ALF, RBA, SAN e TAB ........110

Figura 123: Comparação das concentrações de $\mathrm{SF}_{6}$ em SAL e NAT com as concentrações medidas em SAN, RBA, ALF e TAB 


\section{LISTA DE ABREVIATURAS E/OU SIGLAS}

\begin{tabular}{|c|c|}
\hline ALF & Alta Floresta - MT (perfil vertical de avião) \\
\hline ASC & Ilha de Ascension \\
\hline CCG & Carbon Cycle Gases \\
\hline CQMA & Centro de Química e Meio Ambiente \\
\hline CMDL & Climate Monitoring \& Diagnostics Laboratory \\
\hline CRN & Centro Regional do Nordeste \\
\hline DCE & Detector de Captura Eletrônica \\
\hline EDGAR & Emissions Database for Global Atmospheric Research \\
\hline ESRL & Earth System Research Laboratory \\
\hline DIC & Detector de lonização de Chama \\
\hline DISC & Data and Information Services Center \\
\hline FR & Forçante Radiativa \\
\hline GES & Goddard Earth Sciences \\
\hline GIOVANNI & $\begin{array}{l}\text { Geospatial Interactive Online Visualization and analysis } \\
\text { Infrastructure }\end{array}$ \\
\hline GDAS & Global Data Assimilation System \\
\hline GEE & Gases de Efeito Estufa \\
\hline GMD & Global Monitoring Division \\
\hline $\mathrm{HN}$ & Hemisfério Norte \\
\hline HS & Hemisfério Sul \\
\hline HYSPLIT & Hybrid Single-Particle Lagrangian Integrated Trajectory \\
\hline IBGE & Instituto Brasileiro de Geografia e Estatística \\
\hline INMET & Instituto Nacional de Meteorologia \\
\hline INPE & Instituto Nacional de Pesquisas Espaciais \\
\hline IPEN & Instituto de Pesquisas Energéticas e Nucleares \\
\hline IR & Radiação Infravermelha \\
\hline LAGEE & Laboratório de Análise de Gases de Efeito Estufa \\
\hline LQA & Laboratório de Química Atmosférica \\
\hline
\end{tabular}


MAGICC

MODIS

NASA

NAT

NOAA

OAN

OAS

PAG

RBA

RPB

$\mathrm{SAH}$

SAL

SAN

TAB

WMO

ZCIT
Multiple Analysis of Greenhouse Gases Influence Climate Change

Moderate Resolution Imaging Spectroradiometer

National Aeronautics and Space Administration

Natal/Maxaranguape - RN

National Oceanic \& Atmospheric Administration

Oceano Atlântico Norte

Oceano Atlântico Sul

Potencial de Aquecimento Global

Rio Branco - AC (perfil vertical de avião)

Ilha de Barbados (Ragged Point Barbados)

Salinópolis - PA (perfil vertical de avião)

Salinópolis - PA

Santarém - PA (perfil vertical de avião)

Tabatinga - AM (perfil vertical de avião)

World Meteorological Organization

Zona de Convergência Intertropical 


\section{INTRODUÇÃO}

A intervenção humana no meio ambiente ocorre há milhares de anos, entretanto nos últimos séculos, esta intervenção tem sido mais intensa e recentemente vem alterando muitos dos ciclos biogeoquímicos do planeta, como o ciclo do carbono ${ }^{[1]}$. Essas alterações, aumentando a quantidade de gases traços, os quais representam aproximadamente $1 \%$ dos constituintes na atmosfera, vem intensificando o efeito estufa e consequentemente promovendo mudanças climáticas ${ }^{[2]}$.

Desde a revolução industrial e da agricultura, o delicado balanço entre os processos físicos, químicos e biológicos no sistema terrestre tem sido perturbado. Esta perturbação vem sendo promovida pelo crescimento exponencial da população mundial, e consequentemente aumentando o uso de combustíveis fósseis, a industrialização, a mudança no uso da terra e florestas, intensificação das práticas agrícolas, etc. ${ }^{[3,4]}$. Este impacto sobre o sistema terrestre ainda não é bem compreendido, mas pode ser significante em muitos casos. Mudanças na abundância atmosférica de gases radiativamente ativos estão levando a mudanças na temperatura e precipitação, como também na frequência de ocorrência de eventos extremos ${ }^{[3,5]}$.

Quanto mais gases são lançados na atmosfera, maior sua capacidade de acumular calor na troposfera, e esta tendência vem aumentando nos dois últimos séculos ${ }^{[2,6]}$. Alguns impactos deste aumento de temperatura já puderam ser observados, como o aumento de inundações, de eventos extremos, do nível do mar, etc., causando mudanças nos padrões climáticos e afetando ecossistemas, saúde humana, entre outros ${ }^{[6,7]}$. Embora as alterações climáticas não possam ser totalmente evitadas, reduzir substancialmente a liberação de gases de efeito estufa (GEE) na atmosfera é imprescindível para a preservação do planeta ${ }^{[6]}$.

O efeito estufa ocorre naturalmente devido a presença de GEE na atmosfera, mantendo a temperatura em condições para que haja a existência de vida como a conhecemos, porém as emissões antrópicas tem aumentado à 
concentração de GEE, o que leva a maior retenção de calor e, portanto à mudança do clima ${ }^{[8,9]}$.

Sem os GEE, a superfície terrestre emitiria energia infravermelha (IR), sem que esta fosse acumulada na troposfera. Desta forma a temperatura média da superfície da Terra seria de $-18^{\circ} \mathrm{C}$. No entanto, com a presença dos GEE, e a absorção de energia na faixa do IR elevou a temperatura média da superfície terrestre para $15^{\circ} \mathrm{C}$, um aumento de $33^{\circ} \mathrm{C}$ na temperatura média global como observado na Figura $1^{[9,10]}$.

No entanto, o aumento na emissão desses GEE como dióxido de carbono $\left(\mathrm{CO}_{2}\right)$, metano $\left(\mathrm{CH}_{4}\right)$, óxido nitroso $\left(\mathrm{N}_{2} \mathrm{O}\right)$, ozônio $\left(\mathrm{O}_{3}\right)$, entre outros, produzem um aumento no efeito estufa, elevando a temperatura terrestre e produzindo alterações no clima ${ }^{[11]}$.
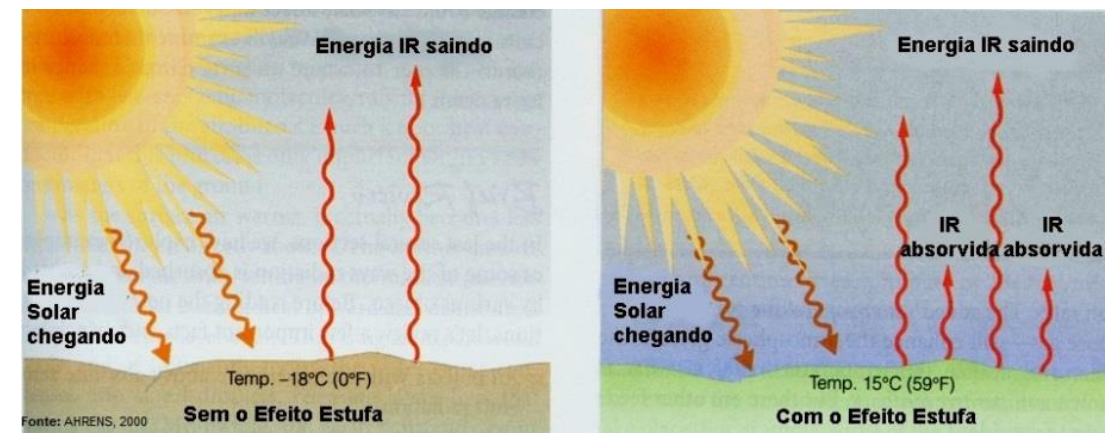

Figura 1: Balanço radiativo sem o efeito estufa e com o efeito estufa ${ }^{[10]}$. (Adaptada de Ahrens, 2000)

O clima terrestre é determinado pelos fluxos de energia que entram e saem do planeta. As distribuições geográficas destes fluxos de energia na superfície são particularmente importantes, pois dirigem as circulações oceânicas, alimentam a evaporação da água da superfície da Terra e governam o ciclo hidrológico do planeta. Alterações no balanço de energia da superfície finalmente também controlam a forma como o ciclo hidrológico responde aos pequenos desequilíbrios energéticos que forçam a mudança climática ${ }^{[12]}$.

A média anual global do balanço de energia da Terra entre o período de 2000 a 2010 é representada na Figura 2. A evaporação da superfície (88 $\pm 10 \mathrm{~W} \mathrm{~m}^{-2}$ ) é o principal processo que consome a maior parte do excesso da energia radiante $\left(165 \pm 6 \mathrm{~W} \mathrm{~m}^{-2}\right)$ seguido pela emissão a partir da superfície $\left(398-345=53 \pm 9 \mathrm{~W} \mathrm{~m}^{-2}\right)$ e do calor sensível $\left(24 \pm 7 \mathrm{~W} \mathrm{~m}^{-2}\right)$. O calor transferido para a atmosfera através do calor latente e sensível equilibra a perda de energia 
radiante da atmosfera $\left(-112 \pm 15 \mathrm{~W} \mathrm{~m}^{-2}=74+398-239-345\right)$. O efeito das nuvens sobre os fluxos no topo da atmosfera, chamado de efeito albedo das nuvens, aumenta o fluxo solar refletido $\left(47,5 \pm 3 \mathrm{~W} \mathrm{~m}^{-2}\right)$, enquanto as nuvens reduzem o fluxo de onda longa em relação ao céu claro em aproximadamente $26,4 \pm 4 \mathrm{~W} \mathrm{~m}^{-2}$ (medida do seu efeito estufa), dando uma perda de radiação da Terra por nuvens de $21,1 \pm 5 \mathrm{~W} \mathrm{~m}^{-2}{ }^{[12]}$.

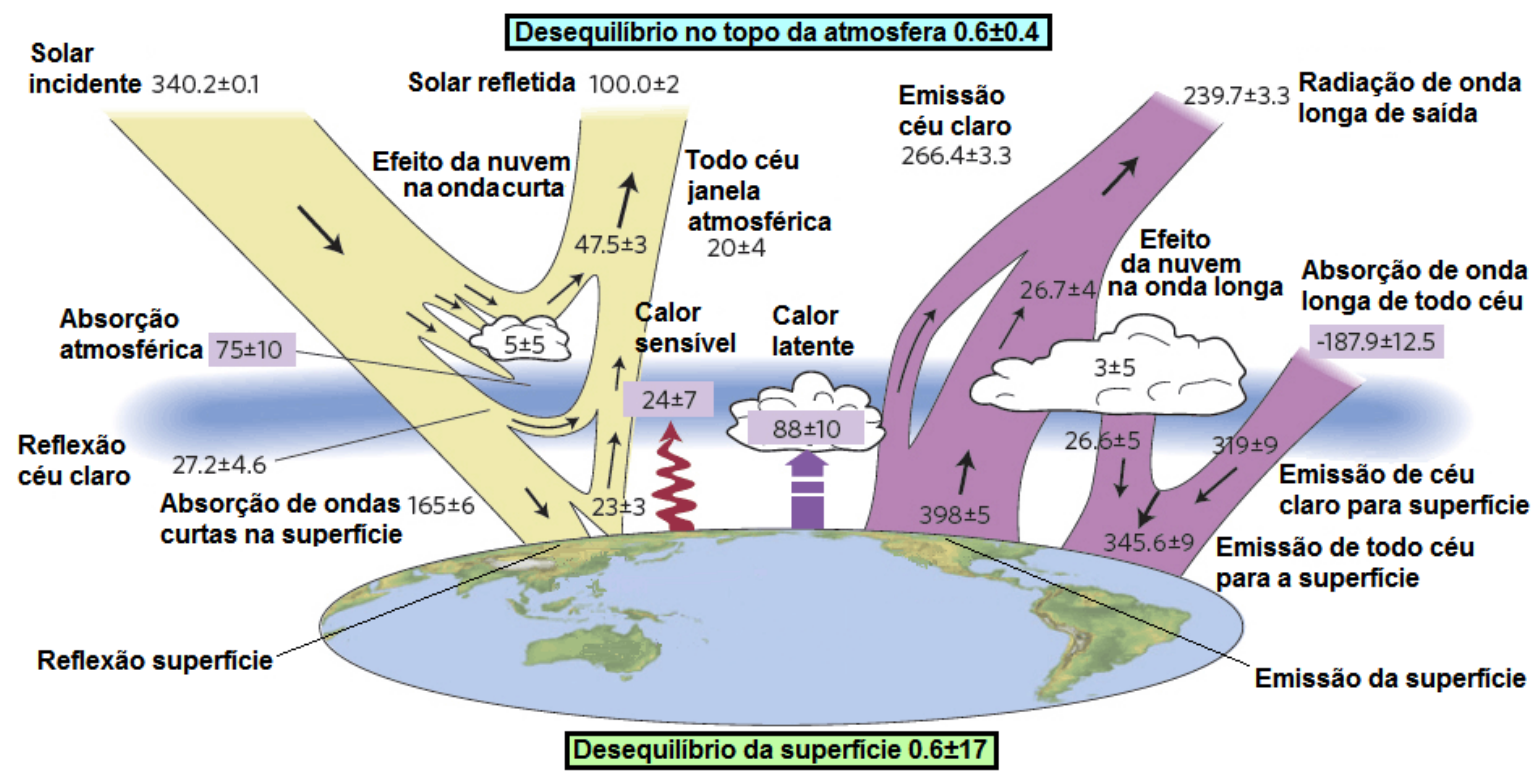

Figura 2: Média anual global do balanço de energia da Terra (2000-2010). Os fluxos solar (amarelo) e infravermelho (rosa) são medidos em W m². As caixas (lilás) representam as principais componentes do balanço de energia ${ }^{[12]}$. (Adaptada de Stephens et al., 2012)

O efeito dos GEE modifica a quantidade de radiação de onda longa de saída, absorvendo-as e reemitindo essa radiação. O albedo é alterado por mudanças na vegetação ou nas propriedades da superfície da terra, neve ou na cobertura de gelo, e da cor do oceano. Estas alterações são conduzidas pelas alterações naturais bem como a influência humana ${ }^{[13]}$.

\subsection{Gases de efeito estufa (GEE)}

Análises realizadas em bolhas de ar que ficaram retidas nos testemunhos de gelo Ártico e Antártico possibilitaram determinar as concentrações de GEE na atmosfera nos últimos 650.000 anos, baseados nessas evidências, cientistas chegaram à conclusão que este aumento da concentração dos GEE é o maior já observado, como apresentado na Figura $3^{[14]}$. 
O aumento das concentrações dos principais GEE nos últimos 2.000 anos, Figura 4, mostra que por volta do ano de 1750, na era industrial, pode ser observado um significativo aumento nessas concentrações que é atribuído às atividades humanas ${ }^{[13,15]}$.

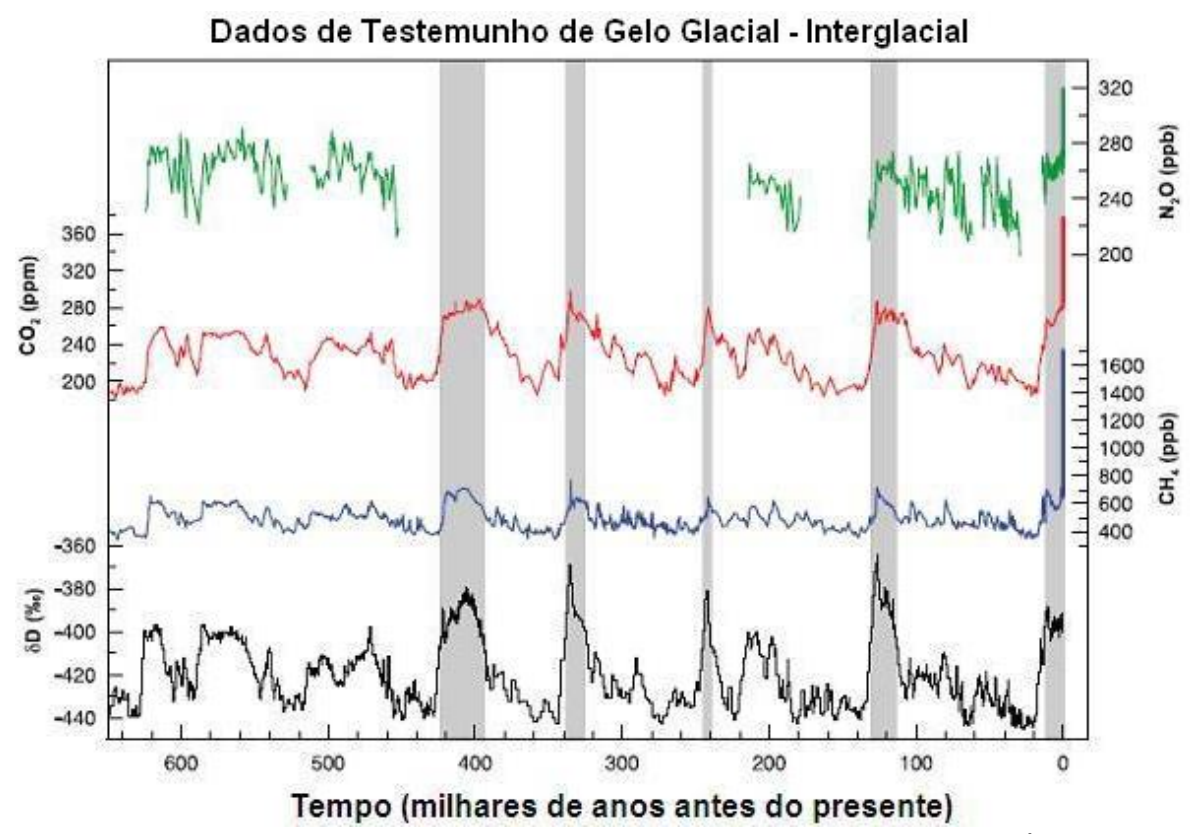

Figura 3: Variações de deutério ( $\delta \mathrm{D}$ - indicador de temperatura) e concentraccões de $\mathrm{CO}_{2}, \mathrm{CH}_{4}$ e $\mathrm{N}_{2} \mathrm{O}$. As sombras indicam os períodos interglaciais quentes ${ }^{[14]}$.

(Adaptada de Solomons et al.,2007)

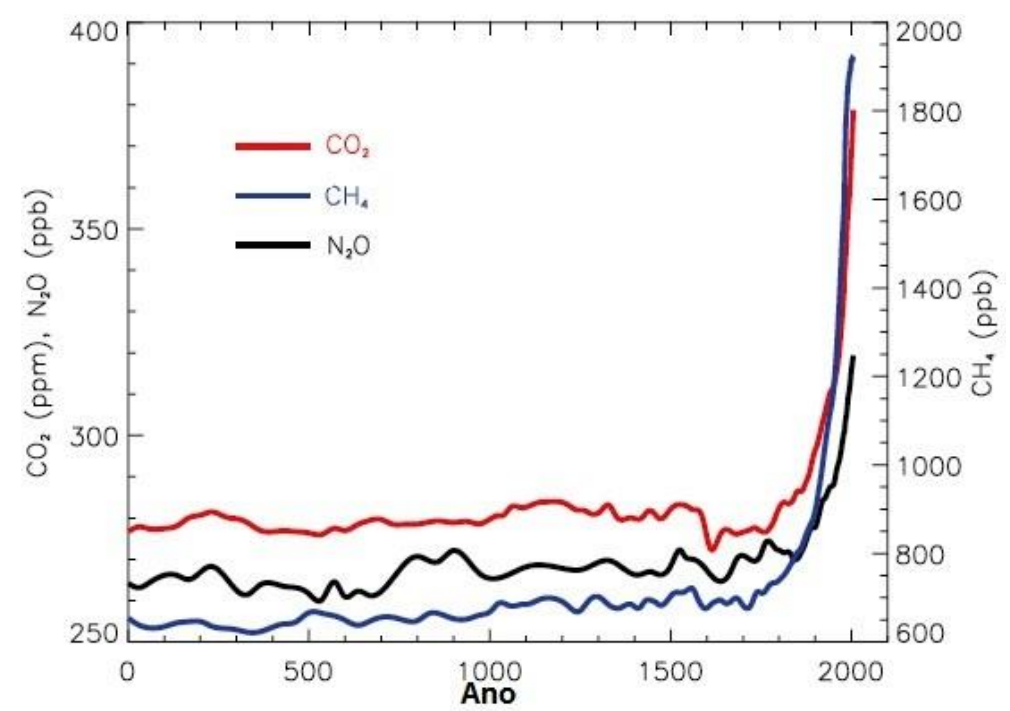

Figura 4: Concentrações atmosféricas de $\mathrm{CO}_{2}, \mathrm{CH}_{4}$ e $\mathrm{N}_{2} \mathrm{O}{ }^{[13]}$. (Adaptada de Forster et al.,2007)

Mudanças na atmosfera, terra, oceano, biosfera, induzidas tanto por atividades naturais quanto por antrópicas, podem perturbar o balanço de radiação da Terra, produzindo uma forçante radiativa (FR) que afeta o clima. A FR é uma 
medida da alteração líquida no balanço de energia em resposta a uma perturbação externa. Quando estes fatores externos influenciam o clima, ocorrem alterações no balanço da radiação solar e na radiação IR. Essas alterações levam ao aquecimento ou resfriamento do sistema como mostra a Figura 5, que apresenta um resumo dos principais componentes da FR nas mudanças climáticas. Os principais GEE apresentam uma FR positiva porque absorvem radiação IR na atmosfera ${ }^{[13]}$.

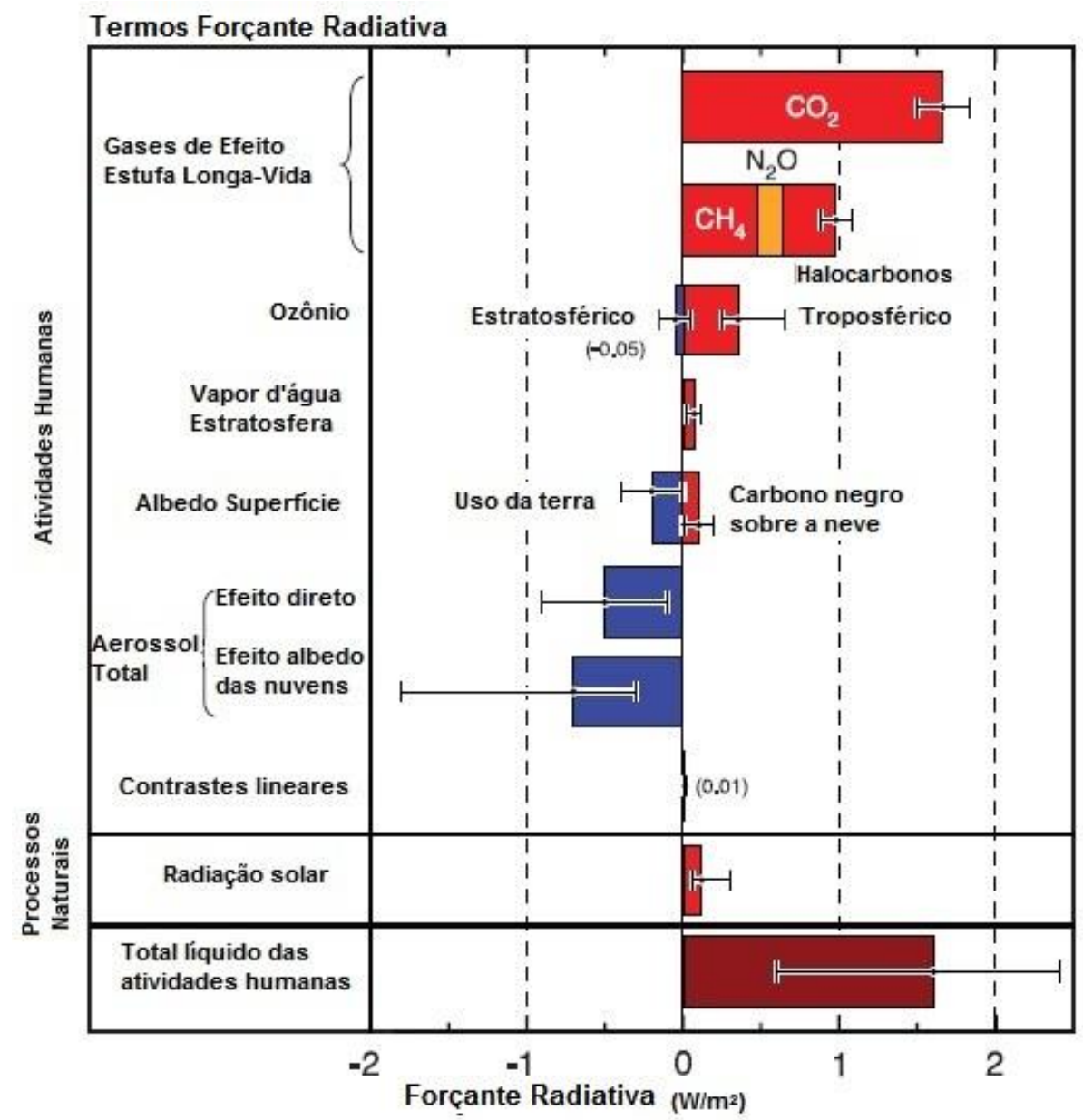

Figura 5: Principais componentes da forçante radiativa ${ }^{[13]}$.

(Adaptada de Forster et al.,2007)

Cada GEE absorve energia com intensidade diferente provocando fenômenos de aquecimento, assim, foi elaborado um índice de Potencial de Aquecimento Global (PAG), gerando uma estimativa do efeito climático baseado na FR e no tempo de vida de cada GEE em função do $\mathrm{CO}_{2}$, como apresentado na Tabela $1{ }^{[13]}$. Podemos observar que o $\mathrm{CH}_{4}$ possui um PAG de 21 vezes maior que o $\mathrm{CO}_{2}$, seguido do $\mathrm{N}_{2} \mathrm{O}$ com 310 vezes e por último o $\mathrm{SF}_{6}$ com o maior $\mathrm{PAG}$ de 23.900 vezes maior que o $\mathrm{CO}_{2}$, em um cenário de 100 anos. 
As concentrações médias globais dos GEE relatadas nos últimos relatórios da WMO (World Meteorological Organization) mostram que as concentrações dos GEE estão aumentando com o passar dos anos, como apresentado na Tabela 2. Estes aumentos não estão apenas ligados às atividades antrópicas como também apresentam fortes interações com a biosfera e com os oceanos, exigindo uma melhor compreensão de suas fontes e sumidouros ${ }^{[16,17,18,19,20]}$.

Tabela 1: PAG e tempo de vida na atmosfera dos principais GEE ${ }^{[13]}$ (Adaptada de Forster et al., 2007)

\begin{tabular}{ccccccc}
\hline \multirow{2}{*}{ Compostos } & $\begin{array}{c}\text { Fórmula } \\
\text { Química }\end{array}$ & $\begin{array}{c}\text { Tempo de Vida } \\
\text { (anos) }\end{array}$ & \multicolumn{4}{c}{ (PAG) } \\
\cline { 4 - 7 } & $\mathrm{CO}_{2}$ & - & 1 & anos & $\mathbf{1 0 0}$ anos & $\mathbf{5 0 0}$ anos \\
\hline Dióxido de Carbono & $\mathrm{CH}_{4}$ & 12 & 72 & 21 & 7,6 \\
Metano & $\mathrm{N}_{2} \mathbf{O}$ & 114 & 289 & 310 & 153 \\
Óxido Nitroso & $\mathrm{SF}_{6}$ & 3.200 & 16.300 & 23.900 & 32.600 \\
\hline Hexafluoreto de enxofre & & &
\end{tabular}

Tabela 2: Concentrações dos principais GEE, observações da WMO ${ }^{[16,17,18,19,20]}$

\begin{tabular}{cccccc}
\hline \multirow{2}{*}{ Principais GEE } & \multicolumn{5}{c}{ Ano da Observação } \\
\cline { 2 - 6 } & $\mathbf{2 0 0 8}$ & $\mathbf{2 0 0 9}$ & $\mathbf{2 0 1 0}$ & $\mathbf{2 0 1 1}$ & $\mathbf{2 0 1 2}$ \\
\hline $\mathrm{CO}_{2}$ & $385,2 \mathrm{ppm}$ & $386,8 \mathrm{ppm}$ & $389,0 \mathrm{ppm}$ & $390,9 \mathrm{ppm}$ & $393,1 \mathrm{ppm}$ \\
$\mathrm{CH}_{4}$ & $1797 \mathrm{ppb}$ & $1803 \mathrm{ppb}$ & $1808 \mathrm{ppb}$ & $1813 \mathrm{ppb}$ & $1819 \mathrm{ppb}$ \\
$\mathrm{N}_{2} \mathrm{O}$ & $321,8 \mathrm{ppb}$ & $322,5 \mathrm{ppb}$ & $323,2 \mathrm{ppb}$ & $324,2 \mathrm{ppb}$ & $325,1 \mathrm{ppb}$ \\
\hline \multicolumn{6}{c}{$p p m$ (parte por milhão) e ppb (parte por bilhão) }
\end{tabular}

Observações mostram que as emissões de $\mathrm{CO}_{2}$ e de gases traço indutores de efeito estufa na atmosfera têm aumentado com o tempo. Em projetos de pesquisas iniciados nos anos 80 e que continuam até hoje, tenta-se, por meio de modelagem computacional, prever as consequências desses aumentos sobre o clima do planeta no futuro. Entretanto, existem algumas incertezas, como o fato de ainda não se entender integralmente todas as fontes e sumidouros dos gases.

A Floresta Amazônica possui uma das maiores áreas de floresta do globo, cerca de 8 milhões de $\mathrm{km}^{2}$, constituindo assim o maior reservatório de carbono e biodiversidade global. Porém, sofre com a ação humana devido à exploração de madeira, a conversão de florestas e outras formas de exploração de seus recursos ${ }^{[21]}$.

Malhi e Wright demonstraram que, desde meados da década de 1970, vem ocorrendo um aquecimento global nas florestas tropicais de $0,26 \pm 0.05^{\circ} \mathrm{C}$ 
por década ${ }^{[22]}$. Alguns cientistas sugerem através de modelos climáticos, um aquecimento entre 1,9 a $7,9 \stackrel{\circ}{ } \mathrm{C}$ para o fim do século $\mathrm{XX|}{ }^{[23]}$. Tal fato observado por esses cientistas é relacionado ao desmatamento nas áreas tropicais.

A América contém cerca de $50 \%$ da floresta tropical do globo, a Floresta Amazônica ${ }^{[24]}$, sendo que a maior parte da área da Bacia e sua floresta estão localizadas no Brasil correspondendo a aproximadamente $62 \%{ }^{[25]}$. Sendo assim necessária a realização de estudos para monitorar as concentrações de GEE, criando uma rede de monitoramento vinculada à rede mundial.

De acordo com a Figura 6, onde se observa os locais hoje monitorados pela WMO, aproximadamente 300 localidades, em parceria com diversos laboratórios, que alimentam os modelos de previsão de mudanças climáticas, pode-se observar que existe apenas um local com medidas contínuas de GEE no Brasil incorporado nesta rede ${ }^{[26]}$. O Laboratório de Química Atmosférica, localizado no Centro de Química e Meio Ambiente do Instituto de Pesquisas Energéticas e Nucleares (LQA/CQMA/IPEN) tem trabalhado para ampliar as informações tanto da Bacia Amazônica como de locais costeiros. Esta escassez de medidas nas áreas tropicais e na Amazônia, gera significativas incertezas nos resultados obtidos por modelos de previsão climática, pois o maior monitoramento está concentrado no Hemisfério Norte $(\mathrm{HN})$.

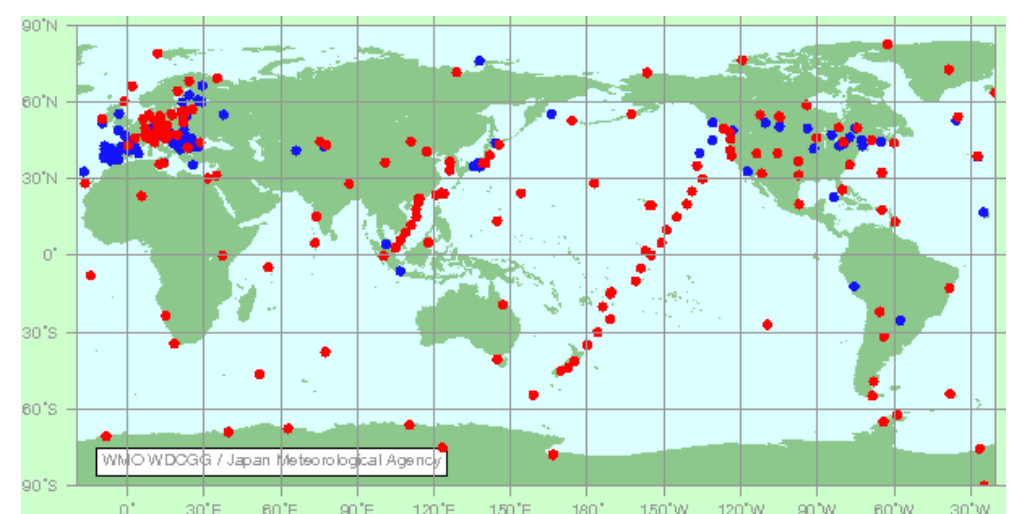

Figura 6: Rede de monitoramento das estações da WMO. Círculos vermelhos indicam que os dados da estação foram atualizados no último ano ${ }^{[26]}$.

O conhecimento da concentração de entrada de GEE na costa brasileira é imprescindível para o cálculo do fluxo de emissão/absorção de GEE por alguns tipos de modelamentos e cálculos matemáticos menos complexos.

No final de 2000 iniciaram-se estudos utilizando perfis verticais de avião na Amazônia (Floresta Nacional do Tapajós), e a partir de 2009 começaram 
outros estudos em Santarém - Pará (SAN), em Alta Floresta - Mato Grosso (ALF), Rio Branco - Acre (RBA) e Tabatinga - Amazonas (TAB), mostrados na Figura 7. Este estudo permite calcular o fluxo de GEE em escala regional, mostrando-se como um método eficaz de medida de fluxo para a Bacia Amazônica ${ }^{[21,27,28]}$.

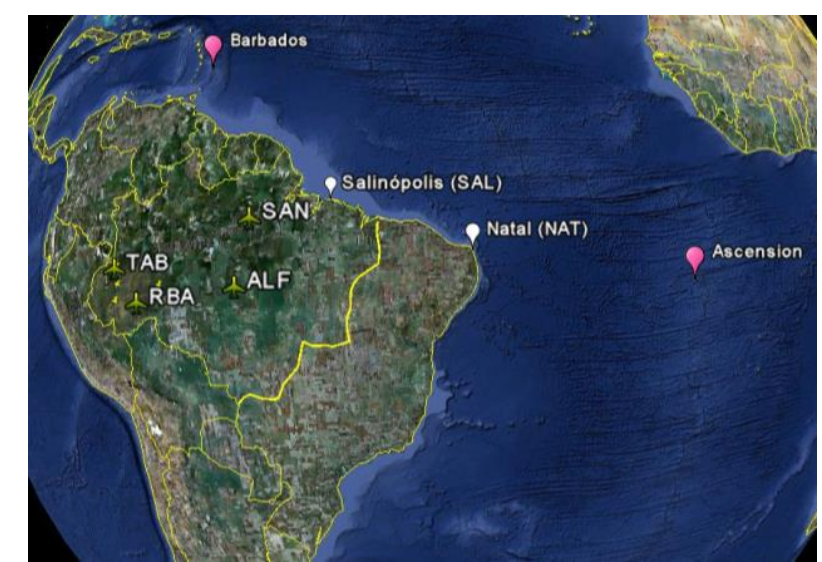

Figura 7: Locais de estudos na Bacia Amazônica e costa brasileira.

As trajetórias das massas de ar que chegaram aos locais de estudo na Amazônia são mostradas na Figura 8, para os voos realizados em 2010 e em SAN desde 2000. Observa-se que as trajetórias das massas de ar abrangem regiões diferentes da Bacia Amazônica. E os estudos relativos aos perfis realizados sobre SAN, refletem a região da costa até o local de amostragem, que corresponde à parte leste da Bacia Amazônica. Com os locais de estudos na costa, abrangem-se outras áreas da Bacia Amazônica e assim obtêm um resultado mais representativo como um todo.

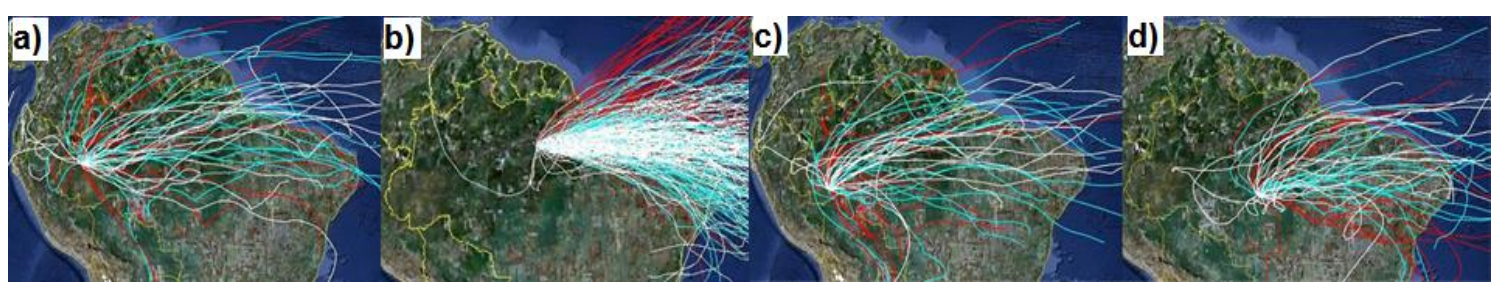

Figura 8: Trajetórias das massas de ar em: (a) TAB, (b) SAN, (c) RBA e (d) ALF. Linhas: vermelhas - 500m, verdes - $2500 \mathrm{~m}$ e brancas - $4000 \mathrm{~m}$.

Para o cálculo do fluxo de emissão dos GEE é fundamental conhecer a concentração de entrada no continente, e este projeto teve como objetivo estudar a concentração de entrada e conhecer a variação da concentração de GEE na costa norte/nordeste brasileira. 


\section{OBJETIVOS}

\subsection{Objetivo geral}

Determinar a concentração de entrada dos gases de efeito estufa no ar que entra na costa norte/nordeste brasileira, proveniente do Oceano Atlântico, na faixa correspondente a Bacia Amazônica.

\subsection{Objetivos específicos}

$\checkmark$ Através de parcerias locais, coletar semanalmente amostras de ar em: Salinópolis - Pará (SAL: 00³6'15,03”S; 47²2’25,02”O) e em Natal - Rio Grande do Norte (NAT: 05²9'22,05”S; 35¹5'39,64"O).

$\checkmark$ As análises dos GEE: $\mathrm{CO}_{2}, \mathrm{CH}_{4}, \mathrm{~N}_{2} \mathrm{O}$ e $\mathrm{SF}_{6}$, além do gás $\mathrm{CO}$, são realizadas no Laboratório de Química Atmosférica do IPEN (LQA/IPEN).

$\checkmark$ Comparar as concentrações encontradas em SAL e NAT com as concentrações medidas nas estações globais, localizadas nas Ilhas de Ascension

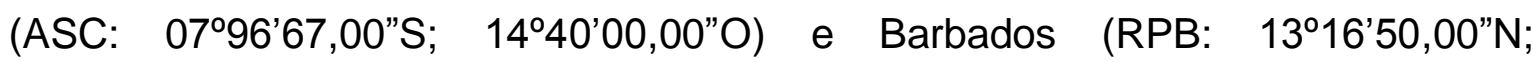
5943'20,00”O).

$\checkmark$ Comparar as concentrações encontradas em SAL e NAT com o cálculo da concentração de entrada, o qual utiliza o método baseado no $\mathrm{SF}_{6}$ descrito por Miller et al. ${ }^{[21,27,28]}$.

$\checkmark$ Simular as trajetórias retrocedentes das massas de ar para cada coleta realizada e determinar a origem das massas de ar para as latitudes estudadas na costa brasileira.

$\checkmark$ Comparar os resultados encontrados com 0 mapeamento das concentrações de GEE em função da latitude realizado pela rede de monitoramento da National Oceanic \& Atmospheric Administration (NOAA). 


\section{REVISÃo BIBLIOGRÁFICA}

\subsection{Dióxido de carbono $\left(\mathrm{CO}_{2}\right)$}

$\mathrm{O} \mathrm{CO}_{2}$ é o mais importante GEE antrópico na atmosfera, contribuindo com aproximadamente $64 \%$ do total da $\mathrm{FR}{ }^{[18,29,30]}$. A concentração de $\mathrm{CO}_{2}$ na atmosfera terrestre vem aumentando de forma constante desde o início deste século sugerindo que sua taxa de remoção não é grande o suficiente para concorrer com a taxa crescente de entrada deste gás devido à queima de combustíveis fósseis ${ }^{[31]}$.

Algumas fontes de $\mathrm{CO}_{2}$ são a evaporação dos oceanos, oxidação química do monóxido de carbono e gases orgânicos, erupção vulcânica, queima de biomassa e queima de combustíveis fósseis ${ }^{[8]}$. $\mathrm{O}$ aumento das concentrações de $\mathrm{CO}_{2}$ foi devido principalmente às emissões provenientes da queima de combustíveis fósseis (total de 8,4 $\pm 0,5 \mathrm{PgC}$ em 2009 e 9,1 $\pm 0,5 \mathrm{PgC}$ em 2010) ${ }^{[29,30]}$, do desmatamento e da mudança do uso da terra ${ }^{[13,18]}$.

O desmatamento, a queima de biomassa, as queimadas agrícolas e os incêndios acidentais, liberam $\mathrm{CO}_{2}$ e desta forma a absorção pelas plantas é reduzida. A maior parte da queima de biomassa ocorre nos trópicos, sendo altamente sazonal, atingindo seu máximo no final da estação seca, entre janeiro a abril no Trópico Norte, e de agosto a outubro no Trópico Sul ${ }^{[13,21,27]}$.

O carbono na atmosfera é trocado com dois grandes reservatórios, a biosfera terrestre e os oceanos. A troca de $\mathrm{CO}_{2}$ entre a atmosfera terrestre e a biosfera ocorre, principalmente, através da absorção pela fotossíntese e emissão pela respiração das plantas, e pela decomposição de solos orgânicos. A troca de $\mathrm{CO}_{2}$ da atmosfera com os oceanos é possível devido aos oceanos absorverem $\mathrm{CO}_{2}$ e utilizá-lo na fotossíntese dos seres vivos aquáticos, e também pelo gradiente da fração molar e variação em função do tempo e espaço ${ }^{[30]}$.

Essas atividades biogênicas resultam em grandes variações sazonais na concentração atmosférica global de $\mathrm{CO}_{2}$ no Hemisfério Norte $(\mathrm{HN})$ e nas latitudes médias, e menores variações sazonais no Hemisfério Sul (HS) ${ }^{[30]}$, como é apresentada na Figura 9. Podemos observar que houve aumento nas concentrações de $\mathrm{CO}_{2}$ em ambos os Hemisférios, como apresentada na Figura 10 
onde são mostradas as concentrações de $\mathrm{CO}_{2}$ a cada $30^{\circ}$ de latitude entre 1983 a 2011, sendo que entre $30^{\circ}$ S e o Equador é onde se encontram as menores variações sazonais ${ }^{[30]}$.

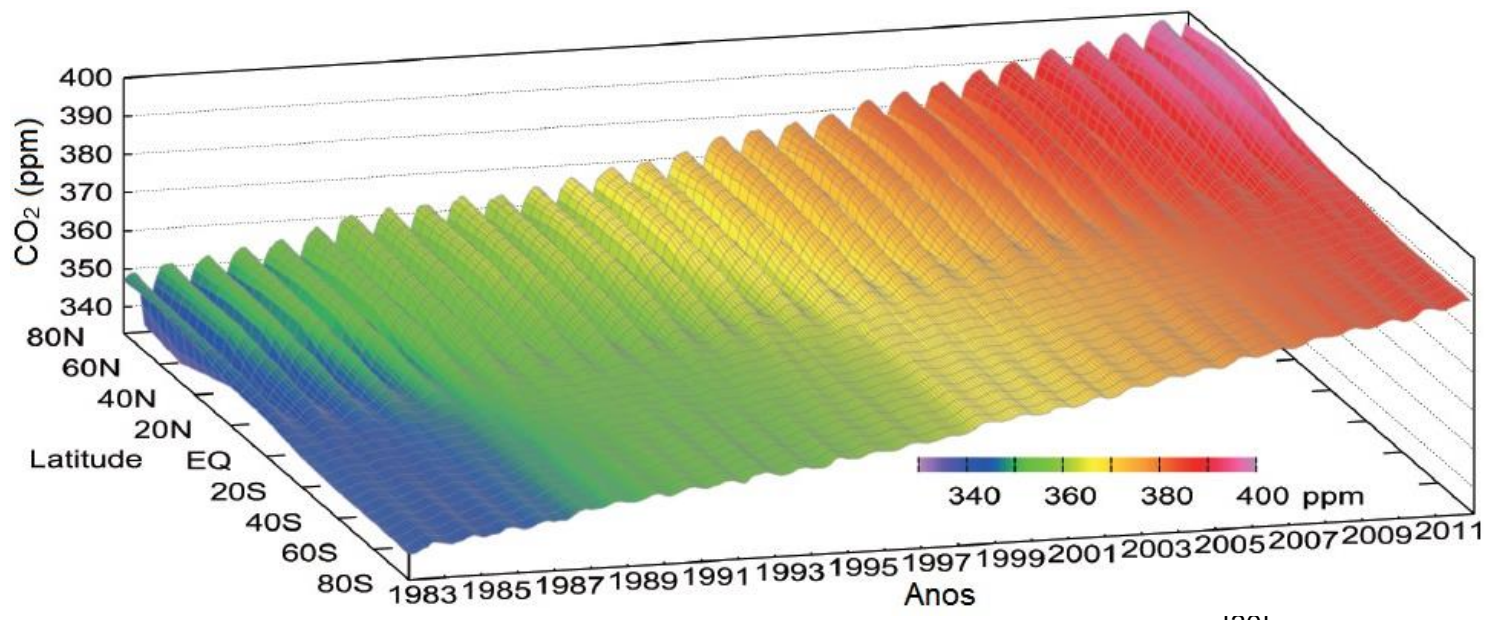

Figura 9: Distribuição da concentração global de $\mathrm{CO}_{2}{ }^{[30]}$. (Adaptada de WMO, 2013)

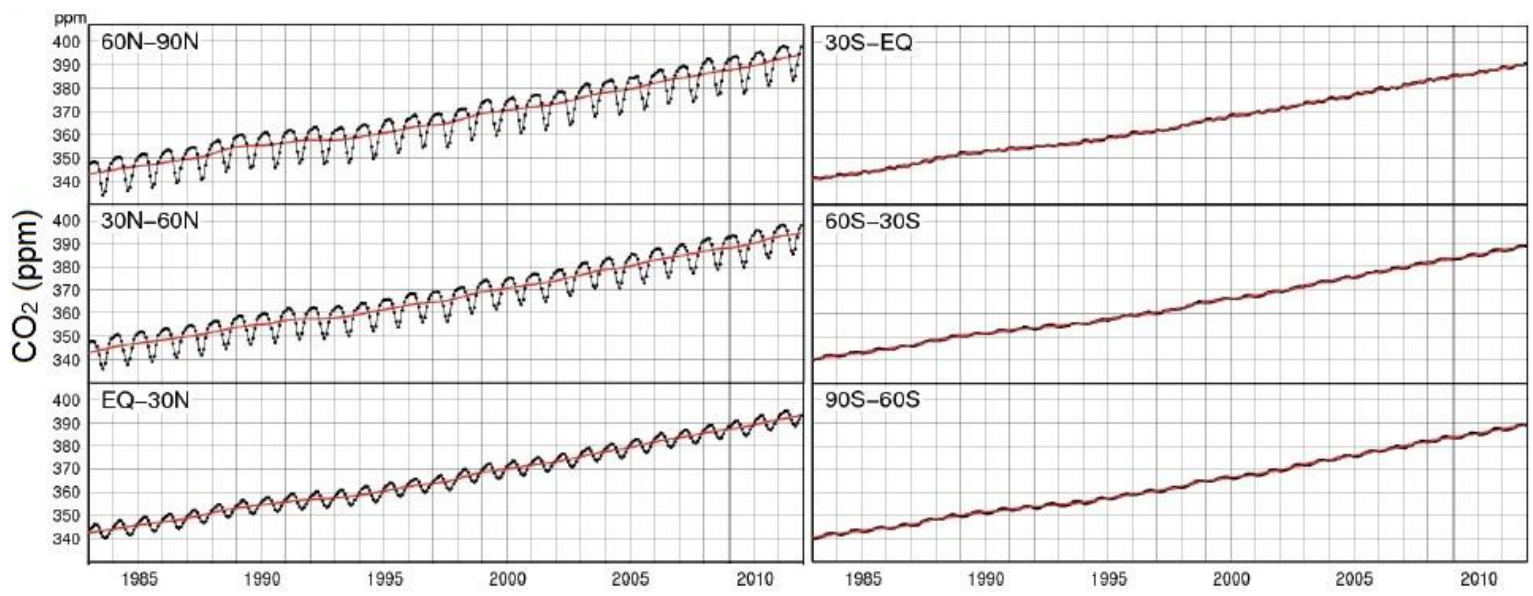

Figura 10: Média mensal das concentrações de $\mathrm{CO}_{2}$ (pontos pretos) e a sua tendência (linhas vermelhas) ${ }^{[30]}$.

(Adaptada de WMO, 2013)

O desenvolvimento da economia mundial combinada com o aumento de emissões tem elevado à taxa de crescimento do $\mathrm{CO}_{2}$ proveniente de combustível fóssil. Em longo prazo as evidências desses aumentos implicam em um declínio na eficiência dos sumidouros de $\mathrm{CO}_{2}$ sobre a terra e oceanos ${ }^{[32]}$.

A contribuição global de cada setor para os principais GEE entre 1970 a 2005 é apresentada na Figura 11, onde se observa que a maior emissão foi referente ao $\mathrm{CO}_{2}$ proveniente da queima de combustíveis fósseis, ressaltando ainda que se considerarmos os quatro setores emissores de $\mathrm{CO}_{2}$, estes são maiores que a contribuição dos outros GEE ${ }^{[33]}$. 


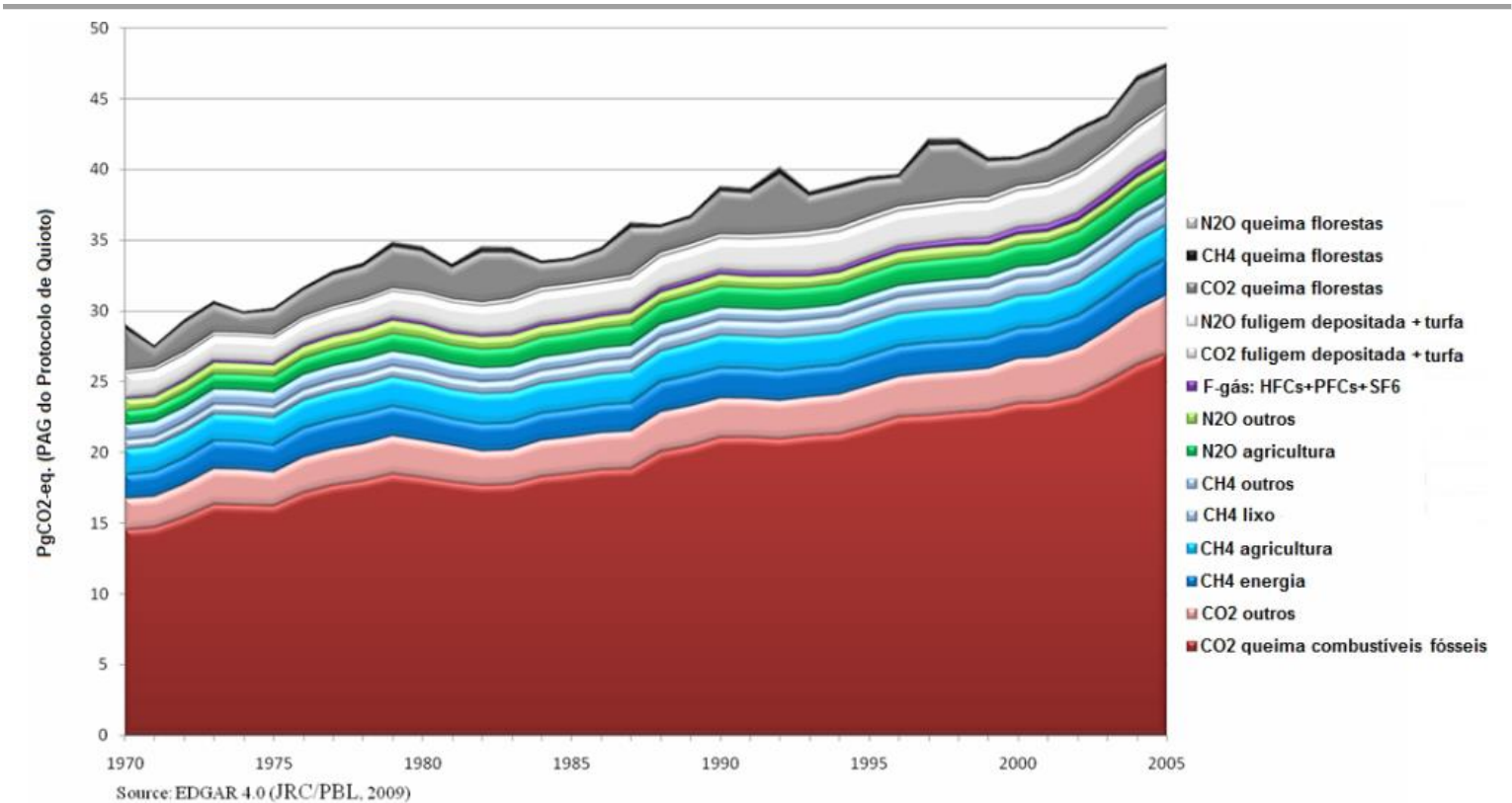

Figura 11: Contribuição das emissões globais dos GEE por setor ${ }^{[33]}$. (Adaptada de WMO/GGB, 2008)

A média global das concentrações de $\mathrm{CO}_{2}$, apresentada na Figura 12, mostram que desde 1984 vem ocorrendo um contínuo aumento deste gás, sendo que sua taxa de crescimento sofreu oscilações durante os anos. A média global de $\mathrm{CO}_{2}$ em 2012 foi de 393,1 \pm 0,1 ppm, um aumento de 2,2 ppm em relação a média registrada em $2011^{[20,30,34]}$.

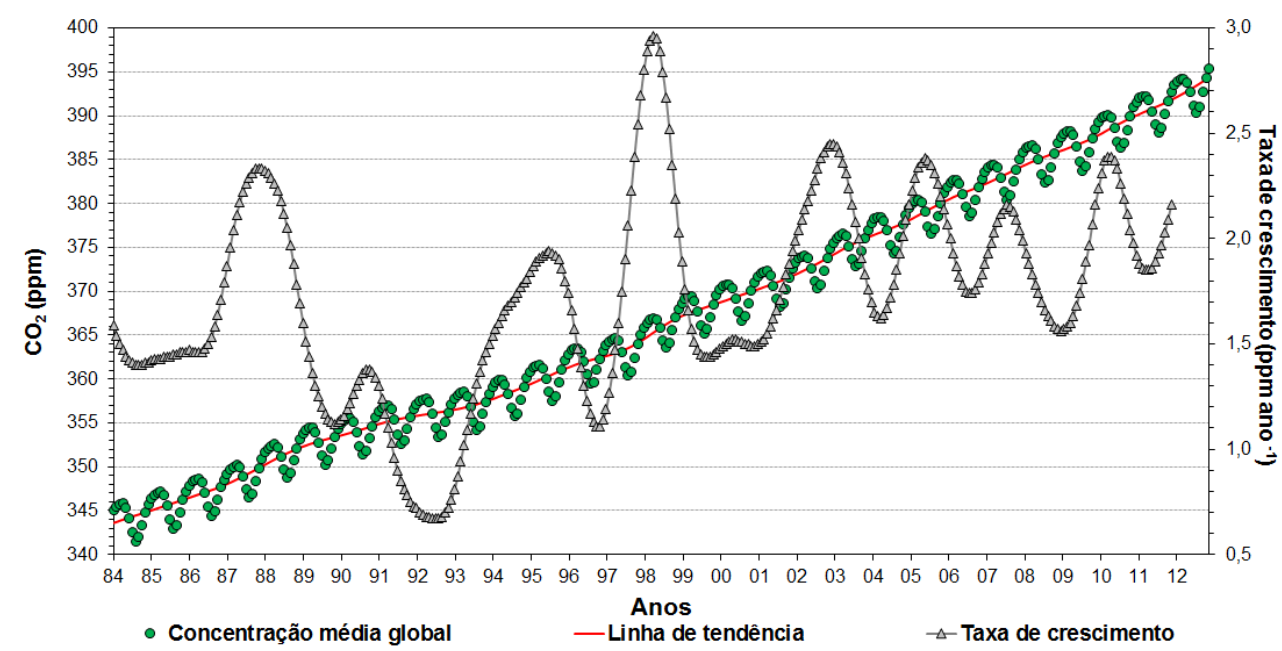

Figura 12: Média mensal global da concentração de $\mathrm{CO}_{2}$ e taxa de crescimento mensal entre 1984 a $2012^{[34]}$.

As emissões de $\mathrm{CO}_{2}$ mostram três grandes contribuidores a partir do combustível fóssil: o carvão, o petróleo e o gás natural. Existem também em menor escala as emissões provenientes da queima de gás natural como subproduto do processamento e extração do petróleo, e as emissões no processo 
de fabricação de cimento pela conversão de carbonato de cálcio $\left(\mathrm{CaCO}_{3}\right)$ para óxido de cálcio $(\mathrm{CaO})^{[35]}$.

As emissões de $\mathrm{CO}_{2}$ em 2011 foram distribuídas entre carvão (43\%), óleo (34\%), gás (18\%) e cimento (4,9\%), sendo as emissões globais provenientes da queima desses combustíveis e produção de cimento de 9,5 $\pm 0,5 \mathrm{PgC}$, e a emissão a partir da mudança no uso da terra de $0,9 \pm 0,5 \mathrm{PgC}{ }^{[4]}$, como pode ser observado na Figura 13.
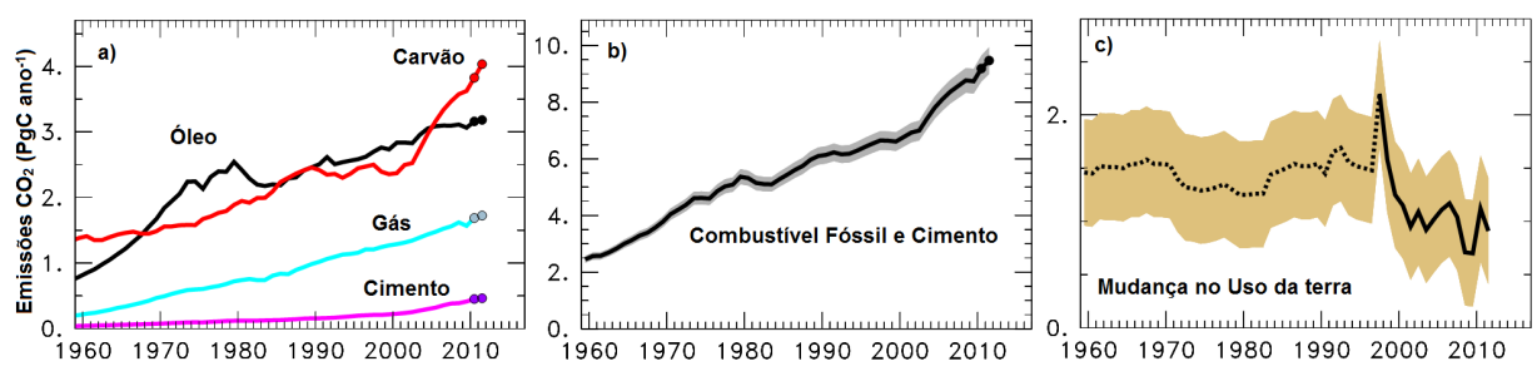

Figura 13: (a) Emissões globais de $\mathrm{CO}_{2}$ por tipo de combustível, os círculos representam valores extrapolados, (b) emissão global de $\mathrm{CO}_{2}$ a partir de combustível fóssil e cimento e (c) pela mudança no uso da terra, baseada em atividades de incêndio em áreas desmatadas ${ }^{[4]}$.

(Adaptada de Le Quéré et al., 2013)

O aumento da utilização de combustíveis fósseis (Figura 13) coincide com o crescimento da população mundial, como apresentado na Figura 14, onde podemos observar que a partir de 1950 houve um crescimento exponencial da população. Segundo estimativa de organizações mundiais, em 2011 foi alcançada a marca de 7 bilhões de habitantes ${ }^{[36,37]}$.

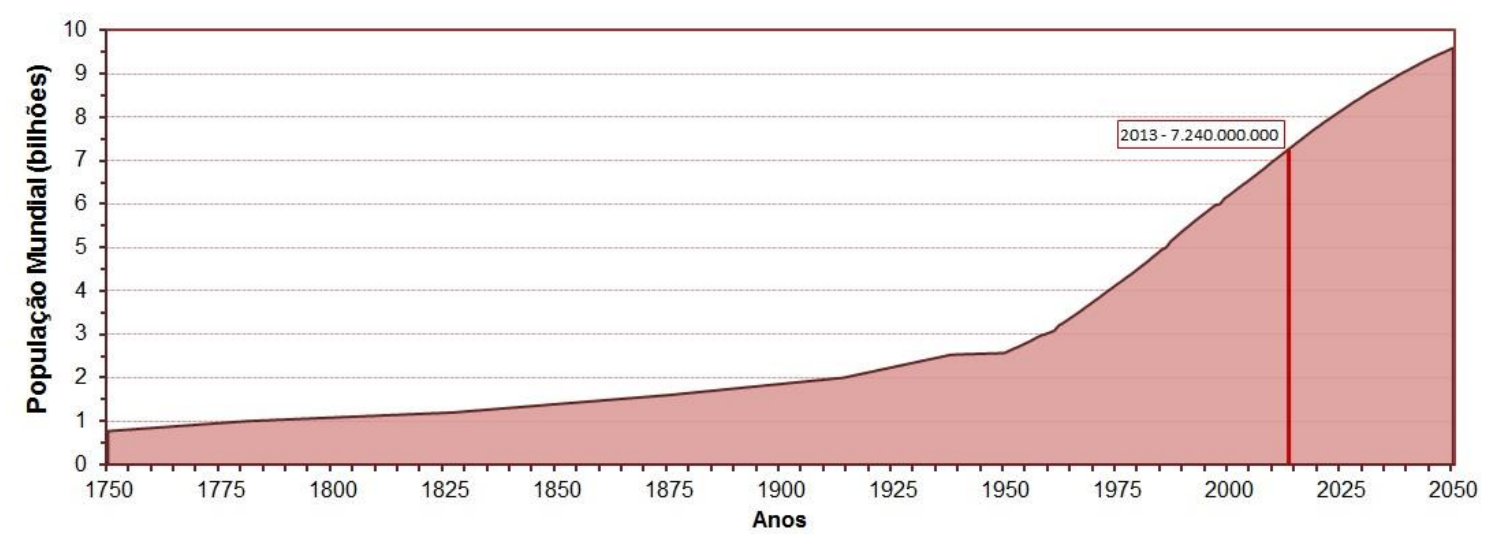

Figura 14: População mundial e estimativa entre 1914 a $2050^{[36,37]}$.

De acordo com a Segunda Comunicação Nacional do Brasil à Convenção-Quadro das Nações Unidas sobre Mudança do Clima e as Estimativas anuais de emissões de gases de efeito estufa no Brasil, a maior 
parcela da emissão de $\mathrm{CO}_{2}$ em 2005, foi proveniente da mudança no uso da terra e florestas ${ }^{[38,39]}$, responsável por $74 \%$ das emissões. Em 2010 este setor foi responsável por 36\% das emissões, como mostra a Figura 15.

Esta redução de $74 \%$ para $36 \%$ esta relacionada a diminuição do desmatamento que a partir de 2005 sofreu uma queda praticamente constante como pode ser observado na Figura $16{ }^{[40]}$. A partir dessa redução no setor de mudança e uso da terra e florestas, a maior parte da emissão de $\mathrm{CO}_{2}$ em 2010 foi relativo ao setor de energia.
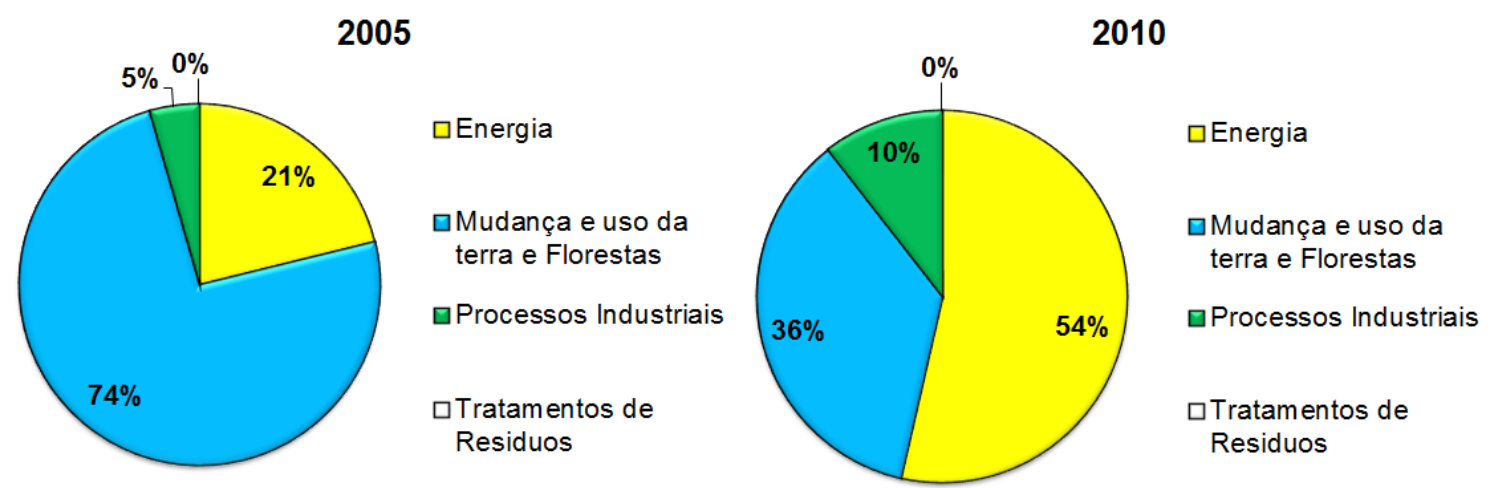

Figura 15: Emissões de $\mathrm{CO}_{2}$ por setor no ano de 2005 e $2010^{[39]}$.

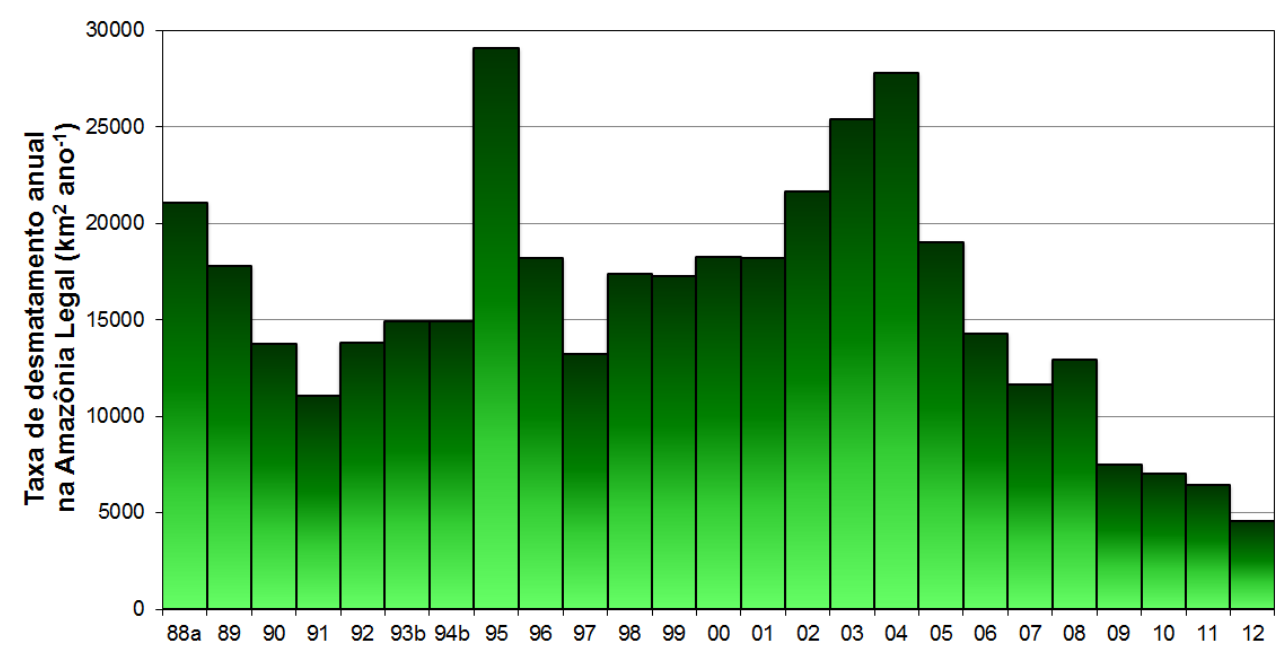

Figura 16: Taxa de desmatamento anual na Amazônia legal entre 1988 a 2012, onde (a) é a média entre 1977-1988, e (b) é a média entre 1993-1994 ${ }^{[40]}$.

A soma da contribuição de todos os setores no Brasil em 2005 revela uma emissão de $1,64 \mathrm{Pg}$ de $\mathrm{CO}_{2}$ provenientes de fontes antrópicas ${ }^{[38]}$. Segundo estimativa de emissão para cada país do mundo com base nos dados do projeto EDGAR versão 4.2 (Emissions Database for Global Atmospheric Research) ${ }^{[41]}$, foi estimada uma emissão de $1,82 \mathrm{Pg}$ de $\mathrm{CO}_{2}$, este valor corresponde a $2,5 \%$ da emissão mundial. 


\subsection{Metano $\left(\mathrm{CH}_{4}\right)$}

$\mathrm{O}_{4}$ é o segundo mais importante GEE na atmosfera, tem um PAG de 21 vezes maior que o $\mathrm{CO}_{2}$ em um cenário de cem anos, possui um tempo de vida de 12 anos e contribuiu com aproximadamente $18 \%$ no aumento da FR de 1750 a $2011^{[8,13,30]}$.

É produzido em ambientes anaeróbicos, onde as bactérias metanogênicas consomem matéria orgânica e liberam $\mathrm{CH}_{4}$, como plantações de arroz, aterros, zonas úmidas e sistema digestivo de bovinos, ovinos e cupins. A decomposição de carbono fóssil no solo resulta em um gás com mais de $90 \%$ de $\mathrm{CH}_{4}$, sendo lançado para a atmosfera, ou utilizado na produção de energia. Outra fonte de $\mathrm{CH}_{4}$ é a queima de biomassa, combustíveis fósseis, e reações químicas atmosféricas ${ }^{[8,31,42]}$.

Aproximadamente $40 \%$ das emissões globais de $\mathrm{CH}_{4}$ ocorrem por fontes naturais como pântanos, oceanos, florestas, cupins, fogo e fontes geológicas, e em torno de $60 \%$ por fontes antrópicas como agriculturas de arroz, pecuária, aterros sanitários, tratamento de resíduos e queima de biomassa e combustível ${ }^{[28,38,43,44,45]}$.

A remoção de $\mathrm{CH}_{4}$ na atmosfera ocorre principalmente por reação com o radical hidroxila $(\mathrm{OH})$ na troposfera e estratosfera ${ }^{[2,3,31]}$. É considerado também uma das mais importantes fontes de vapor d'água na estratosfera ${ }^{[8,30,45]}$.

A maior emissão de $\mathrm{CH}_{4}$ ocorre no $\mathrm{HN}$ como pode ser observado pelas altas variações sazonais apresentadas na Figura 17, e entre o equador e $30^{\circ}$ ao Sul é observada uma menor magnitude sazonal como mostra a Figura 18. Ao longo dos anos também é observado um aumento nas concentrações de $\mathrm{CH}_{4} \mathrm{em}$ ambos os Hemisférios ${ }^{[30]}$.

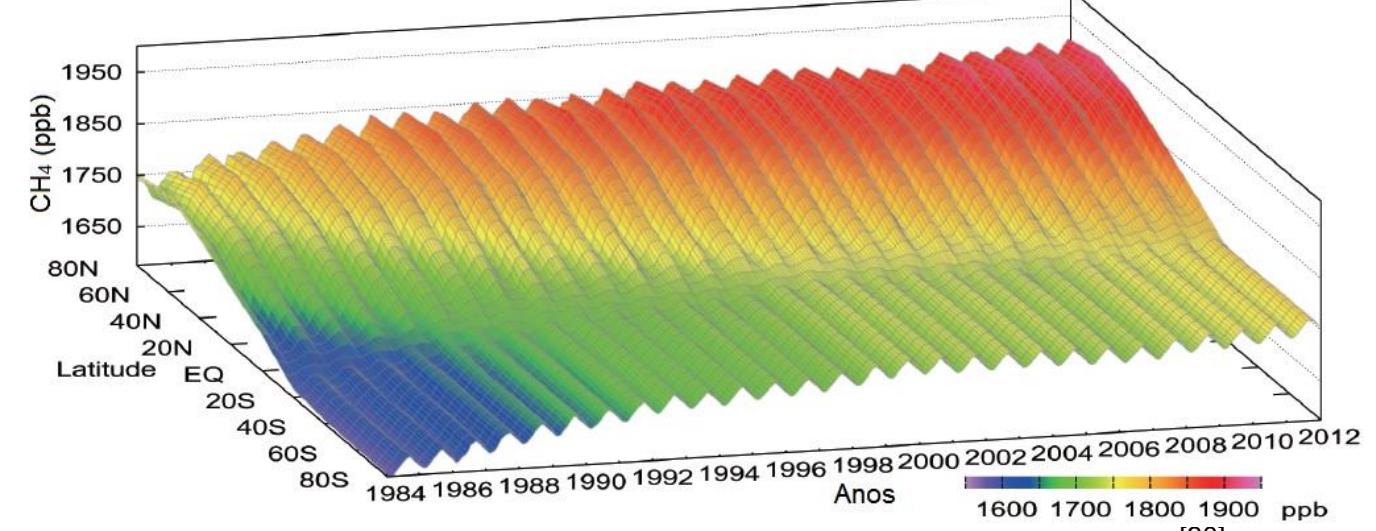

Figura 17: Distribuição da concentração global de $\mathrm{CH}_{4}{ }^{[30]}$. (Adaptada de WMO, 2013) 


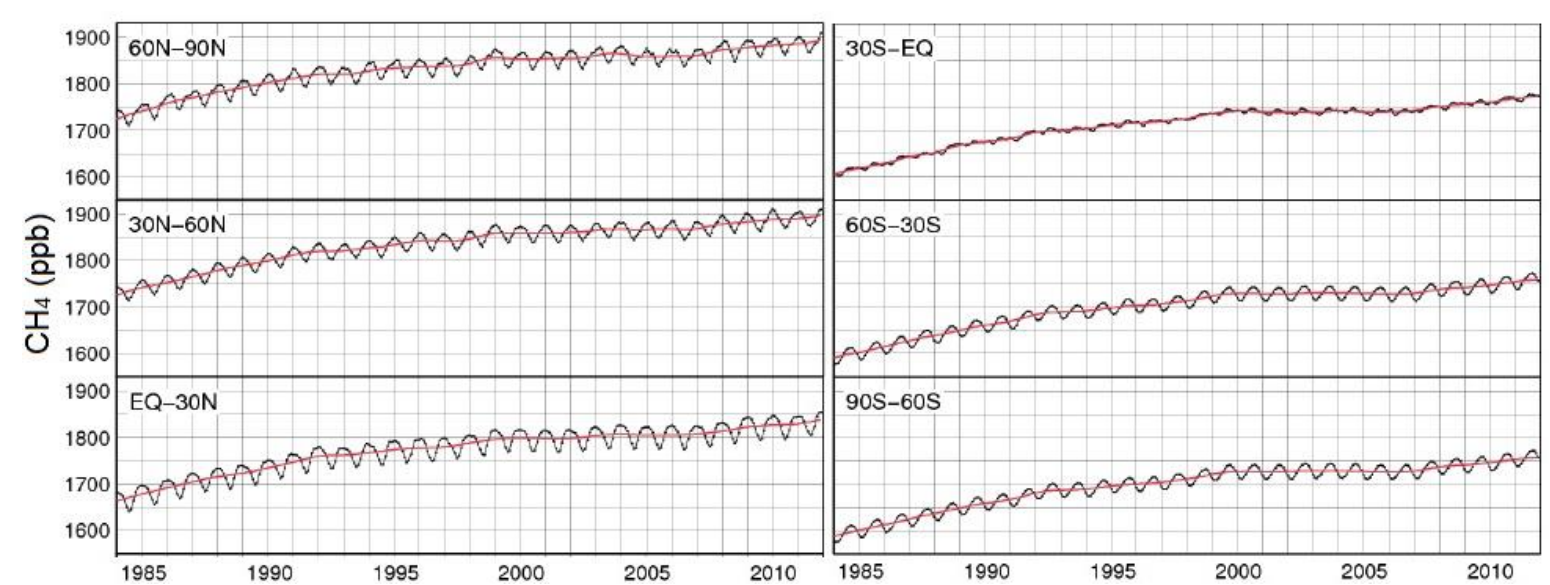

Figura 18: Média mensal das concentrações de $\mathrm{CH}_{4}$ (pontos pretos) e a sua tendência (linhas vermelhas) ${ }^{[30]}$.

(Adaptada de WMO, 2013)

Estudos constataram que o aumento observado em 2007 foi possivelmente devido a elevada temperatura nas altas latitudes no $\mathrm{HN}$, nas regiões polares, resultando no aumento da emissão de áreas alagadas, e as emissões de regiões tropicais alagadas entre 2007 a 2008 foram relacionadas com a maior precipitação durante o episódio La Niña ${ }^{[17,46]}$.

A média global de $\mathrm{CH}_{4}$ em 2012 foi de $1.819 \mathrm{ppb} \pm 1 \mathrm{ppb}$, um aumento de $6 \mathrm{ppb}$ em relação ao ano anterior. A taxa de crescimento diminuiu de aproximadamente $13 \mathrm{ppb} \mathrm{ano}^{-1}$ durante a década de 1980 para próximo de zero entre 1999 a 2006. E desde 2007 a concentração atmosférica do $\mathrm{CH}_{4}$ tem aumentando com uma taxa constante nos últimos três anos, como apresentado na Figura 19. A distribuição das observações ainda é muito escassa, principalmente nos trópicos, para compreender plenamente o novo aumento em abundância de $\mathrm{CH}_{4}{ }^{[20,30,34]}$.

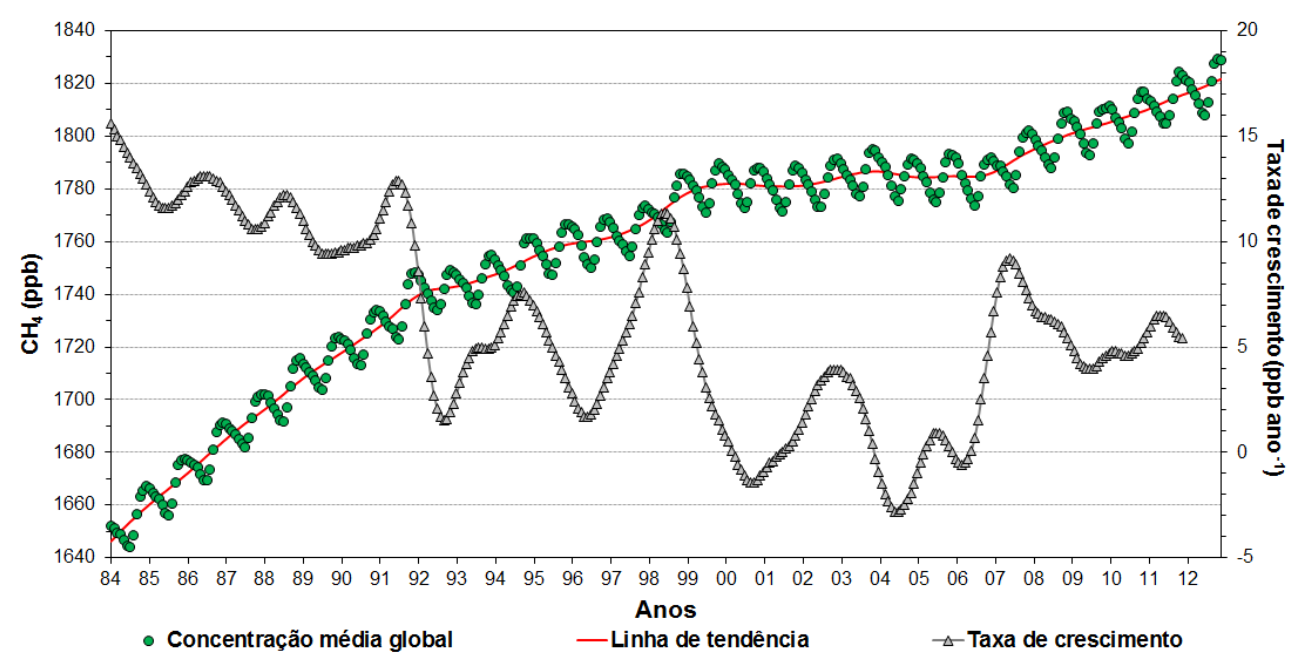

Figura 19: Média mensal global da concentração de $\mathrm{CH}_{4}$ e taxa de crescimento mensal entre 1984 a $2012^{[34]}$. 
De acordo com a Segunda Comunicação Nacional e com as

Estimativas anuais de emissões de gases de efeito estufa no Brasil para o ano de 2005, 71\% das emissões de $\mathrm{CH}_{4}$ foram provenientes da Agropecuária [38,39]. Sendo a principal fonte emissora desse setor a fermentação entérica do rebanho de ruminante, maioria referente ao gado bovino (considerado o segundo maior do mundo), contribuindo com $11,4910^{-3} \mathrm{Pg}$ de $\mathrm{CH}_{4}{ }^{[38]}$. Em 2010, a contribuição deste setor se elevou para 78\% conforme pode ser observado na Figura 20.
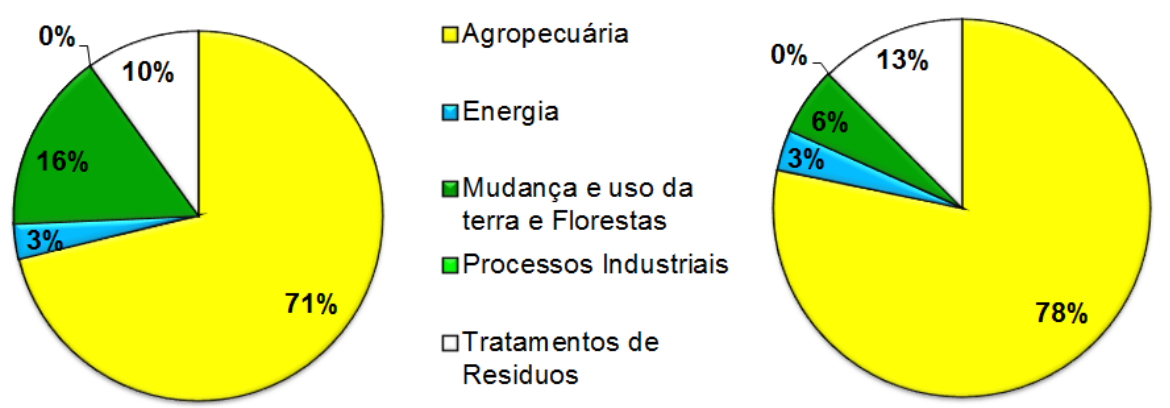

$\square$ Agropecuária

口Energia

qMudança e uso da terra e Florestas

口Processos Industriais

$\square$ Tratamentos de

Residuos

Figura 20: Emissões de $\mathrm{CH}_{4}$ por setor no ano de 2005 e $2010^{\text {[39]. }}$

A segunda maior contribuição em 2005 foi do setor de mudança do uso da terra e florestas, contribuindo com $16 \%$ das emissões de $\mathrm{CH}_{4}{ }^{[38]}$, e em 2010 este setor sofreu uma diminuição de $10 \%{ }^{[39]}$ sendo isso relacionado a redução do desmatamento.

De acordo com esse inventário brasileiro, o total da contribuição nacional na emissão de $\mathrm{CH}_{4}$ em 2005 foi de $18,1110^{-3} \mathrm{Pg}{ }^{[38]}$. $\mathrm{E}$, segundo os resultados disponíveis na base de dados EDGAR ${ }^{[41]}$, para o mesmo ano, essa contribuição nacional foi de $23,4410^{-3} \mathrm{Pg}$, o qual representa aproximadamente $7 \%$ da emissão mundial.

\section{3 Óxido nitroso $\left(\mathrm{N}_{2} \mathrm{O}\right)$}

$\mathrm{O} \mathrm{N}_{2} \mathrm{O}$ é o terceiro mais importante GEE na atmosfera e contribui com aproximadamente $6 \%$ da $\mathrm{FR}$, o seu PAG é 310 vezes maior que do $\mathrm{CO}_{2} \mathrm{em}$ um cenário de cem anos, e apresenta um tempo de vida de 114 anos ${ }^{[13,30,43]}$.

Este gás é emitido quase totalmente por fontes naturais principalmente por ação das bactérias no solo, e por fontes biológicas nos solos e água, sendo o solo tropical uma importante fonte individual para a atmosfera. $\mathrm{O} \mathrm{N}_{2} \mathrm{O}$ pode ser emitido em pequenas quantidades por inúmeras fontes como a queima de 
biomassa, atividades agrícolas e processos industriais. O oceano também é uma fonte significante deste gás ${ }^{[2]}$.

Aproximadamente $60 \%$ da emissão de $\mathrm{N}_{2} \mathrm{O}$ para a atmosfera ocorrem a partir de fontes naturais e $40 \%$ por fontes antrópicas. Como exemplo de fontes temos os oceanos, os solos, a queima de combustíveis e biomassa, o uso de fertilizantes nitrogenados e processos industriais ${ }^{[13,43,47]}$. A decomposição de $\mathrm{N}_{2} \mathrm{O}$ ocorre por processos fotoquímicos na estratosfera. No entanto, o ciclo de $\mathrm{N}_{2} \mathrm{O}$ como parte do ciclo de nitrogênio global, ainda não é bem compreendido ${ }^{[18,30]}$.

As concentrações globais de $\mathrm{N}_{2} \mathrm{O}$ entre os anos de 1980 a 2012 apresentaram pequenas variações sazonais entre o $\mathrm{HN}$ e $\circ \mathrm{HS}$, como pode ser observado na Figura 21. Entre os anos de 1980 a 2011 as concentrações globais de $\mathrm{N}_{2} \mathrm{O}$ apresentaram uma diferença de 1,1 ppb entre os Hemisférios indicando uma fonte de emissão um pouco maior do $\mathrm{HN}$, principalmente da agricultura, como observado na Figura $22^{[30]}$.

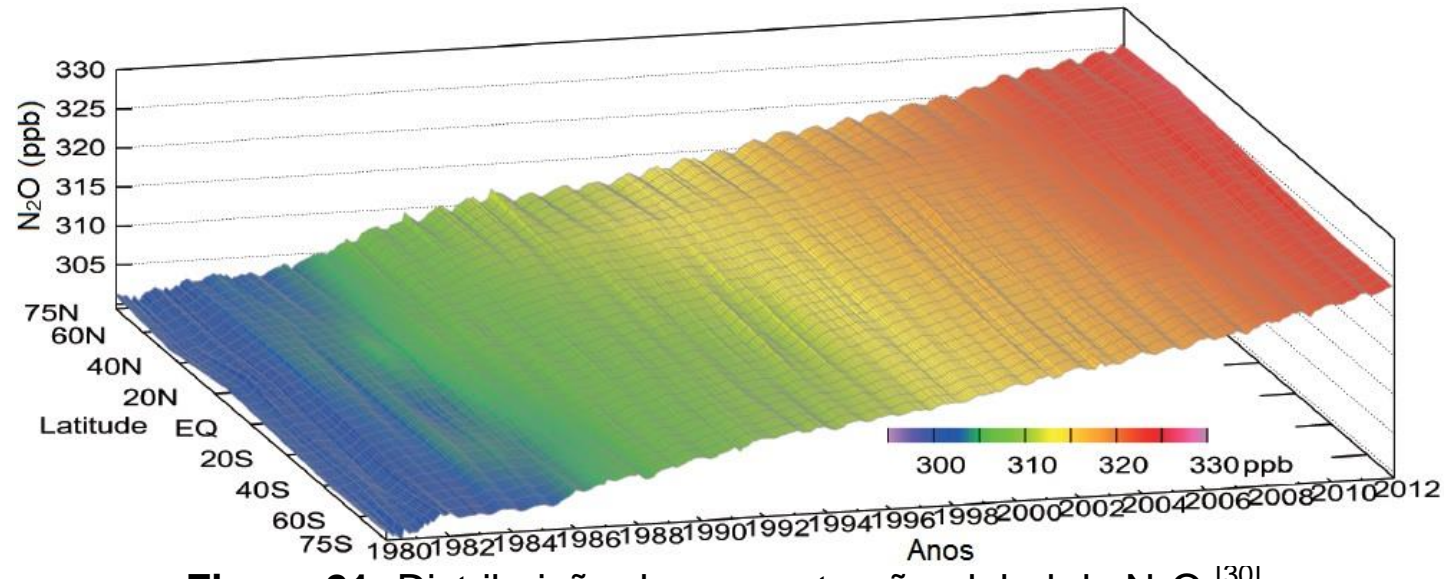

Figura 21: Distribuição da concentração global de $\mathrm{N}_{2} \mathrm{O}{ }^{[30]}$. (Adaptada de WMO, 2013)
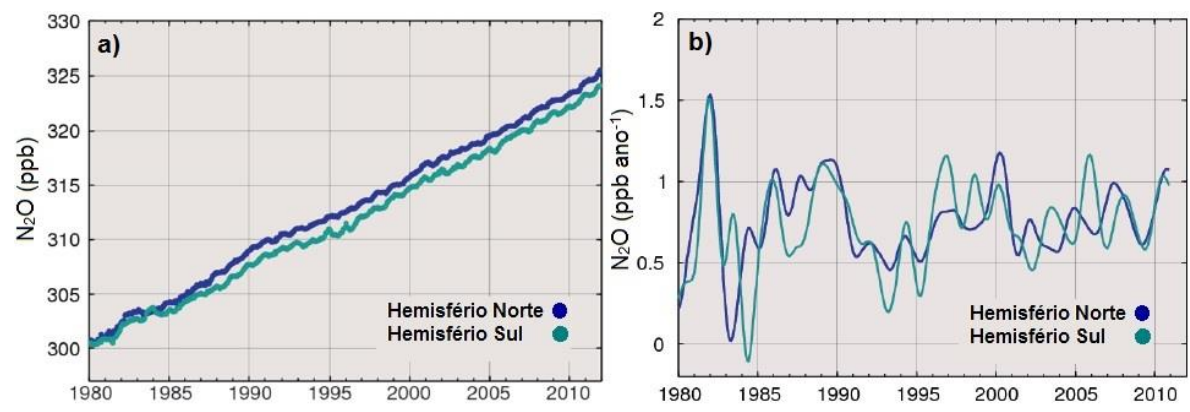

Figura 22: (a) Média mensal das concentrações de $\mathrm{N}_{2} \mathrm{O}$ e (b) a taxa de crescimento anual, sobre a média dos Hemisférios Norte e Sul ${ }^{[30]}$ (Adaptada de WMO, 2013) 
A concentração média global de $\mathrm{N}_{2} \mathrm{O}$ entre 1980 a 2012 é apresentada na Figura 23. No ano de 2012, a média global de $\mathrm{N}_{2} \mathrm{O}$ foi de $325,1 \mathrm{ppb} \pm 0,1 \mathrm{ppb}$, ocorrendo o aumento de $0,9 \mathrm{ppb}$ em relação ao ano anterior. A concentração média registrada em 2012 representa em torno de $20 \%$ acima do valor registrado na era industrial que era de $270 \mathrm{ppb}{ }^{[20,30,34]}$.

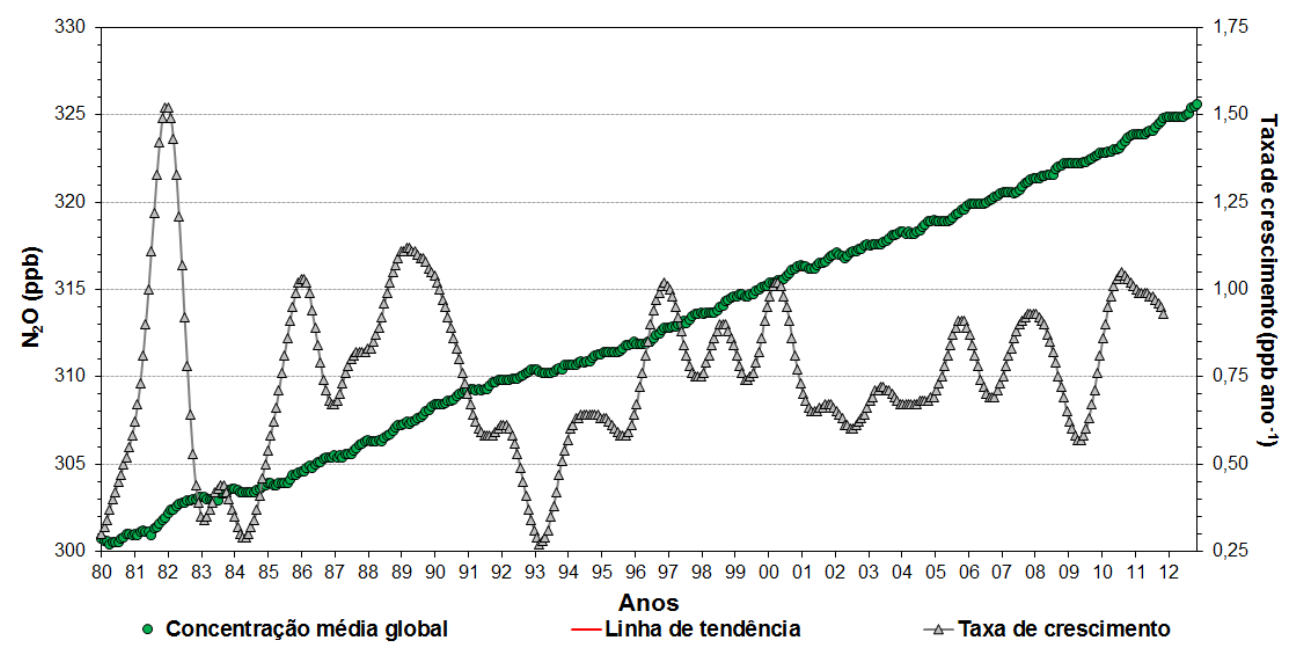

Figura 23: Média mensal global da concentração de $\mathrm{N}_{2} \mathrm{O}$ e taxa de crescimento mensal entre 1980 a $2012^{[34]}$.

Alguns modelos mostram fontes adicionais na emissão de $\mathrm{N}_{2} \mathrm{O}$ como rios, estuários e plataformas continentais, que têm aumentado como resultado das atividades humanas que resultam em maior disponibilidade de nitrogênio nos sistemas aquáticos. Esses modelos estimaram uma emissão a partir de rios e estuários de $1,5010^{-3} \mathrm{Pg} \mathrm{N}_{\text {ano }}{ }^{-1}$, e indicam que maior parte do $\mathrm{N}_{2} \mathrm{O}$ emitido foi do Oceano Atlântico ${ }^{[48]}$.

De acordo com a Segunda Comunicação Nacional e com as Estimativas anuais de emissões de gases de efeito estufa no Brasil para o ano de 2005, 87\% das emissões de $\mathrm{N}_{2} \mathrm{O}$ foram provenientes da Agropecuária, e em 2010 houve um aumento de $6 \%$ em relação a 2005 , como apresenta a Figura $24{ }^{[38,39]}$. Os outros setores que contribuíam com emissões de $\mathrm{N}_{2} \mathrm{O}$ em 2005 representavam 13\% e em 2010 praticamente reduziram para metade deste valor contribuindo com $7 \%$.

Segundo o inventário brasileiro em 2005 o total das emissões de $\mathrm{N}_{2} \mathrm{O}$ foi de $5,4610^{-4} \mathrm{Pg}{ }^{[38]}$, e segundo estimativa da base de dados EDGAR ${ }^{[41]}$, a emissão foi em torno de $7,7210^{-4} \mathrm{Pg}$, representando aproximadamente $7,4 \%$ da emissão mundial. 


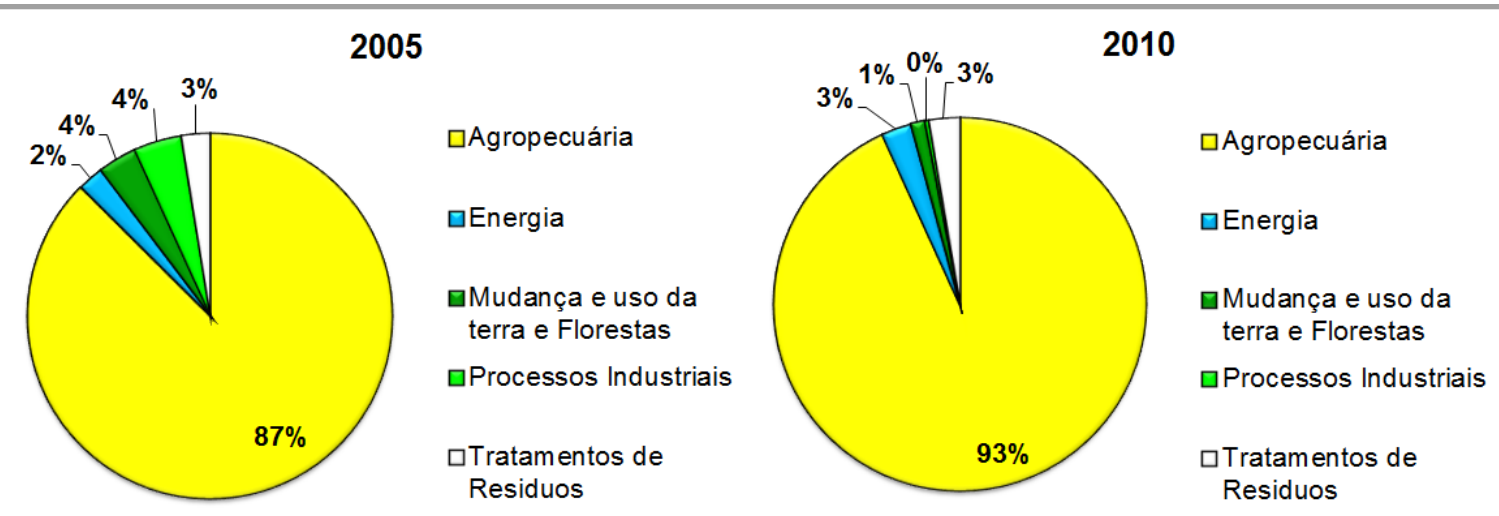

Figura 24: Emissões de $\mathrm{N}_{2} \mathrm{O}$ por setor no ano de 2005 e $2010^{[39]}$.

\subsection{Hexafluoreto de enxofre $\left(\mathrm{SF}_{6}\right)$}

$\mathrm{O} \mathrm{SF}_{6}$ é um potente GEE possuindo um PAG de 23.900 vezes maior que o $\mathrm{CO}_{2}$ e um tempo de vida na atmosfera de 3.200 anos ${ }^{[13,19]}$. É um gás inerte ao longo da troposfera e da estratosfera e lentamente sofre fotólise na mesosfera. É um gás produzido artificialmente, e seu principal uso é como isolante em sistemas de transmissão de eletricidade, além de sua utilização no processo de produção de magnésio. Como não existe fonte natural deste gás, o $\mathrm{SF}_{6}$ é utilizado para traçar massas de ar, avaliando o transporte troposférico previsto pelos modelos, já que sua emissão está ligada à atividade humana ${ }^{[38,49,50,51]}$.

Como o $\mathrm{SF}_{6}$ possui solubilidade muito baixa, sua taxa de absorção é muito lenta, fazendo com que sumidouros como a mesosfera e os oceanos sejam insignificantes quando comparados às emissões antrópicas ${ }^{[49]}$. Estudos revelam que $94 \%$ do total da contribuição mundial são relativos ao $\mathrm{HN}^{[50]}$.

A concentração de $\mathrm{SF}_{6}$ em 2012 mais que dobrou em relação ao ano de 1995, estando próximo de 8 ppt no final de 2012. O contínuo aumento da concentração média deste gás, representado por 20 estações de monitoramento global, pode ser observado na Figura $25^{[20]}$.

O Brasil não é produtor de $\mathrm{SF}_{6}$, assim sendo, as emissões informadas no inventário brasileiro devem-se apenas a vazamentos em equipamentos instalados no país devido a sua manutenção ou descarte. As emissões brasileiras de $\mathrm{SF}_{6}$ em 2005 foram de 2,50 10-8 $\mathrm{Pg}$, aumentando $153 \%$ entre 1990 e $2005^{[38]}$. Segundo estimativa da base de dados EDGAR ${ }^{[41]}$ para o ano de 2005, esta contribuição foi de $5,0010^{-8} \mathrm{Pg}$, representando quase $1 \%$ da emissão mundial. No ano de 2010 ocorreu uma redução na emissão de $\mathrm{SF}_{6}$ sendo estimado um valor de $7,0010^{-9} \mathrm{Pg}^{[39]}$. 


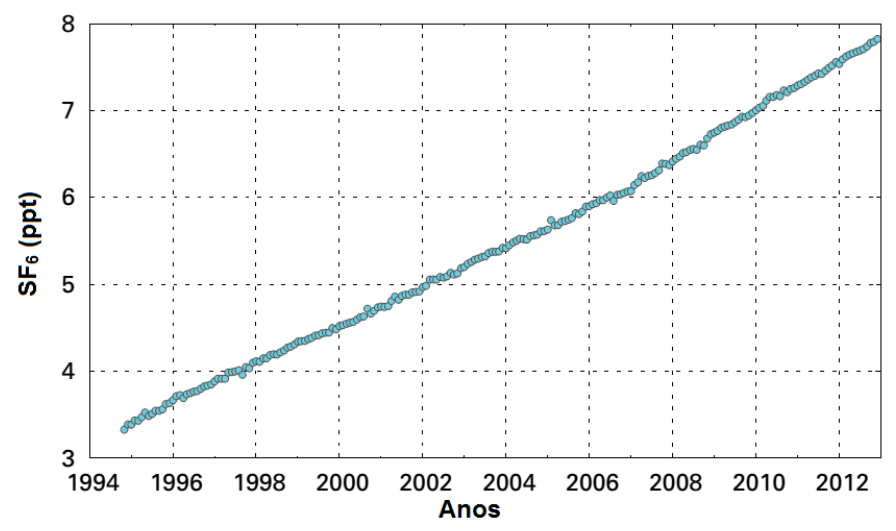

Figura 25: Média da concentração mensal de $\mathrm{SF}_{6}$ de 1995 a $2012^{[20]}$. (Adaptada de WMO-GHG Bulletin, 2013)

\subsection{Monóxido de carbono (CO)}

O CO apesar de não ser propriamente um GEE, é um importante traçador de queimadas. As principais fontes de $\mathrm{CO}$ estão relacionadas à oxidação de $\mathrm{CH}_{4}$, queima imperfeita de combustíveis fósseis ou resíduos e queima de biomassa, apenas uma pequena parcela resulta de processos produtivos, como a produção de alumínio ${ }^{[3,8,30,31,38]}$.

Os principais sumidouros incluem reações $\mathrm{com} \mathrm{OH}$ e deposição na superfície. As emissões antrópicas de CO não levam ao acumulo de $\mathrm{CO}$ na atmosfera e, além disso, a distribuição desigual de fontes acaba provocando grandes variações na concentração de $C \mathrm{O}^{[2,30,31]}$.

A variação sazonal da concentração global de $\mathrm{CO}$ ocorre com maior intensidade no $\mathrm{HN}$ e com menor intensidade no HS, como mostra a Figura 26. Essa variação provavelmente está relacionada à presença de inúmeras fontes antrópicas nas altas latitudes juntamente com a destruição deste gás nos trópicos onde radicais $\mathrm{OH}$ são abundantes ${ }^{[30]}$.

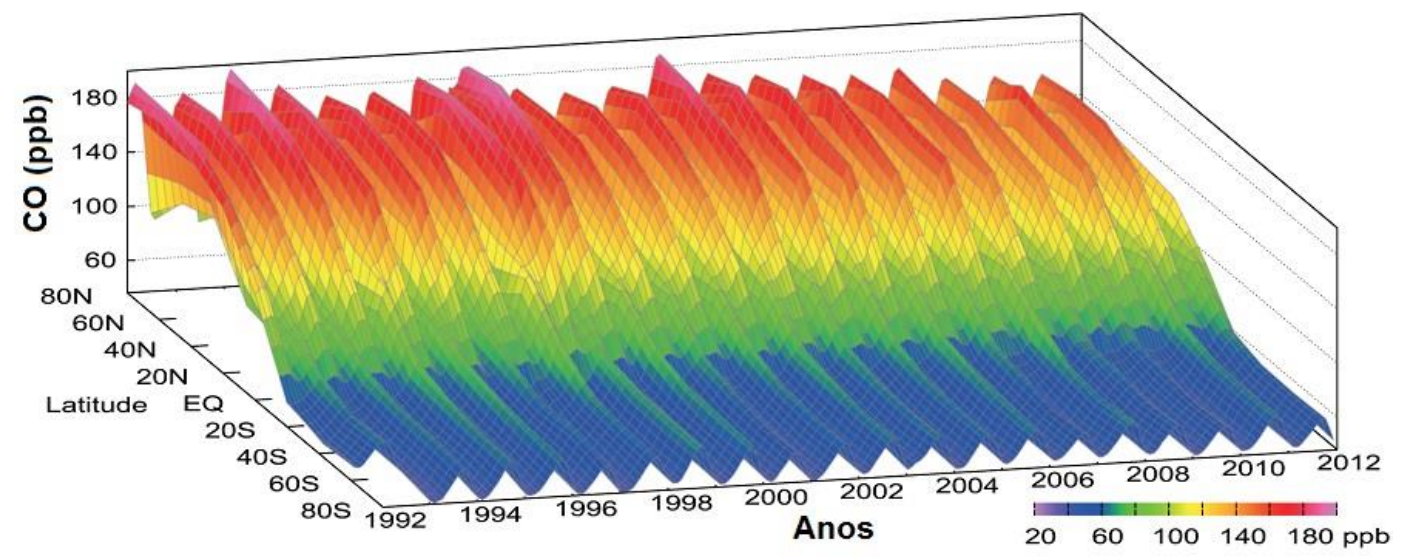

Figura 26: Distribuição da concentração global de $\mathrm{CO}{ }^{[30]}$. (Adaptada de WMO, 2013) 
As variações sazonais a cada $30^{\circ}$ são apresentadas na Figura 27 , onde podemos observar que entre o equador e $30^{\circ}$ ao Sul ocorre uma menor variação sazonal quando comparada as outras faixas de latitude, além de não apresentar uma sazonalidade definida como ocorre nas outras latitudes. A concentração média global de CO foi de $89 \pm 2$ ppb no ano de $2011^{[30]}$.

Segundo o inventário brasileiro no ano de 2005 , o total das emissões de $\mathrm{CO}$ foram de $41,3410^{-3} \mathrm{Pg}$, sendo $64 \%$ das emissões provenientes do setor de mudança do uso da terra e florestas e, $27 \%$ do setor de energia como mostra a Figura $28{ }^{[38]}$. Com base nas estimativas dos dados do projeto EDGAR ${ }^{[41]}$, a contribuição brasileira na emissão de CO em 2005 foi de $101,8110^{-3} \mathrm{Pg}$, este valor representa aproximadamente $11 \%$ da emissão mundial. A diferença entre 0 inventário brasileiro e o estimado pelo projeto EDGAR foi de $60,4710^{-3} \mathrm{Pg}$, representando que os inventários brasileiros podem estar subestimando os valores de emissão no país.

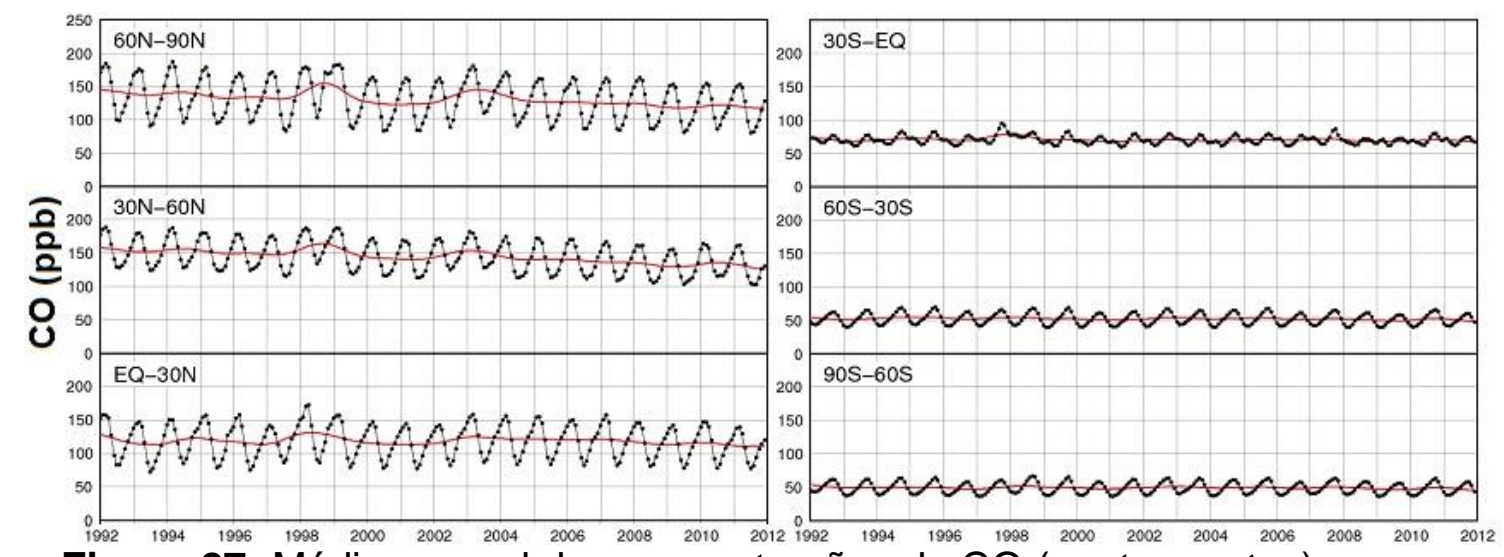

Figura 27: Média mensal das concentrações de CO (pontos pretos) e a sua tendência (linhas vermelhas).

(Adaptada de WMO, 2013)

2005

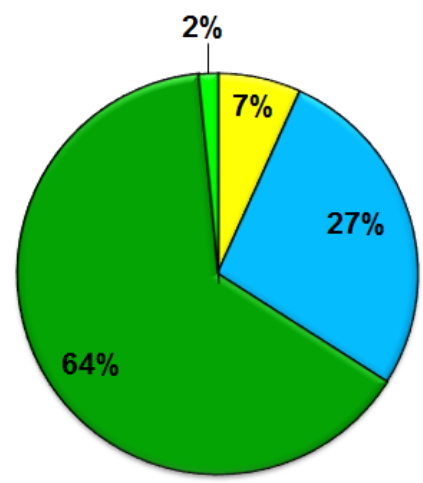

$\square$ Agropecuária (queima de resíduos)

口Energia

घMudança no uso da terra e florestas

$\square$ Processos industriais

Figura 28: Emissões de CO por setor no ano de $2005^{[38]}$. 


\section{METODOLOGIA}

\subsection{Costa Brasileira}

A área costeira abrange ambientes climáticos diversos, desta forma, mudanças climáticas que ocorram tanto no continente quanto no Oceano Atlântico, como ciclones extratropicais na porção norte e sul, Zona de Convergência Intertropical e tempestades tropicais, potencialmente podem trazer consequências importantes sobre a região costeira. Essa extensa área da costa abriga um rico mosaico de ecossistemas como estuários, ilhas, manguezais, restingas, dunas, praias, falésias, costões rochosos e recifes de corais ${ }^{[38]}$.

A distribuição geográfica da população nos estados costeiros é bem diferenciada, levando-se em conta apenas as microrregiões, situadas na região costeira, e dentro delas os municípios banhados pelo mar ou em ambientes estuarinos, a porcentagem da população brasileira que efetivamente reside na costa está entre $22 \%$ a $25 \%{ }^{[38]}$.

A região costeira pode ser considerada bem diversificada, pois nela há áreas com intensa urbanização, atividades portuária e industrial, e exploração turística. Por outro lado também se encontram áreas de baixa densidade ocupacional e ocorrência de ecossistemas de grande significado ambiental ${ }^{[38]}$.

\subsection{Locais de estudo}

Salinópolis, também conhecida como Salinas é um município brasileiro localizado na região norte do país, no Estado do Pará. Apresenta como bioma o amazônico, além de possuir 37.421 habitantes em uma área territorial de $237,738 \mathrm{~km}^{2}$, de acordo com dados do Instituto Brasileiro de Geografia e Estáticas (IBGE) em $2010^{\text {[52]. }}$

A cidade de Salinópolis localiza-se a $00^{\circ} 36^{\prime} 49^{\prime \prime}$ de latitude ao sul e longitude de $47^{\circ} 21^{\prime} 22^{\prime \prime}$ a oeste, e altitude de 21 metros, estando distante cerca de $220 \mathrm{~km}$ da capital do Estado, Belém. A economia desta cidade é baseada no turismo e na pesca, além de ser considerada o balneário preferido da população de Belém que nas férias lota a cidade. 
As praias de Salinópolis possuem areia fina e branca, com águas de tons verde-acinzentada devido aos sedimentos carregados pelo rio Amazonas. Em geral a paisagem é formada por praias, rios, igarapés, mangues e dunas.

O local de coleta no Estado do Rio Grande do Norte fica no município de Maxaranguape, localizando-se a 0531'02" de latitude ao sul e 351'ㄱ' a oeste, estando aproximadamente a $50 \mathrm{~km}$ ao norte da capital Natal, possuindo uma área de $131,316 \mathrm{~km}^{2}$ e 10.441 habitantes, tendo como biomas a Caatinga e a Mata Atlântica, de acordo com dados do IBGE de $2010^{[52]}$.

Os locais de estudo na costa brasileira são apresentados na Figura 29, assim como as estações de monitoramento global localizadas nas llhas de Ascension no Hemisfério Sul e Barbados no Hemisfério Norte. As coordenadas, em graus e em decimais, dos locais de coleta na costa brasileira e das estações globais da rede NOAA são apresentadas na Tabela 3, assim como as siglas que serão utilizadas para denominar esses locais ao decorrer do texto.

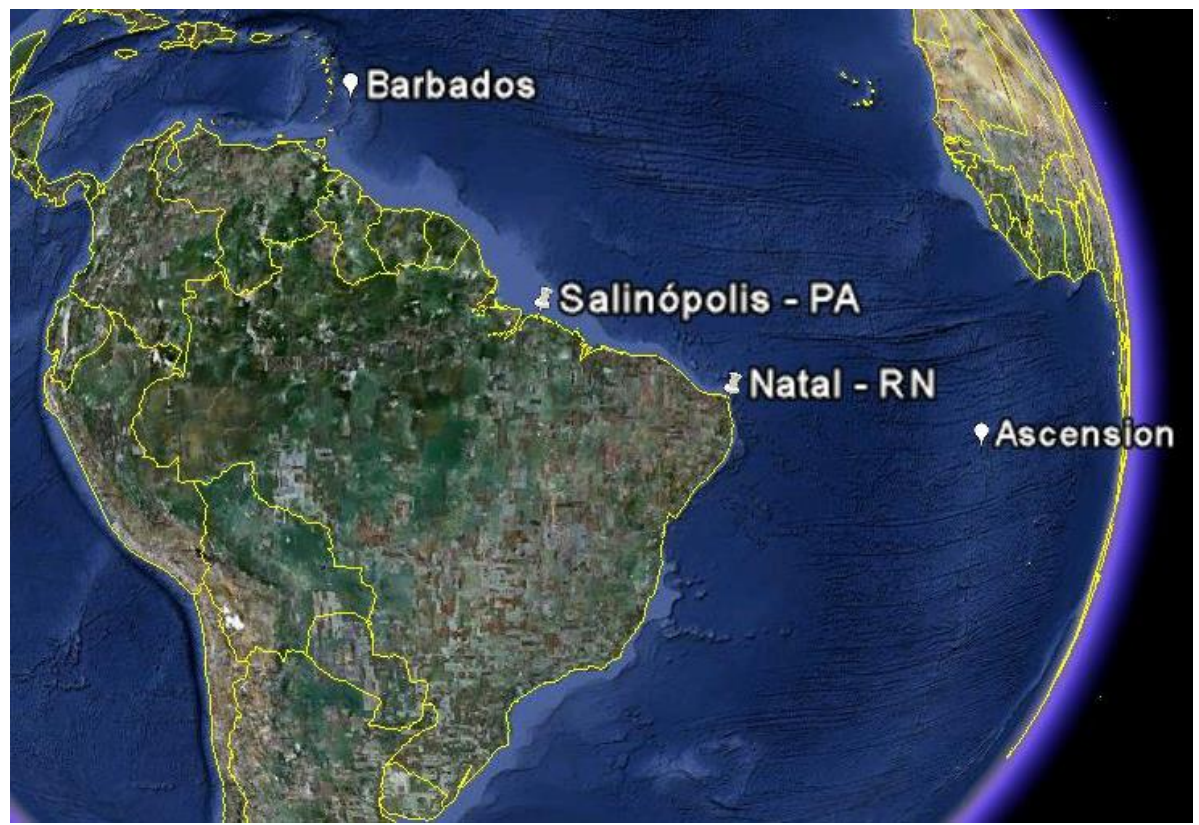

Figura 29: Locais de coleta na costa brasileira.

Tabela 3: Coordenadas dos locais de estudo e das estações globais da NOAA

\begin{tabular}{cccccc}
\hline \multicolumn{5}{c}{ Coordenadas e Locais } \\
\hline \multirow{2}{*}{ Locais } & \multirow{2}{*}{ Siglas } & \multicolumn{2}{c}{ Graus } & \multicolumn{2}{c}{ Decimal } \\
\cline { 3 - 6 } & Latitude & Longitude & Latitude & Longitude \\
\hline Salinópolis & SAL & $00^{\circ} 36^{\prime} 15,03^{\prime \prime} S$ & $47^{\circ} 22^{\prime} 25,02^{\prime \prime}$ & $-0,604$ & $-47,374$ \\
Natal & NAT & $05^{\circ} 29^{\prime} 22,05^{\prime \prime} S$ & $35^{\circ} 15^{\prime} 39,64^{\prime \prime} \mathrm{O}$ & $-5,489$ & $-35,261$ \\
Ascension & ASC & $07^{\circ} 96^{\prime} 67,00^{\prime \prime} \mathrm{S}$ & $14^{\circ} 40^{\prime} 00,00^{\prime \prime} \mathrm{O}$ & $-8,619$ & $-14,667$ \\
Barbados & RPB & $13^{\circ} 16^{\prime} 50,00^{\prime \prime} \mathrm{N}$ & $59^{\circ} 43^{\prime} 20,00^{\prime \prime} \mathrm{O}$ & 13,280 & $-59,722$ \\
\hline
\end{tabular}




\subsection{Amostragem}

As amostragens de ar foram realizadas em superfície semanalmente, nas duas localidades da costa brasileira em SAL e NAT.

Para a amostragem de ar foram utilizados frascos de vidro Pirex de 2,5 L, preparados previamente segundo procedimento do LQA/IPEN. A preparação consistiu em duas etapas: a primeira sendo uma etapa de limpeza, passando ar comprimido com 2,0\% de umidade relativa máxima, por 2 horas, como apresentado na Figura 30.

Este sistema contém filtros para a remoção de água do ar, um manômetro para medir a pressão de entrada no equipamento que deve estar entre 80 e 100 psi, e um equipamento de secagem com duas grandes colunas com peneira molecular $5 \mathrm{~A}$ e um sistema de autorregeneração.

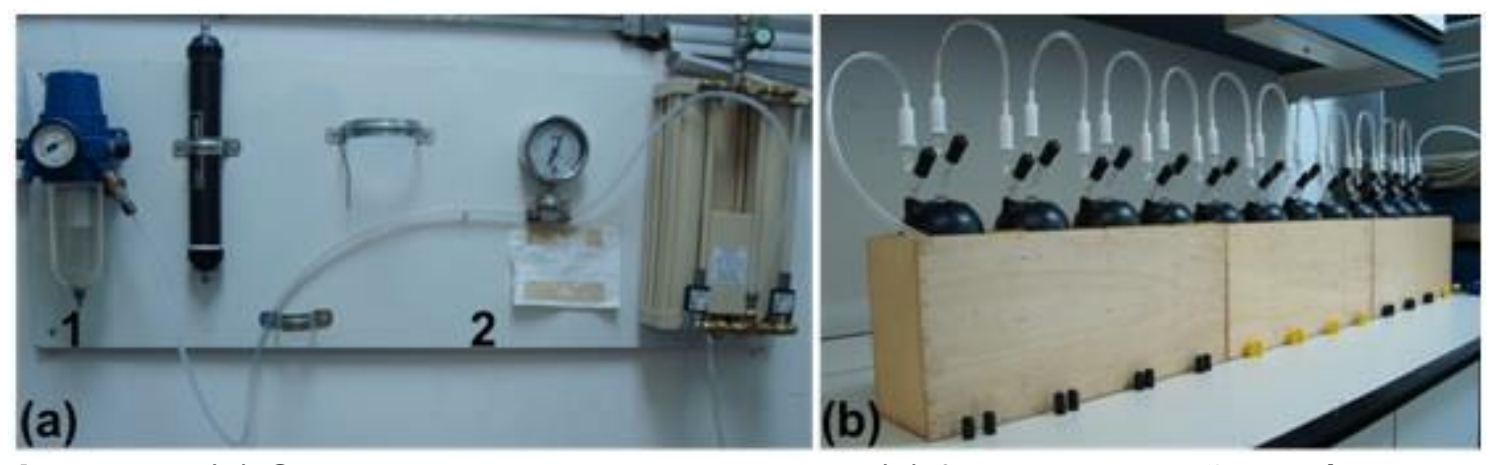

Figura 30: (a) Sistema de secagem de ar com: (1) filtro de remoção de água com manômetro e (2) equipamento de autorregeneração para secagem de ar com manômetro acoplado, e (b) limpeza de frascos com ar ultrasseco.

A segunda etapa consistiu em passar um gás preparado com ar sintético e com baixa concentração dos demais gases que serão analisados. Foi passado o gás pelos frascos por 20 minutos, com uma pressão de 4 psi, e finalizados com esta mesma pressão dentro do frasco. Os frascos são acondicionados com um gás de $330 \mathrm{ppm}$ de $\mathrm{CO}_{2}$ em balanço de Nitrogênio. $\mathrm{A}$ função deste procedimento é garantir que o gás dentro do frasco, antes da amostragem, tenha concentrações menores que a concentração dos GEE e demais gases traço que serão medidos no ar, para se evitar variação na concentração devido a adsorção pelos sítios ativos do vidro do frasco. Assim, o $\mathrm{CO}_{2}$ tem a função de evitar que esse processo ocorra, conservando o frasco adequadamente até o momento da coleta. 
As amostragens foram realizadas em torno de 5 metros acima do nível do mar, entre às 12 - 13 horas (horário local) e em duplicata, sendo dois frascos coletados simultaneamente. Em Natal, devido a um programa de intercomparação com o Laboratório da NOAA, foram coletados 4 frascos simultaneamente, sendo 2 para o IPEN e 2 para a NOAA. A duplicação na amostragem ocorre como um controle de qualidade da amostragem. Se a diferença entre os resultados dos 2 frascos for maior que um valor pré-determinado significa que ocorreu vazamento durante a amostragem. Para cada gás foi determinado um valor máximo aceitável de diferença entre os resultados dos dois frascos. Para $\circ \mathrm{CO}_{2}$, por exemplo, a diferença limite é de 0,5 ppm, estabelecida pela NOAA. Caso ultrapasse este valor a amostragem era desprezada.

O procedimento de amostragem foi realizado com o auxílio de um amostrador portátil, idealizado por nosso colaborador Doug Guenther da NOAA e desenvolvido o design e construído no LQA/IPEN, apresentado na Figura 31. Para a entrada de ar foi utilizado um mastro com 5 metros de tubo de teflon de $1 / 4^{\prime \prime}$ de diâmetro interno conectado ao amostrador. Primeiramente foi passado em torno de $50 \mathrm{~L}$ de ar dentro dos frascos $\left(6 \mathrm{~L} \mathrm{~min}^{-1}\right)$ como um procedimento de condicionamento dos frascos nas condições locais, finalizando a amostragem com uma pressão de 6 psi acima da pressão atmosférica.

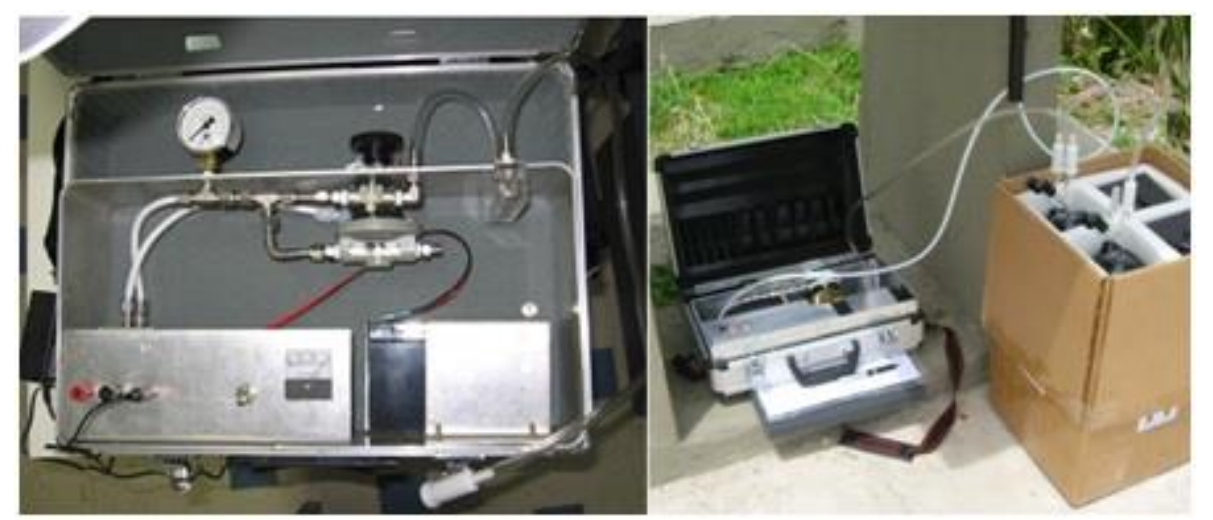

Figura 31: Amostrador portátil utilizado nas coletas.

Em SAL, as coletas foram iniciadas em janeiro de 2010, com a parceria de uma equipe do Rádio Farol de Salinópolis, $4^{\circ}$ Distrito Naval da Marinha do Brasil. A amostragem foi realizada na praia Corvina, conforme pode ser visto na Figura 32. 


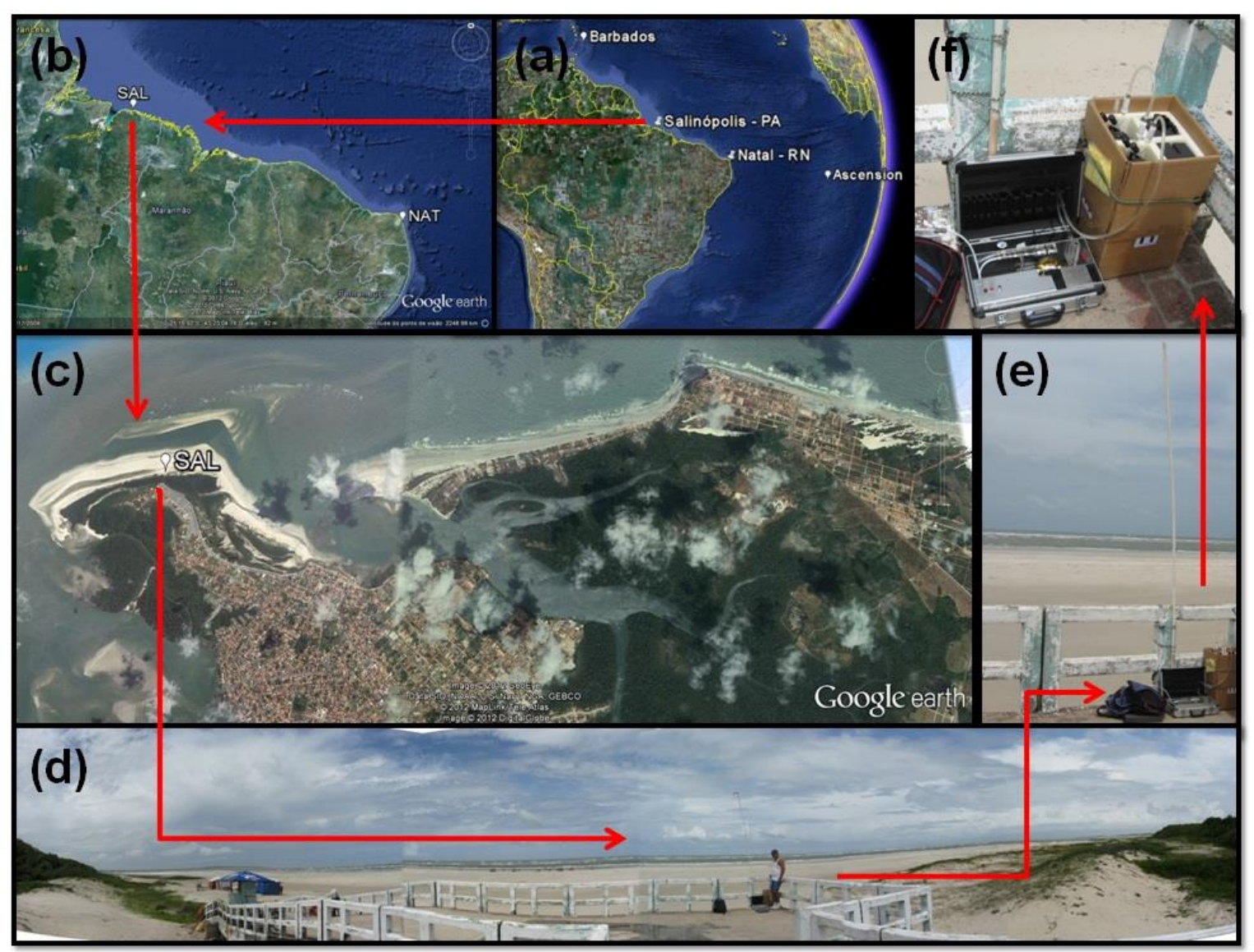

Figura 32: Praia Corvina - SAL: (a) e (b) local na costa; (c) praia Corvina; (d) foto panorâmica do ponto de coleta; (e) amostrador e tubo coletor; (f) amostragem.

Em NAT, as coletas foram iniciadas em maio de 2010, com a parceria de uma equipe do Instituto Nacional de Pesquisas Espaciais - INPE/CRN (Centro Regional do Nordeste). A amostragem foi realizada na estação do CRN do INPE, no município de Maxaranguape, como pode ser visto na Figura 33. O inlet foi instalado sobre a laje desta estação, em um mastro de 2,5 metros de altura, ficando a 15 metros acima do nível do mar. O amostrador foi instalado dentro da estação, tendo o tubo, desde o inlet até o amostrador, em torno de 7 metros de comprimento. 


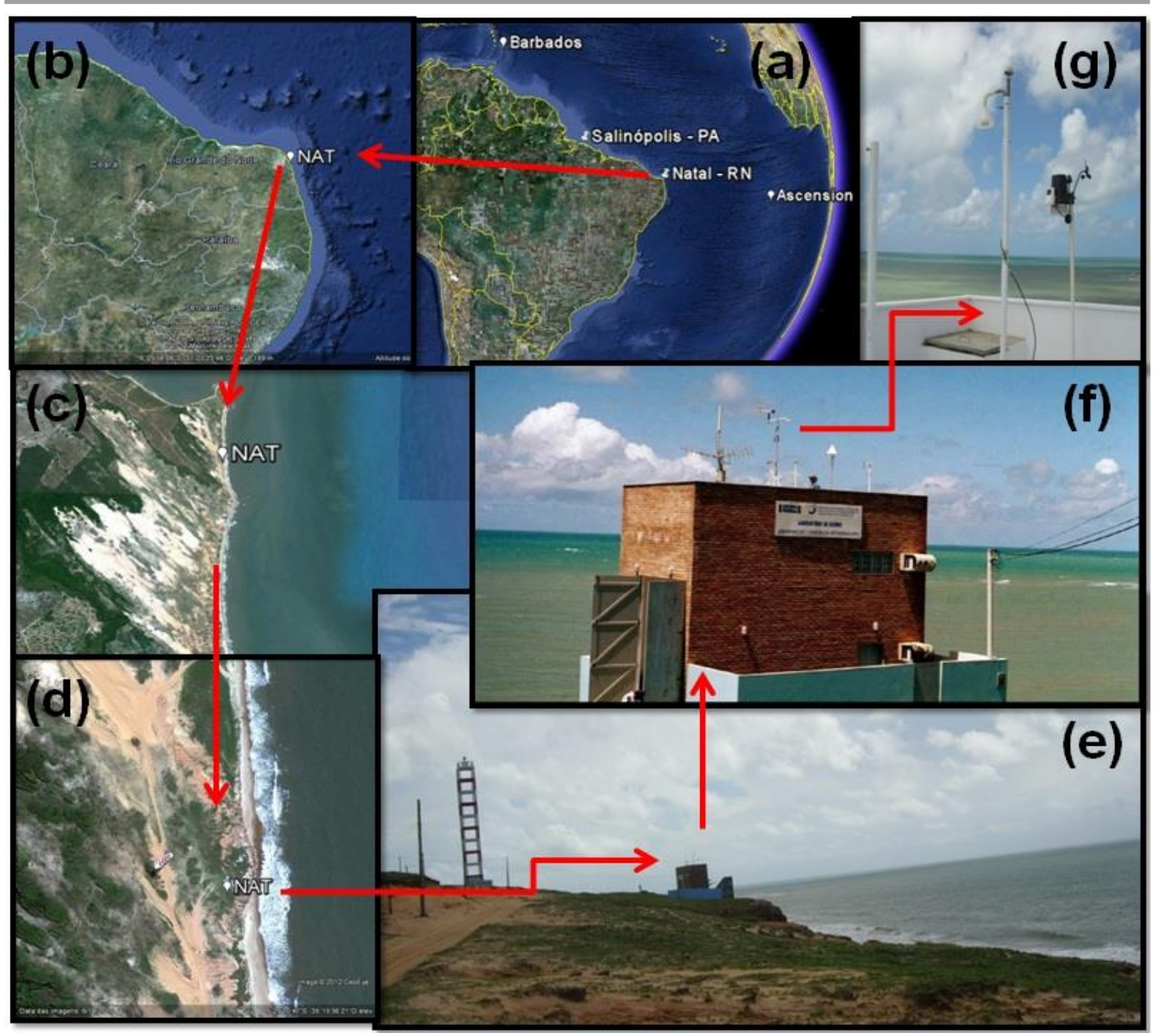

Figura 33: Maxaranguape - NAT: (a) e (b) local na costa; (c) praia em Maxaranguape; (d) ponto de coleta; (e) e (f) estação de Maxaranguape; (g) instalação do tubo coletor.

\subsection{Quantificação dos GEE}

As análises foram realizadas no LQA/CQMA/IPEN, onde foram quantificados todos os gases de interesse $\mathrm{CO}_{2}, \mathrm{CH}_{4}, \mathrm{~N}_{2} \mathrm{O}, \mathrm{SF}_{6}$ e o $\mathrm{CO} . \mathrm{O}$ laboratório possui um sistema de análise em sequência, LAGEE (Laboratório de Análise de Gases de Efeito Estufa), e foi construído na NOAA por Andrew Crotwell e Dra. Luciana Vanni Gatti e instalado no LQA/CQMA/IPEN, iniciando suas operações em maio de 2004, sendo este uma réplica exata do Laboratório de GEE da NOAA/CMDL/GMD/ESRL (Climate Monitoring \& Diagnostics Laboratory / Global Monitoring Division / Earth System Research Laboratory), em Boulder, Colorado - Estados Unidos da América, como apresentado na Figura 34. 


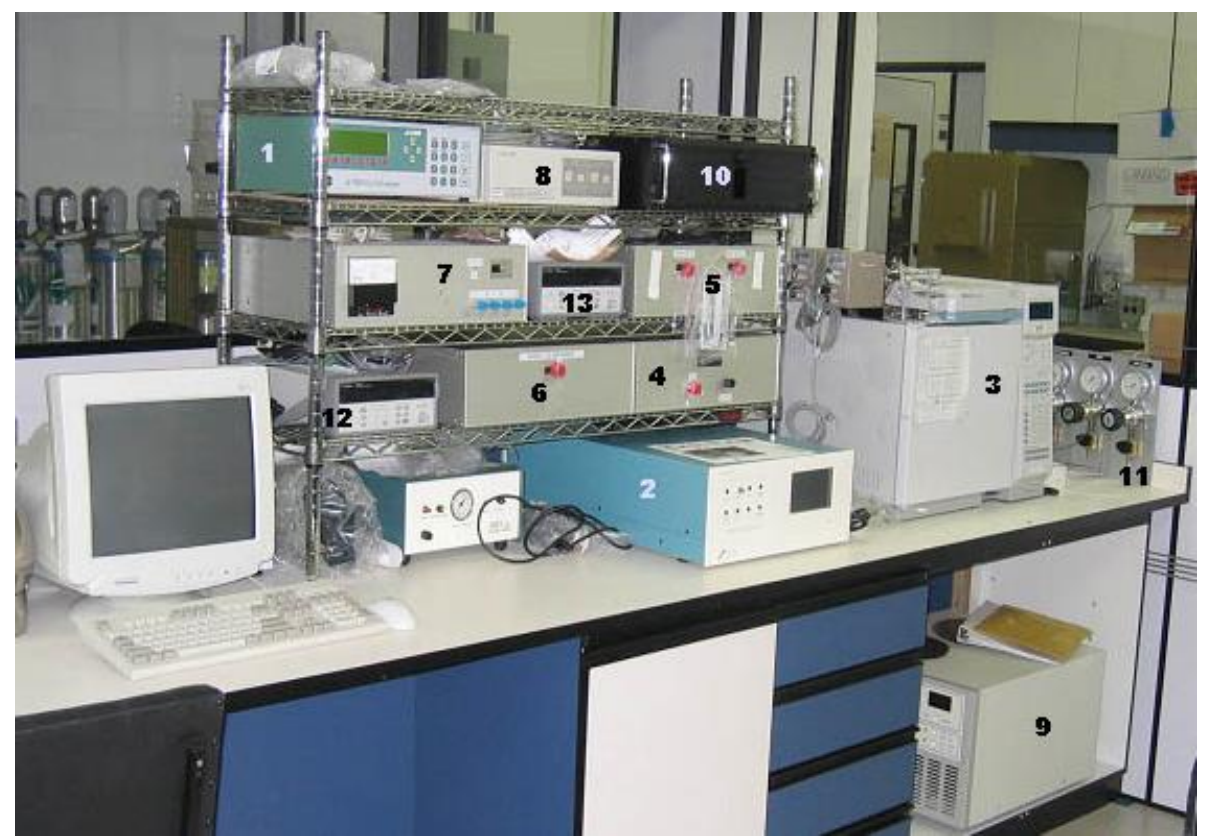

Figura 34: LAGEE: (1) monitor $\mathrm{CO}_{2}$; (2) cromatógrafo CO; (3) cromatógrafo $\mathrm{N}_{2} \mathrm{O} / \mathrm{SF}_{6} / \mathrm{CH}_{4}$; (4) controlador de fluxo; (5) válvula de seleção; (6) amostra/CO referência; (7) medidor de vácuo e receptor de amostras; (8) interface do cromatógrafo; (9) banho resfriador; (10) microcomputador; (11) painel de gases;

(12) interface monitor $\mathrm{CO}_{2} ;(13)$ interfaces das válvulas e cromatógrafo $\mathrm{CO}$.

\subsection{Sistema analítico}

O LAGEE é um sistema totalmente automatizado e a representação analítica deste sistema é apresentada na Figura 35, para facilitar o entendimento do método de análise. Três válvulas de múltiplas posições compõem o sistema de separação dos gases de referência e amostras para os respectivos instrumentos de análise. Todas as válvulas possuem um sistema de funcionamento semelhante, sendo permitida a passagem de apenas um gás por vez, assim é possível fazer a seleção dos gases. A válvula 1 denominada "Seleção de Amostra e Gases Referência", seleciona entre a entrada de amostra ou dos gases referência dos vários gases a serem analisados ou os padrões da curva de calibração do $\mathrm{CO}_{2}$. A válvula 2 denominada "Seleção de Padrões" possui várias entradas e apenas uma saída, selecionando os gases padrão das curvas de calibração do $\mathrm{CO}$ e $\mathrm{N}_{2} \mathrm{O}$. Já a válvula 3 chamada de "Seleção dos Equipamentos" possui apenas uma entrada e várias saídas que permitem o direcionamento de cada gás ou amostra para os equipamentos analíticos de cada gás.

O gás a ser analisado (amostra ou referência) é selecionado pela válvula 1 a qual direciona o mesmo para um controlador de fluxo, sendo para os gases $\mathrm{CH}_{4}, \mathrm{~N}_{2} \mathrm{O}, \mathrm{SF}_{6}$ e $\mathrm{CO}$, um fluxo de $150 \mathrm{~mL} \mathrm{~min}^{-1}$, e para a análise do $\mathrm{CO}_{2}$ de 
$200 \mathrm{~mL} \mathrm{~min}{ }^{-1}$. A amostra ou referência passa por um loop resfriado por um banho contendo álcool a uma temperatura de aproximadamente $-60,0^{\circ} \mathrm{C}$, para a remoção de possível água existente na amostra e posteriormente é transferido para a válvula 3 que direciona o gás para os instrumentos analíticos dos gases a serem determinados.

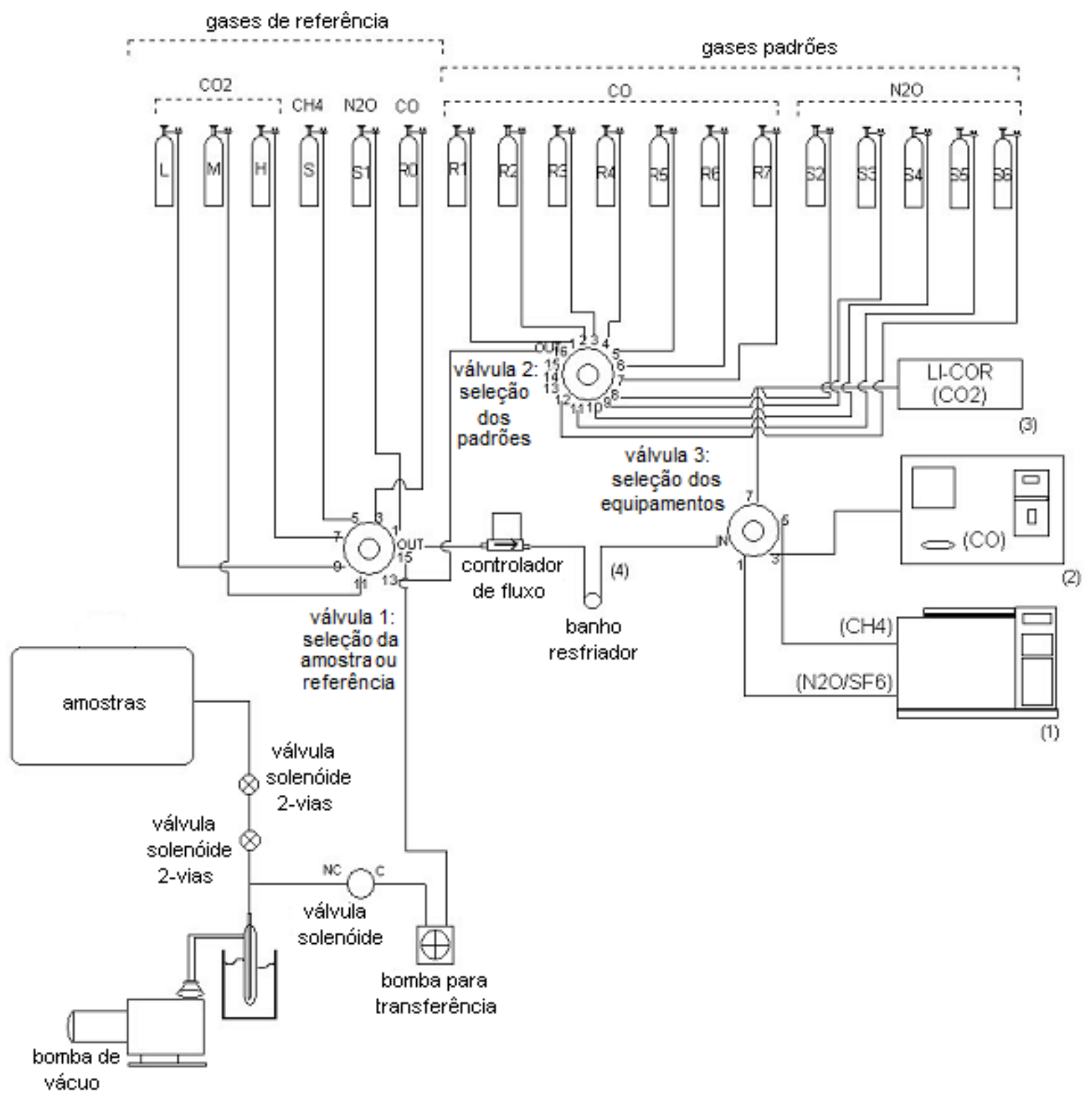

Figura 35: Esquema de funcionamento do Sistema LAGEE-Brasil.

Para a análise do $\mathrm{CO}_{2}$, foi utilizado um analisador de gás infravermelho (IR) (LICOR modelo LI-7000), diferencial, não dispersivo de alta precisão (NDIR). A fonte de IR é constituída por um filamento de tungstênio selada a vácuo. $O$ sistema diferencial trabalha por diferença de absorção da radiação do IR o qual passa por duas células de amostragem ${ }^{[53,54]}$. 
A Figura 36 (a) apresenta um esquema de entrada e saída dos gases de referência e amostra nas células do monitor de $\mathrm{CO}_{2}$. Na célula $A$ é passado o gás de referência com concentração em torno de 350 ppm e fluxo constante de $5 \mathrm{~mL} \mathrm{~min}{ }^{-1}$, sempre abaixo da concentração da amostra e dos padrões, e na célula B é passada a amostra. A Figura 36 (b) apresenta um esquema mais detalhado de uma célula. A radiação IR é transmitida para as duas células que possuem detectores que absorvem a radiação medindo a mesma. São usados filtros ópticos para ajustar o detector de $\mathrm{CO}_{2}$ para absorção na faixa de 4,255 mícron (banda emitida pelo $\mathrm{CO}_{2}$ ) rejeitando radiação em outra banda aumentando a precisão do instrumento. A concentração da amostra é calculada em relação à concentração conhecida do gás de referência.

a)

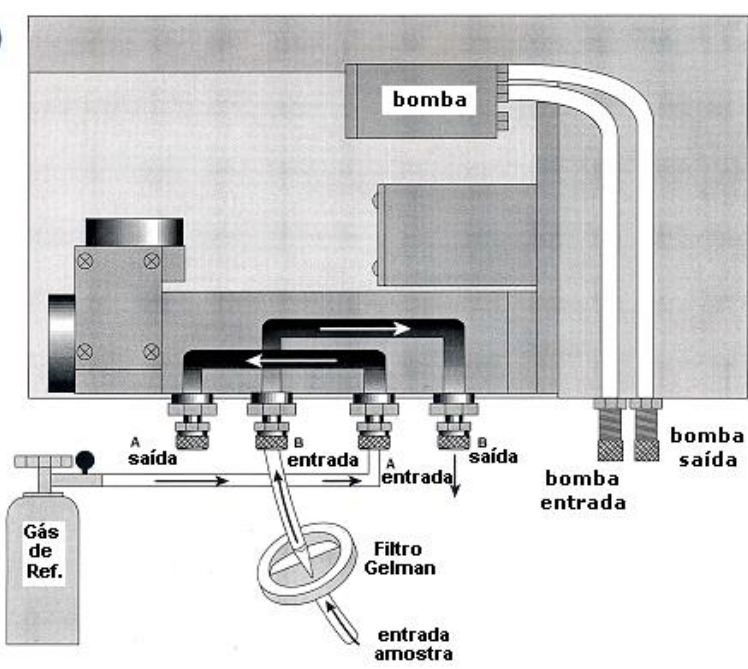

b)

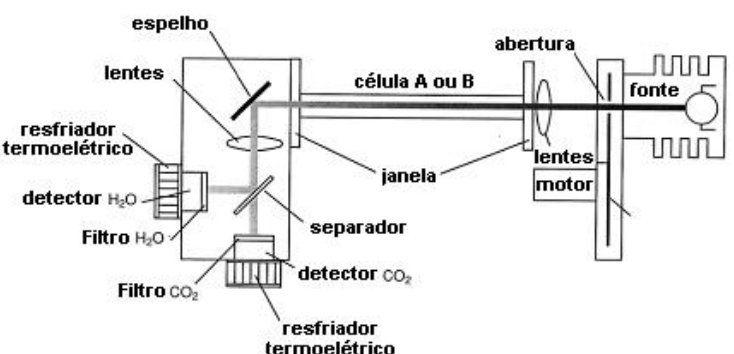

Figura 36: (a) Esquema de entrada e saída dos gases de referência e amostra nas células do monitor de $\mathrm{CO}_{2}$ e (b) esquema detalhado de uma célula.

$\mathrm{Na}$ quantificação do $\mathrm{CH}_{4}$ foi utilizado um cromatógrafo gasoso (HP Hewlett Packard modelo HP 6890 series Plus) com detector de ionização de chama (DIC), com pré-coluna de $198 \mathrm{~cm}$ de comprimento e 3/16" de diâmetro externo (coluna 1), empacotada com Sílica Gel 60/80 mesh e uma coluna de $106 \mathrm{~cm}$ de comprimento e 3/16" de diâmetro externo (coluna 2), empacotada com Peneira Molecular 5A 60/80 mesh. O sistema utiliza uma válvula de 10 vias com duas posições inject e load, e um loop de $12 \mathrm{~mL}$ para a injeção da amostra ou do gás referência. $O$ uso das colunas 1 e 2 tem como função a separação de compostos indesejados na análise ${ }^{[45,53]}$.

$\mathrm{Na}$ Figura 37, é apresentado um esquema de funcionamento do cromatógrafo. $\mathrm{O}$ gás carreador utilizado foi o Nitrogênio 6.0 a $95 \mathrm{~mL} \mathrm{~min}^{-1}$ e a 
temperatura do forno foi constante a $70 \stackrel{\circ}{ } \mathrm{C}$. No esquema (a), quando a válvula está na posição load, a amostra passa pelo loop por 3 minutos para limpeza e descontaminação, enquanto que o gás carreador se subdivide e passa pela coluna 2 levando a amostra ao detector e também retirando o que estava retido na coluna 1 para a saída, levando os contaminantes indesejados da amostra. No esquema (b), quando a válvula muda para a posição inject, a amostra contida no loop é transferida para a coluna 1 com o auxílio do gás carreador.
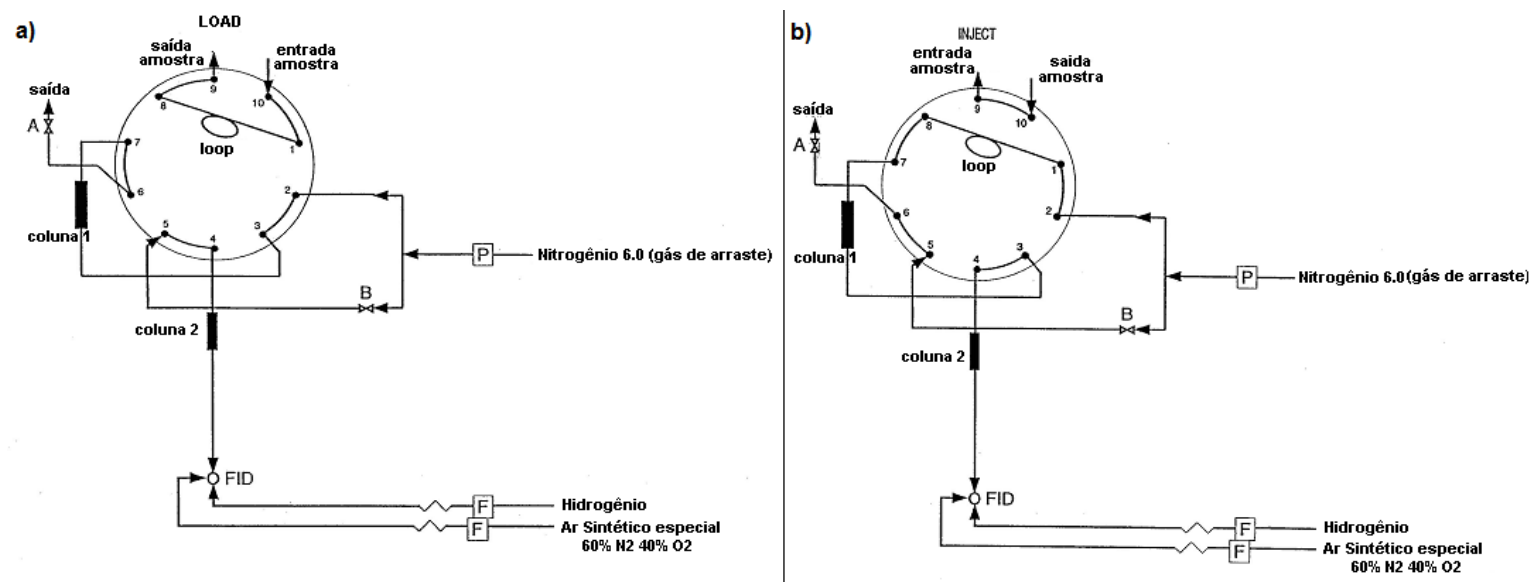

Figura 37: Esquema de funcionamento do cromatógrafo na análise do $\mathrm{CH}_{4}$ (a) posição de espera e (b) posição de injeção da amostra no equipamento.

No momento em que a amostra atinge a coluna 2, a válvula de 10 vias retorna para a posição load evitando que os contaminantes cheguem até a coluna 2, iniciando a limpeza da coluna 1, através da passagem do gás carreador em sentido oposto. No DIC, a amostra queimada na chama alimentada por uma mistura de hidrogênio a $45 \mathrm{~mL} \mathrm{~min}^{-1}$ e ar sintético especial enriquecido de $\mathrm{O}_{2}$ $\left(60 \% \mathrm{~N}_{2}\right.$ e $\left.40 \% \mathrm{O}_{2}\right)$ a $250 \mathrm{~mL} \mathrm{~min}^{-1}$. Quando a amostra passa pela chama o $\mathrm{CH}_{4}$ é oxidado a $\mathrm{CO}_{2}$, em estado excitado e é atraído pelo cátodo gerando uma corrente elétrica proporcional a quantidade de $\mathrm{CH}_{4}$ na amostra (Figura 38 ) ${ }^{[45,53]}$.

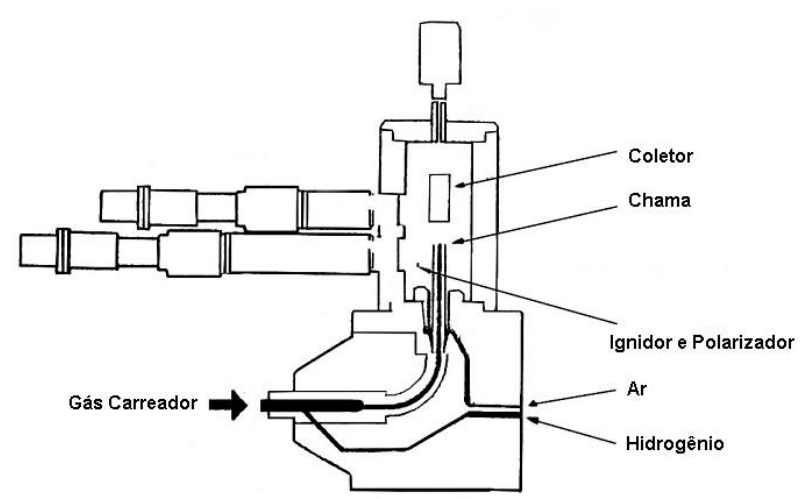

Figura 38: Esquema do detector DIC. 
A quantificação de $\mathrm{N}_{2} \mathrm{O}$ e $\mathrm{SF}_{6}$ é realizada por um cromatógrafo gasoso (HP - Hewlett Packard modelo HP 6890 series Plus) com detector de captura eletrônica (DCE), como esquematizado na Figura 39. Este cromatógrafo possui uma pré-coluna de $183 \mathrm{~cm}$ de comprimento e 3/16" de diâmetro externo (Coluna 1) empacotada com Haysep Q $100 / 120$ mesh, e uma coluna com essas mesmas especificações (Coluna 2), além de um loop de $15 \mathrm{~mL}$, em um forno a $70 \stackrel{\circ}{ } \mathrm{C}$. Este sistema também possui uma válvula de 10 vias com duas posições (inject e load) e o mecanismo de funcionamento deste cromatógrafo é o mesmo anteriormente descrito na Figura 37 para $\circ \mathrm{CH}_{4}$. Porém neste caso, o gás de arraste é uma mistura de argônio com $5 \%$ de $\mathrm{CH}_{4}\left(74 \mathrm{~mL} \mathrm{~min}^{-1}\right)$. O DCE utiliza uma fonte de ${ }^{63} \mathrm{Ni}$ aquecida a $350 \stackrel{\circ}{\mathrm{C}}$ a qual ioniza as moléculas e são formados elétrons lentos que migram para o ânodo (célula voltaica), os quais produzem uma corrente padrão. Quando a amostra ionizada entra no detector, a corrente é reduzida, e esta diferença é proporcional à quantidade de composto ${ }^{[53]}$.

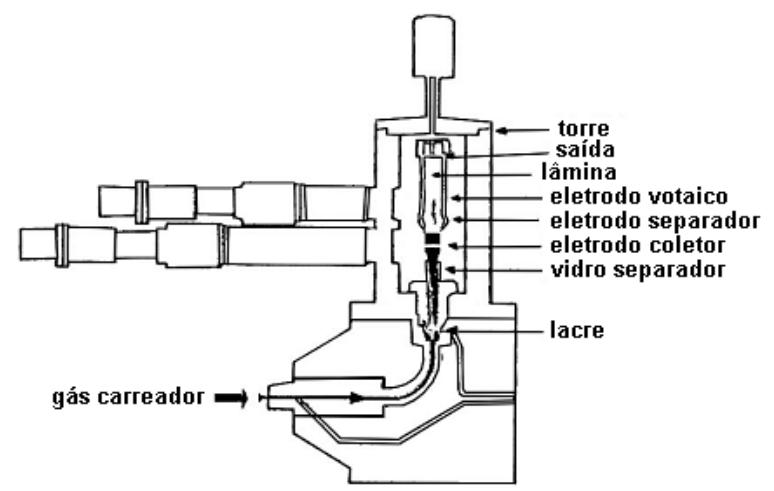

Figura 39: Esquema de funcionamento do detector DCE.

A quantificação de $\mathrm{CO}$ foi realizada por meio de um cromatógrafo da Peak Laboratories, que consiste em uma pré-coluna de 30 1/4" x 1/8" empacotada com pérolas esféricas de sílica porosa 1S 60/80 (coluna 1) e uma coluna de 51 " x 1/8" empacotada com Peneira Molecular 13x 60/80 (coluna 2) em um forno com temperatura constante a $100^{\circ} \mathrm{C}$. O gás carreador utilizado é o $\mathrm{Ar}$ Sintético a $20 \mathrm{~mL} \mathrm{~min}^{-1}$. A amostra passa por um loop de $20 \mathrm{~mL}$ e é inserida nas colunas $1 \mathrm{e}$ 2. O esquema deste cromatógrafo é apresentado na Figura 40. Para remover contaminação de CO no gás carreador utilizou-se um catalizador, desenvolvido pela NOAA, que oxida o $\mathrm{CO}$ a $\mathrm{CO}_{2}$. O Detector consiste em um leito de óxido de mercúrio $(\mathrm{HgO})$ aquecido a $265^{\circ} \mathrm{C}$, e o $\mathrm{CO}$ contido na amostra reage com o $\mathrm{HgO}$ 
indo ao estado metálico, e quantificado pela absorção de luz ultravioleta (254 nm), conforme a Figura $41^{[53]}$.

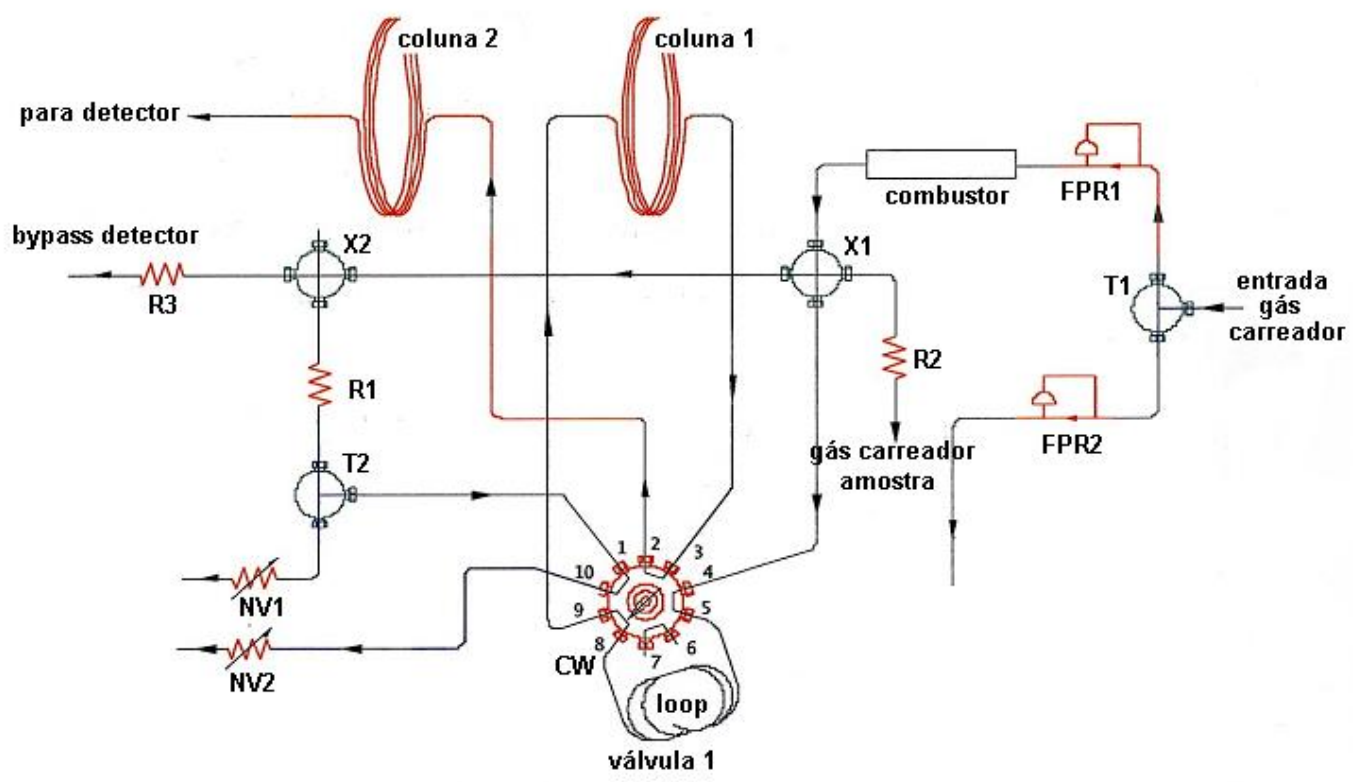

Figura 40: Esquema de funcionamento do cromatógrafo de $\mathrm{CO}$.

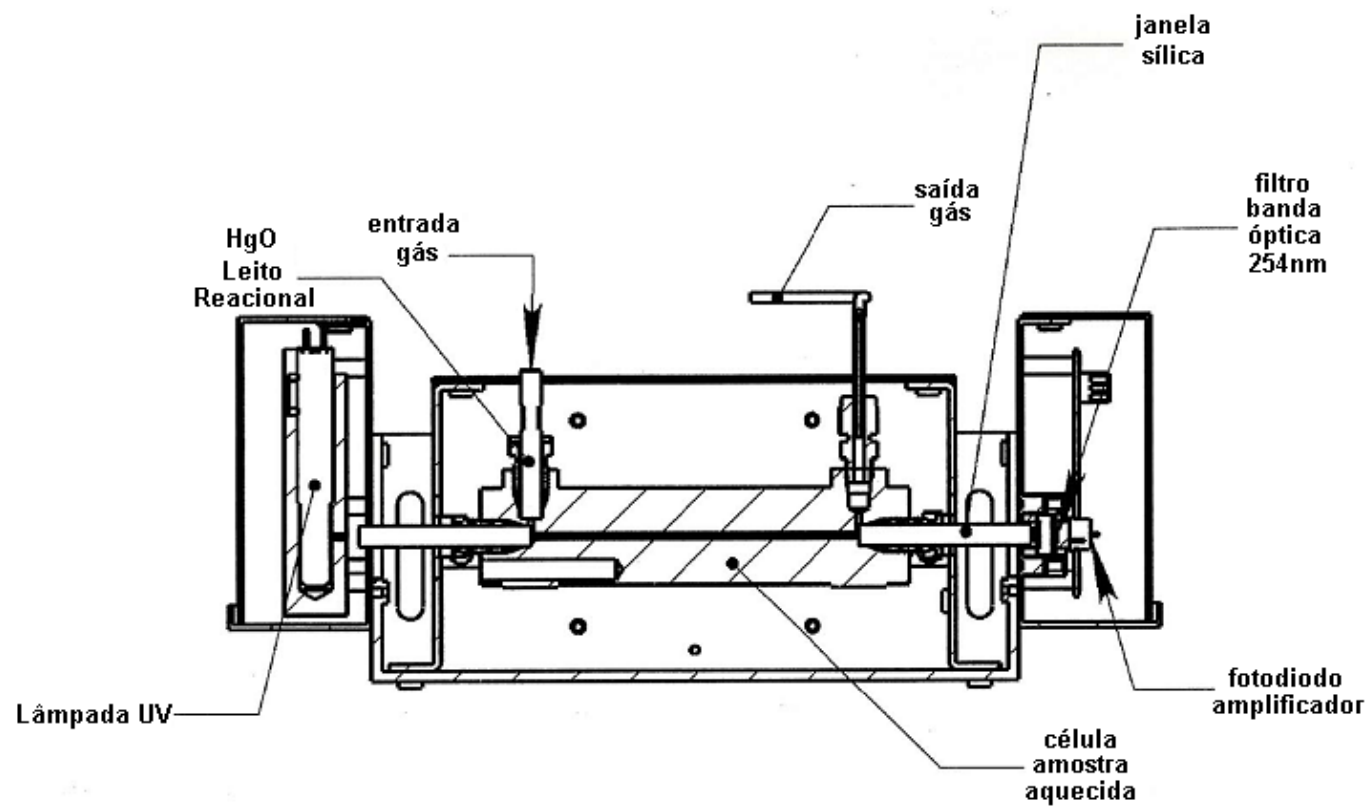

Figura 41: Esquema do detector do cromatógrafo de CO.

\subsection{Precisão e Acurácia dos resultados}

A precisão dos resultados é alcançada intercalando a detecção de padrões referência com as amostras. Este procedimento garante que, com as variações de temperatura e pressão do ambiente, que alteram a resposta do detector, seja normalizada, pois o gás referência também vai sofrer a mesma alteração com as variações, garantindo assim a precisão da análise, uma vez que 
sua quantificação sempre é o produto da relação entre a amostra e o gás referência, que tem sua concentração conhecida, podendo a sequência ser representada da seguinte maneira:

referência - amostra - referência - amostra - referência - amostra - referência

Para o cálculo da concentração, é feita a média das referências anterior e posterior à amostra, e o valor utilizado para a quantificação é a razão da amostra pela média das referências, como mostra a Figura 42(a) representada pelo retângulo vermelho. Esta fração é utilizada na curva de calibração, sendo que a curva também é construída com a razão dos vários pontos de concentração e do gás referência. Normalizando assim, alterações que a variação de temperatura e pressão acarretaria na resposta do detector.
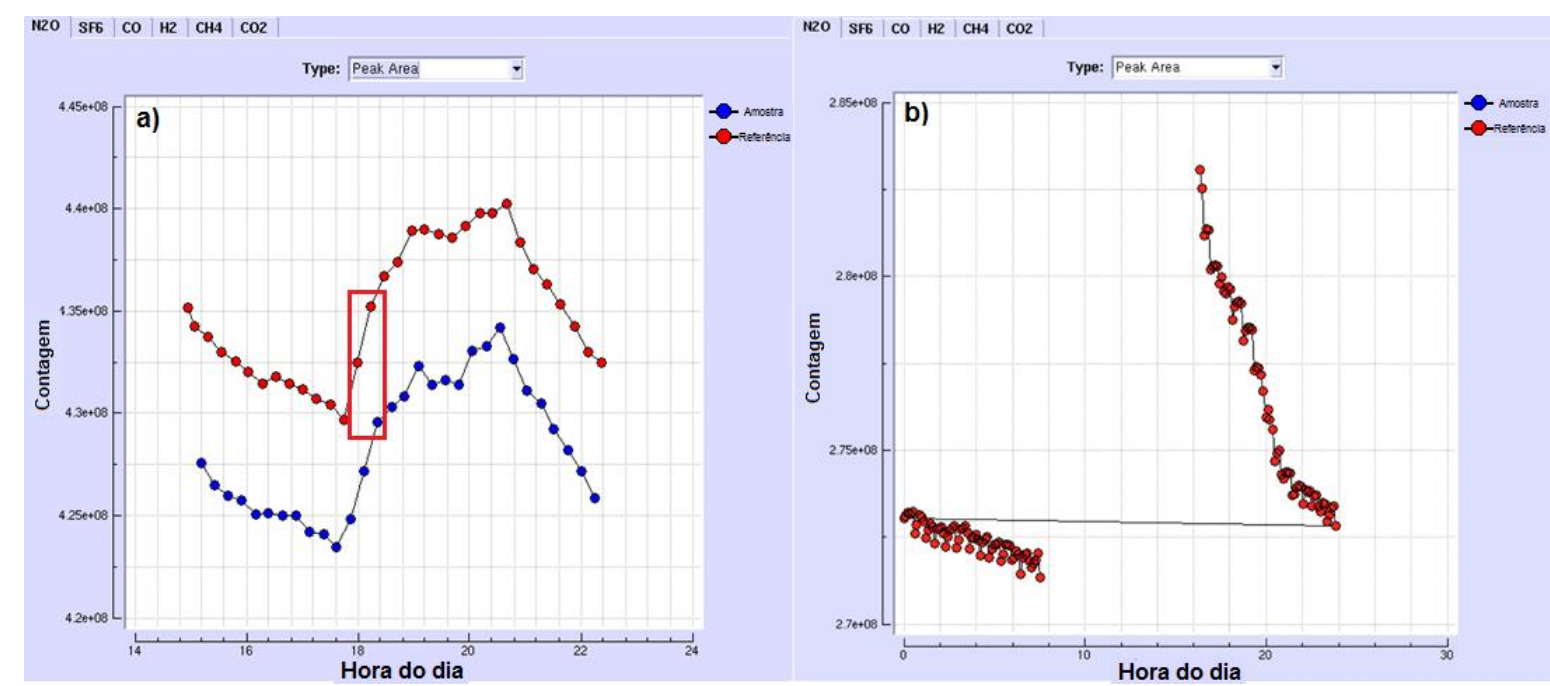

Figura 42: (a) Curva do tanque de calibração e (b) curva de calibração do $\mathrm{N}_{2} \mathrm{O}$.

Podemos observar pela calibração do "tanque de calibração denominado de Target tank', onde foram realizadas 30 medidas sequentes para testar a variabilidade com as mudanças de temperatura e pressão, que a resposta do instrumento varia ao longo do dia. No entanto, como o padrão referência varia junto com a amostra, estas variações são minimizadas utilizando a razão entre a resposta da amostra pela média do padrão referência anterior e posterior a esta.

Outro importante procedimento relativo a acurácia dos resultados é obtido pelos seguintes procedimentos: A) a utilização dos padrões primários, de trabalho e de referência calibrados pela GMD/ESRL/NOAA, que é o laboratório Referência da rede mundial da WMO. B) o controle da acurácia pela realização da calibração por 20 vezes do "Target tank" e o acompanhamento deste resultado ao 
longo do tempo. C) participação nas intercomparações da rede mundial, denominado WMO-20XX World Round Robin Comparison Experiment, que acontece a cada 3-4 anos. D) intercomparação semanal entre o LQA e a NOAA através das amostragens em Natal (NAT), que será apresentado no capítulo dos resultados. A intercomparação entre o LQA com outros laboratórios filiados, a NOAA é apresentada na Figura 43. Podemos observar que para os principais GEE, a diferença apresentada entre as concentrações do LQA em relação a NOAA, são próximas de zero, garantindo assim a acurácia de nossos resultados.

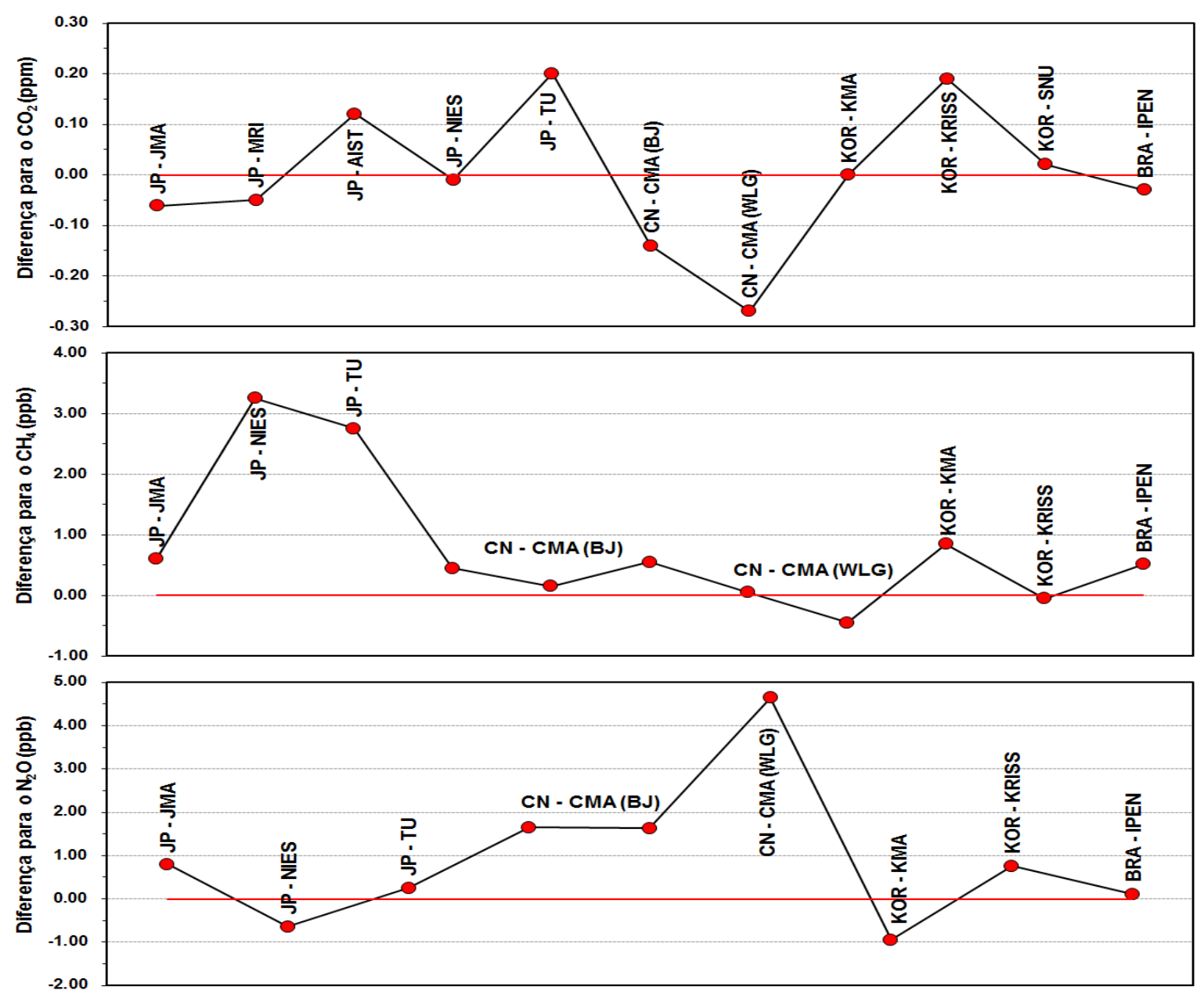

Figura 43: Intercomparação entre o LQA (BRA-IPEN) com outros laboratórios filiados a NOAA.

\subsubsection{Curva de calibração}

Os gases $\mathrm{CH}_{4}$ e $\mathrm{SF}_{6}$ possuem relação linear da concentração com a área, para as concentrações estudadas, sendo também valores bastante estáveis. Assim, apenas um gás de referência é necessário para o cálculo da concentração 
desses, uma vez que o gás de referência tem uma concentração muito próxima da medida nas amostras.

Os gases $\mathrm{CO}$ e $\mathrm{N}_{2} \mathrm{O}$ não possuem relação linear da concentração com a área, motivo pelo qual, as curvas de calibração são construídas com 7 e 5 padrões, respectivamente. Estudos do laboratório da CCG/CMDL/NOAA (Carbon Cycle Gases) recomendam a cada 15 dias a calibração para o CO e a cada 30 dias para $\circ \mathrm{N}_{2} \mathrm{O}$. Os padrões utilizados na construção destas curvas foram calibrados neste laboratório de calibração. As concentrações dos padrões utilizados na calibração desses gases estão apresentadas na Tabela 4.

Tabela 4: Concentrações dos padrões das curvas de calibração de $\mathrm{CO}$ e $\mathrm{N}_{2} \mathrm{O}$

\begin{tabular}{cccccc}
\hline & \multicolumn{3}{c}{$\mathrm{CO}$} & \multicolumn{3}{c}{$\mathrm{N}_{2} \mathrm{O}$} \\
\hline Referência & Padrão & $\begin{array}{c}\text { Concentração } \\
\text { (ppb) }\end{array}$ & Referência & Padrão & $\begin{array}{c}\text { Concentração } \\
\text { (ppb) }\end{array}$ \\
\hline CA05938 & 1 & 0,00 & FA03075 & 1 & $257,04 \pm 0,12$ \\
CA03823 & 2 & 53,0 & FF13160 & 2 & $294,41 \pm 0,13$ \\
CA03885 & 3 & 71,8 & FF138 & 3 & $321,75 \pm 0,16$ \\
CA03801 & 4 & 76,0 & FF35820 & 4 & $337,27 \pm 0,14$ \\
CA06539 & 5 & 122,1 & FF17254 & 5 & $377,15 \pm 0,28$ \\
CA03900 & 6 & 199,2 & & & \\
CA03803 & 7 & 295,5 & & & \\
\hline
\end{tabular}

Para a quantificação do $\mathrm{CO}_{2}$, é construída uma curva de calibração a cada duas amostras, onde são utilizados três gases de referência, como pode ser observado na Tabela 5 e na Figura 44. Neste caso, o sistema pode ser representado da seguinte maneira:

ref.(L) - ref.(M) - amostra - ref.(H) - amostra - ref.(L) - amostra - ref.(M) amostra - ref. $(H)$ - amostra - ref. $(L)$ - amostra - ref.(M) - amostra -ref. $(H)$

Os símbolos $L, M$ e $H$ significam concentrações baixa "Low", média "Medium" e alta "High", respectivamente.

Tabela 5: Concentrações dos padrões para a curva de calibração do $\mathrm{CO}_{2}$

\begin{tabular}{ccc}
\hline & \multicolumn{2}{c}{$\mathrm{CO}_{2}$} \\
Referência & Padrão & Concentração $(p p b)$ \\
\hline CA08222 & $\mathrm{L}$ & $381,77 \pm 0,02$ \\
CA06352 & $\mathrm{M}$ & $405,74 \pm 0,01$ \\
CA08191 & $\mathrm{H}$ & $429,58 \pm 0,00$ \\
\hline
\end{tabular}




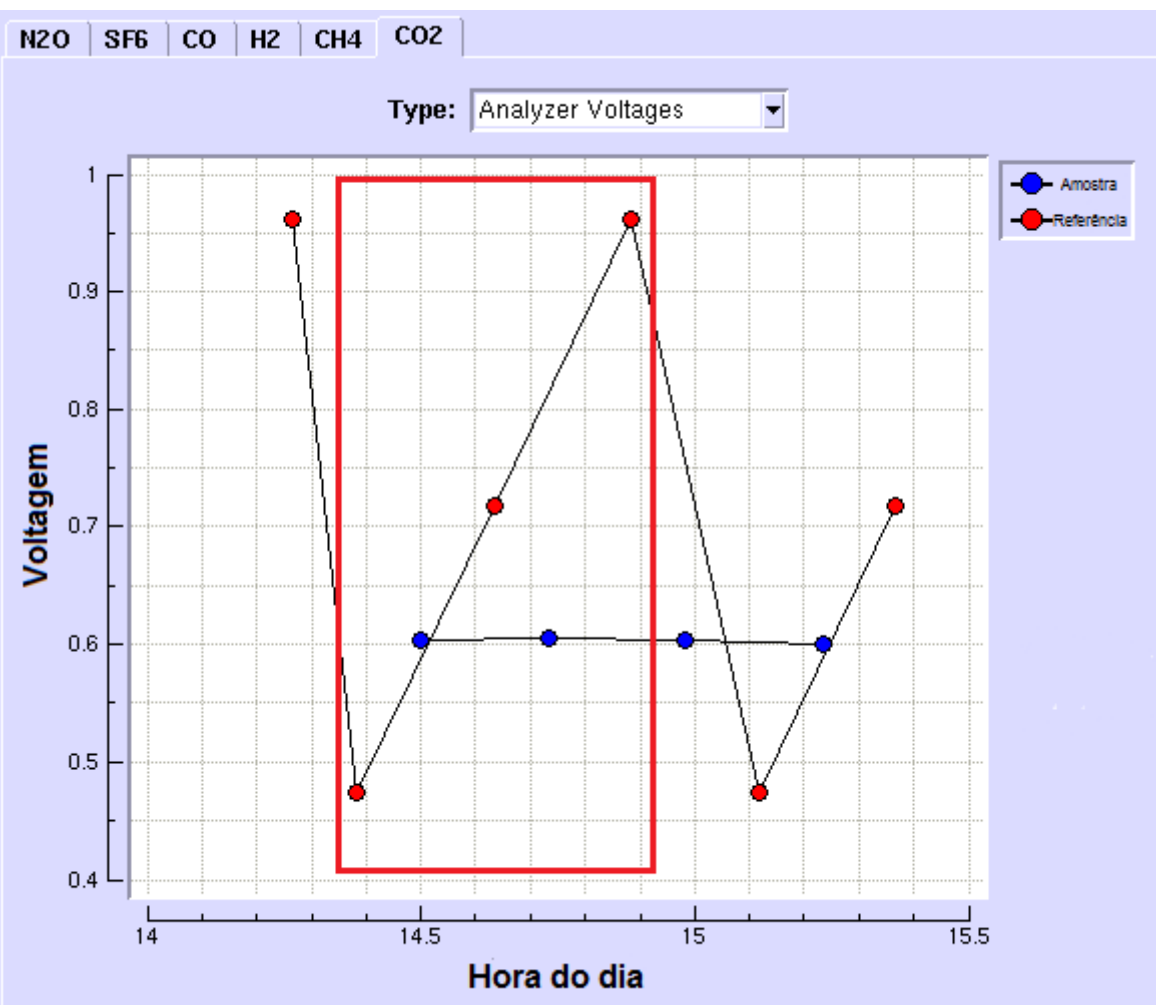

Figura 44: Análise de $\mathrm{CO}_{2}$ mostrando a sequência das referências (círculos vermelhos) e as amostras (círculos azuis).

\subsubsection{Estabilidade do sistema analítico}

A garantia da estabilidade do sistema analítico é verificada por meio da realização da calibração de dois cilindros constituídos de ar natural, previamente calibrado no laboratório da NOAA, denominados "Target tank". Estes cilindros são analisados um desde 2004 (CA05558) e o outro desde 2007 (CA04533). São realizadas 20 medidas de cada cilindro a cada 60 e 15 dias, respectivamente. $\mathrm{Na}$ Figura 45 são apresentadas, como exemplo, as concentrações da calibração do cilindro CA04533 para os dois principais GEE.

A precisão das calibrações é verificada pela variabilidade das 20 medidas. Na Tabela 6, são mostrados os valores das calibrações dos laboratórios LQA e GMD/NOAA para todos os gases $\mathrm{CO}_{2}, \mathrm{~N}_{2} \mathrm{O}, \mathrm{SF}_{6}, \mathrm{CH}_{4}$ e $\mathrm{CO}$, onde podemos observar que estamos com a precisão dentro da recomendada pela WMO. 

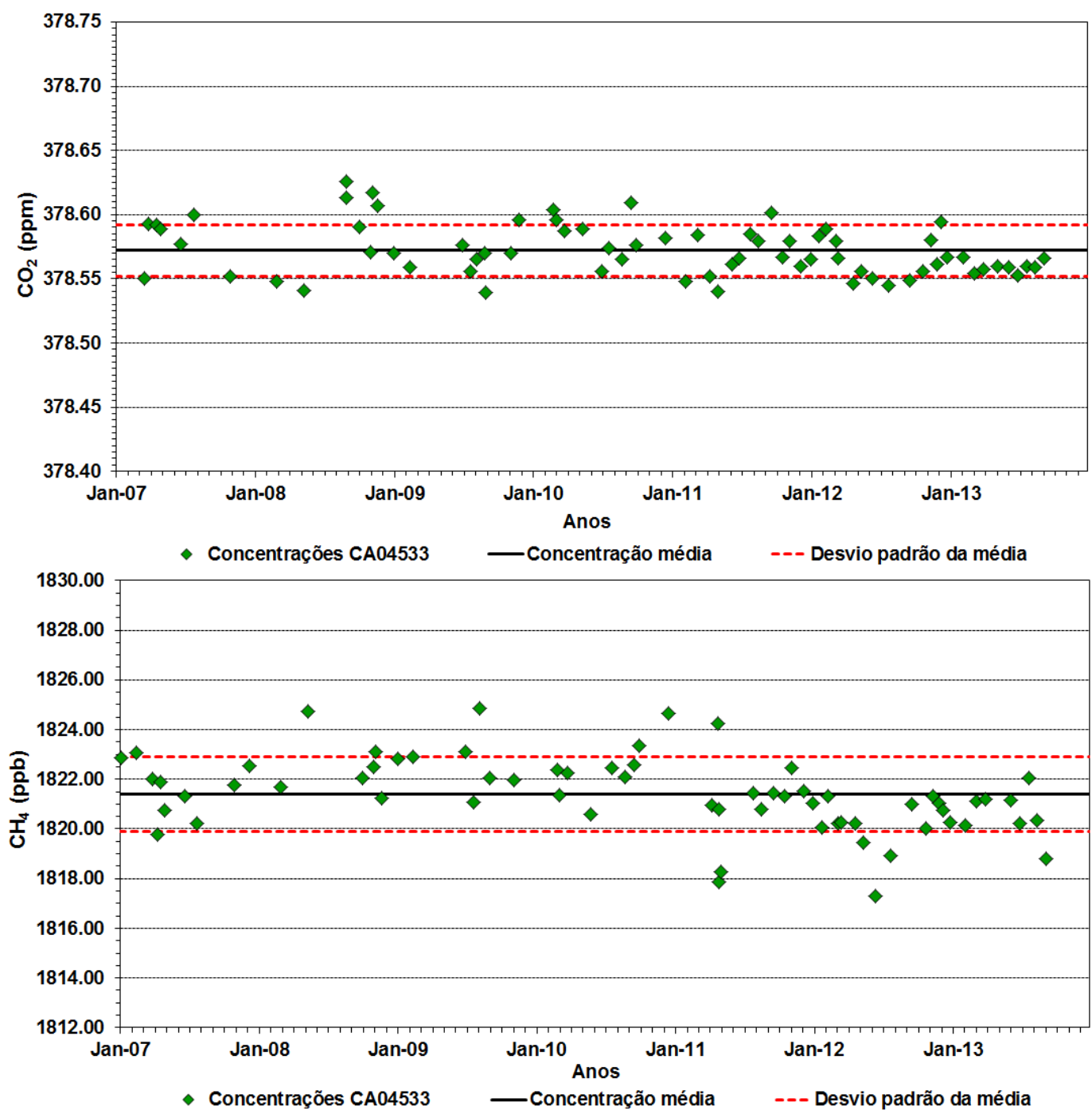

Figura 45: Tanque de calibração do cilindro $\mathrm{CA04533}$, para $\mathrm{CO}_{2}$ e $\mathrm{CH}_{4}$.

Tabela 6: Precisão dos gases analisados no laboratório de GEE da GMD/ESRL/NOAA e no LAGEE/LQA

\begin{tabular}{cccccc}
\hline \multicolumn{7}{c}{ Precisão nas análises } \\
\hline Espécie Química & $\mathrm{CO}_{2}(\mathrm{ppm})$ & $\mathrm{CH}_{4}(p p b)$ & $\mathrm{N}_{2} \mathrm{O}(\mathrm{ppb})$ & $\mathrm{CO}(\mathrm{ppb})$ & $\mathrm{S} F_{6}(\mathrm{ppt})$ \\
\hline $\begin{array}{c}\text { Precisão da } \\
\text { NOAA/ESRL/GMD/ }\end{array}$ & 0,03 & $<1$ & 0,2 & 0,5 & 0,02 \\
$\begin{array}{c}\text { Precisão do } \\
\text { LQA/CQMA/IPEN }\end{array}$ & 0,02 & 1,5 & 0,2 & 1,1 & 0,02 \\
$\begin{array}{c}\text { Precisão requerida } \\
\text { pela WMO }\end{array}$ & 0,05 & 2 & 0,1 & 2 & 0,02 \\
\hline
\end{tabular}

\subsection{Simulação das trajetórias das massas de ar}

Para o cálculo da trajetória das massas de ar que chegam aos locais estudados, foi utilizado o modelo de trajetórias HYSPLIT (Hybrid Single-Particle Lagrangian Integrated Trajectory) [55], que é um modelo de uso público 
(http://ready.arl.noaa.gov/HYSPLIT_traj.php), onde informamos data, horário, altitude e localização da coleta, para o cálculo da trajetória retrocedente utilizando à base de dados meteorológicos GDAS (Global Data Assimilation System).

No cálculo das trajetórias retrocedentes foram utilizadas 120 horas, para todos os dias de coletas realizadas, para se conhecer a origem e a sazonalidade das trajetórias das massas de ar. A Figura 46 mostra um exemplo de trajetórias retrocedentes simuladas para o dia 05 de janeiro 2011 em NAT e dia 06 de janeiro de 2011 para SAL, mostrando que essas massas de ar têm origem tanto no Oceano Atlântico Norte como no Oceano Atlântico Sul.

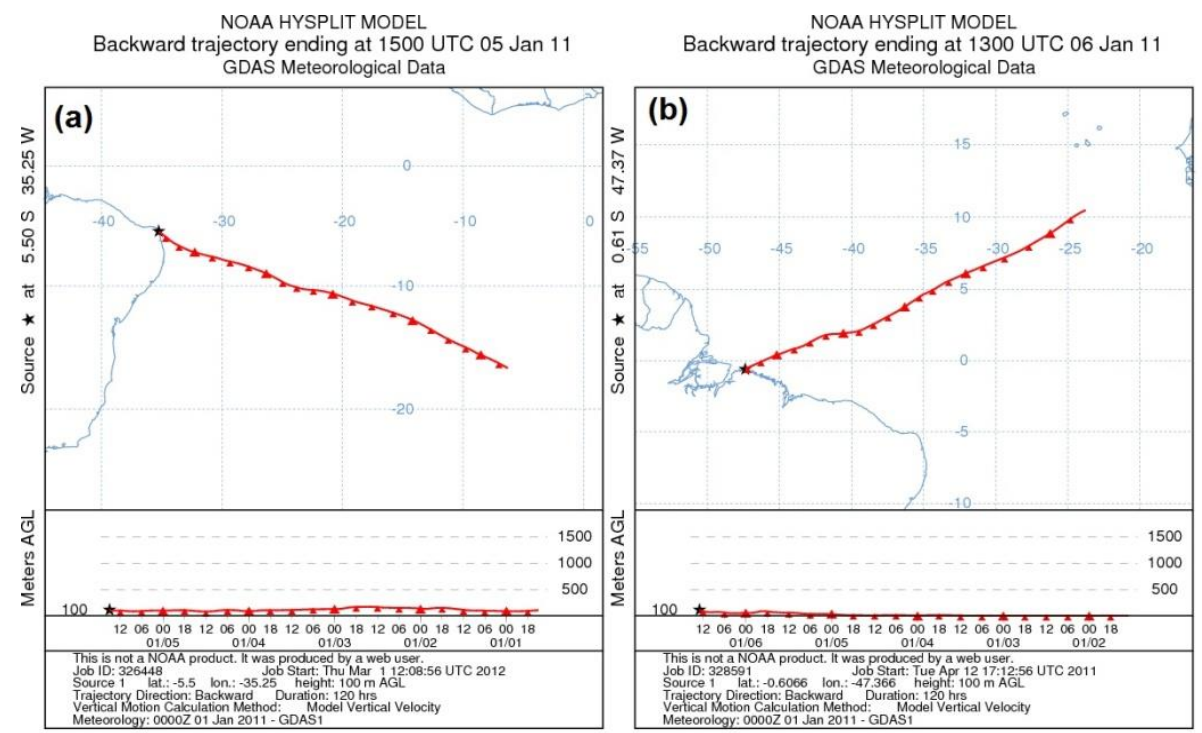

Figura 46: Trajetória da massa de ar para: (a) NAT e (b) SAL ${ }^{[55]}$.

Os dados de velocidade e direção do vento foram obtidos pelas informações da estação meteorológica de Maxaranguape no dia e hora da coleta, e em Salinópolis pela estação automática do INMET (Instituto Nacional de Meteorologia) ${ }^{[56]}$.

\subsection{Formas de análise de dados}

Os gases foram quantificados nos equipamentos descritos no item 4.4, instalados no LQA/IPEN. O LQA utiliza os padrões primários de GEE que foram calibrados e fornecidos pela NOAA para o cálculo das concentrações dos GEE.

Foi realizado o cálculo da concentração média dos pares de frascos amostrados em SAL e NAT, e os resultados obtidos para os gases $\mathrm{CO}_{2}, \mathrm{CH}_{4}$, $\mathrm{N}_{2} \mathrm{O}, \mathrm{SF}_{6}$ e $\mathrm{CO}$, foram comparados com as concentrações que foram medidas pela NOAA nas estações globais de ASC e RPB. 
Os resultados obtidos em NAT pelo LQA foram comparados com os resultados obtidos pela NOAA neste mesmo local de coleta, uma vez que a coleta foi realizada em duplicata para haver a intercomparação dos laboratórios envolvidos. Em SAL os resultados de superfície foram comparados com o perfil vertical de avião.

As concentrações medidas nos locais de estudo na costa foram comparadas com as concentrações de entrada no continente, calculadas por outros membros do grupo de pesquisa, sendo este cálculo baseado no $\mathrm{SF}_{6}$ descrito por Miller et al. para a Bacia Amazônica ${ }^{[21,27,28]}$.

As trajetórias de massas de ar foram obtidas por meio do programa HYSPLIT ${ }^{[55]}$. E a partir destas trajetórias foi possível estudar a sazonalidade das massas de ar, isto é, foi possível verificar os períodos do ano em que se recebeu mais influência do HN ou do HS.

Esses resultados também foram comparados com o mapeamento das concentrações de GEE em função da latitude realizado pela rede de monitoramento da NOAA.

Nas estações globais da rede da NOAA de ASC e RPB, as coletas de $\mathrm{CO}_{2}, \mathrm{CH}_{4}, \mathrm{~N}_{2} \mathrm{O}, \mathrm{SF}_{6}$ e $\mathrm{CO}$ são realizadas semanalmente, sendo em ASC duas vezes por semana, e em RPB apenas uma vez por semana. A partir dos dados dessas concentrações a NOAA produz uma curva ajustada, denominada "smooth curve". Esses dados calculados pela NOAA foram disponibilizados no sistema de análise do LQA.

A Figura 47 apresenta como exemplo todos os gases $\mathrm{CO}_{2}, \mathrm{CH}_{4}, \mathrm{~N}_{2} \mathrm{O}$, $\mathrm{SF}_{6}$ e CO, com os valores das concentrações medidas em ASC e RPB e a curva ajustada a partir destes dados. Podemos observar que a curva ajustada permite uma melhor visualização das concentrações e sua variabilidade. Assim para a comparação das concentrações obtidas em SAL e NAT com as concentrações das estações globais da NOAA, utilizaremos as curvas ajustadas de ASC e RPB. 

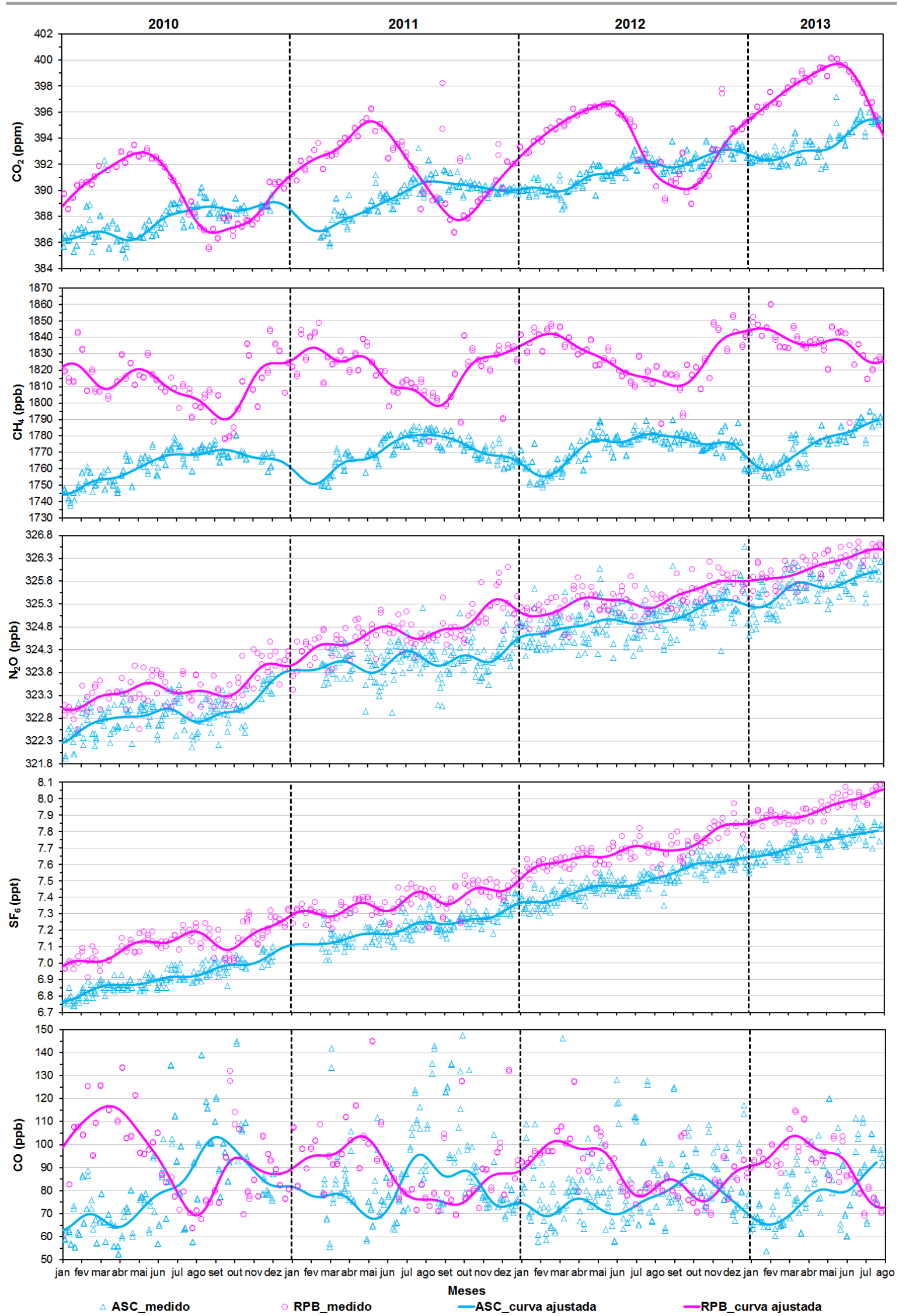

Figura 47: Concentrações medidas para os GEE em ASC e RPB e as curvas ajustadas dessas concentrações realizadas pela NOAA. 


\section{RESULTADOS E DISCUSSÃO}

Os resultados obtidos em SAL são referentes aos anos de 2010, 2011, 2012 e medidas realizadas até setembro de 2013. Em NAT os resultados são referentes a 2010 (medidas a partir do mês de maio), 2011, 2012 e medidas realizadas até agosto de 2013. A quantidade de coletas realizadas em cada local de estudo está apresentada na Tabela 7, onde em SAL foram realizadas 182 coletas e em NAT foram 149 coletas em todo período estudado.

Tabela 7: Quantidade de amostras coletadas em cada local de estudo

\begin{tabular}{cccccc}
\hline \multicolumn{7}{c}{ Quantidade de amostragens } \\
\hline Locais & 2010 & 2011 & 2012 & 2013 & Total \\
\hline SAL & 57 & 42 & 48 & 35 & 182 \\
NAT & 30 & 48 & 40 & 31 & 149 \\
\hline
\end{tabular}

\subsection{Análise da qualidade das amostragens de ar em SAL e NAT}

Um critério importante de qualidade de coleta de amostra é a diferença de resultado entre um frasco e outro do par amostrado. As coletas sempre ocorrem aos pares para possibilitar esta avaliação. Para cada gás foi definido um valor máximo, $\mathrm{CO}_{2}-0,5 \mathrm{ppm}, \mathrm{CH}_{4}$ e $\mathrm{CO}-6 \mathrm{ppb}, \mathrm{N}_{2} \mathrm{O}-1,0$ ppb e $\mathrm{SF}_{6}-0,1$ ppt. Para cada par de frasco coletado tanto em SAL como em NAT, foi realizado o cálculo da diferença entre esses pares. Assim diferenças superiores ao valor máximo estabelecido pela ESRL/GMD/NOAA, significavam a anulação das amostras. A Tabela 8 apresenta a frequência obtida para cada gás analisado, a média, o desvio padrão, assim como os valores máximos estabelecidos.

Podemos observar para o $\mathrm{CO}_{2}$ que $70 \%$ das amostras em SAL e $80 \%$ em NAT, apresentaram diferenças de até 0,30 ppm entre os pares de frascos. Para o $\mathrm{CH}_{4}, 77 \%$ das amostras em SAL e 83\% em NAT apresentaram diferenças de até 4,00 ppb, sendo a média das diferenças obtida para ambos os locais de aproximadamente 2,37 ppb. Os resultados obtidos para $\circ \mathrm{N}_{2} \mathrm{O}$ mostraram que 85\% das amostras em SAL e 90\% em NAT, tiveram diferenças de até 0,75 ppb, apresentando uma média das diferenças em torno de 0,40 ppb. Para as amostras de $\mathrm{SF}_{6}, 77 \%$ em SAL e $81 \%$ em NAT tiveram diferenças entre os pares de frascos 
de até 0,050 ppt. E, 93\% das amostras de CO em SAL e 94\% em NAT apresentaram até 2,00 ppb de diferença entre os pares de frascos.

Tabela 8: Frequência observada entre os pares de frascos de SAL e NAT para todos os anos de estudos

\begin{tabular}{|c|c|c|}
\hline \multicolumn{3}{|c|}{ Resultados das diferenças entre os pares de frascos } \\
\hline $\mathrm{CO}_{2}(\mathrm{ppm})$ & SAL - 147 amostras & NAT - 118 amostras \\
\hline 0,00 & $5 \%$ & $2 \%$ \\
\hline 0,10 & $31 \%$ & $42 \%$ \\
\hline 0,20 & $18 \%$ & $24 \%$ \\
\hline 0,30 & $16 \%$ & $12 \%$ \\
\hline 0,40 & $18 \%$ & $11 \%$ \\
\hline 0,50 & $11 \%$ & $9 \%$ \\
\hline Média & $0,19 \pm 0,15$ & $0,16 \pm 0,14$ \\
\hline $\mathrm{CH}_{4}(\mathrm{ppb})$ & SAL -150 amostras & NAT -135 amostras \\
\hline 0,00 & $3 \%$ & $0 \%$ \\
\hline 1,00 & $23 \%$ & $21 \%$ \\
\hline 2,00 & $23 \%$ & $27 \%$ \\
\hline 3,00 & $19 \%$ & $17 \%$ \\
\hline 4,00 & $9 \%$ & $18 \%$ \\
\hline 5,00 & $13 \%$ & $11 \%$ \\
\hline 6,00 & $9 \%$ & $6 \%$ \\
\hline Média & $2,37 \pm 1,67$ & $2,36 \pm 1,48$ \\
\hline $\mathrm{N}_{2} \mathrm{O}(p p b)$ & SAL - 164 amostras & NAT - 138 amostras \\
\hline 0,00 & $4 \%$ & $1 \%$ \\
\hline 0,25 & $35 \%$ & $28 \%$ \\
\hline 0,50 & $28 \%$ & $40 \%$ \\
\hline 0,75 & $18 \%$ & $21 \%$ \\
\hline 1,00 & $15 \%$ & $10 \%$ \\
\hline Média & $0,39 \pm 0,28$ & $0,40 \pm 0,25$ \\
\hline$S F_{6}(p p t)$ & SAL -176 amostras & NAT - 143 amostras \\
\hline 0,000 & $10 \%$ & $7 \%$ \\
\hline 0,025 & $28 \%$ & $31 \%$ \\
\hline 0,050 & $39 \%$ & $43 \%$ \\
\hline 0,075 & $14 \%$ & $14 \%$ \\
\hline 0,100 & $9 \%$ & $5 \%$ \\
\hline Média & $0,035 \pm 0,024$ & $0,033 \pm 0,020$ \\
\hline$C O(p p b)$ & SAL -163 amostras & NAT - 146 amostras \\
\hline 0,00 & $4 \%$ & $0 \%$ \\
\hline 1,00 & $71 \%$ & $84 \%$ \\
\hline 2,00 & $18 \%$ & $10 \%$ \\
\hline 3,00 & $4 \%$ & $3 \%$ \\
\hline 4,00 & $1 \%$ & $2 \%$ \\
\hline 5,00 & $2 \%$ & $1 \%$ \\
\hline 6,00 & $0 \%$ & $0 \%$ \\
\hline Média & $0,79 \pm 0,88$ & $0,64 \pm 0,75$ \\
\hline
\end{tabular}




\subsection{Avaliação dos resultados dos GEE medidos em SAL}

\subsubsection{Análise das trajetórias das massas de ar que chegaram a SAL}

Foram simuladas para cada coleta realizada em todo o período estudado as trajetórias retrocedentes das massas de ar que chegaram a SAL. O tempo retrocedente utilizado foi de 120 horas, equivalente há 5 dias. Foi observado nessas simulações uma pequena parte de massas de ar provenientes do Oceano Atlântico Norte (OAN) e outra grande parte foram provenientes do Oceano Atlântico Sul (OAS) como está apresentado na Figura 48.

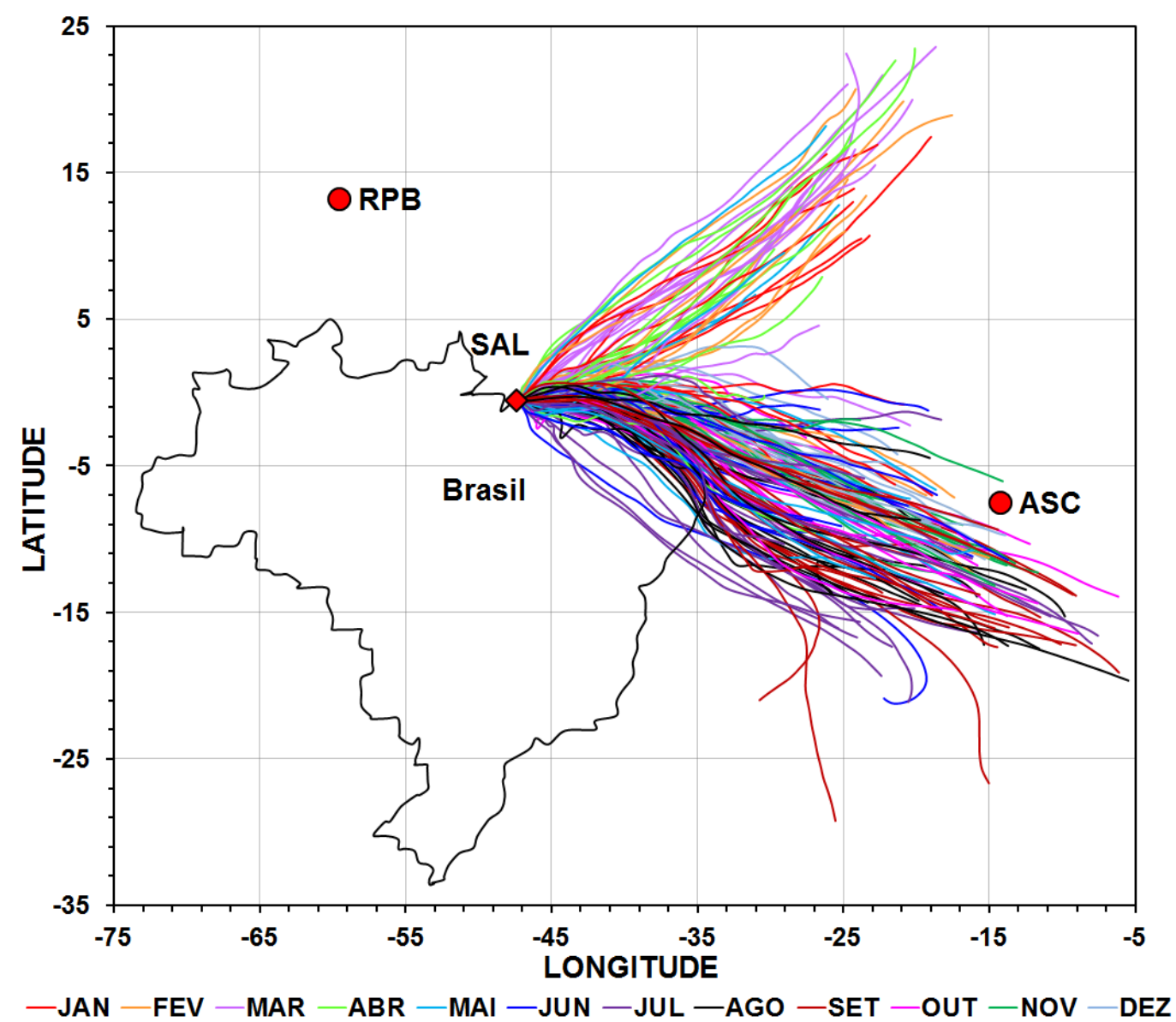

Figura 48: Trajetórias retrocedentes das massas de ar que chegaram a SAL, simuladas pelo modelo HYSPLIT ${ }^{[55]}$ para cada coleta realizada em todos os anos de estudo (2010, 2011, 2012 e 2013).

Em todo o período pode ser observado que as massas apresentam origem em diversas latitudes tanto no OAN quanto no OAS. Dessa forma essas massas vindas do OAN poderiam influenciar as concentrações medidas em SAL, já que o HN apresenta variações sazonais mais elevadas quando comparado ao HS pelas observações das concentrações globais de GEE. 
Para poder estudar a sazonalidade das trajetórias das massas de ar ao longo dos anos em SAL, foi realizada a separação dessas trajetórias para cada mês, como apresenta a Figura 49.

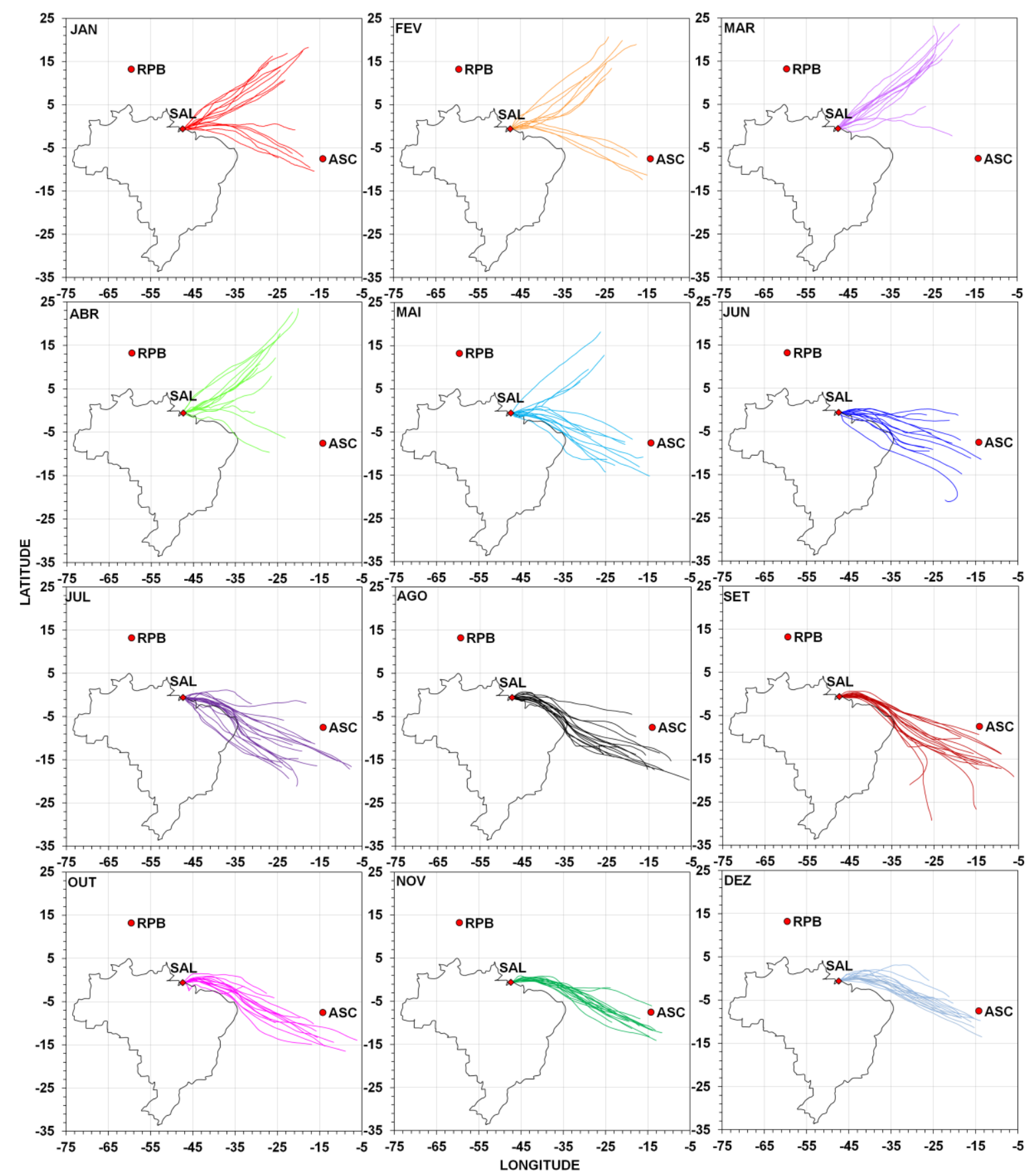

Figura 49: Trajetórias retrocedentes das massas de ar que chegaram a SAL, separadas para cada mês referentes a todos os anos de estudos.

Podemos observar entre os meses de janeiro à maio, que a maior parte das trajetórias tiveram origem no OAN, no entanto, eventualmente também foram observadas trajetórias com origem no OAS. Já no mês de junho, a totalidade das 
trajetórias passam a ter origem abaixo da linha do Equador. Observa-se entre junho a agosto que algumas trajetórias passam sobre o continente, e a partir de setembro as trajetórias iniciam um processo de elevação de latitude que prossegue até dezembro, iniciando um novo ciclo sazonal.

Essa variação observada na origem das trajetórias das massas de ar pode ser explicada pela posição da Zona de Convergência Intertropical (ZCIT). Estudos observados e simulados para a região do Atlântico Tropical revelaram que a posição média da ZCIT entre os meses de janeiro a abril fica compreendida entre $0^{\circ}$ a $-2^{\circ}$ de latitude, e a partir do mês de maio a posição da ZCIT começa a se elevar chegando a aproximadamente $10^{\circ}$ de latitude no mês de outubro ${ }^{[57]}$.

Levando em consideração essas observações relatadas na literatura, foi verificado que entre janeiro a abril a posição da ZCIT fica abaixo da posição onde está SAL, como mostra a Figura 50, e assim as massas de ar teriam como origem o OAN, condizendo com as trajetórias simuladas para este local de estudo.

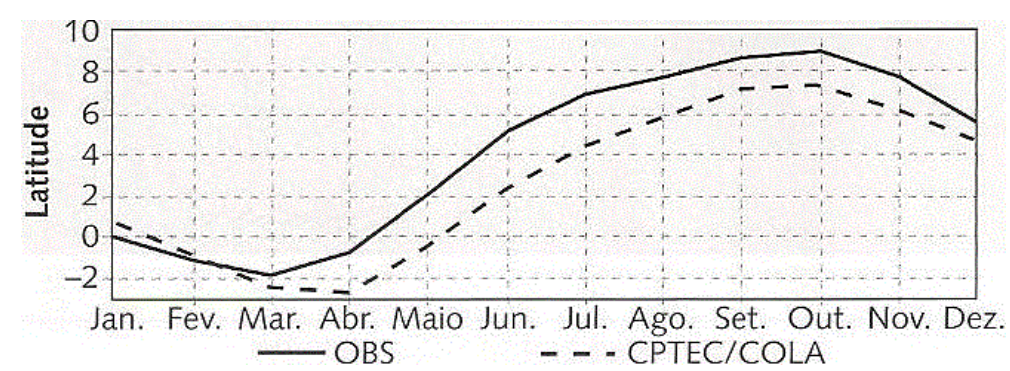

Figura 50: Variabilidade sazonal da posição da ZCIT observada e simulada para a região do Atlântico Tropical, próximo à costa sul-americana ${ }^{[57]}$.

A posição média da ZCIT apresenta variações ao longo do ano, assim ocorrem períodos em que massas de ar chegam do OAN e em outros períodos chegam do OAS, como apresentado na Figura 51. Nesta figura podemos observar o escoamento do vento a $925 \mathrm{hPa}$, resultante de uma simulação climática entre 1976 a 2001, onde mostra que os ventos até o mês de maio são provenientes do OAN, e a partir de junho passam a ser provenientes apenas do OAS ${ }^{[57]}$.

A ZCIT está localizada mais ao norte de julho a outubro, e entre março e abril sua posição fica mais ao sul do equador, como mostra a Figura 52. A região nordeste do Brasil, propensa a secas, fica particularmente deficiente de umidade durante períodos em que a ZCIT permanece em uma posição setentrional ${ }^{[58]}$. Podemos observar nesta figura as várias faixas de posição da 
ZCIT, sendo que entre os meses de fevereiro a maio, a ZCIT está localizada abaixo da latitude onde se encontra SAL, e todas estão acima da latitude de NAT.

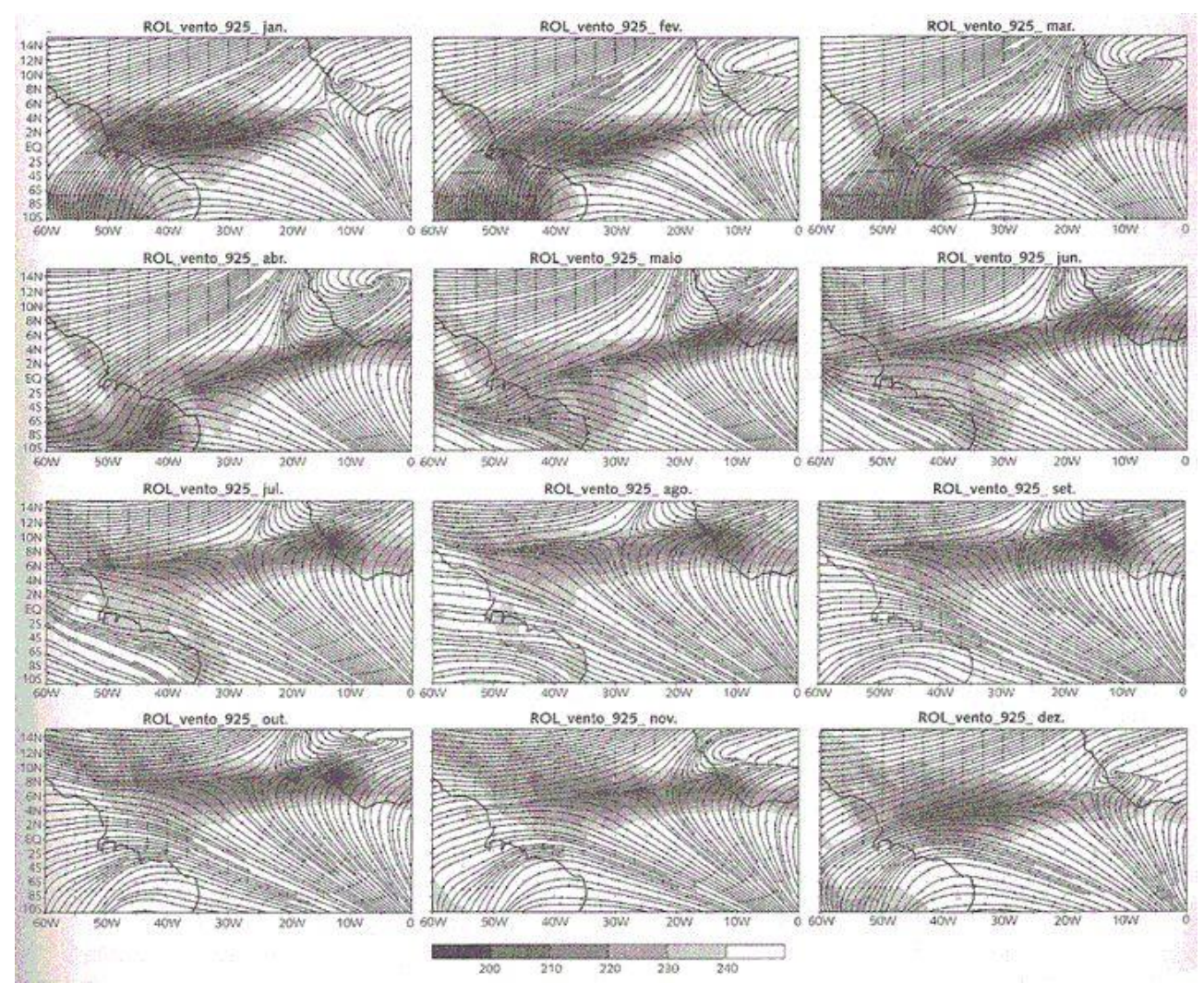

Figura 51: Médias climatológicas mensais de Radiação Onda Longa (período de 1976 a 2001), para valores menores que $240 \mathrm{~W} \mathrm{~m}^{-2}$, e escoamento do vento em $925 \mathrm{hPa}$, resultantes de uma simulação climática ${ }^{[57]}$.

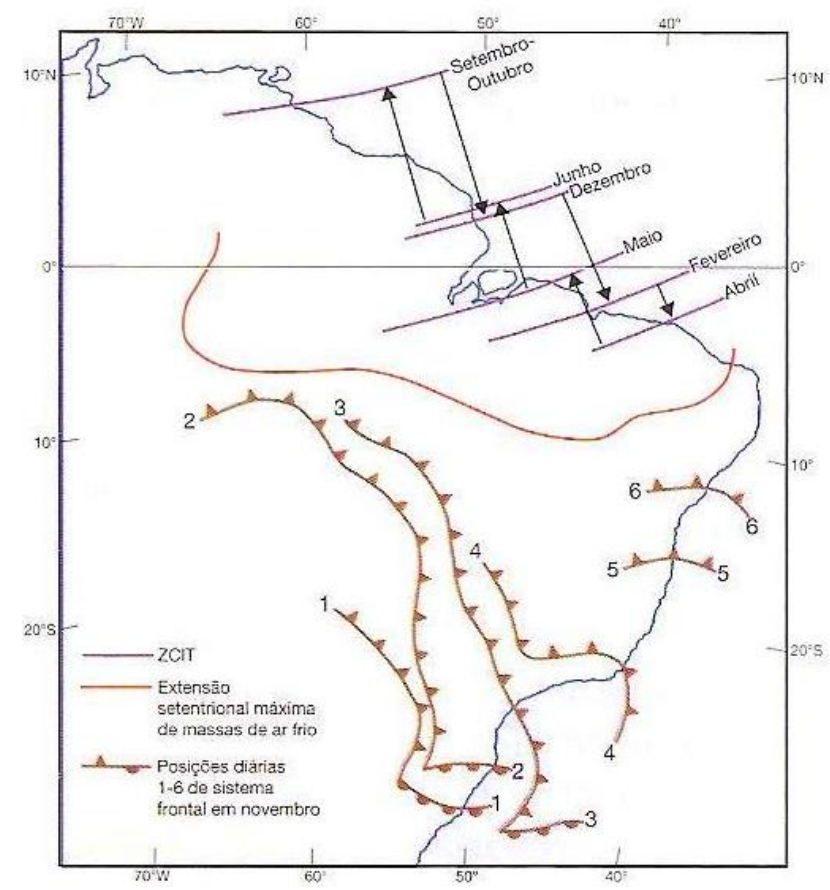

Figura 52: Posições sazonais da Zona de Convergência Intertropical costeira ${ }^{[58]}$. 
Com base nos dados obtidos a partir do satélite Terra/MODIS (Moderate Resolution Imaging Spectroradiometer) da NASA (National Aeronautics and Space Administration) pode ser observado que a ZCIT a cada mês forma uma faixa de nuvens persistentes próximo a linha do Equador, onde os ventos alísios dos Hemisférios Norte e Sul se encontram. Esse encontro dos ventos aquecidos impulsionam para o alto o ar úmido da atmosfera. $\mathrm{O}$ ar se expande $\mathrm{e}$ se resfria, condensando o vapor de água em nuvens e chuva. A faixa de nuvem se localiza mais ao norte e ao sul do da linha do Equador, de acordo com as estações do ano. Nas áreas tropicais, este deslocamento da ZCIT acaba provocando períodos chuvosos e secos ${ }^{[59]}$. Na Figura 53, Figura 54 e Figura 55 são apresentadas as variações da ZCIT para os três anos de estudo (2010, 2011 e 2012, respectivamente), onde se observa uma faixa de nuvens ao centro de cada mapa na região da linha do Equador. Estas faixas se apresentam mais ao sul da linha do Equador entre janeiro a maio, e se elevam a partir do mês de junho, ficando ao norte da linha equatorial.

Foi realizado um estudo da velocidade e direção do vento em SAL, para o período de amostragem, para se avaliar a sazonalidade desses parâmetros. Para isso foram utilizados dados disponíveis no portal do Instituto Nacional de Meteorologia - INMET [56]. Foram utilizados apenas os dados referentes às 12 horas, devido à realização da coleta ocorrer neste horário.

Este estudo mostrou que a direção dos ventos nesta região, na maior parte do tempo, está concentrada entre $0^{\circ}$ a $90^{\circ}$, entretanto, entre os meses de janeiro a junho a direção do vento também apresenta variabilidade estando entre $90^{\circ}$ a $360^{\circ}$ como pode ser observado na Figura 56. Foi observado que neste período, onde a direção do vento varia de leste a sul, ocorre também a diminuição da velocidade do vento, chegando a ficar abaixo de $2 \mathrm{~m} \mathrm{~s}^{-1}$. As amostragens ocorreram dentro de condições pré-estabelecidas, como: direção do vento de $310^{\circ}$ a $70^{\circ}$ (de noroeste, passando pelo norte a nordeste) e apresentando velocidade do vento acima de $2 \mathrm{~m} \mathrm{~s}^{-1}$. Velocidades mais elevadas são observadas entre os meses de julho a dezembro onde estas alcançam até $6 \mathrm{~m} \mathrm{~s}^{-1}$. 


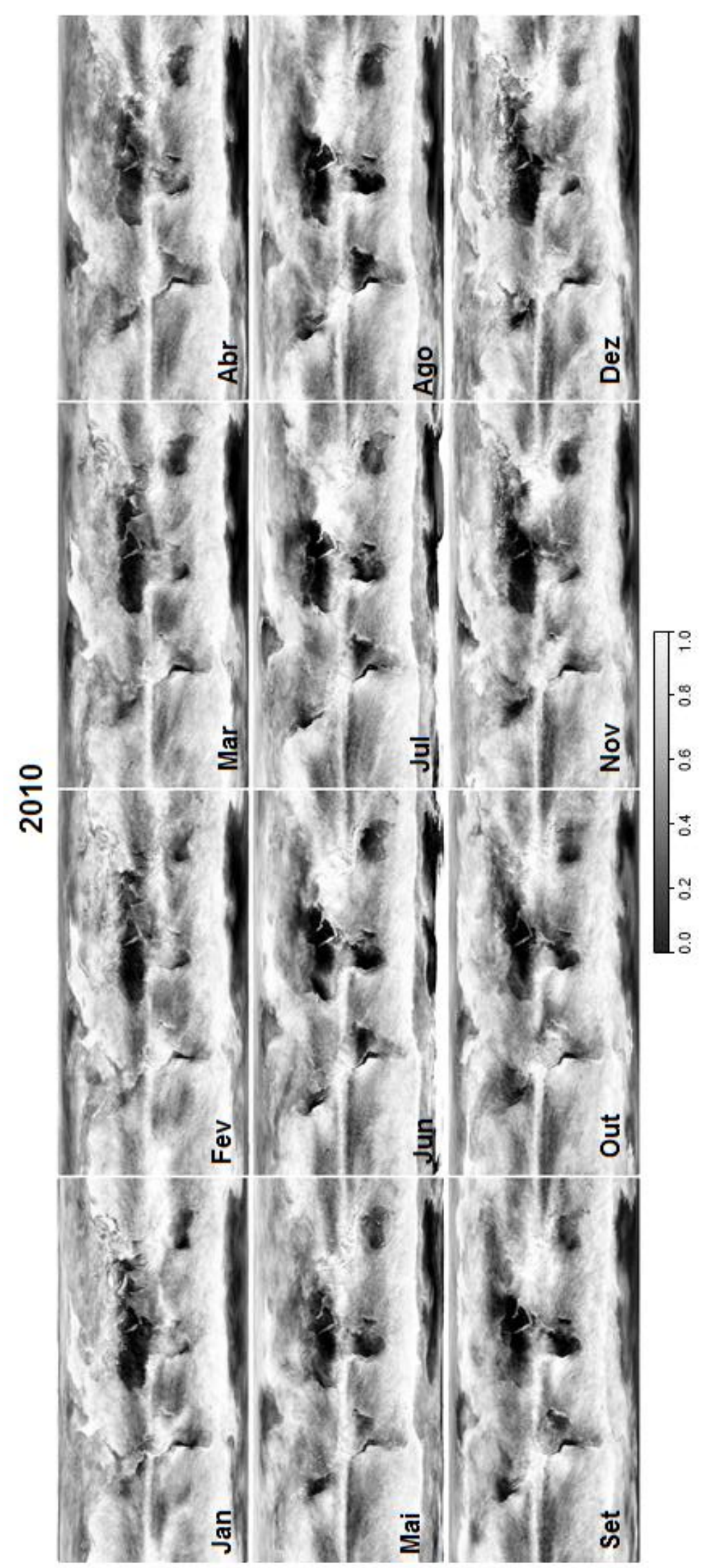

Figura 53: Mapas da fração média mensal de nuvens para o ano de 2010. As medidas foram coletadas pelo satélite Terra/MODIS da NASA. As cores variam do cinza (sem nuvens) ao branco (com nuvens) ${ }^{[59]}$. 


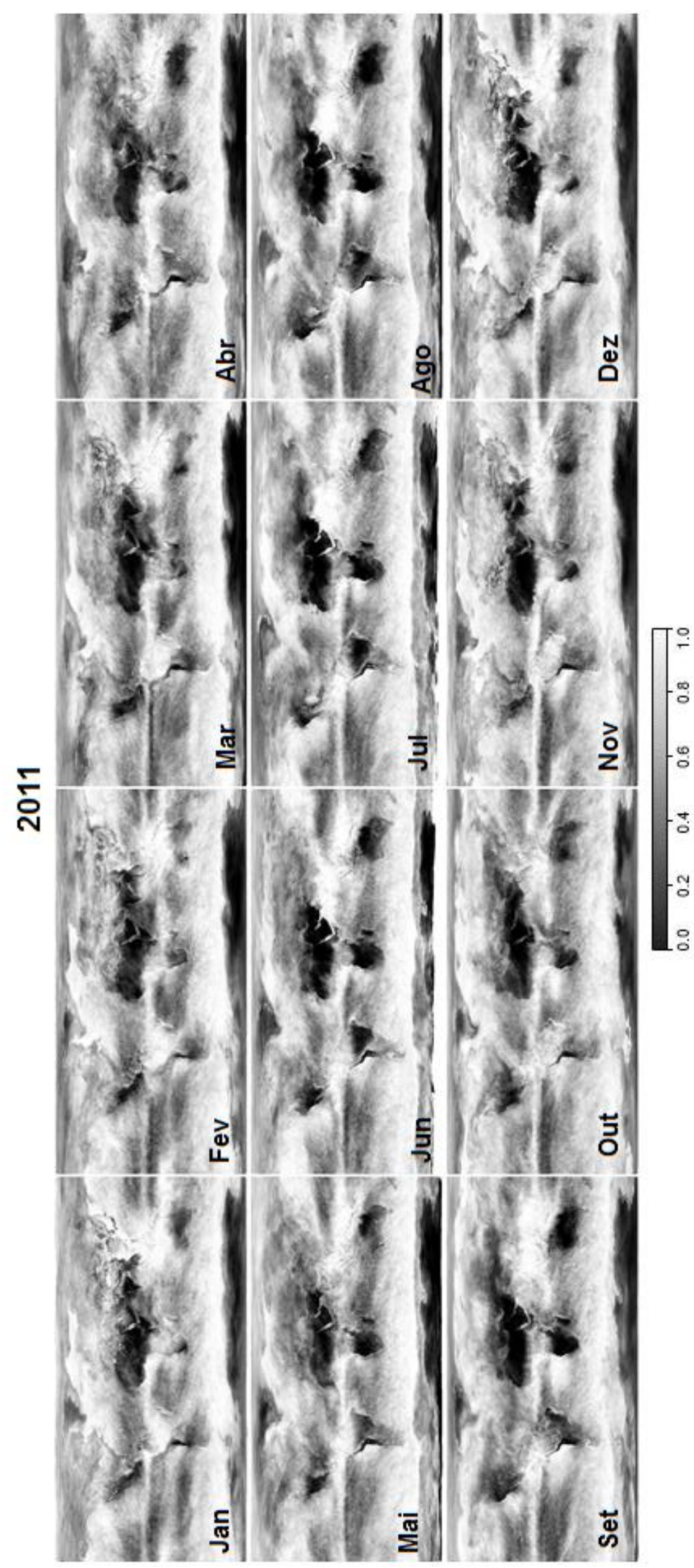

Figura 54: Mapas da fração média mensal de nuvens para o ano de 2011. As medidas foram coletadas pelo satélite Terra/MODIS da NASA. As cores variam do cinza (sem nuvens) ao branco (com nuvens) ${ }^{[59]}$. 


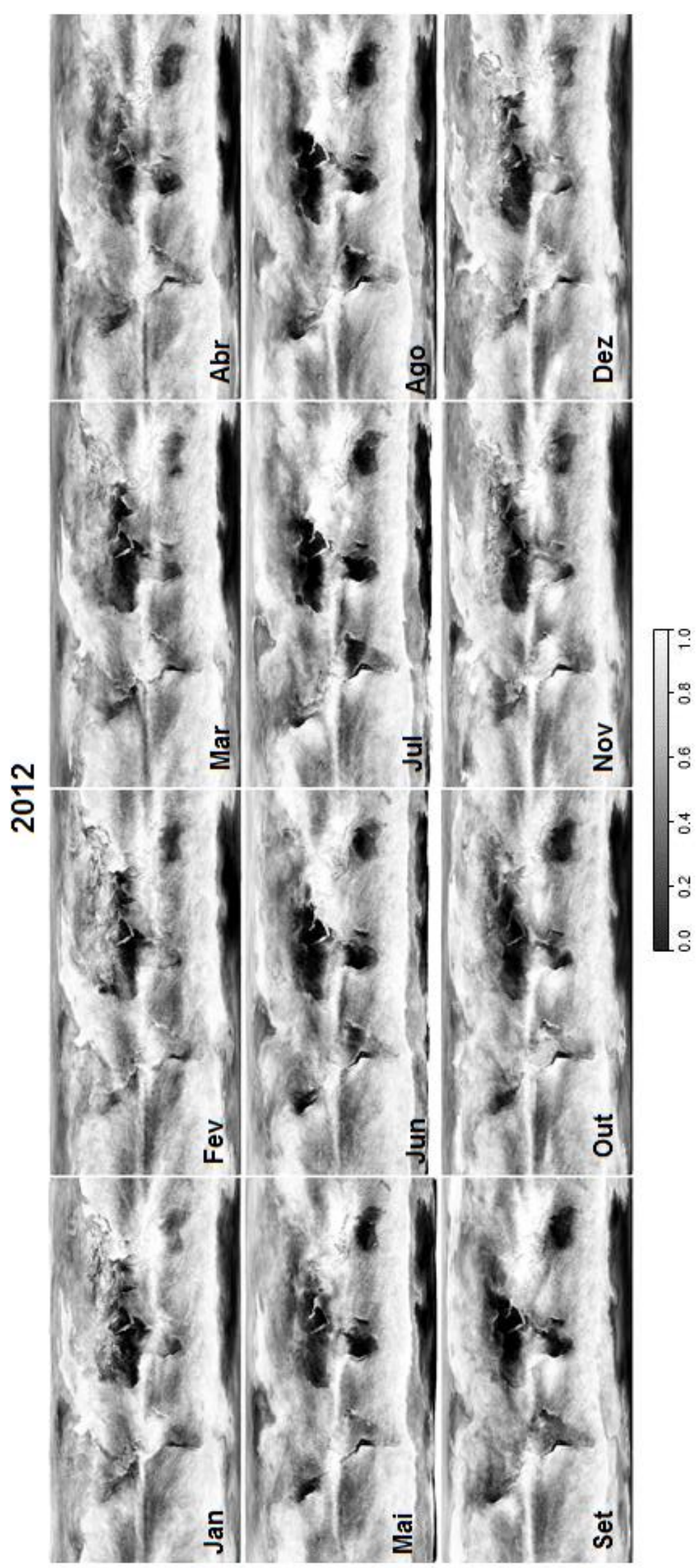

Figura 55: Mapas da fração média mensal de nuvens para o ano de 2012. As medidas foram coletadas pelo satélite Terra/MODIS da NASA. As cores variam do cinza (sem nuvens) ao branco (com nuvens) ${ }^{[59]}$. 


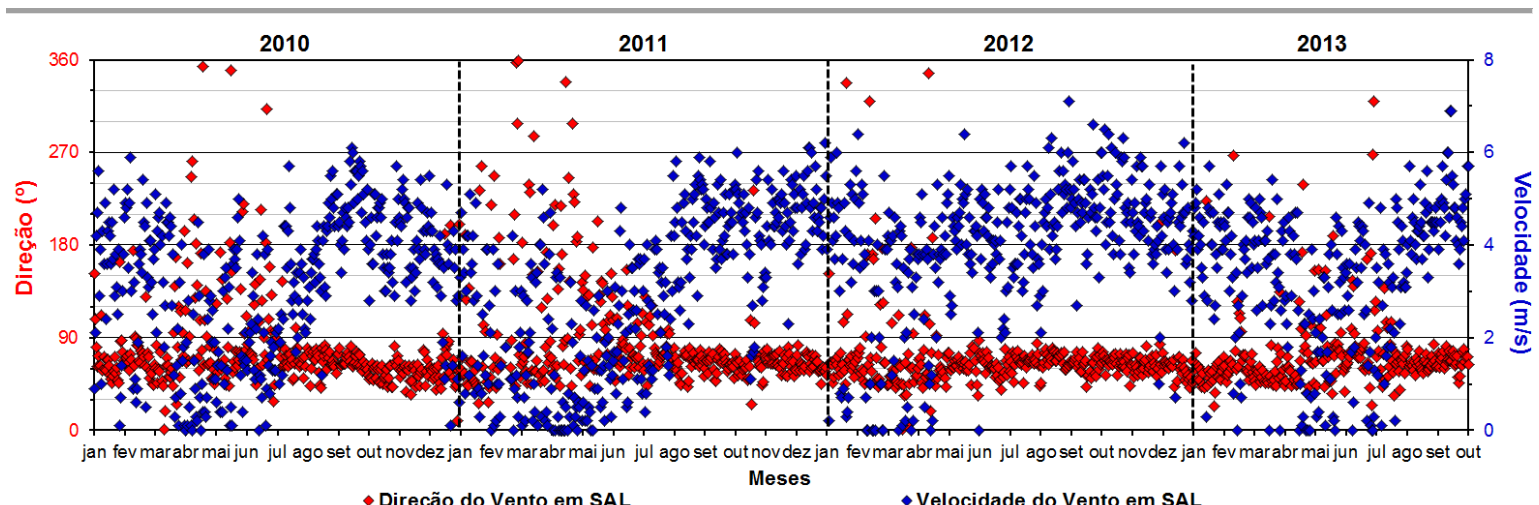

Figura 56: Direção e velocidade do vento às 12 horas em SAL, utilizando a base de dados do INMET ${ }^{[56]}$.

\subsubsection{Avaliação das concentrações de $\mathrm{CO}_{2}$}

Os resultados foram apresentados em série temporal, onde são mostradas as concentrações de $\mathrm{CO}_{2}$ de $\mathrm{SAL}$ e das estações globais. Podemos observar que os resultados medidos para este gás, apresentaram períodos tanto de concentrações mais elevadas, como de concentrações mais baixas, quando comparadas com as estações de monitoramento global da NOAA.

Nos períodos de janeiro a abril, para todos os anos de estudo, pode ser observado que as concentrações de $\mathrm{CO}_{2}$ apresentaram o mesmo comportamento da estação global de RPB, como apresentado na Figura 57. Neste período as concentrações estiveram mais elevadas, sendo este, um comportamento associado às massas de ar vindas do OAN, e que chegaram nesta região devido à posição ZCIT se encontrar abaixo da latitude de SAL. Este fato pode então influenciar nas concentrações de $\mathrm{CO}_{2}$, já que o $\mathrm{HN}$ possui maiores concentrações de GEE, quando comparadas ao HS.

Foi observado que as concentrações de $\mathrm{CO}_{2}$ apresentaram-se em determinados períodos abaixo das estações globais de ASC e RPB. Este período se inicia a partir de maio e se estende geralmente até o mês de julho ou agosto. Em 2010 este período ficou compreendido entre os meses de maio a julho, em 2011 e 2012 entre maio a agosto, e em 2013 de maio a julho.

As concentrações médias obtidas em SAL para todos os anos de estudo são apresentados na Tabela 9. Podemos notar que as concentrações estão sofrendo um aumento de aproximadamente $2 \mathrm{ppm}$ ao ano, acompanhando o incremento mundial, que mostrou de 2010 a 2011 um crescimento de aproximadamente 2,0 ppm, e de 2011 a 2012 de 2,2 ppm. Existem variáveis locais que podem estar interferindo nestas médias anuais, que foram a mudança 
de local de coleta, para a próxima praia a oeste, em janeiro de 2011. Foi observado que no local do primeiro ano, durante o verão existia uma importante influência de emissões antrópicas da praia a leste deste ponto. Então, esta diferença maior entre 2010 e 2011 pode ser relacionada a este fato. Além da média mundial não significar que existe homogeneidade destes valores sobre todo o globo terrestre.

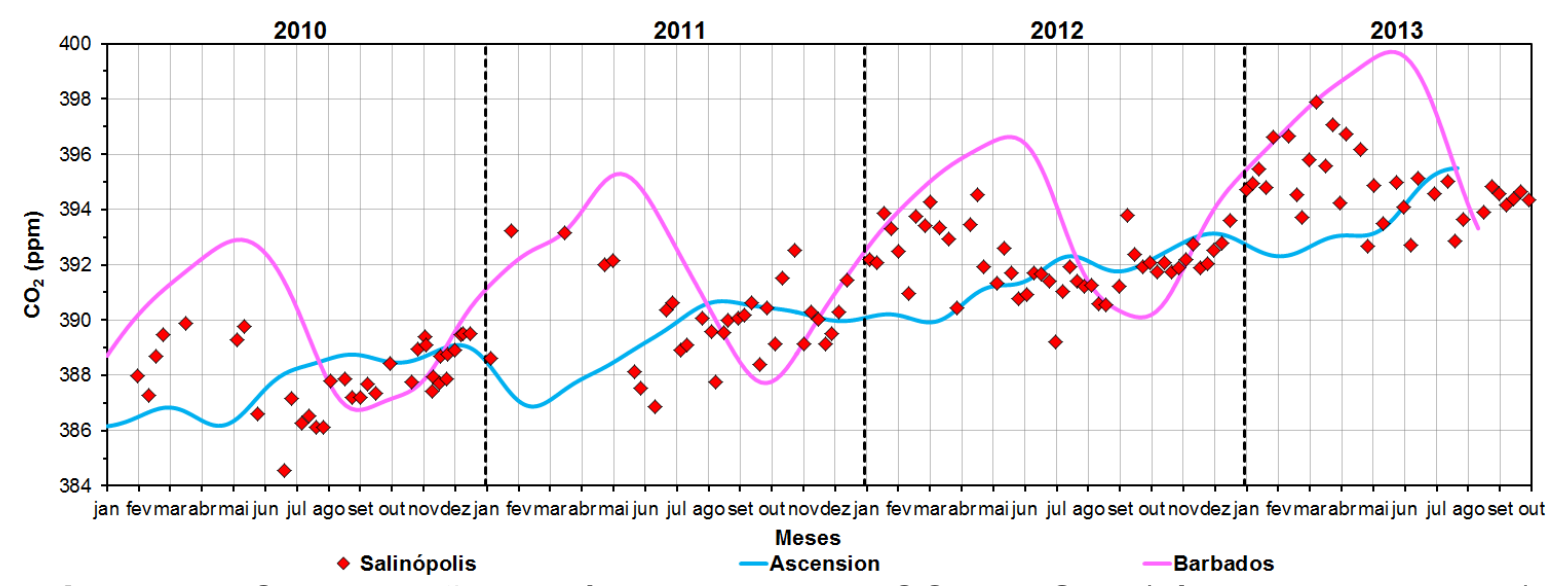

Figura 57: Comparação da série temporal de $\mathrm{CO}_{2}$ em SAL (símbolos vermelhos) com os resultados medidos em ASC e RPB realizados pela NOAA.

Tabela 9: Concentração média anual de $\mathrm{CO}_{2}$ em SAL

\begin{tabular}{ccccc}
\hline \multicolumn{5}{c}{ Concentração média de $\mathrm{CO}_{\mathbf{2}}(\mathbf{p p m})$} \\
\hline Local & $\mathbf{2 0 1 0}$ & $\mathbf{2 0 1 1}$ & $\mathbf{2 0 1 2}$ & $\mathbf{2 0 1 3}$ \\
\hline SAL & $388,01 \pm 1,19$ & $390,39 \pm 1,29$ & $392,14 \pm 0,82$ & $394,75^{1} \pm 0,77$ \\
Média global & $389,00 \pm 1,43$ & $390,90 \pm 1,49$ & $393,10 \pm 1,54$ & - \\
\hline \multirow{2}{*}{ Variação entre os anos } & $\mathbf{2 0 1 0 - 2 0 1 1}$ & $\mathbf{2 0 1 1 - 2 0 1 2}$ & $\mathbf{2 0 1 2 - 2 0 1 3}$ \\
\cline { 2 - 5 } & 2,38 & 1,75 & - \\
\hline
\end{tabular}

${ }^{1}$ Média entre os meses de janeiro a setembro. - Sem dados.

A concentração média anual em SAL, foi comparada com a concentração média global por latitude a cada ano, sendo este dado fornecido pela NOAA, e disponibilizado no sistema LAGEE. Esta comparação pode ser vista na Figura 58, onde podemos observar que a concentração média para cada ano em SAL, esteve abaixo da média global.

Em 2010, a diferença entre a concentração média global e a de SAL, para a latitude onde se localiza SAL, foi de 0,9 ppm, em 2011 foi de 0,4 ppm e, em 2012 essa diferença foi de 0,5 ppm. Como em SAL, foi observado períodos de concentrações inferiores as estações de ASC e RPB, por uma possível 
absorção de $\mathrm{CO}_{2}$, esta concentração média de 2010 a 2012, abaixo da média global pode ter sido influenciada por este fato.
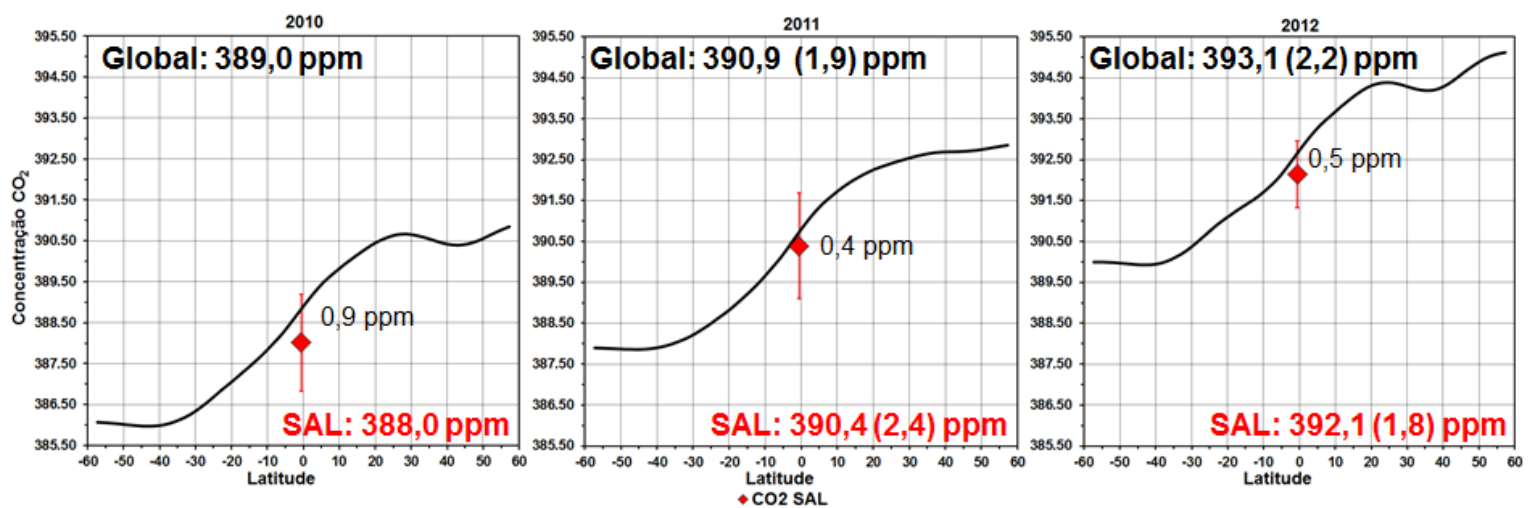

Figura 58: Comparação da concentração média anual do $\mathrm{CO}_{2}$ em SAL (símbolo vermelho) com a concentração média anual global por latitude (linha preta).

Estas concentrações mais baixas de $\mathrm{CO}_{2}$ que foram observadas na série temporal, podem estar relacionadas com o material orgânico e com os nutrientes que são levados pelo rio Amazonas até o oceano, contribuindo assim para o aumento da produção primária, resultando em sequestro de carbono, já que esta região da plataforma continental é considerada um forte sumidouro de $\mathrm{CO}_{2}{ }^{[60,61,62]}$. A vazão do rio Amazonas contribui com aproximadamente $17 \%$ do total global de entrada de água doce nos oceanos ${ }^{[63]}$. A variação sazonal da vazão do rio Amazonas apresenta dois períodos característicos. No primeiro período ocorre uma elevação da vazão, entre maio a junho, atingindo a vazão máxima de $2,4010^{5} \mathrm{~m}^{3} \mathrm{~s}^{-1}$. O segundo período ocorre uma diminuição da vazão sendo esta de $0,9010^{5} \mathrm{~m}^{3} \mathrm{~s}^{-1}$ entre os meses de novembro a dezembro ${ }^{[64]}$.

Este período em que se observa uma maior absorção de $\mathrm{CO}_{2}$ coincide com o período de maio a setembro onde a pluma do rio Amazonas leva consigo grande quantidade de matéria orgânica e nutrientes atingindo uma área de $1,310^{6} \mathrm{~km}^{2}[61]$.

Uma forma de avaliar a influência da matéria orgânica nos oceanos, estuários e lagos, é a quantificação da "Clorofila a", que tem sua concentração expressa em $\mathrm{mg} \mathrm{m}^{-3}$, indicando a concentração de pigmentos fotossintéticos, calculados por sensoriamento remoto a partir de observações da superfície do oceano com dados de comprimento de onda visíveis. Este tipo de análise foi produzido a partir do sistema de dados on-line Giovanni (Geospatial Interactive Online Visualization and analysis Infrastructure), desenvolvido e mantido pelo 
GES/DISC/NASA (Goddard Earth Sciences / Data and Information Services Center), utilizando neste estudo o satélite AQUA/MODIS $-4 \mathrm{~km}{ }^{[65]}$.

A quantidade de "Clorofila a" no oceano é apresentada na Figura 59, Figura 60 e Figura 61, para os anos de 2010, 2011 e 2012, respectivamente. Podemos notar entre maio a agosto de 2010, uma maior concentração de clorofila quando comparada aos outros meses. O mesmo período foi observado em 2011 e 2012, porém estes dois anos apresentaram um fluxo de concentração menor quando comparados a 2010, onde podemos notar concentrações altas de clorofila desde a costa brasileira até latitudes acima das Guianas.

A matéria orgânica dissolvida no oceano é apresentada na Figura 62, Figura 63 e Figura 64, para os anos de 2010, 2011 e 2012, respectivamente, sendo esta opticamente detectável, pois absorve mais fortemente a luz azul da faixa do ultravioleta, proporcionando cor à água em que está dissolvido [65]. Podemos observar entre junho a setembro de 2010, maior quantidade de matéria dissolvida próxima à costa norte/nordeste brasileira. Em 2011 podemos notar similaridade com o ano de 2010, porém em setembro próximo à costa uma maior quantidade de matéria orgânica estava presente numa extensa faixa no oceano. O ano de 2012 apresentou menor quantidade de matéria orgânica quando comparado aos outros anos.

A concentração de "Clorofila a" nos indica a presença de fitoplâncton, estando relacionada com a produção primária oceânica. As tendências ao longo do tempo podem estar relacionadas às mudanças nas condições do oceano, como alteração da temperatura da superfície do mar, aumento de nutrientes, fornecimento de água do rio aos oceanos, ou mudanças nas correntes oceânicas. As atividades humanas e os processos naturais podem influenciar a concentração de nutrientes em um rio, porém nem todas as tendências em clorofila estão diretamente ligadas à mudança climática, embora elas provavelmente indiquem uma mudança ambiental ${ }^{[65]}$. 


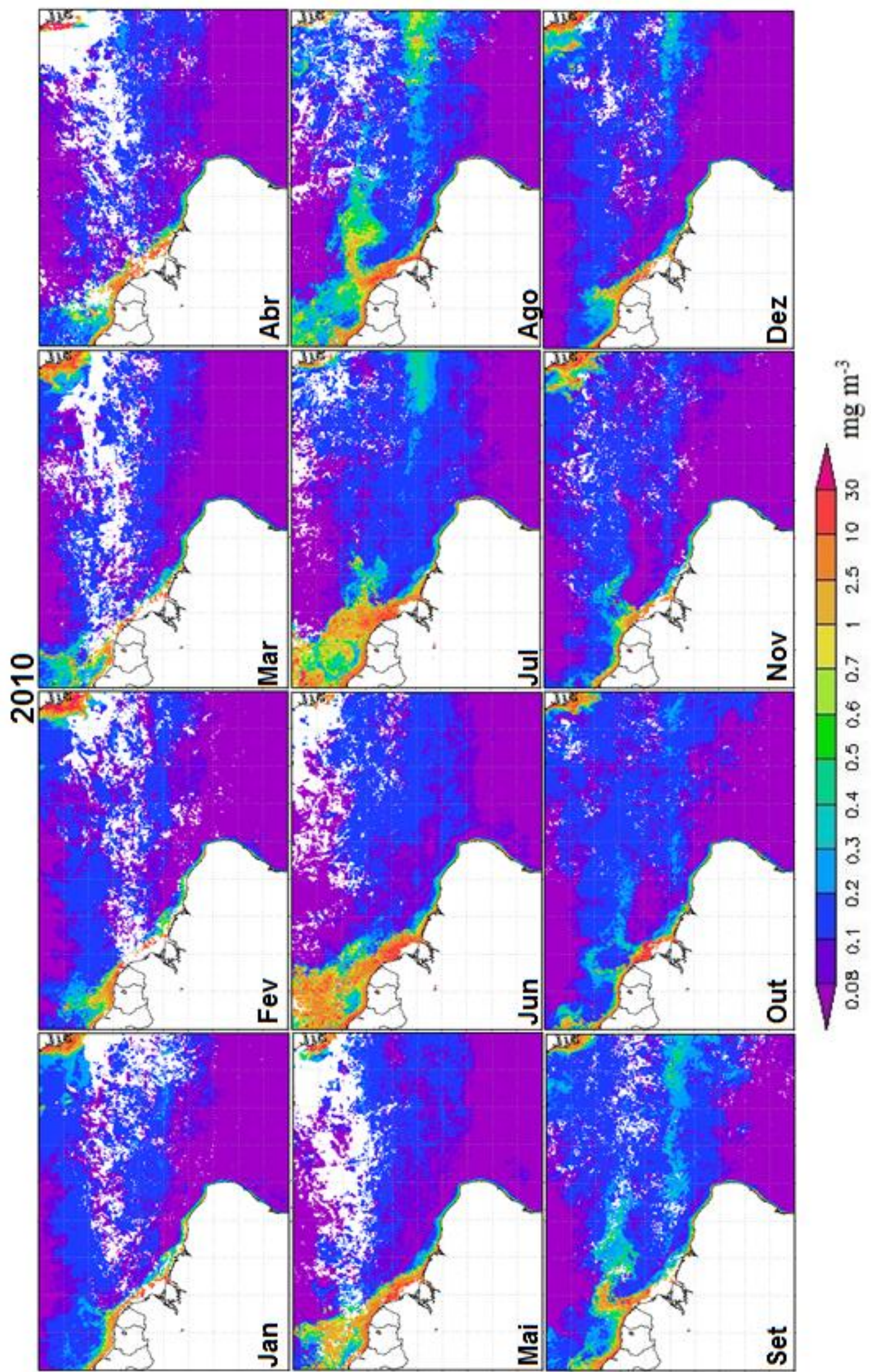

Figura 59: Concentração de "Clorofila a" no Oceano Atlântico em $2010^{[65]}$. 


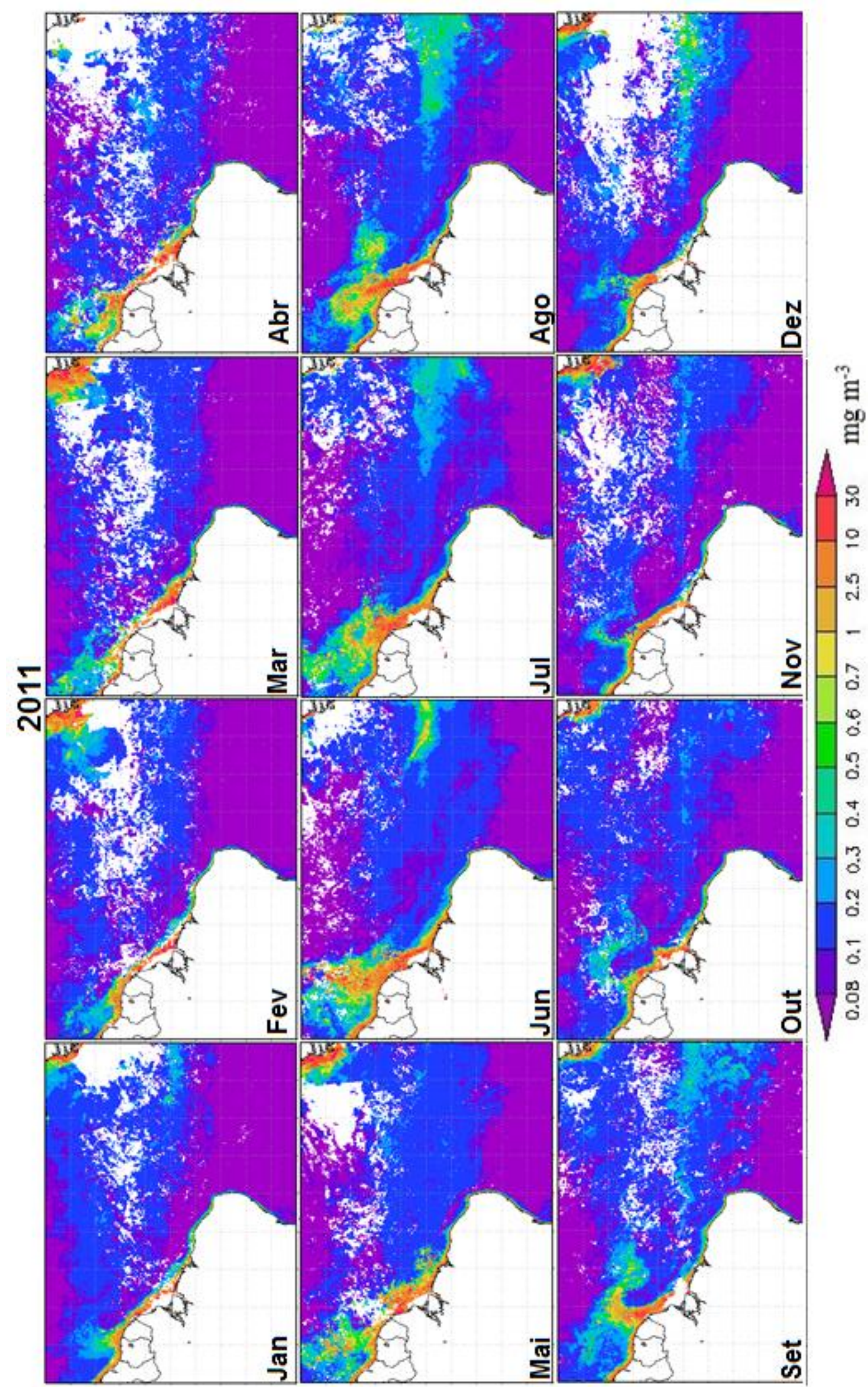

Figura 60: Concentração de "Clorofila a" no Oceano Atlântico em $2011^{\text {[65]. }}$ 


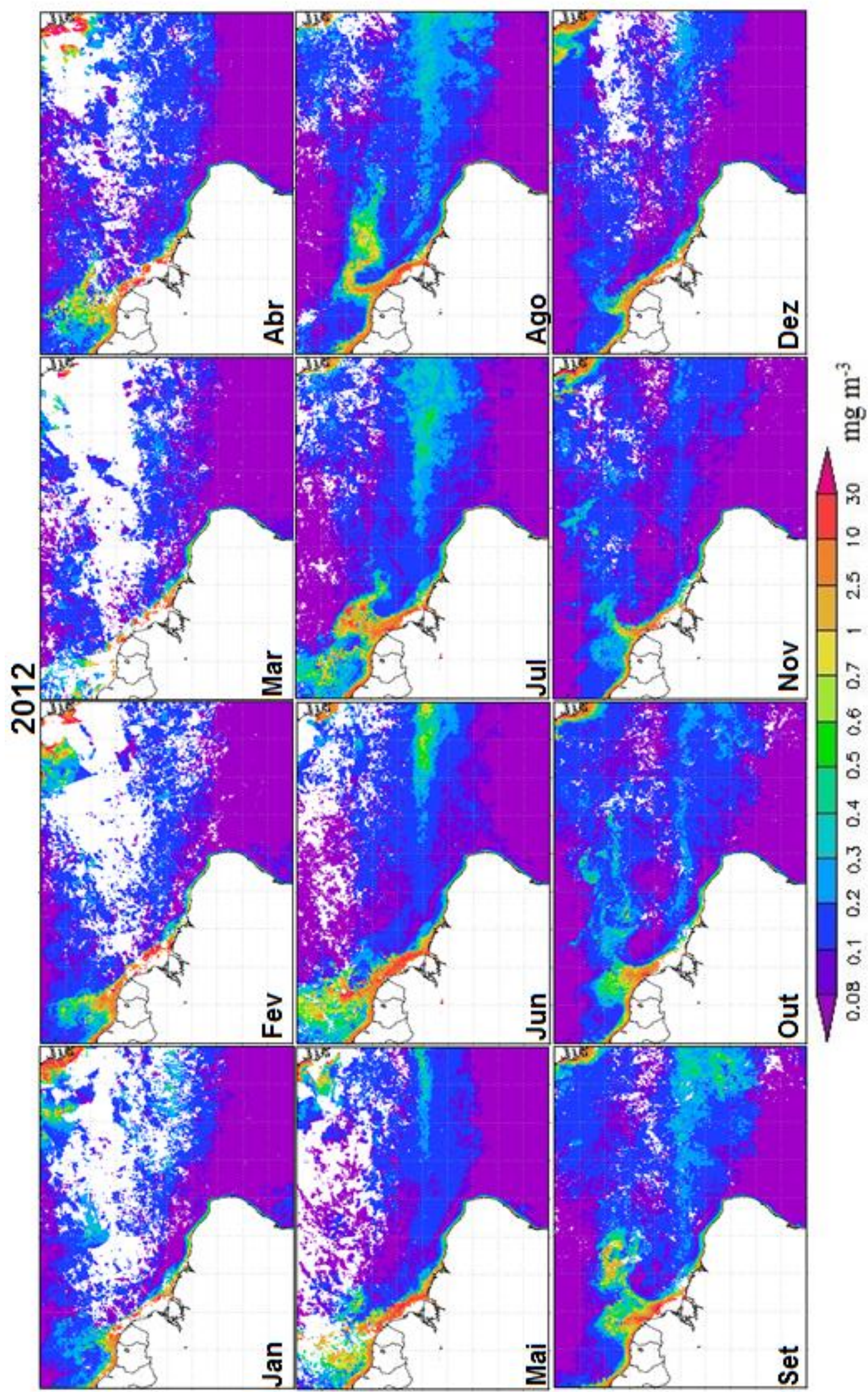

Figura 61: Concentração de "Clorofila a" no Oceano Atlântico em 2012 [65]. 


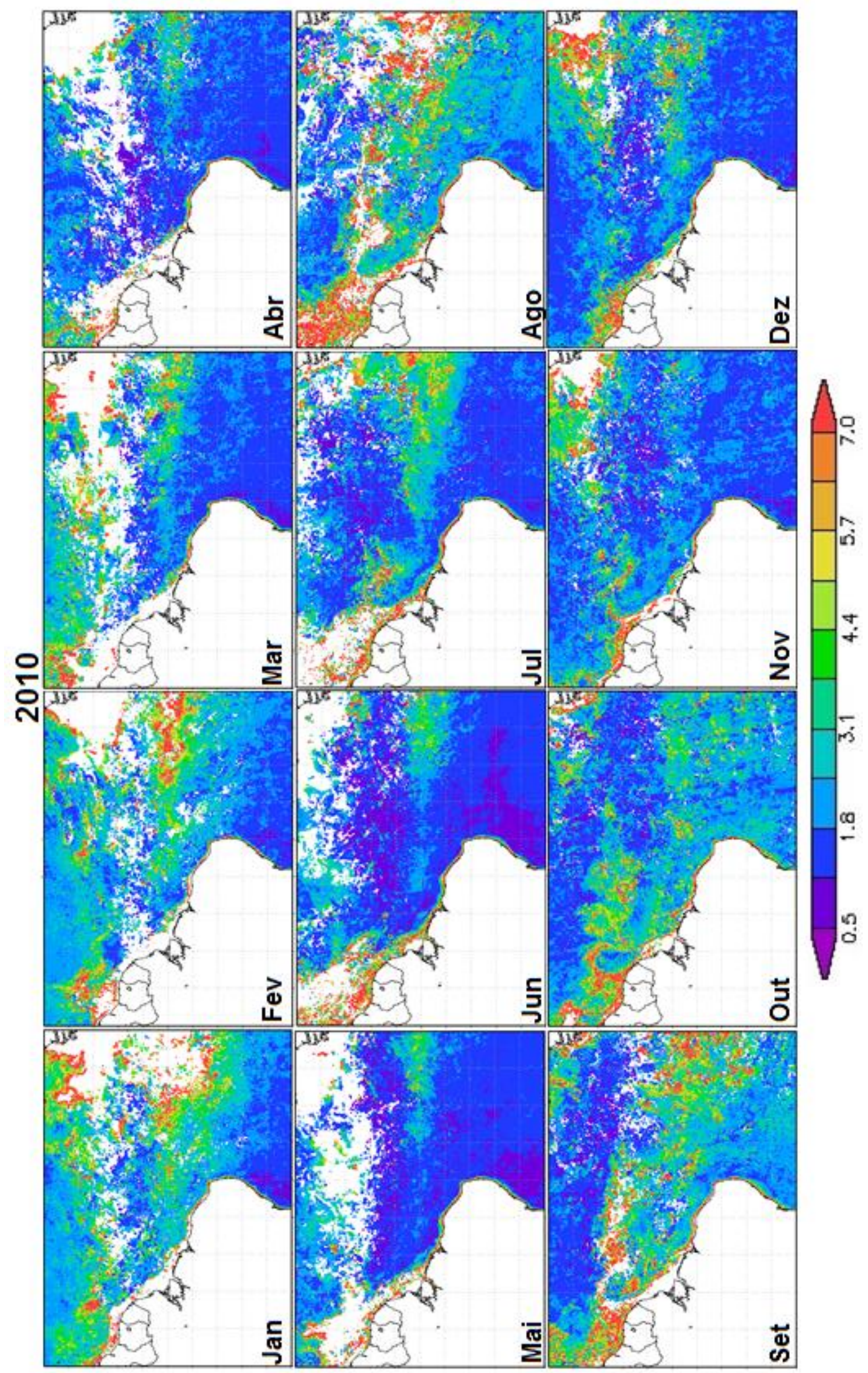

Figura 62: Matéria orgânica dissolvida no Oceano Atlântico em $2010^{\text {[65]. }}$ 


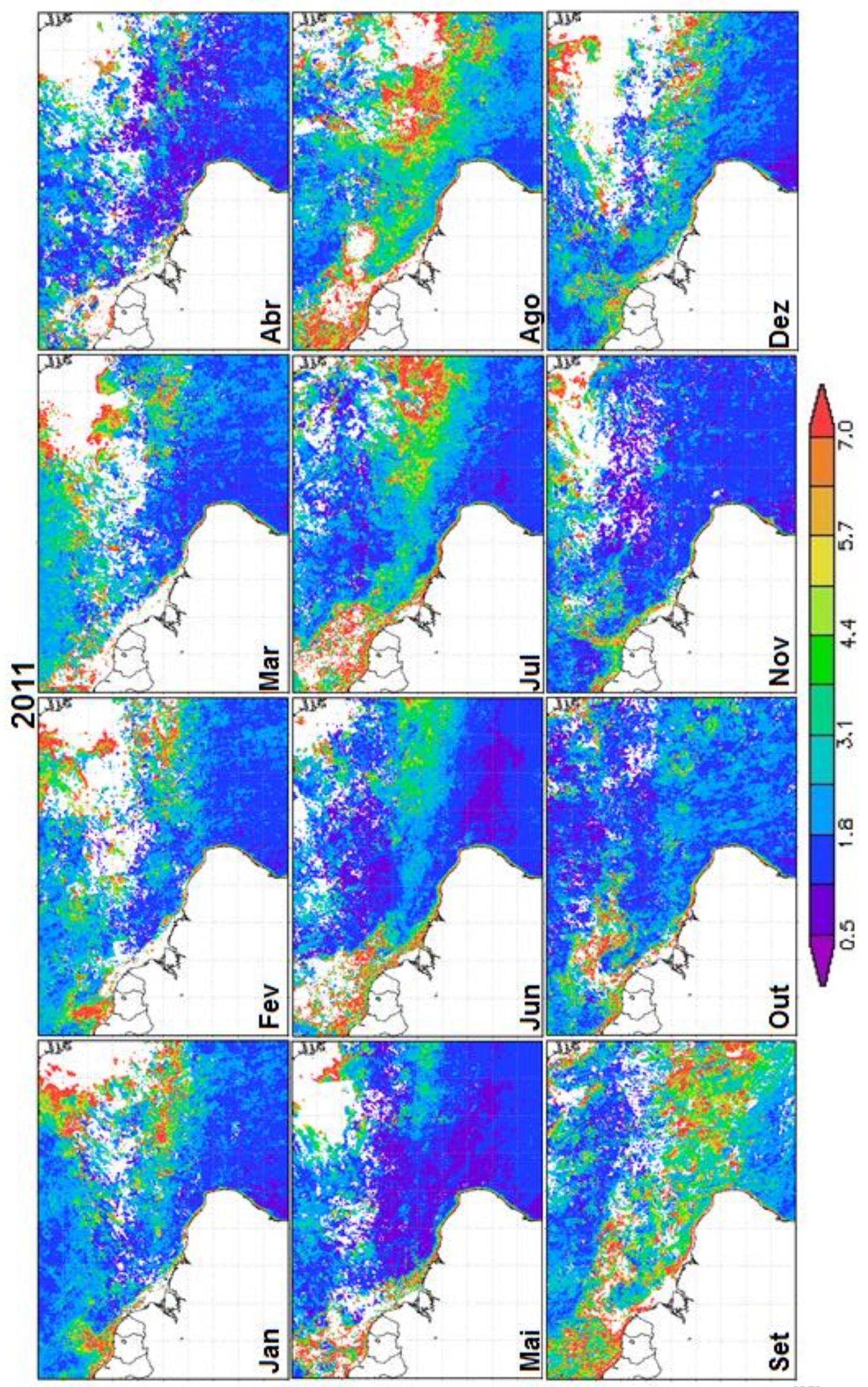

Figura 63: Matéria orgânica dissolvida no Oceano Atlântico em $2011^{165]}$. 


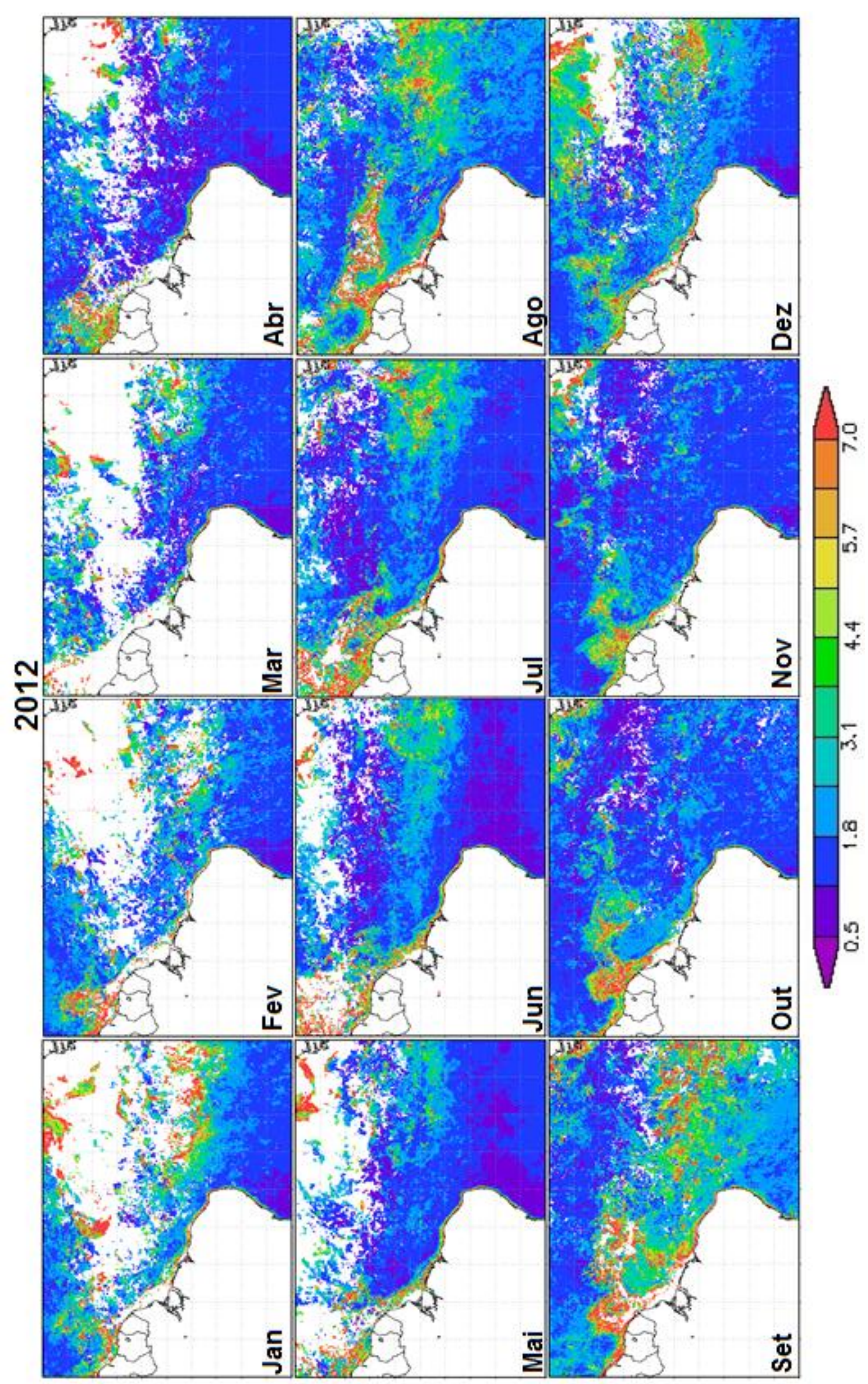

Figura 64: Matéria orgânica dissolvida no Oceano Atlântico em $2012^{165 !}$. 
Em janeiro de 2013 foram iniciados perfis verticais de avião há aproximadamente $55 \mathrm{~km}$ de distância de SAL. Este local de coleta foi denominado como SAH e tem como localização a latitude de $0^{\circ} 45^{\prime} 36^{\prime \prime S}$ e longitude $47^{\circ} 50$ '24"O, sendo realizada uma coleta mensal.

Para efetuar essas amostragens em SAH um avião de pequeno porte, porém em condição de voar a $6,7 \mathrm{~km}$ de altitude, foi equipado com um sistema semiautomático, que compreende em uma mala com dois compressores e baterias recarregáveis, e outra contendo 17 frascos de vidro para amostragem e um microprocessador para controle e armazenamento de informações ${ }^{[45,53,54]}$. A amostragem foi realizada em forma de espiral onde o primeiro frasco foi coletado a $6706 \mathrm{~m}$ de altitude e o último a $305 \mathrm{~m}$.

Os resultados das concentrações de $\mathrm{CO}_{2}$ medidas em SAH estão apresentados na Figura 65. Podemos notar a ocorrência de absorção de $\mathrm{CO}_{2}$ nos meses de março, maio e julho, onde as concentrações foram inferiores ao das estações globais. Esse comportamento do perfil mostra que há um processo de absorção local de $\mathrm{CO}_{2}$ nesta região como foi observado para os frascos coletados em superfície, para aproximadamente o mesmo período.

Para verificar a sazonalidade das concentrações de $\mathrm{CO}_{2}$ em SAL foi efetuada a separação dessas concentrações para cada mês, e para cada ano de estudo como representado na Figura 66. Podemos notar sazonalidade em SAL, onde entre os meses de janeiro a abril essas concentrações se apresentaram mais elevadas quando comparadas com o restante do ano. Também podemos observar que as concentrações deste gás estão aumentando a cada ano, onde a media de 2013 já está acima dos anos anteriores.

A diferença observada entre os períodos de janeiro a abril e de maio a dezembro está apresentada na Tabela 10, onde podemos notar que a concentração média para o primeiro período foi mais elevado quando comparado ao segundo período para todos os anos de estudo, tendo uma variação mínima de 0,76 e uma máxima de 1,99 ppm entre os períodos. 

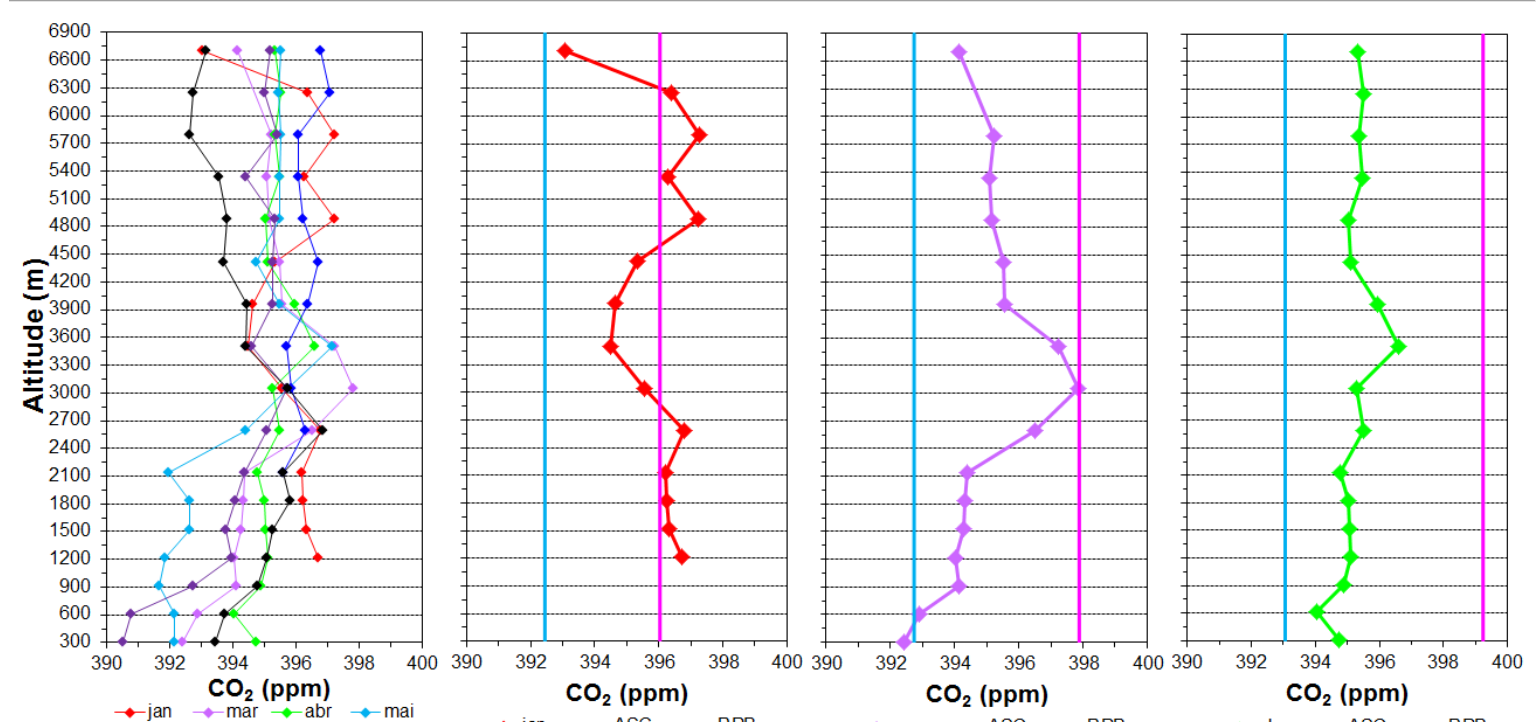

$\rightarrow$-jan $\leftrightarrow$-mar $\rightarrow$ abr $\leftrightarrow$ -
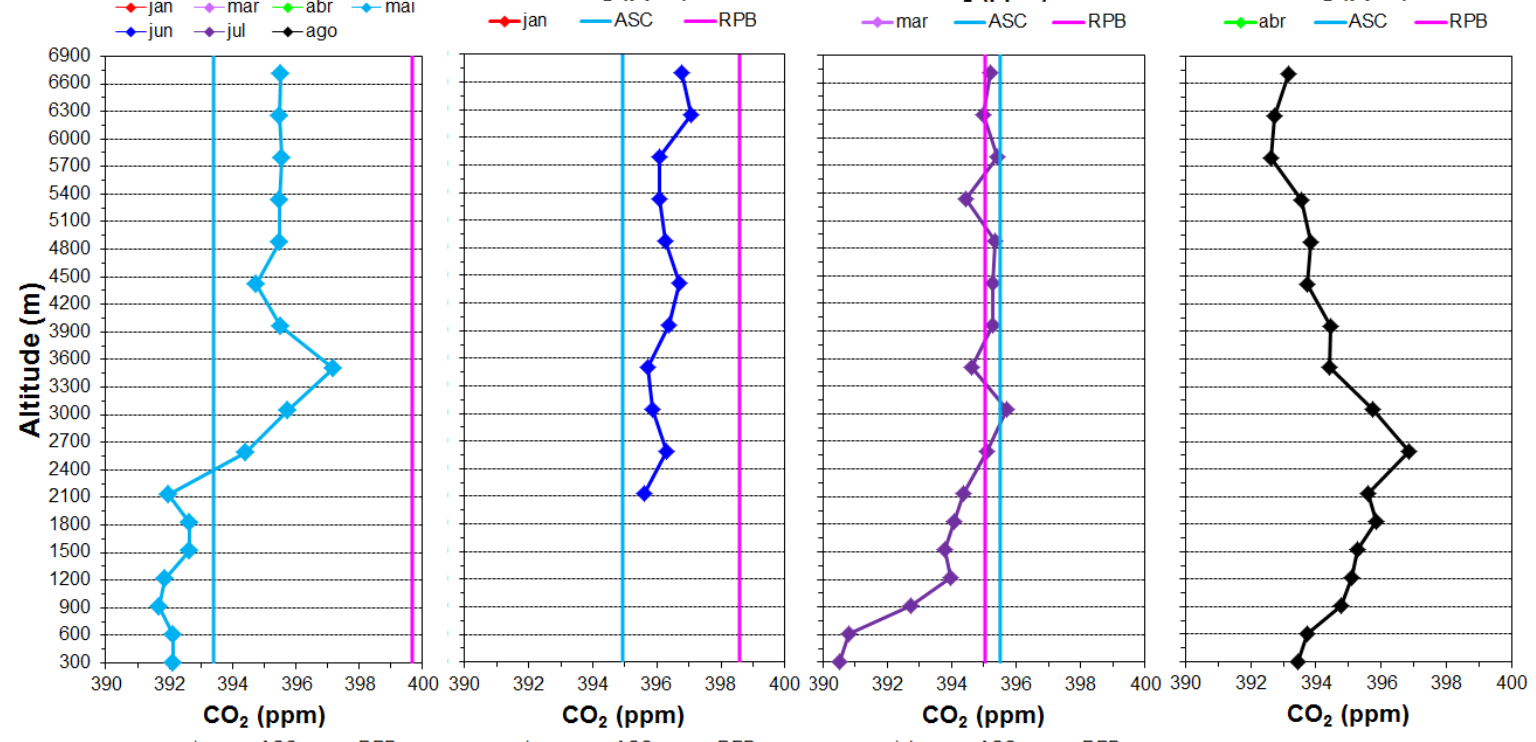

$\rightarrow$ mai - ASC $-\mathrm{R}$

$\rightarrow$-jun -ASC -RPB

$\rightarrow$ jul -ASC -RPB

$\rightarrow$ ago

Figura 65: Concentrações de $\mathrm{CO}_{2}$ medidas em perfis verticais de avião em SAH.

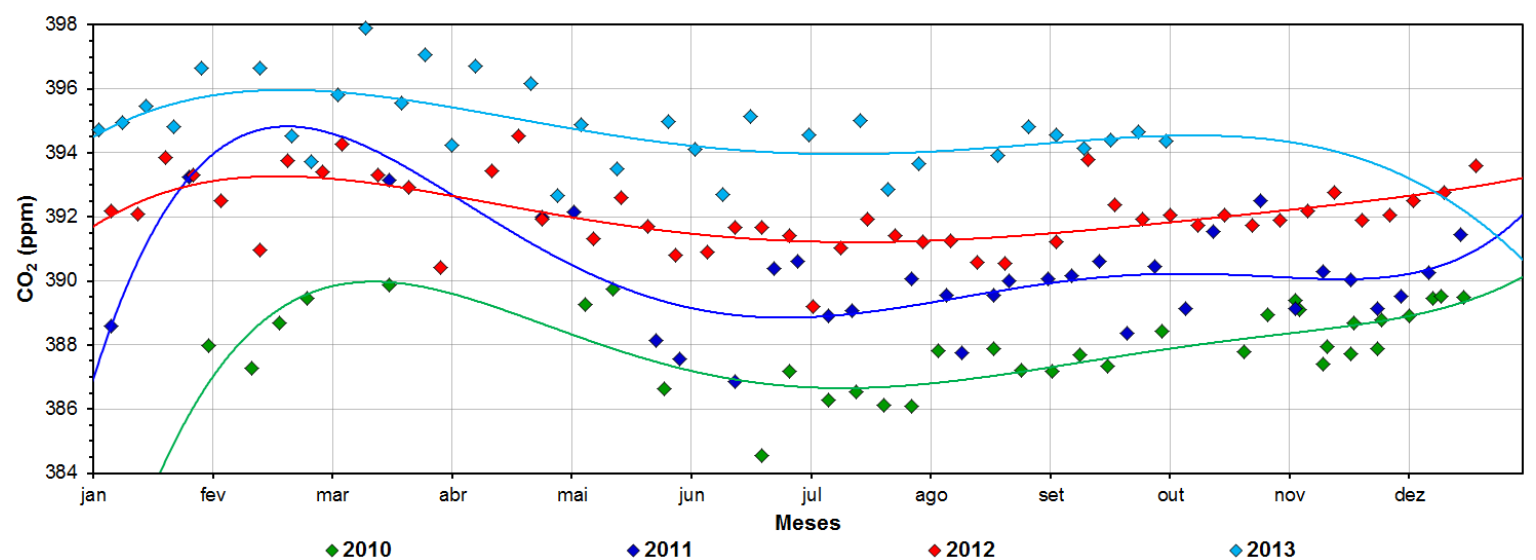

Figura 66: Concentrações de $\mathrm{CO}_{2}$ mensais e polinomiais para cada ano de estudo em SAL. 
Tabela 10: Concentração média de $\mathrm{CO}_{2}$ por período em SAL

\begin{tabular}{ccccc}
\hline \multicolumn{5}{c}{ Concentração média de $\mathrm{CO}_{2}(\mathbf{p p m})$ por período de cada ano } \\
\hline Períodos & 2010 & 2011 & 2012 & 2013 \\
\hline Jan-Abr & $388,66 \pm 1,07$ & $391,75 \pm 2,17$ & $392,86 \pm 1,17$ & $395,48 \pm 1,36$ \\
Mai-Dez & $387,90 \pm 1,26$ & $389,76 \pm 1,32$ & $391,74 \pm 0,89$ & $394,25^{1} \pm 0,72$ \\
\hline Variação & 0,76 & 1,99 & 1,12 & - \\
\hline
\end{tabular}

Média entre os meses de maio a setembro de 2013. - Sem dados.

Foi realizado um estudo comparando as concentrações de SAL com as de ASC e RPB, para verificar suas correlações. A correlação é uma medida da relação entre duas variáveis, não podendo ser superior a 1 ou inferior a -1 . Correlação próxima a zero, indica que as duas variáveis não estão relacionadas, se positiva, indica que elas se movem juntas e quanto mais próximo de 1 maior a correlação. Quando a correlação é negativa indica que as duas variáveis movemse em direções opostas, e a relação é maior quanto mais próxima de -1. Duas variáveis perfeitamente correlacionadas positivamente $(r=1)$, movem-se proporcionalmente na mesma direção, enquanto que as correlacionadas negativamente movem-se proporcionalmente em direções opostas ${ }^{[66]}$.

Para realizar este estudo, utilizou-se a média das concentrações de 5 dias retrocedentes em ASC e RPB, a partir da coleta em SAL, com as concentrações de SAL. O diagrama de dispersão deste estudo é apresentado na Figura 67. Para todo o período estudado foi encontrada uma correlação de 0,71 entre SAL e ASC, e uma correlação de 0,74 entre SAL e RPB. As correlações para o período de janeiro a abril entre SAL com ASC e RPB foram de 0,83 e 0,80 respectivamente, e para o período de maio a dezembro foram de 0,84 e 0,64 respectivamente.

Desta forma quando comparado apenas o período de maio a dezembro, há uma clara correlação maior com ASC como pode ser percebido na Figura 67 (c), comparando acima e abaixo (RPB e ASC). Já o período de janeiro a abril apresenta correlações muito próximas para ambos os casos, conforme pode ser observado na série temporal, pois as concentrações em SAL estão entre as estações de ASC e RPB. 

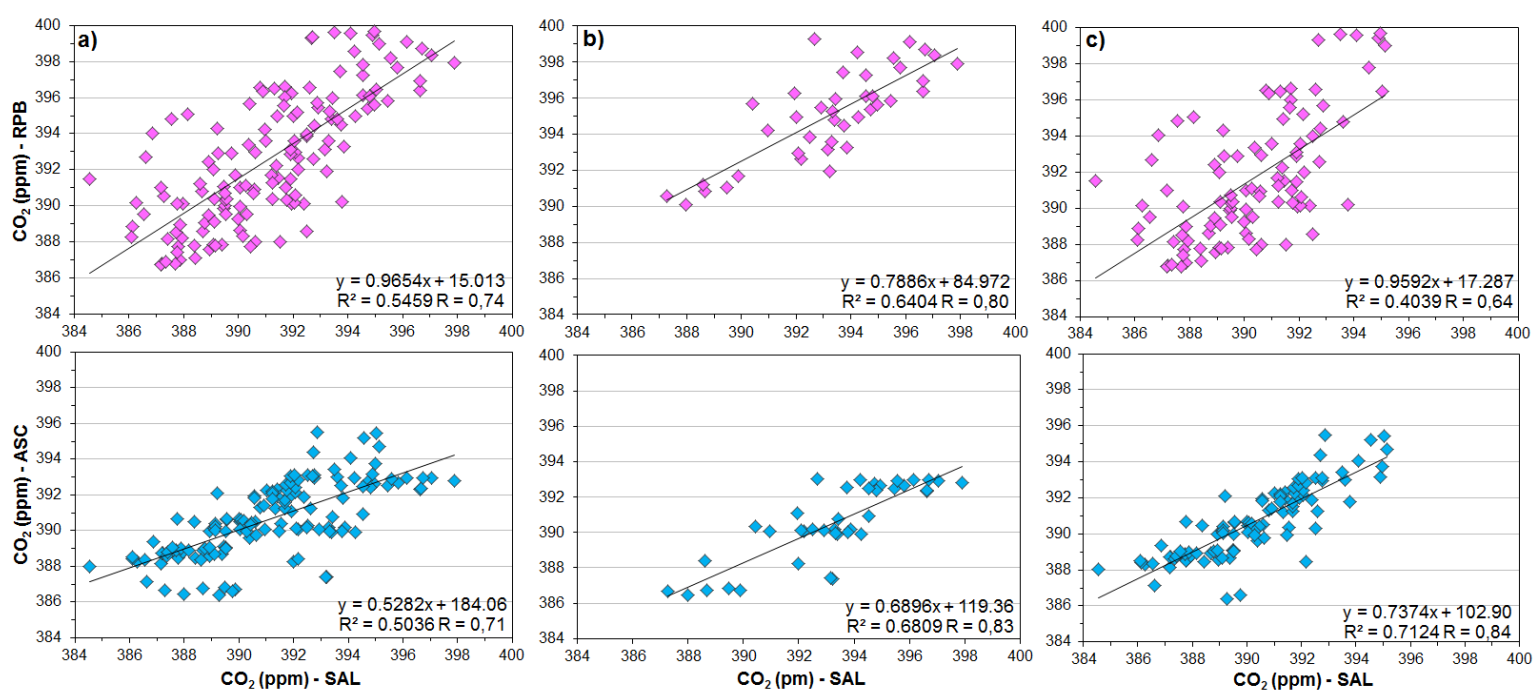

Figura 67: Diagrama de dispersão entre as concentrações de $\mathrm{CO}_{2}$ em SAL com as estações de ASC (abaixo) e RPB (acima), onde: (a) representa todo o período, (b) período de janeiro-abril e (c) período de maio-dezembro.

Para verificar o comportamento das concentrações em SAL em relação às estações globais, foi efetuada a média das concentrações de ASC e RPB nos 5 dias anteriores ao dia da coleta em SAL. As diferenças obtidas entre o local de estudo e as estações é apresentada na Figura 68. Podemos observar entre janeiro a março concentrações de $\mathrm{CO}_{2}$ mais próximas de RPB devido a menor diferença neste período. Entre maio a julho a diferença de SAL com RPB se torna mais elevada, coincidindo com o período onde ocorre absorção de $\mathrm{CO}_{2}$, e entre agosto a dezembro, as diferenças de ambas as estações em relação a SAL diminuem, pois neste período ocorre a proximidade das concentrações de ASC e RPB devido ao ciclo sazonal de $\mathrm{CO}_{2}$.

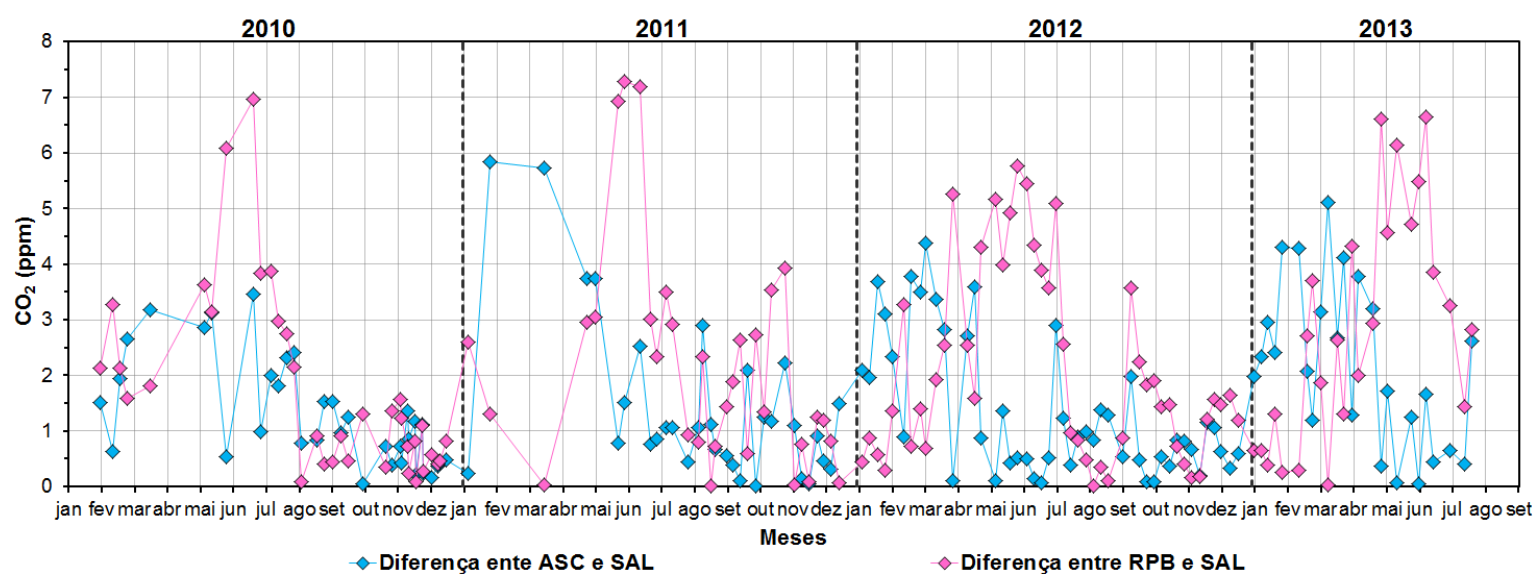

Figura 68: Diferença entre as concentrações de $\mathrm{CO}_{2}$ das estações globais com as concentrações obtidas em SAL para todos os anos de estudo. 


\subsubsection{Avaliação das concentrações de $\mathrm{CH}_{4}$}

Podemos observar nos resultados medidos em SAL para o gás $\mathrm{CH}_{4}$ períodos de concentrações próximas de ASC e em outros períodos próximos de RPB, no entanto estas se mantiveram entre as concentrações destas duas estações, como apresenta a Figura 69.

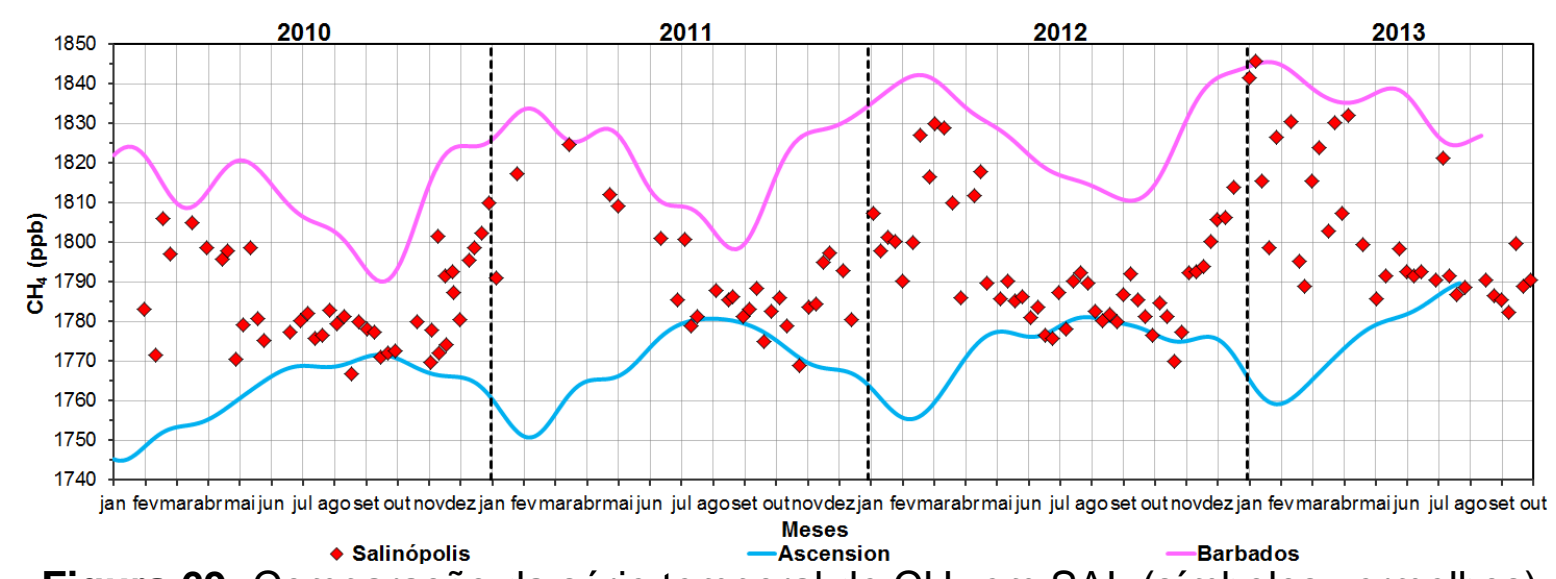

Figura 69: Comparação da série temporal de $\mathrm{CH}_{4}$ em SAL (símbolos vermelhos) com os resultados medidos em ASC e RPB realizados pela NOAA.

Podemos observar ainda que as concentrações em SAL possuem comportamento sazonal, onde no período de janeiro a abril estiveram mais elevadas e, entre maio a outubro, as concentrações foram mais baixas, iniciando um aumento a partir de novembro que se estende até abril. Nestes anos de estudo, as concentrações de $\mathrm{CH}_{4}$ apresentaram comportamento semelhante ao observado em RPB. Este período, onde as concentrações foram mais elevadas, coincide com o período onde a ZCIT está abaixo da latitude de SAL e, portanto, as massas de ar são provenientes do OAN, onde as concentrações de GEE são mais elevadas, podendo assim, influenciar as concentrações medidas em SAL.

As concentrações médias obtidas em SAL para todos os anos de estudo são apresentados na Tabela 11, onde se observa ao longo do tempo um aumento nas concentrações de $\mathrm{CH}_{4}$. O aumento de 2010 a 2011 foi de aproximadamente $10,86 \mathrm{ppb}$ e, de 2011 para 2012 houve uma diminuição 1,42 ppb. A primeira importante observação é da diferença entre a média global para as médias de SAL, que mostram aproximadamente 23 ppb, 17 ppb e 25 ppb menores para 2010, 2011 e 2012, respectivamente. A segunda, é a diferença de crescimento nas concentrações de $\mathrm{CH}_{4}$, nesta faixa do $\mathrm{HS}$, nos anos de $2011 \mathrm{e}$ 2012, mostrando uma desaceleração do crescimento em 2012. 
Tabela 11: Concentração média anual de $\mathrm{CH}_{4}$ em SAL

\begin{tabular}{ccccc}
\hline \multicolumn{5}{c}{ Concentração média de $\mathrm{CH}_{4}$ (ppb) } \\
\hline Local & $\mathbf{2 0 1 0}$ & $\mathbf{2 0 1 1}$ & $\mathbf{2 0 1 2}$ & $\mathbf{2 0 1 3}$ \\
\hline SAL & $1784,92 \pm 9,42$ & $1795,78 \pm 14,65$ & $1794,36 \pm 12,84$ & $1800,94^{1} \pm 13,54$ \\
Média global & $1808 \pm 6,63$ & $1813 \pm 6,93$ & $1819 \pm 7,42$ & - \\
\hline \multirow{2}{*}{ Variação entre os anos } & $\mathbf{2 0 1 0 - 2 0 1 1}$ & $\mathbf{2 0 1 1 - 2 0 1 2}$ & $\mathbf{2 0 1 2 - 2 0 1 3}$ \\
\cline { 2 - 5 } & & 10,86 & $-1,42$ & - \\
\hline
\end{tabular}

${ }^{1}$ Média entre os meses de janeiro a setembro. - Sem dados.

A concentração média para cada ano de estudo em SAL, apresentou valores acima da concentração média global por latitude, como observado na Figura 70. Porém, não podemos afirmar ao certo que está ocorrendo emissão deste gás, pois se considerarmos a menor variação da medida, as concentrações seriam praticamente as mesmas da média global nesta latitude. Em 2010, a diferença entre a média global e SAL, para a latitude onde se localiza $S A L$, foi de 10,2 ppb, em 2011 foi de 18,0 ppb e, em 2012 essa diferença foi de 6,5 ppb.
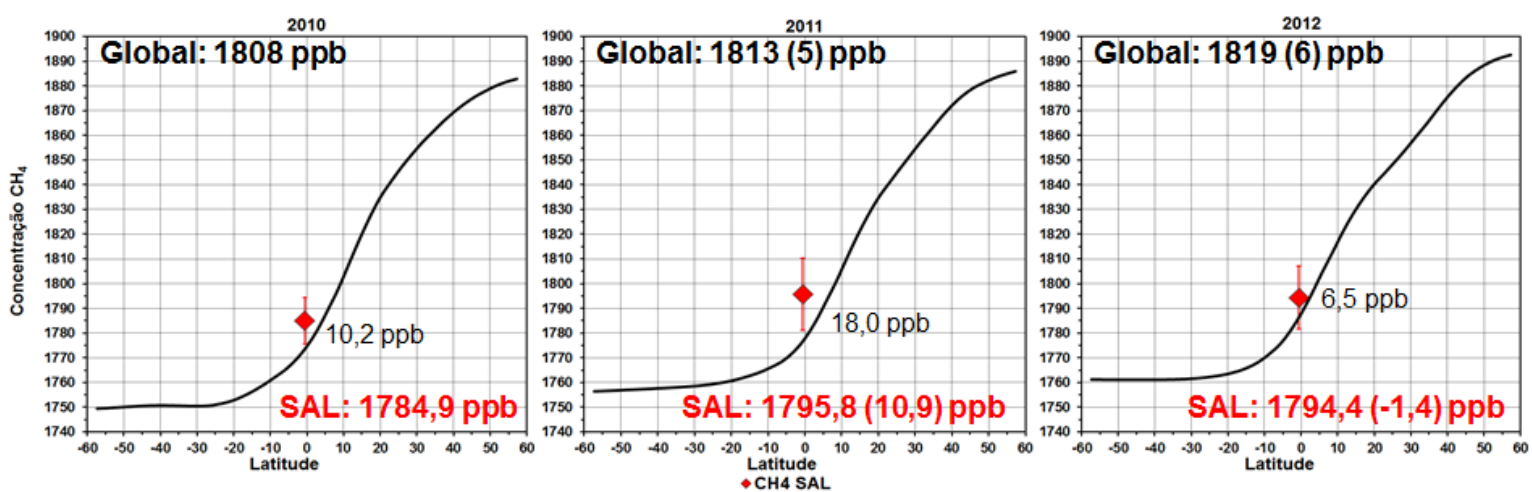

Figura 70: Comparação da concentração média anual do $\mathrm{CH}_{4}$ em SAL (símbolo vermelho) com a concentração média anual global por latitude (linha preta).

Podemos observar, a partir dos resultados obtidos para as concentrações de $\mathrm{CH}_{4}$ em $\mathrm{SAH}$, que o mês de janeiro foi o que apresentou concentração mais elevada, quando comparada aos outros meses, conforme apresentados na Figura 71. Os perfis, em altitudes mais elevadas, mostram concentrações mais altas, e à medida que este se aproxima da superfície, a concentração sofre um decréscimo. Este comportamento é indicativo de absorção por parte da superfície, o que indicaria absorção por parte do oceano ou da região costeira próxima. Este decréscimo foi observado em SAL para 2013, onde as concentrações a partir de maio apresentaram uma diminuição. 


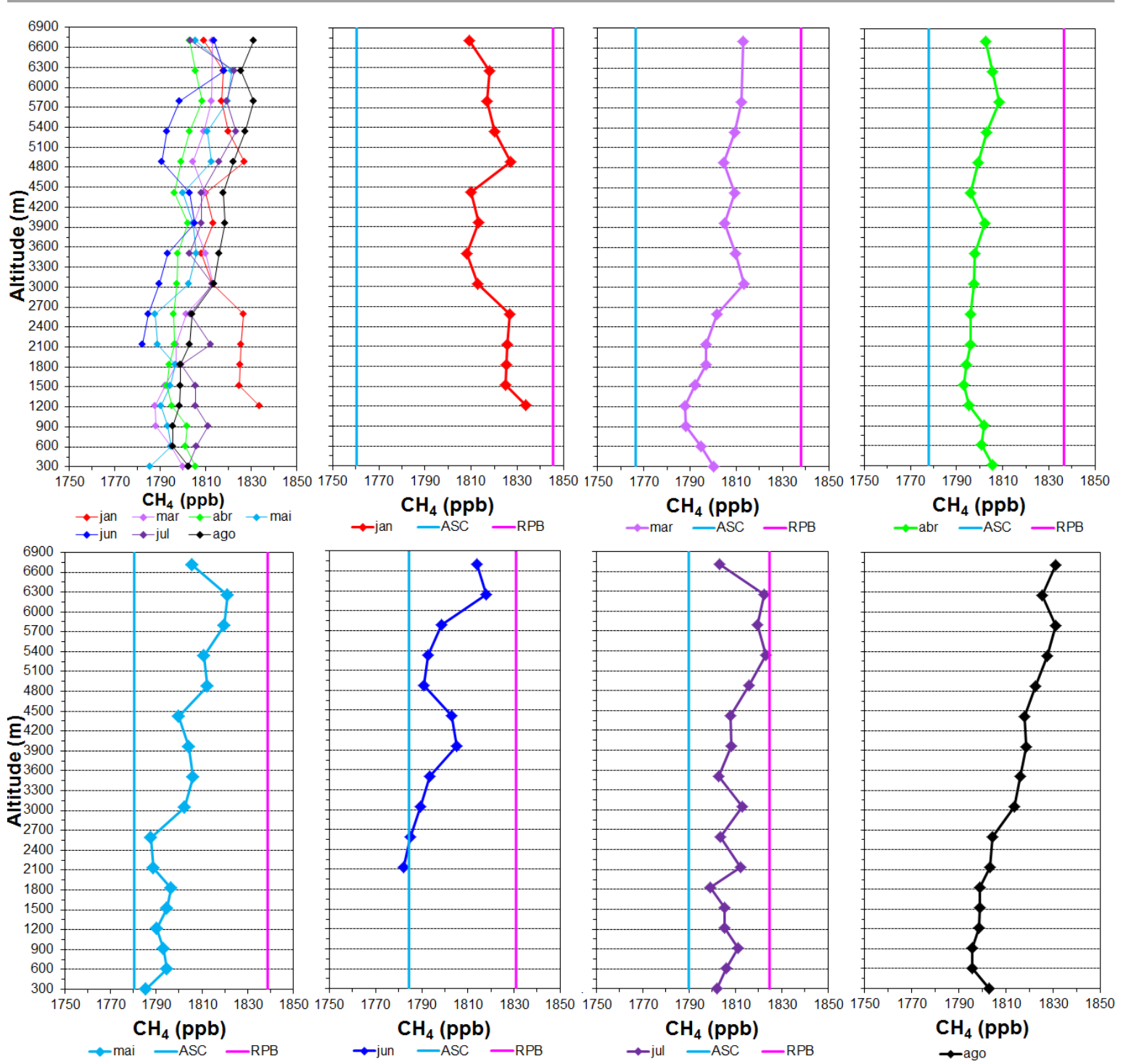

Figura 71: Concentrações de $\mathrm{CH}_{4}$ medidas em perfis verticais de avião em SAH.

As concentrações de $\mathrm{CH}_{4}$ em SAL também apresentam sazonalidade como pode ser observado na Figura 72, onde as concentrações foram separadas mês a mês para cada ano de estudo. Concentrações mais elevadas são observadas entre janeiro a abril para todos os anos. Entre maio a outubro ocorre uma diminuição nestas concentrações e a partir de novembro novo aumento pode ser observado, iniciando um novo ciclo sazonal neste local.

A diferença observada entre esses períodos é mostrada na Tabela 12. Desta forma podemos notar que no ano de 2010 ocorreu uma diferença menor do que a observada entre 2011 a 2012, esta diferença entre os períodos foram superiores a 20 ppb, sendo o período de janeiro a abril o de maior concentração. 


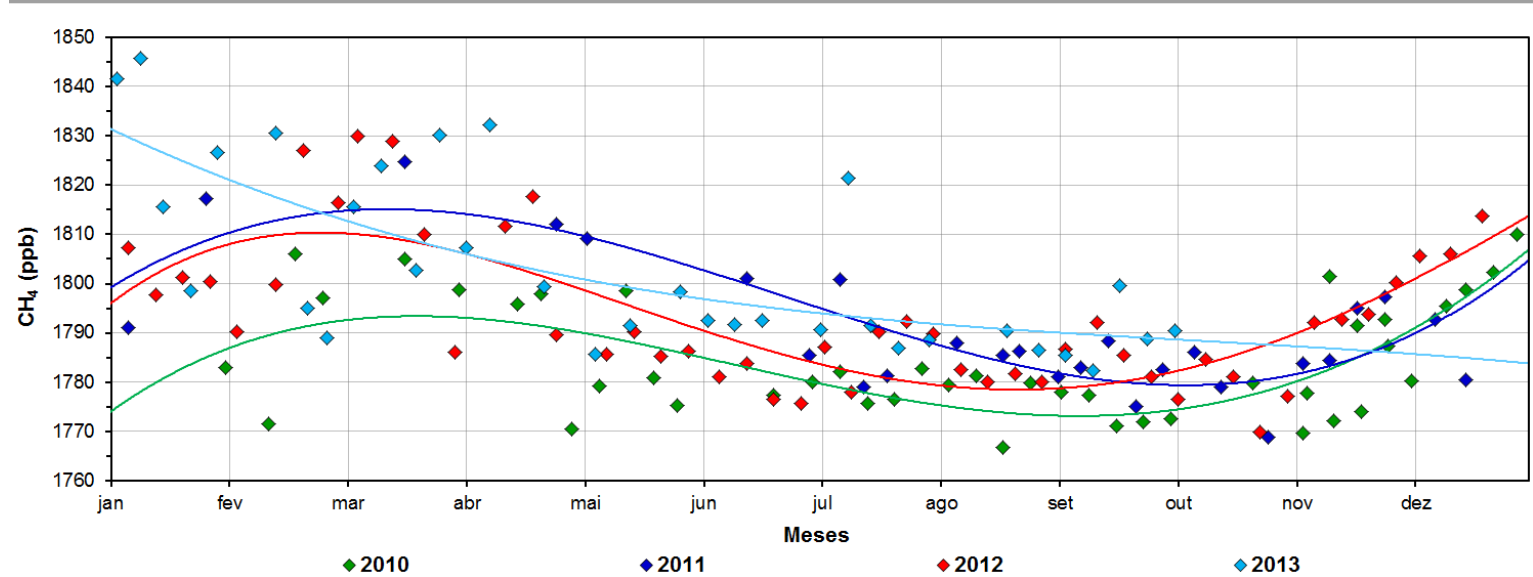

Figura 72: Concentrações de $\mathrm{CH}_{4}$ mensais e polinomiais para cada ano de estudo em SAL.

Tabela 12: Concentração média de $\mathrm{CH}_{4}$ por período em SAL

\begin{tabular}{lcccc}
\hline \multicolumn{5}{c}{ Concentração média de $\mathrm{CH}_{4}$ (ppb) por período de cada ano } \\
\hline Períodos & 2010 & 2011 & 2012 & 2013 \\
\hline Jan-Abr & $1791,73 \pm 13,46$ & $1811,27 \pm 14,49$ & $1807,62 \pm 14,32$ & $1816,91 \pm 17,66$ \\
Mai-Dez & $1782,44 \pm 10,62$ & $1786,69 \pm 9,15$ & $1786,84 \pm 9,48$ & $1791,94^{1} \pm 8,46$ \\
\hline Variação & 9,30 & 24,58 & 20,79 & - \\
\hline
\end{tabular}

${ }^{1}$ Média entre maio a setembro de 2013. - Sem dados.

O diagrama de dispersão entre as concentrações de SAL com ASC e RPB é apresentado na Figura 73, onde para todo o período foi encontrada uma correlação de -0,29 entre SAL e ASC, e 0,64 entre SAL e RPB. A correlação de janeiro a abril entre SAL com ASC e RPB foram de 0,27 e 0,47, respectivamente. $E$ entre maio a dezembro foram de 0,11 e 0,54 entre SAL com ASC e RPB respectivamente, mostrando que as concentrações em SAL apresentaram maior correlação com a estação global de RPB.

As diferenças entre as concentrações de $\mathrm{CH}_{4}$ em SAL com as estações globais, demostraram que elas foram menores entre o período de janeiro a abril para todos os anos de estudo quando comparado a RPB. Entre maio a dezembro foi observado menores diferenças entre SAL com ASC, coincidindo com o período onde as concentrações de SAL estão muito próximas desta estação, como pode ser visto na Figura 74. 

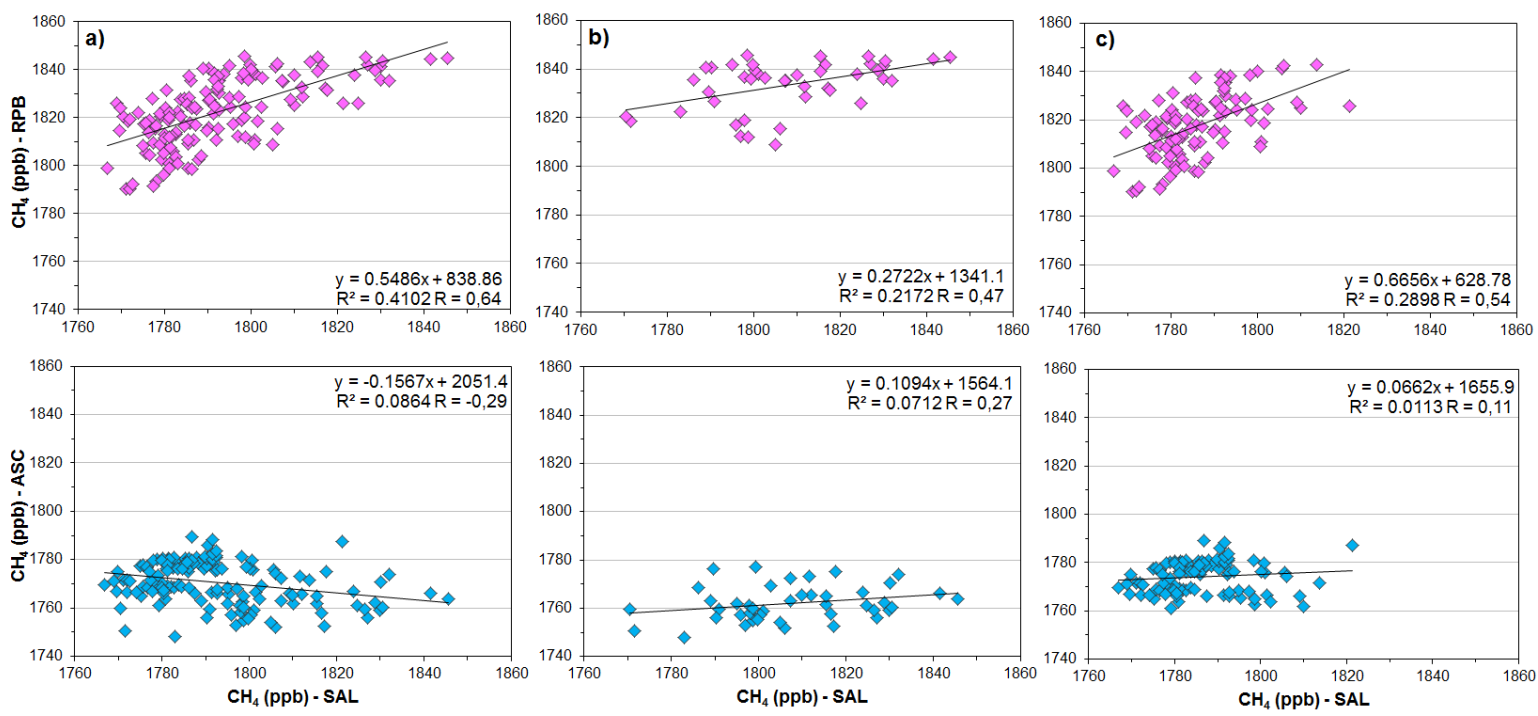

Figura 73: Diagrama de dispersão entre as concentrações de $\mathrm{CH}_{4} \mathrm{em} \mathrm{SAL} \mathrm{com}$ as estações de ASC e RPB, onde: (a) representa todo o período, (b) período de janeiro-abril e (c) período de maio-dezembro.

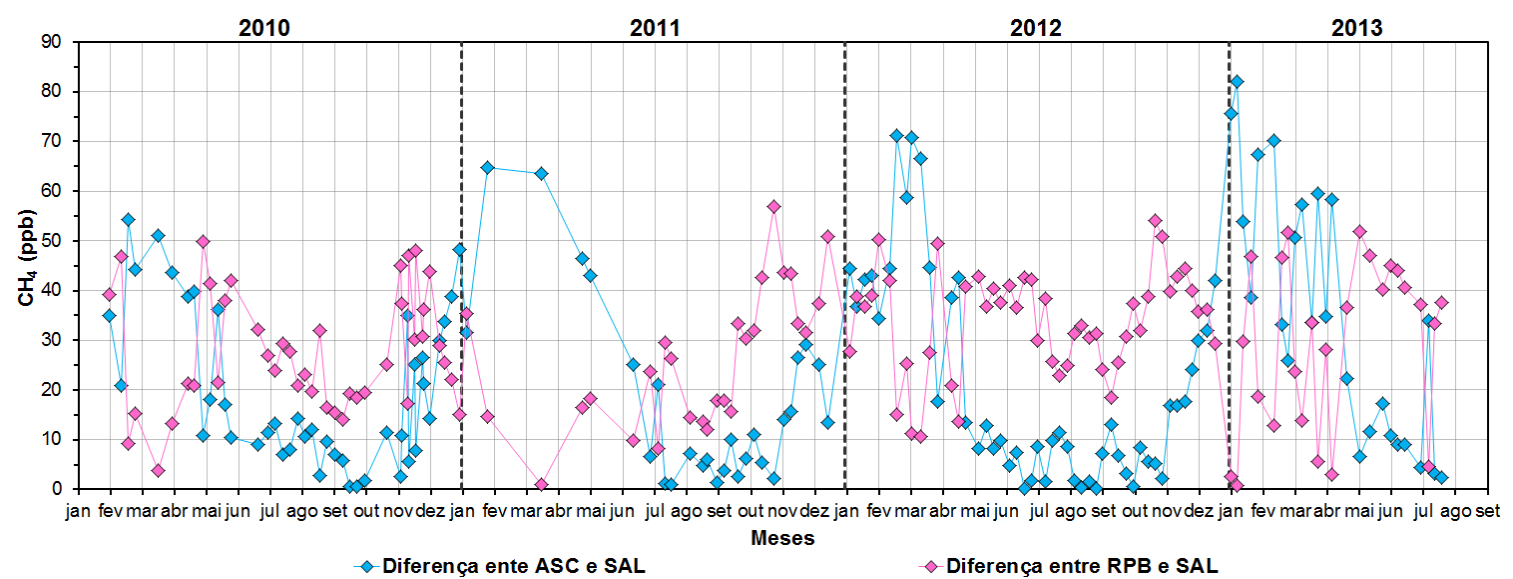

Figura 74: Diferença entre as concentrações de $\mathrm{CH}_{4}$ das estações globais com as concentrações obtidas em SAL para todos os anos de estudo.

\subsubsection{Avaliação das concentrações de $\mathrm{N}_{2} \mathrm{O}$}

As concentrações de $\mathrm{N}_{2} \mathrm{O}$ medidas em SAL mostraram dispersão em praticamente todo o período estudado com valores acima das estações globais como observado na Figura 75. Porém, mesmo apresentando esta dispersão é possível notar que as concentrações de $\mathrm{N}_{2} \mathrm{O}$ acompanham o aumento observado em ASC e RPB. Essa dispersão nas concentrações de $\mathrm{N}_{2} \mathrm{O}$ também foi observada nas concentrações medidas nas estações globais como apresentado anteriormente na Figura 47 do item 4.8 .

As concentrações médias obtidas em SAL para todo o período estudado são apresentadas na Tabela 13, onde podemos notar o aumento das concentrações de $\mathrm{N}_{2} \mathrm{O}$ com o passar dos anos. O aumento de 2010 para 2011 foi 
de $0,83 \mathrm{ppb}$, sendo este valor abaixo do apresentado pela média global que foi de 1,0 ppb, e de 2011 para 2012 o aumento foi de 1,18 ppb, sendo este valor maior que o aumento global que foi de 0,9 ppb. Pode ser observado também, que SAL apresenta uma diferença de $0,76 \mathrm{ppb}$, entre sua concentração média e a média global para o ano de 2010, 0,59 ppb em 2011 e de 0,87 ppb em 2012.

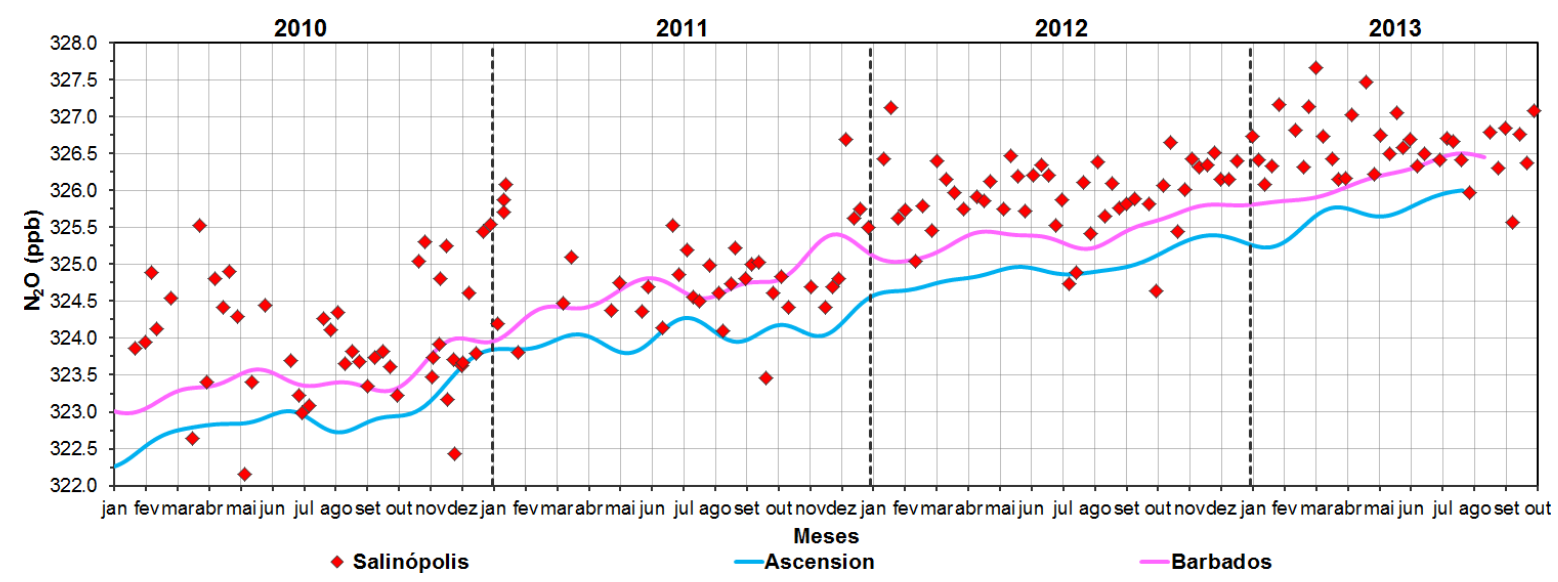

Figura 75: Comparação da série temporal de $\mathrm{N}_{2} \mathrm{O}$ em $\mathrm{SAL}$ (símbolos vermelhos) com os resultados medidos em ASC e RPB realizados pela NOAA.

Tabela 13: Concentração média anual de $\mathrm{N}_{2} \mathrm{O}$ em SAL

\begin{tabular}{ccccc}
\hline \multicolumn{5}{c}{ Concentração média de $\mathrm{N}_{\mathbf{2}} \mathrm{O}$ (ppb) } \\
\hline Local & $\mathbf{2 0 1 0}$ & $\mathbf{2 0 1 1}$ & $\mathbf{2 0 1 2}$ & $\mathbf{2 0 1 3}$ \\
\hline SAL & $323,96 \pm 0,42$ & $324,79 \pm 0,35$ & $325,97 \pm 0,31$ & $326,65^{1} \pm 0,20$ \\
\hline Média global & $323,2 \pm 0,37$ & $324,2 \pm 0,33$ & $325,1 \pm 0,27$ & - \\
\hline \multirow{2}{*}{ Variação entre os anos } & $\mathbf{2 0 1 0 - 2 0 1 1}$ & $\mathbf{2 0 1 1 - 2 0 1 2}$ & $\mathbf{2 0 1 2 - 2 0 1 3}$ \\
\cline { 3 - 5 } & & 0,83 & 1,18 & - \\
\hline
\end{tabular}

${ }^{1}$ Média entre os meses de janeiro a setembro. - Sem dados.

A comparação da concentração média anual em SAL, com a concentração média global por latitude foi realizada apenas para os anos de 2010 e 2011, pois o ano de 2012 ainda não foi disponibilizado pela NOAA. Esta comparação pode ser vista na Figura 76, onde podemos observar que a concentração média em SAL, esteve $0,4 \mathrm{ppb}$ acima da média global por latitude em 2010, e 0,2 ppb em 2011, para a latitude onde se localiza SAL. Estas concentrações mais elevadas podem estar relacionadas a emissão deste gás pelo Oceano Atlântico, porém, se considerarmos a menor variação da medida, as concentrações seriam praticamente as mesmas da média global nesta latitude. 


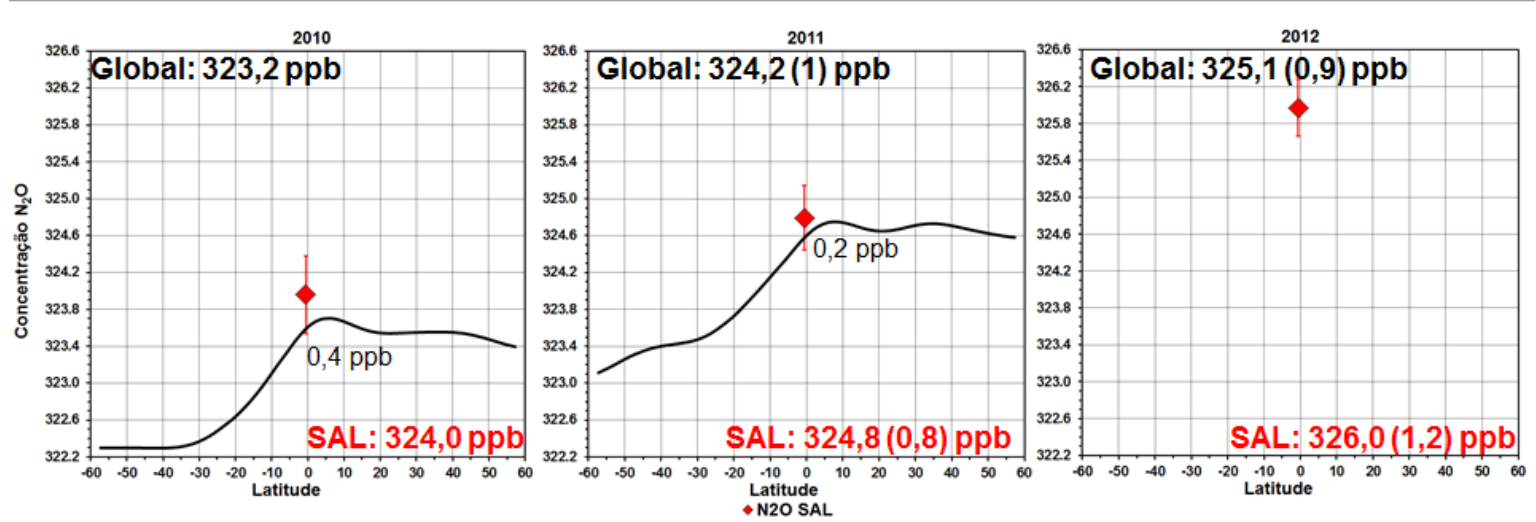

Figura 76: Comparação da concentração média anual do $\mathrm{N}_{2} \mathrm{O}$ em SAL (símbolo vermelho) com a concentração média anual global por latitude (linha preta).

$\mathrm{Na}$ região da costa, as condições são mais favoráveis devido à ressurgência das águas costeiras criarem ecossistemas produtivos, bem como aos estuários (mistura da água marinha com a água doce oriunda das áreas terrestres) pela abundância de nutrientes e ao fluxo da água ${ }^{[67]}$. Dessa forma esta parte do Oceano Atlântico, pode ser influenciada pela produtividade oceânica, devido à fertilização de rios, ressurgência das águas da costa e plataforma tropical que sustentam aproximadamente $30 \%$ da produção oceânica total, influenciados pelas correntes marítimas ${ }^{[68]}$.

Estudos revelam que as maiores emissões de $\mathrm{N}_{2} \mathrm{O}$, a partir de rios e estuários, estão no Oceano Atlântico, totalizando $70810^{-6} \mathrm{Pg} \mathrm{N}_{\text {ano }}{ }^{-1}$, e a América do Sul apresenta uma emissão de $39010^{-6} \mathrm{Pg} \mathrm{N}$ ano ${ }^{-1}$, este estudo ainda estima uma emissão de $\mathrm{N}_{2} \mathrm{O}$ referente aos rios e estuários de todos os oceanos de $150010^{-6} \mathrm{Pg} \mathrm{N}$ ano $^{-1}{ }^{[68]}$.

As concentrações de $\mathrm{N}_{2} \mathrm{O}$ medidas a partir de perfis de avião em SAH, apresentadas na Figura 77, mostram-se mais elevadas em janeiro e março, em relação às estações globais de ASC e RPB. Entre abril a julho foi observado concentrações de $\mathrm{N}_{2} \mathrm{O}$ entre as estações globais. Os perfis também nos mostram que conforme se aproximam da superfície as concentrações diminuem. Este comportamento observado nos perfis nos mostra que os resultados obtidos em superfície realmente sofrem alguma influência local, pois em SAL se observou concentrações mais elevadas que ASC e RPB, sendo este comportamento observado até o mês de março em SAH.

As concentrações de $\mathrm{N}_{2} \mathrm{O}$ não apresentaram sazonalidade definida como observado para o $\mathrm{CO}_{2}$ e $\mathrm{CH}_{4}$, como mostra a Figura 78 , porém é possível 
notar que as concentrações deste gás estão aumentando a cada ano, em média, 1,0 ppb, conforme relatado anteriormente na Tabela 13.
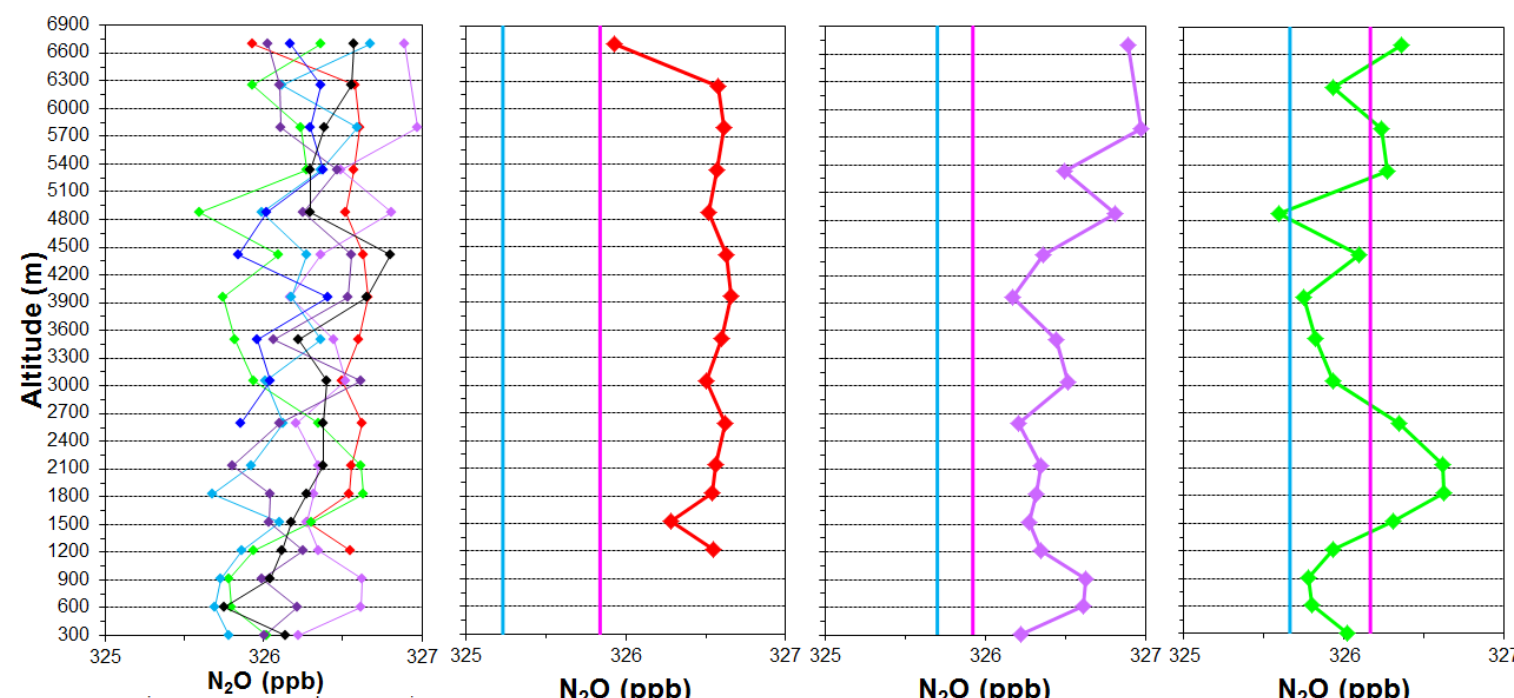

$\rightarrow$ jan $\rightarrow$ mar $\rightarrow$ abr

$\mathrm{N}_{2} \mathrm{O}(\mathrm{ppb})$

$\mathbf{N}_{\mathbf{2}} \mathbf{O}(\mathbf{p p b})$
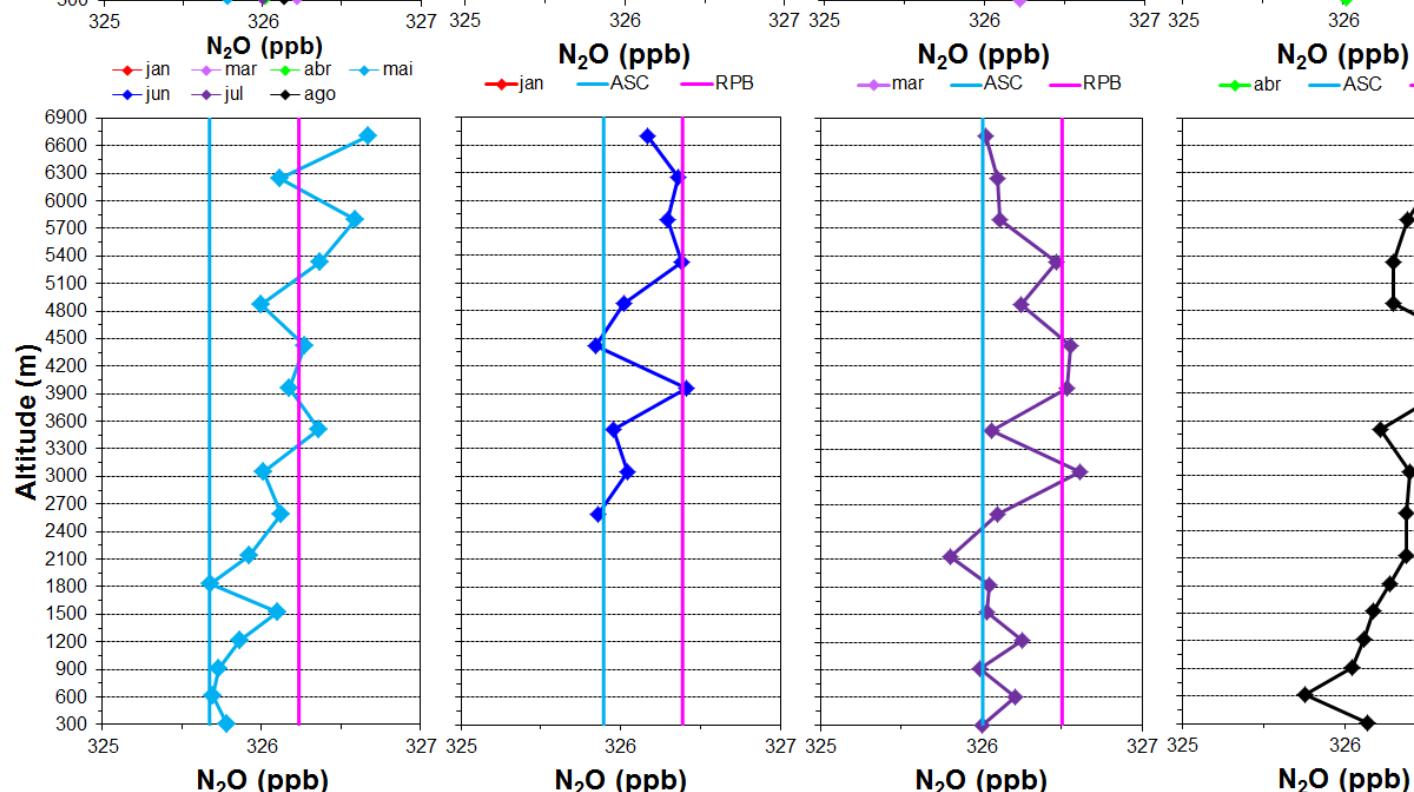

$\mathrm{N}_{2} \mathrm{O}(\mathrm{ppb})$

$\mathrm{N}_{2} \mathrm{O}(\mathrm{ppb})$

$\rightarrow \rightarrow$ mai - ASC $-\mathrm{RPB}$

$\rightarrow$ iun $-\mathrm{ASC}-\mathrm{RPB}$
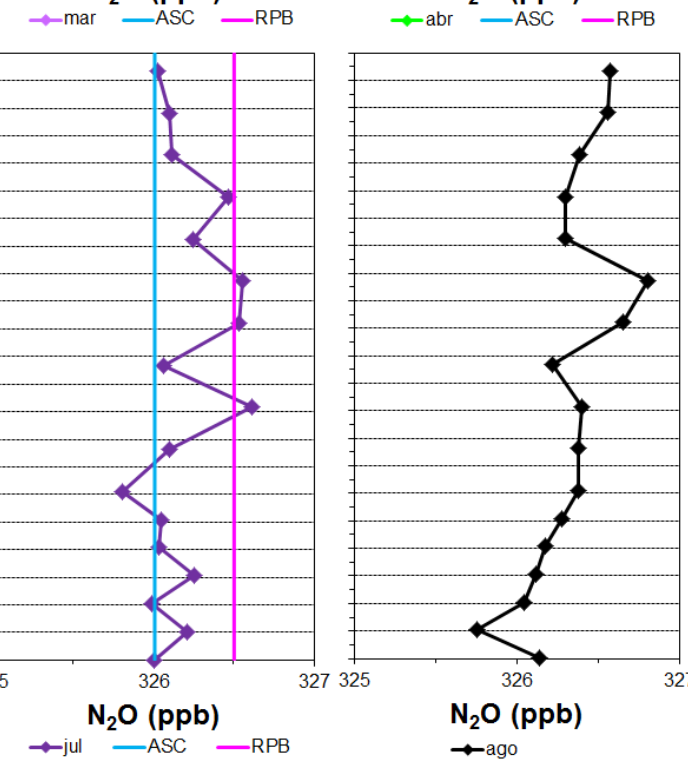

Figura 77: Concentrações de $\mathrm{N}_{2} \mathrm{O}$ medidas em perfis verticais de avião em $\mathrm{SAH}$.

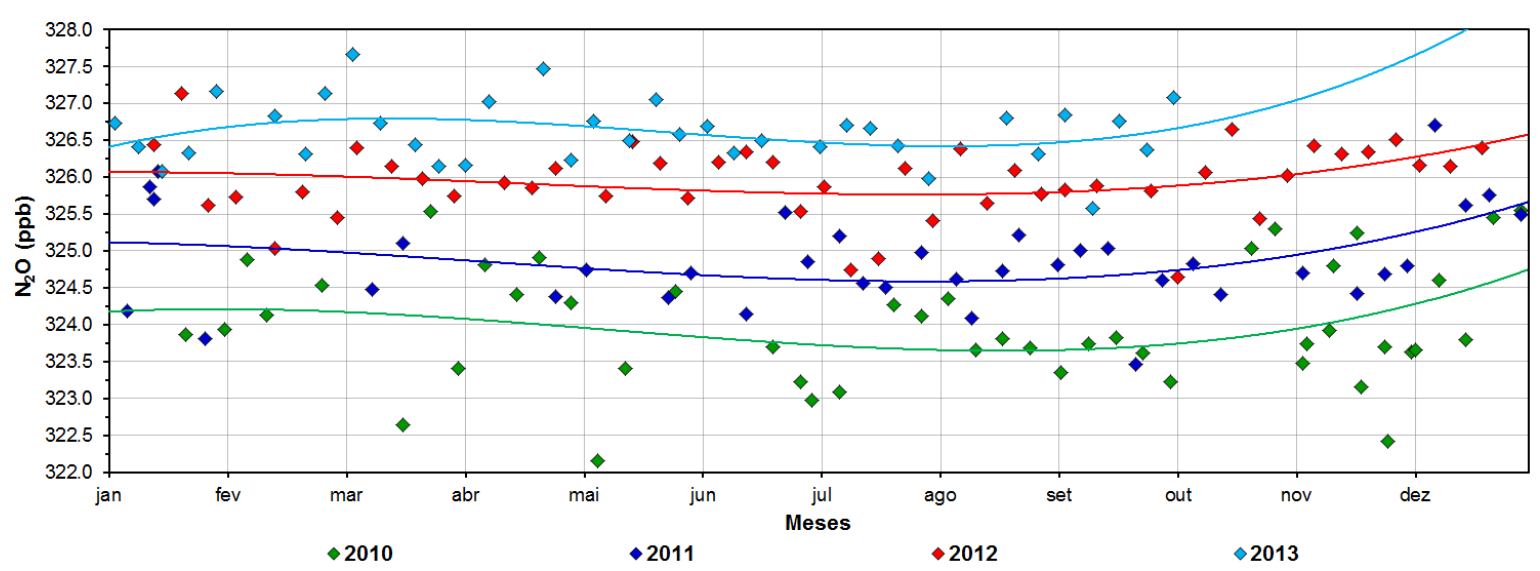

Figura 78: Concentrações de $\mathrm{N}_{2} \mathrm{O}$ mensais e polinomiais para cada ano de estudo em SAL. 
Como as concentrações de $\mathrm{N}_{2} \mathrm{O}$, não apresentaram uma sazonalidade definida, foi feito um estudo baseado nos períodos em que SAL recebe massas de ar do OAN, assim foi observada uma discreta diferença entre os períodos de janeiro a abril, quando comparado com os meses de maio a dezembro, como apresentado na Tabela 14. Podemos notar que as diferenças observadas são menores que o erro analítico da medida, que é de 0,2, exceto para o ano de 2010.

Tabela 14: Concentração média de $\mathrm{N}_{2} \mathrm{O}$ por período em SAL

\begin{tabular}{lcccc}
\hline \multicolumn{5}{c}{ Concentração média de $\mathrm{N}_{2} \mathrm{O}(\mathbf{p p b})$ por período de cada ano } \\
\hline Períodos & 2010 & 2011 & 2012 & 2013 \\
\hline Jan - Abr & $324,28 \pm 0,77$ & $324,95 \pm 0,86$ & $325,96 \pm 0,50$ & $326,68 \pm 0,50$ \\
Mai-Dez & $323,89 \pm 0,81$ & $324,85 \pm 0,60$ & $325,94 \pm 0,50$ & $326,54^{1} \pm 0,36$ \\
\hline Variação & 0,39 & 0,10 & 0,02 & - \\
\hline
\end{tabular}

${ }^{1}$ Média entre maio a setembro de 2013. - Sem dados.

O diagrama de dispersão entre as concentrações de SAL com as de ASC e RPB são apresentadas na Figura 79, onde para todo o período estudado foi encontrada uma correlação de 0,84 entre SAL e ASC, e 0,82 entre SAL e RPB. De janeiro a abril foram de 0,83 e 0,82, e de maio a dezembro foram de 0,86 e 0,85 entre SAL com ASC e RPB, respectivamente.
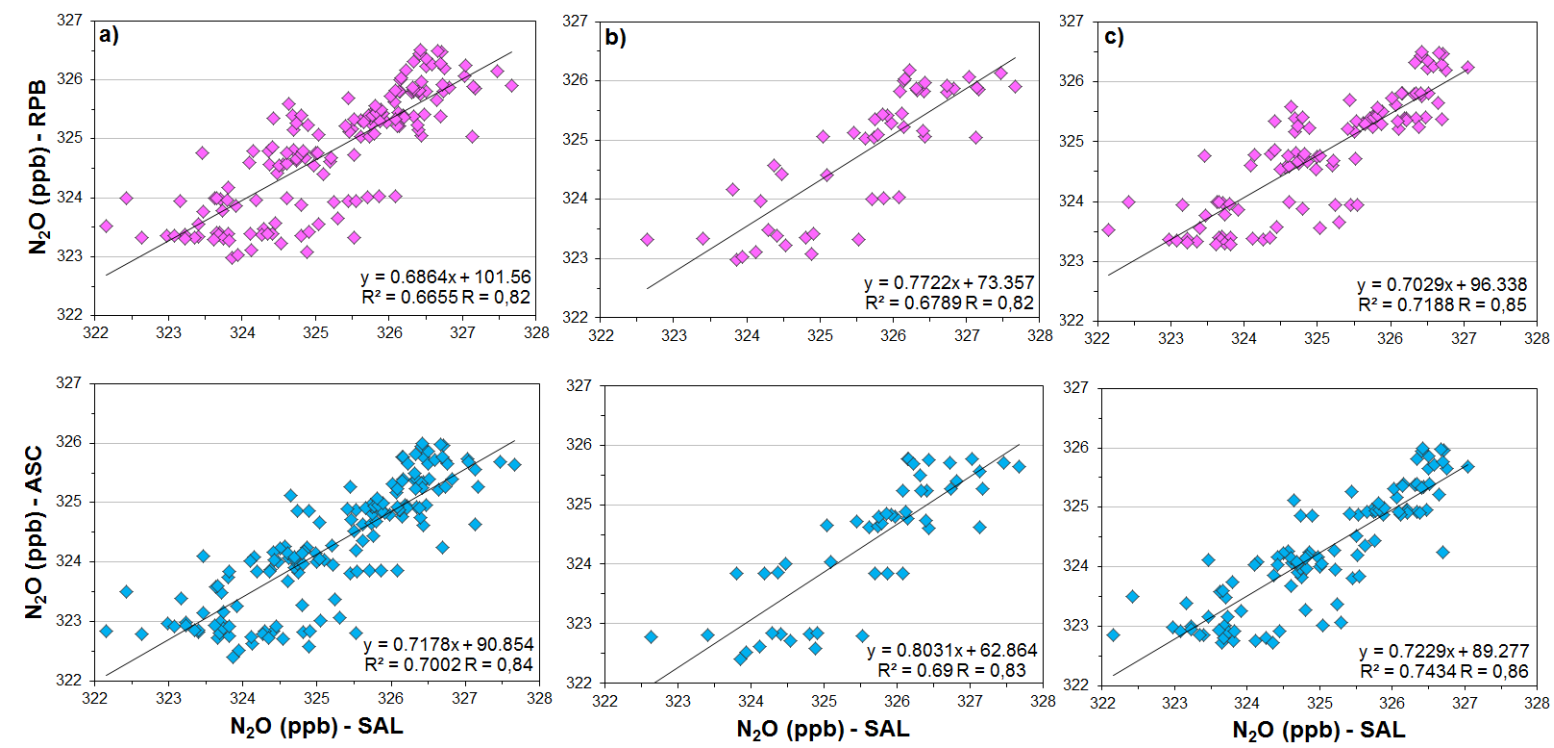

Figura 79: Diagrama de dispersão entre as concentrações de $\mathrm{N}_{2} \mathrm{O}$ em SAL com as estações de ASC e RPB, onde: (a) representa todo o período, (b) período de janeiro-abril e (c) período de maio-dezembro. 
Podemos notar que as concentrações de $\mathrm{N}_{2} \mathrm{O}$, tanto para todo $\mathrm{O}$ período de estudo, assim como entre janeiro a abril e de maio a dezembro, apresentou praticamente a mesma correlação com as estações de ASC e RPB, mostrando que este gás não apresenta uma clara sazonalidade para SAL e igualmente para as estações ASC e RPB.

As diferenças das concentrações de $\mathrm{N}_{2} \mathrm{O}$ de SAL com as de ASC e RPB nos mostram que SAL apresenta concentrações mais próximas de RPB, sendo a maior parte dessas diferenças abaixo de 1,0 ppb, o que não é observado entre SAL e ASC, onde as diferenças são mais elevadas, como pode ser observado na Figura 80. Observa-se ainda que no primeiro ano de medidas são observadas diferenças maiores. Este comportamento pode estar relacionado ao primeiro local de coleta, que era situado em uma reentrância do mar, onde a emissão de $\mathrm{N}_{2} \mathrm{O}$ poderia ser maior.

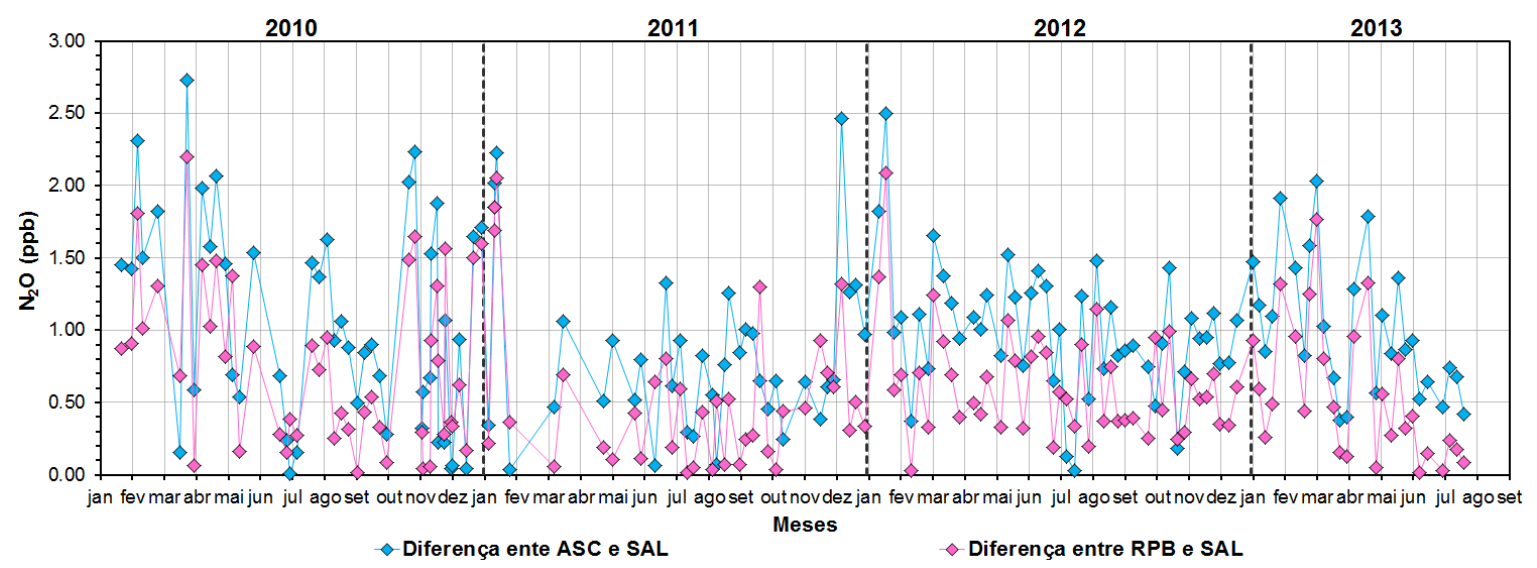

Figura 80: Diferença entre as concentrações de $\mathrm{N}_{2} \mathrm{O}$ das estações globais com as concentrações obtidas em SAL para todos os anos de estudo.

\subsubsection{Avaliação das concentrações de $\mathrm{SF}_{6}$}

Os resultados medidos para o $\mathrm{SF}_{6}$ em $\mathrm{SAL}$, na maior parte do período estudado, se mantiveram entre as concentrações das estações de ASC e RPB, como apresenta a Figura 81, apesar de eventualmente apresentaram períodos com concentrações maiores ou menores que as estações globais referidas.

As concentrações em SAL apresentam comportamento sazonal, onde no período de janeiro a abril estiveram mais elevadas e, entre maio a dezembro, as concentrações estiveram mais baixas. Este período, onde as concentrações foram mais elevadas, coincide com o período onde a ZCIT está abaixo da latitude de SAL, e isso mostra que este local de estudo recebe influências das massas de 
ar provenientes do OAN, pois sua emissão é maior no $\mathrm{HN}$ e, portanto sua concentração aumenta quando SAL recebe influência deste hemisfério.

As concentrações médias em SAL, apresentadas na Tabela 15, mostram um aumento de aproximadamente 0,27 ppt a cada ano, sendo este muito próximo do aumento global de 0,29 ppt. A concentração média de $\mathrm{SF}_{6}$ em SAL, também foi inferior a média global em torno de 0,05 ppt por ano.

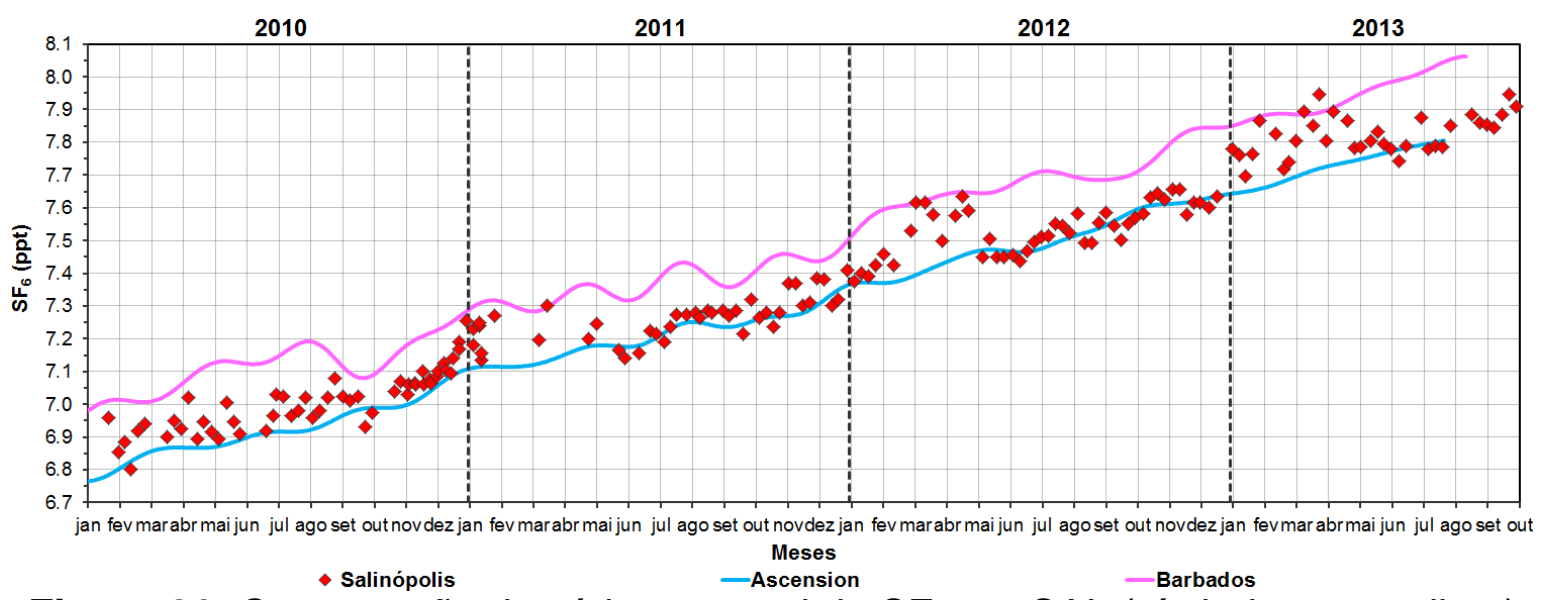

Figura 81: Comparação da série temporal de $\mathrm{SF}_{6}$ em SAL (símbolos vermelhos) com os resultados medidos em ASC e RPB realizados pela NOAA.

Tabela 15: Concentração média anual de $\mathrm{SF}_{6}$ em $S A L$

\begin{tabular}{ccccc}
\hline \multicolumn{5}{c}{ Concentração média de SF (ppt) } \\
\hline Local & $\mathbf{2 0 1 0}$ & $\mathbf{2 0 1 1}$ & $\mathbf{2 0 1 2}$ & $\mathbf{2 0 1 3}$ \\
\hline SAL & $6,98 \pm 0,07$ & $7,25 \pm 0,06$ & $7,54 \pm 0,07$ & $7,83^{1} \pm 0,05$ \\
Média global & $7,02 \pm 0,09$ & $7,31 \pm 0,09$ & $7,60 \pm 0,08$ & - \\
\hline \multirow{2}{*}{ Variação entre os anos } & $\mathbf{2 0 1 0 - 2 0 1 1}$ & $\mathbf{2 0 1 1 - 2 0 1 2}$ & $\mathbf{2 0 1 2 - 2 0 1 3}$ \\
\cline { 3 - 5 } & & 0,27 & 0,28 & - \\
\hline
\end{tabular}

${ }^{1}$ Média entre os meses de janeiro a setembro. - Sem dados.

A concentração média anual de $\mathrm{SF}_{6}$ em SAL, foi comparada com a concentração média global por latitude apenas para os anos de 2010 e 2011, pois os dados de 2012 ainda não foram disponibilizados. Esta comparação pode ser observada na Figura 82, onde a concentração média em SAL, esteve muito próxima da média global por latitude nos dois anos apresentados, sendo a diferença de apenas 0,01 ppt em 2010, e de 0,02 ppt em 2011, levando em consideração apenas a latitude onde se localiza SAL. Isso nos mostra que este local de estudo não apresenta emissões deste gás, já que os valores acompanham as concentrações globais assim como o seu crescimento. 

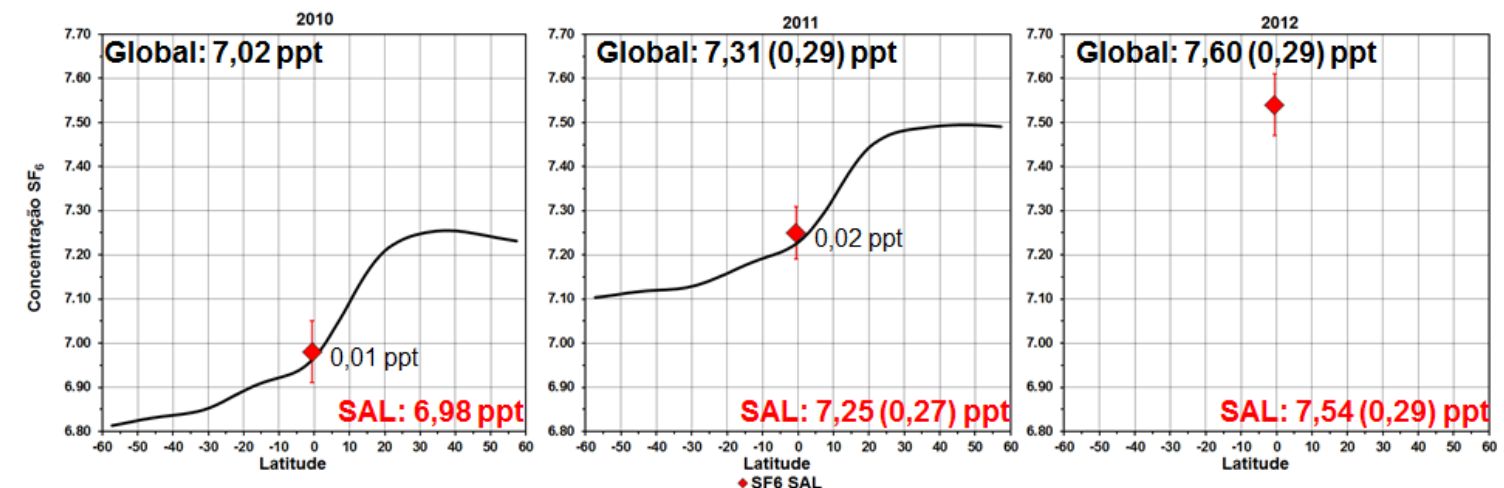

Figura 82: Comparação da concentração média anual do $\mathrm{SF}_{6}$ em SAL (símbolo vermelho) com a concentração média anual global por latitude (linha preta).

As concentrações de $\mathrm{SF}_{6}$ medidas nos perfis de avião em $\mathrm{SAH}$, na Figura 83, mostram que em 2013, essas concentrações apresentaram o mesmo comportamento das que foram medidas em superfície. O mês de março apresentou concentrações mais próximas de RPB em altas altitudes, e maio e julho estiveram mais próximas de ASC, assim como observado em SAL.
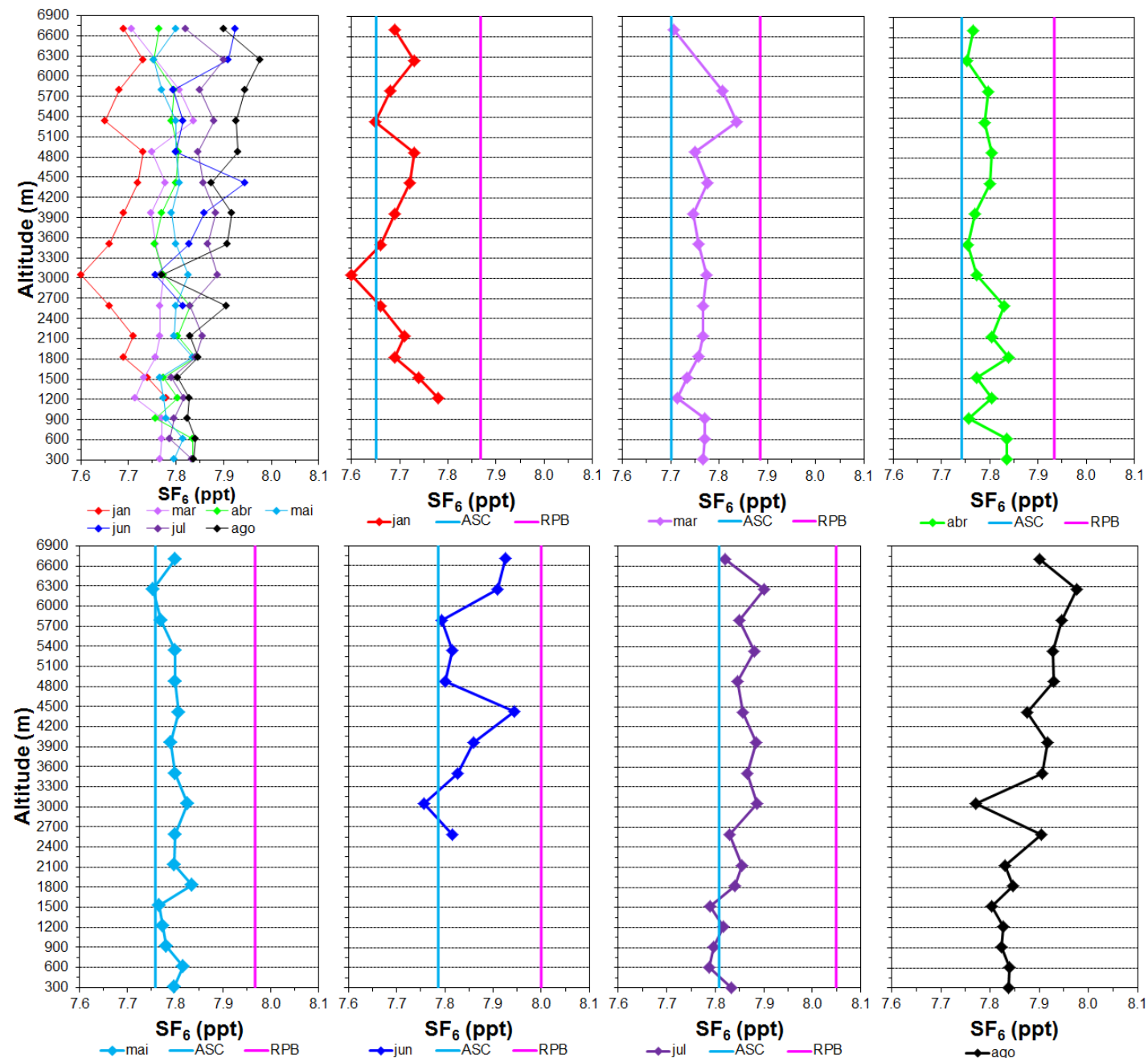

Figura 83: Concentrações de $\mathrm{SF}_{6}$ medidas em perfis verticais de avião em $\mathrm{SAH}$. 
Entre os meses de janeiro a abril podemos notar que as concentrações de $\mathrm{SF}_{6}$ apresentam valores maiores, como mostra a Figura 84, devido a influência do HN neste período. Também podemos observar que as concentrações aumentam ao longo do ano, e mostram uma tendência de crescimento, considerando também o ano de 2013, até o presente momento.

A média das concentrações observadas entre os períodos do ano em SAL é apresentada na Tabela 16, onde podemos notar que os resultados para o período de janeiro a abril foi menor que o período de maio a dezembro entre os anos de 2010 a 2013, porém esse valor menor é devido ao contínuo aumento da concentração deste gás, fazendo com que na média os resultados não sejam tão significativos quanto o observado na série temporal.

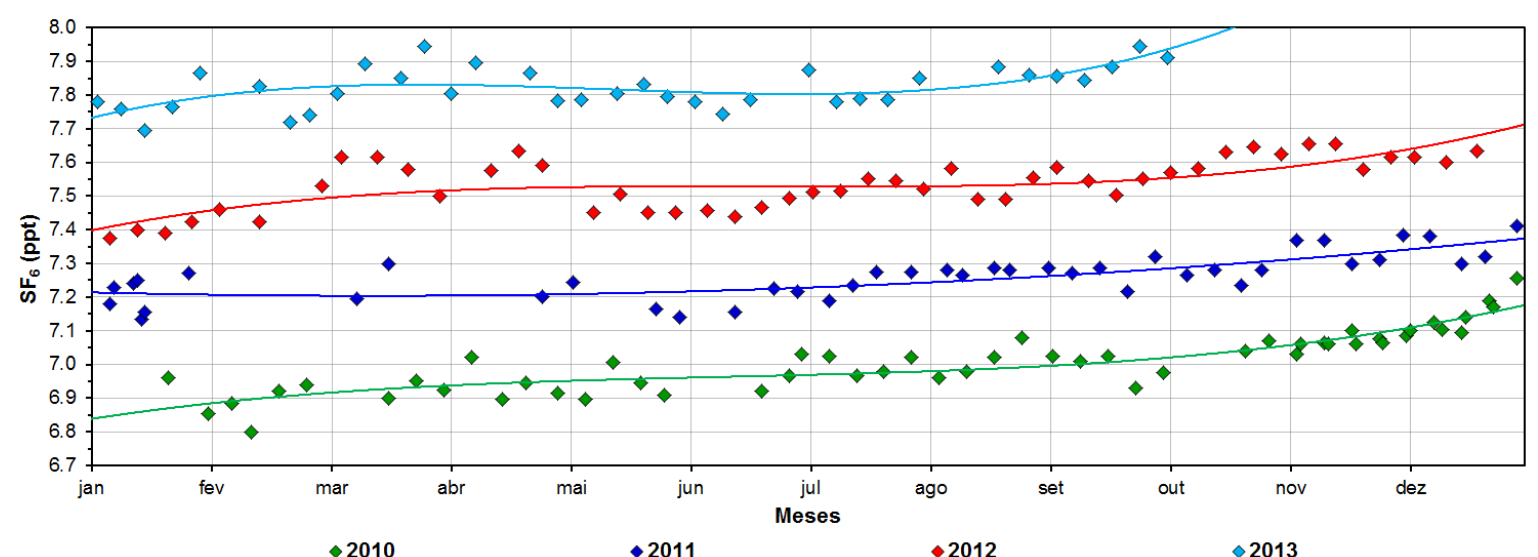

Figura 84: Concentrações de $\mathrm{SF}_{6}$ mensais para cada ano de estudo em SAL.

Tabela 16: Concentração média de $\mathrm{SF}_{6}$ por período em SAL

\begin{tabular}{ccccc}
\hline \multicolumn{5}{c}{ Concentração média de $S_{6}$ (ppt) por período de cada ano } \\
\hline Períodos & 2010 & 2011 & 2012 & 2013 \\
\hline Jan - Abr & $6,92 \pm 0,05$ & $7,22 \pm 0,05$ & $7,51 \pm 0,09$ & $7,81 \pm 0,07$ \\
Mai - Dez & $7,04 \pm 0,08$ & $7,28 \pm 0,07$ & $7,55 \pm 0,07$ & $7,83^{1} \pm 0,05$ \\
\hline Variação & 0,12 & 0,06 & 0,04 & - \\
\hline
\end{tabular}

${ }^{1}$ Média de maio a setembro de 2013. - Sem dados.

O diagrama de dispersão entre as concentrações de SAL com as estações globais de ASC e RPB são apresentadas na Figura 85, onde para todo o período estudado foi encontrada uma correlação de 0,98 , e entre janeiro a abril e de maio a dezembro foi de 0,99. Isso nos mostra que SAL apresenta o mesmo comportamento observado nas estações globais, onde temos um contínuo crescimento das concentrações ao longo de todos os anos de estudo. 

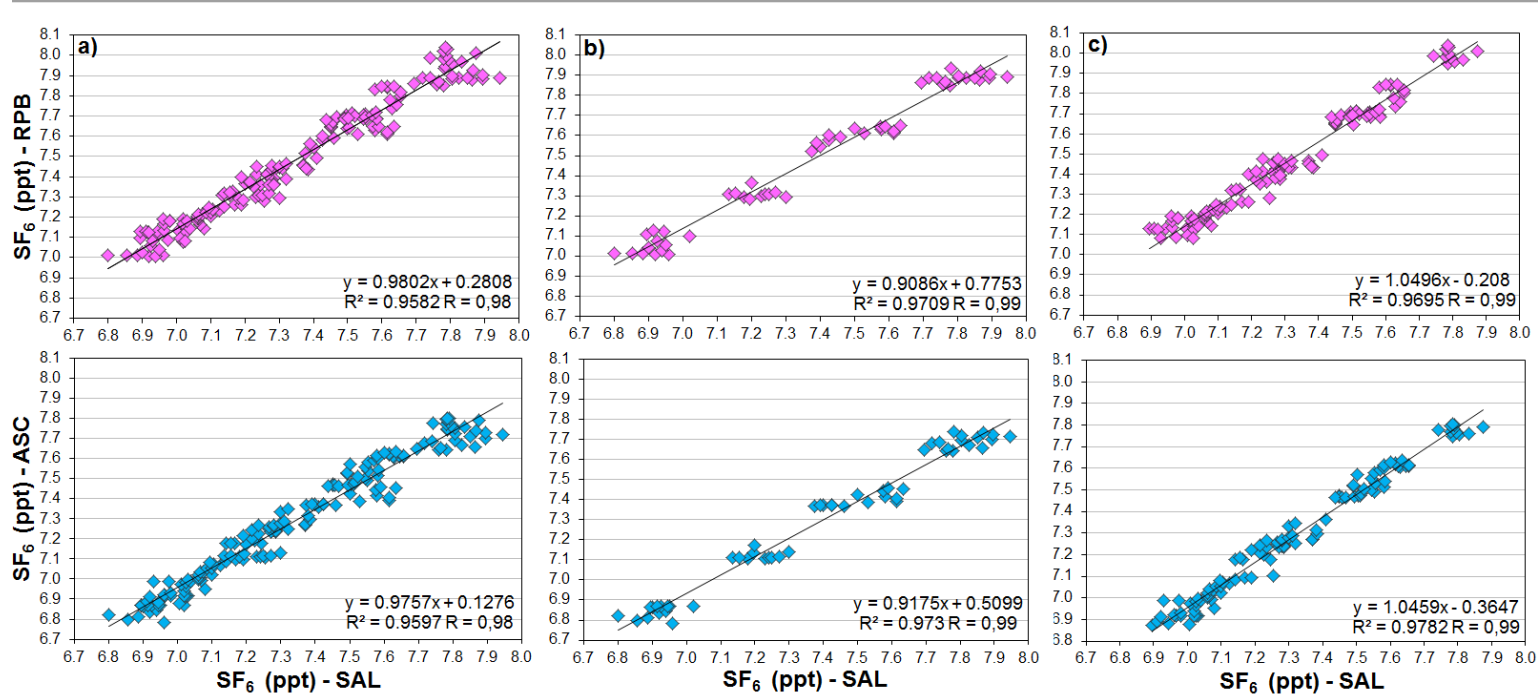

Figura 85: Diagrama de dispersão entre as concentrações de $\mathrm{SF}_{6}$ em SAL com as estações de ASC e RPB, onde: (a) representa todo o período, (b) período de janeiro-abril e (c) período de maio-dezembro.

A diferença entre as concentrações de SAL com ASC e RPB, apresentada na Figura 86, nos mostra que o mês de março para os anos de 2011 a 2013 apresentaram as menores diferenças, sendo este o mês onde a concentração de SAL é próxima de RPB. Entre maio a dezembro SAL passa a ter menor diferença em relação a ASC, onde as concentrações passam a ser próximas desta estação. Esta característica não é observada no ano de 2010, onde as concentrações de SAL apresentaram menor diferença em relação à ASC.

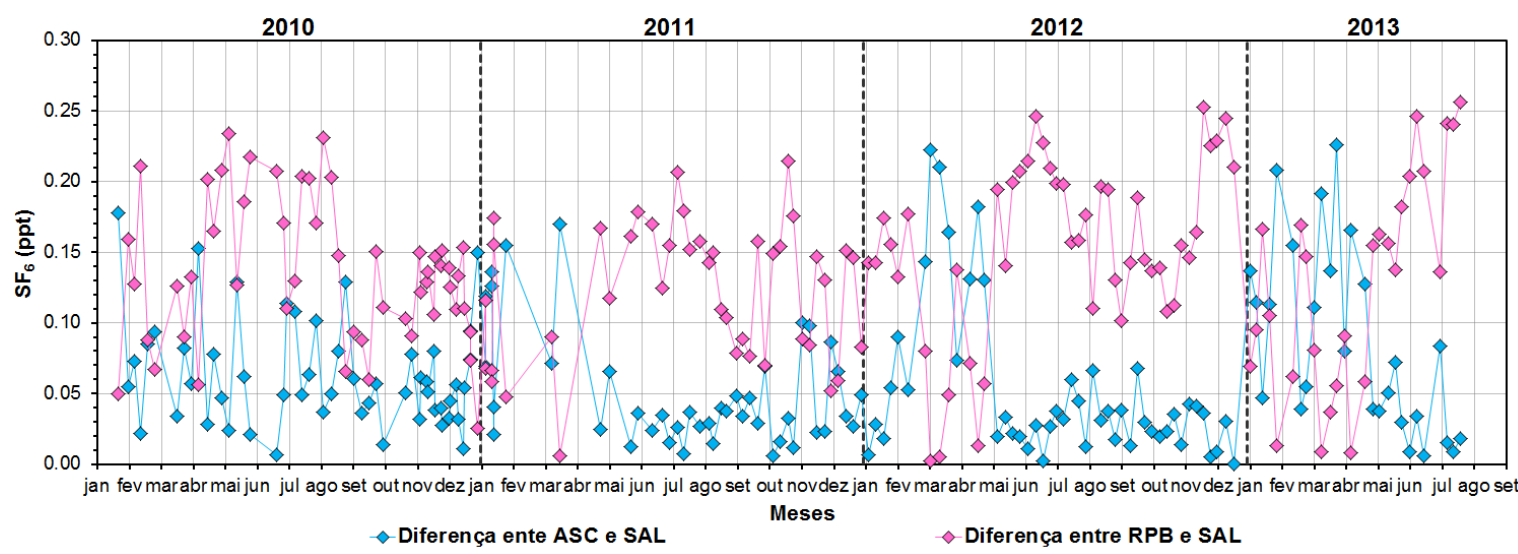

Figura 86: Diferença entre as concentrações de $\mathrm{SF}_{6}$ das estações globais com as concentrações obtidas em SAL para todos os anos de estudo.

\subsubsection{Avaliação das concentrações de CO}

As concentrações de CO, medidas em SAL apresentaram períodos de concentrações mais elevadas que as estações globais como pode ser observado na Figura 87, e em outros momentos apresentaram concentrações mais baixas. 
Podemos observar que as concentrações de CO de janeiro a maio e de outubro a novembro de 2010, apresentaram comportamento semelhante com a estação de RPB, e de junho a setembro as concentrações apresentam mais similaridade com ASC. Em 2011, foram obtidas concentrações mais elevadas que as estações globais entre janeiro a março, em junho e entre agosto a dezembro, porém entre abril a novembro também foram observadas concentrações entre ASC e RPB. Em 2012, na maior parte do ano as concentrações estiveram mais elevadas que as estações globais, e apenas entre junho a agosto foi observado concentrações abaixo de ASC e RPB. Em 2013, de janeiro a março foram observadas concentrações acima de RPB, e a partir de abril ocorre uma diminuição nas concentrações, onde estas ficam abaixo de ASC, porém em setembro estas voltam a aumentar.

Como podemos observar por esta série temporal, existem dois períodos onde observa-se aumento nas concentrações de SAL. O primeiro no início do ano, onde podemos supor que neste período o aumento seja devido as emissões antrópicas oriundas da Praia do Atalaia, situada a leste do local de coleta, e no mesmo sentido das massas de ar que chegam ao ponto de coleta. $\mathrm{E}$ o segundo, no período de seca, com emissões de queima de biomassa, inclusive na África, como pode ser observado na Figura 88, onde mostra um exemplo de trajetória retrocedente com origem no continente africano em um período de grande incidência de queimada, podendo dessa forma ocorrer o transporte de $\mathrm{CO}$, através das massas de ar, influenciando as concentrações em SAL ${ }^{[55,69]}$.

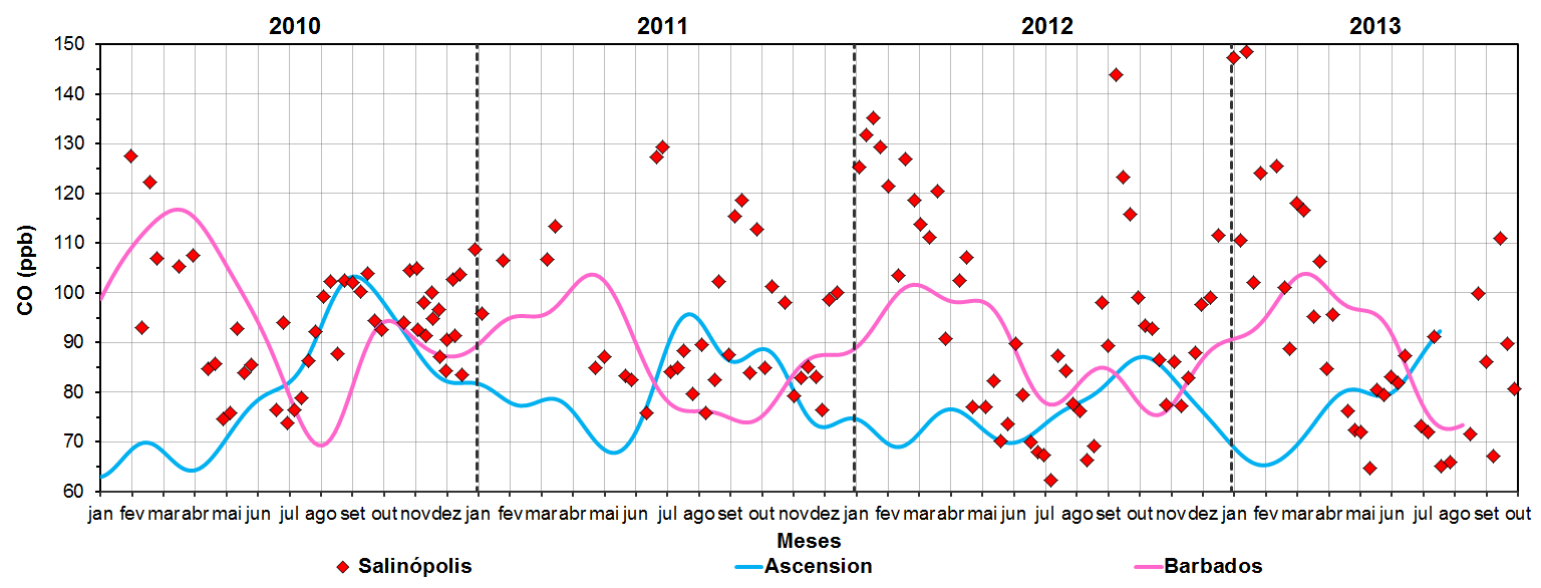

Figura 87: Comparação da série temporal de CO em SAL (símbolos vermelhos) com os resultados medidos em ASC e RPB realizados pela NOAA. 

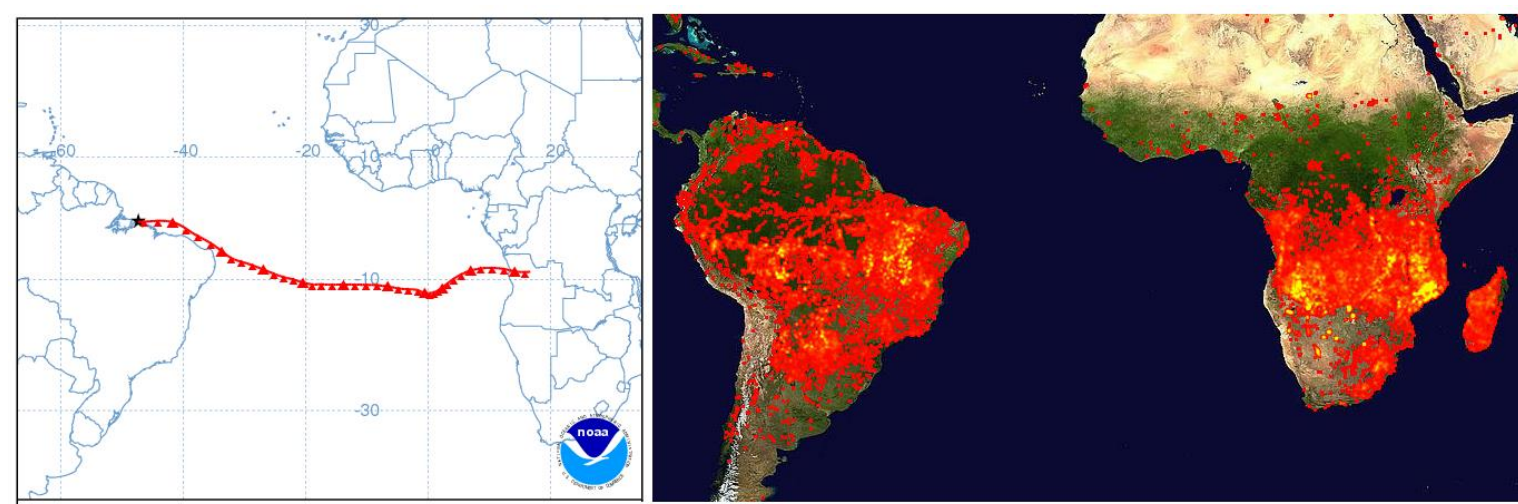

Figura 88: Trajetória retrocedente de 240 horas para o dia 18/09/12 e focos de queimadas entre o período de $17 / 09$ a 26/09/12 ${ }^{[55,69]}$.

As concentrações médias em SAL são apresentadas na Tabela 17, onde podemos observar que entre o ano de 2010 para 2011, a concentração de CO sofreu um decréscimo em torno de 3 ppb, porém de 2011 para 2012, houve um aumento de $1,90 \mathrm{ppb}$. O decréscimo de 2010 para 2011, pode ter sido influenciado pela mudança de local de amostragem, pois o primeiro recebia maior influência da praia turística situada a leste do local. Podemos notar concentrações de CO, mais elevadas que a média global tanto em 2010 como em 2011, sendo a diferença de 4,00 ppb e 5,00 ppb, respectivamente.

Tabela 17: Concentração média anual de CO em SAL

\begin{tabular}{ccccc}
\hline \multicolumn{5}{c}{ Concentração média de CO $(\mathbf{p p b})$} \\
\hline Local & $\mathbf{2 0 1 0}$ & $\mathbf{2 0 1 1}$ & $\mathbf{2 0 1 2}$ & $\mathbf{2 0 1 3}$ \\
\hline SAL & $97,10 \pm 12,56$ & $94,15 \pm 10,66$ & $96,05 \pm 19,29$ & $90,95^{1} \pm 17,14$ \\
Média global & 93 & 89 & - & - \\
\hline \multirow{2}{*}{ Variação entre os anos } & $\mathbf{2 0 1 0 - 2 0 1 1}$ & $\mathbf{2 0 1 1 - 2 0 1 2}$ & $\mathbf{2 0 1 2 - 2 0 1 3}$ \\
\cline { 3 - 5 } & & 2,96 & 1,90 & - \\
\hline
\end{tabular}

'Média entre os meses de janeiro a setembro. - Sem dados.

A concentração média de CO para cada ano de estudo em SAL, apresentou valores acima da concentração média global por latitude, como observado na Figura 89. Mesmo considerando a menor variação nas medidas, a concentração em SAL, ainda assim foi mais elevada que a média global nesta latitude. Em 2010, a diferença entre a média global e a de SAL, para a latitude onde se localiza SAL, foi de 21,9 ppb, em 2011, foi de 24,5 ppb e, em 2012 essa diferença foi de $18,9 \mathrm{ppb}$, mostrando que neste local de coleta existem contribuições antrópicas deste gás. 

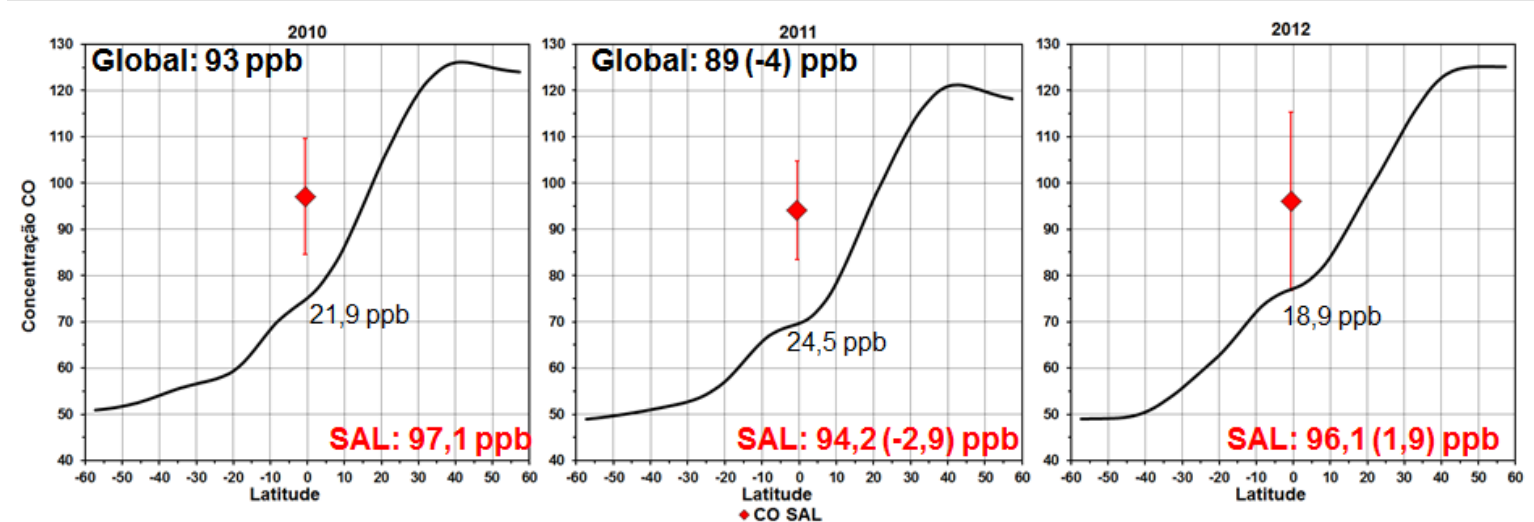

Figura 89: Comparação da concentração média anual do CO em SAL (símbolo vermelho) com a concentração média anual global por latitude (linha preta).

A partir dos resultados obtidos em SAH, Figura 90, podemos notar que as concentrações de $\mathrm{CO}$ em janeiro estavam acima de RPB, e conforme se aproximava da superfície esta foi aumentando, onde foi registrado $170 \mathrm{ppb}$ de $\mathrm{CO}$, sendo que nas medidas de superfície em SAL foi registrado $150 \mathrm{ppb}$ de CO.
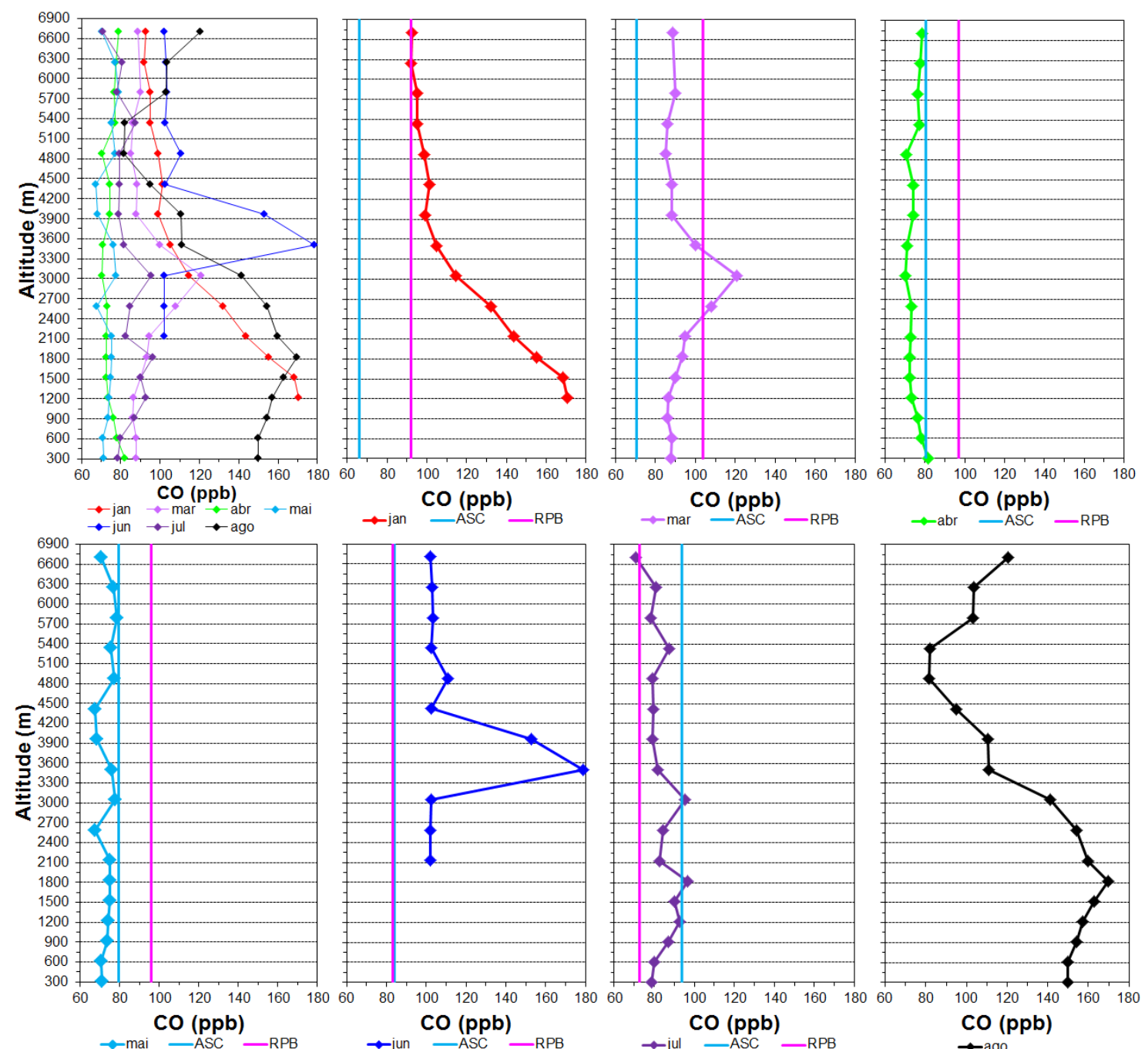

Figura 90: Concentrações de CO medidas em perfis verticais de avião em SAH. 
Ainda analisando os perfis de avião, podemos notar que em março e julho as concentrações ficaram entre ASC e RPB. E em abril e maio foram os meses de menores concentrações de $\mathrm{CO}$, sendo os valores registrados menores que ASC. Em junho as concentrações voltaram a aumentar ficando acima de ASC e RPB, e em agosto novamente ocorre emissão próximo à superfície.

As concentrações de $\mathrm{CO}$ apresentam sazonalidade, como pode ser visto na Figura 91. Entre janeiro a abril as concentrações foram mais elevadas em relação ao período de maio a agosto para todos os anos de estudo. A partir de julho, com o máximo em setembro, as concentrações apresentaram elevação, coincidindo com período de queima de biomassa no continente africano.

A diferença das concentrações de SAL com ASC e RPB, Figura 92, foram pequenas entre janeiro a março entre SAL e RPB, e maiores entre SAL e ASC. Entre julho a setembro de 2010 e 2011 observa-se uma maior diferença entre SAL e RPB, já em 2012 as diferenças ocorrem para as duas estações. E, em 2013 uma diferença maior ocorreu de janeiro a maio entre SAL e ASC.

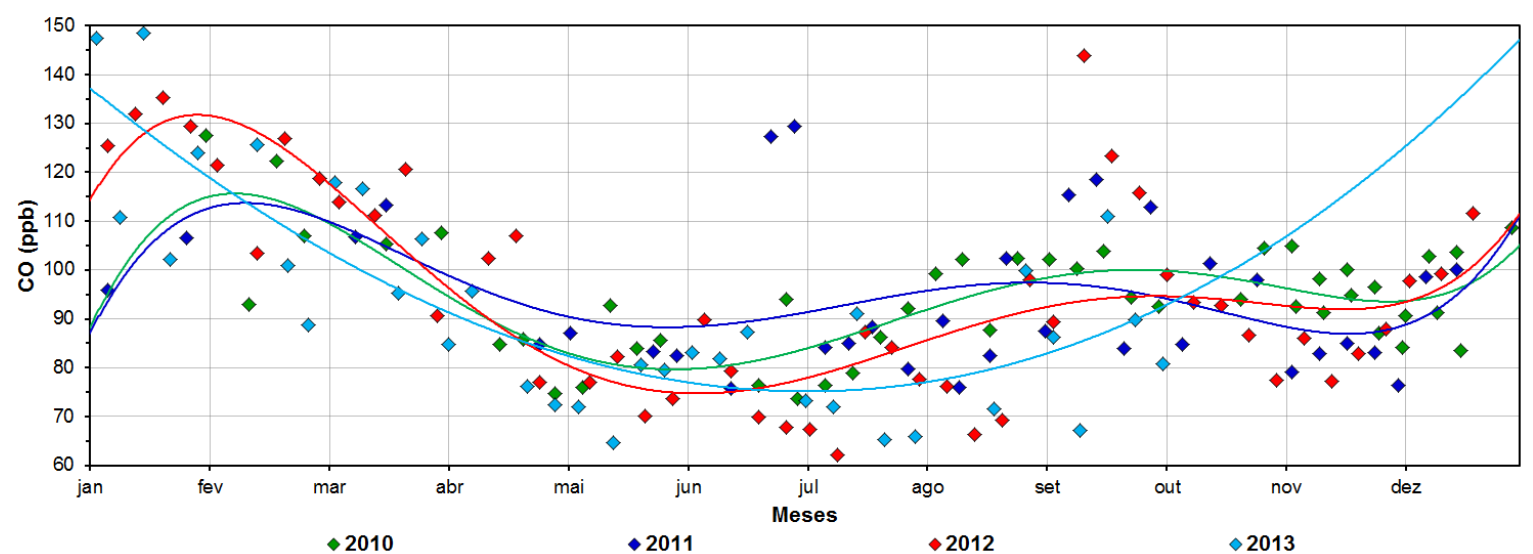

Figura 91: Concentrações de CO mensais e polinomiais para cada ano de estudo

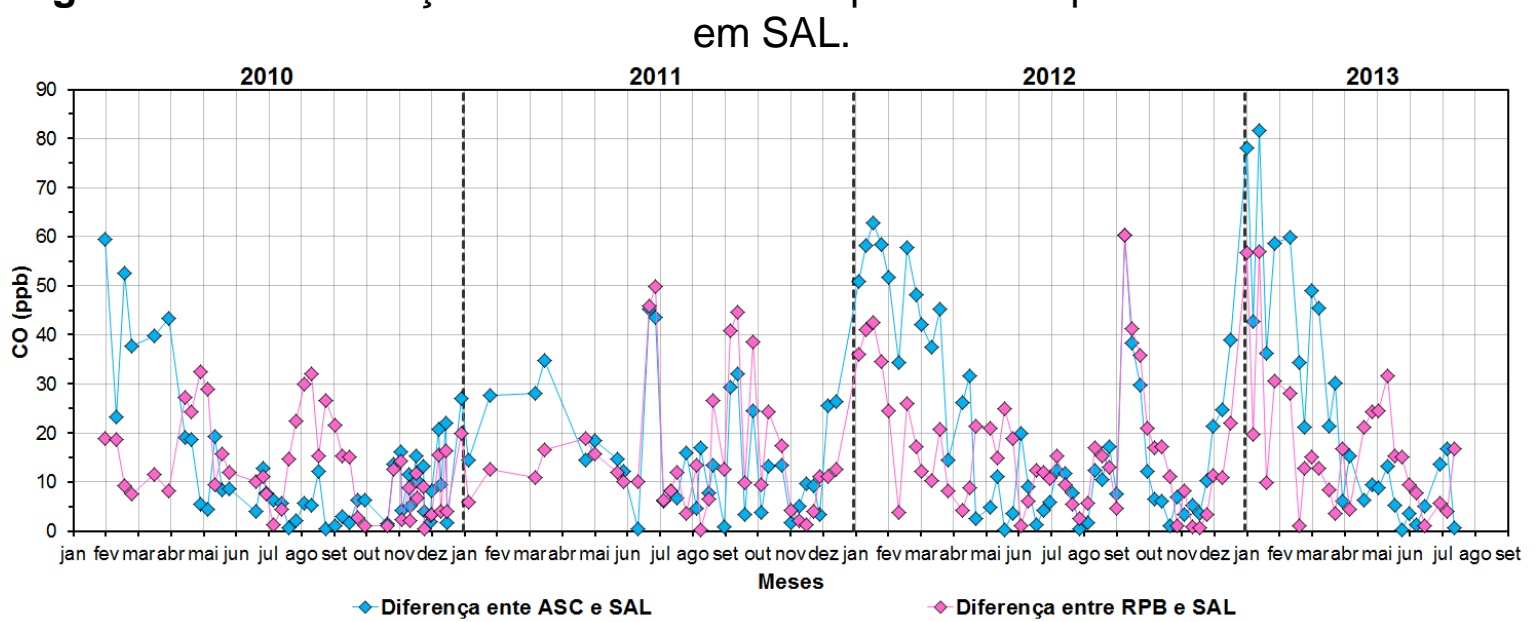

Figura 92: Diferença entre as concentrações de CO das estações globais com as concentrações obtidas em SAL para todos os anos de estudo. 


\subsection{Avaliação dos resultados dos GEE medidos em NAT}

Em NAT foi realizado um estudo de intercomparação entre os laboratórios do IPEN e da NOAA para todos os GEE.

\subsubsection{Análise das trajetórias das massas de ar que chegaram a NAT}

Em NAT foram simuladas trajetórias das massas de ar com 120 horas retrocedentes para cada coleta realizada em todo o período estudado. Foi observado a partir dessas trajetórias que as massas de ar que chegaram a NAT apresentam origem apenas no OAS, como pode ser visto na Figura 93.

Pode ser observado que durante todo o período estudado as massas apresentaram origem em diversas latitudes no OAS, no entanto sempre abaixo da latitude da estação global de ASC.

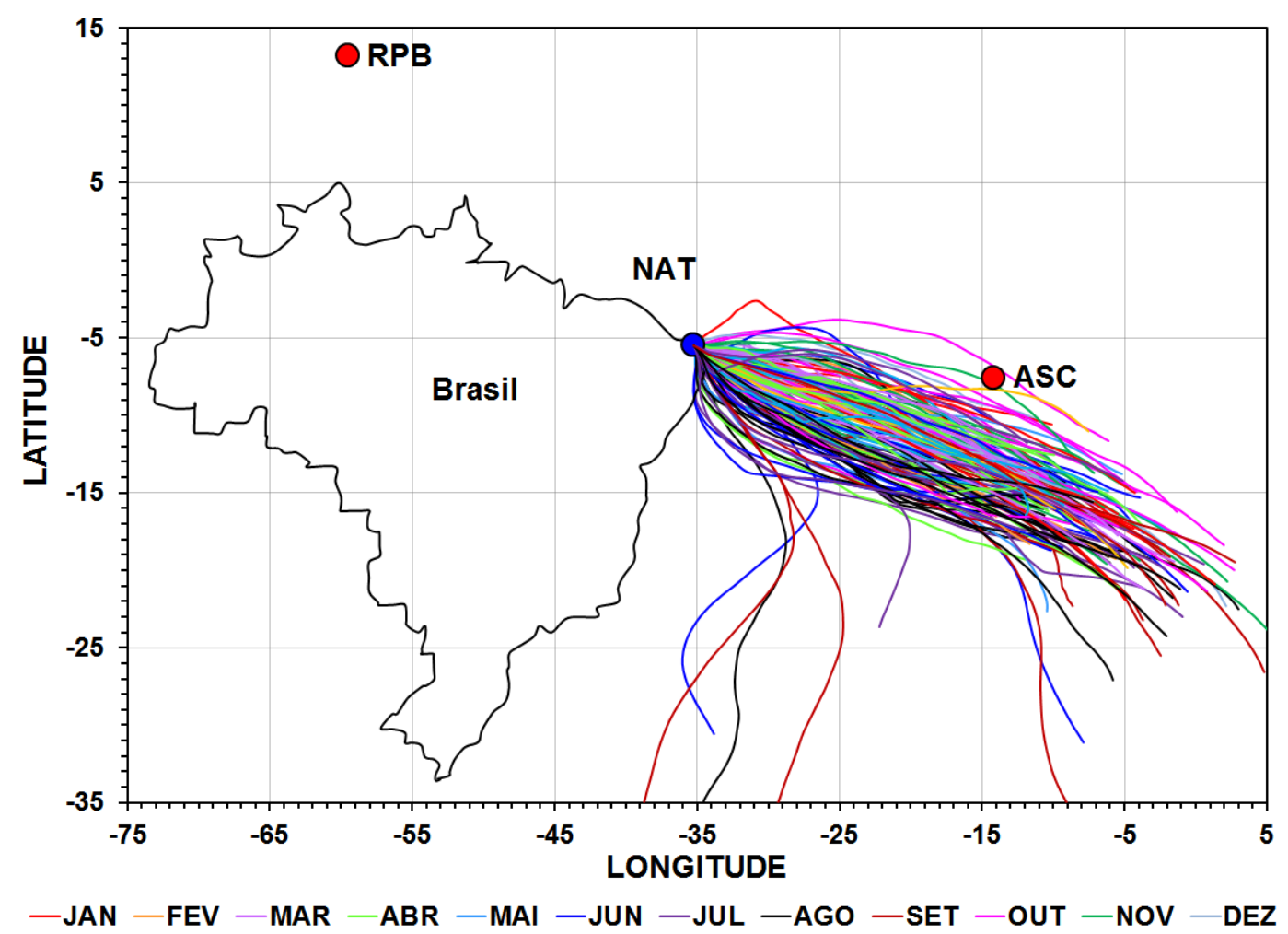

Figura 93: Trajetórias retrocedentes das massas de ar que chegaram a NAT, simuladas pelo modelo HYSPLIT ${ }^{[55]}$ para cada coleta realizada em todos os anos de estudo (2010, 2011, 2012 e 2013).

As trajetórias das massas de ar em NAT também foram separadas por mês para poder se observar a sazonalidade ao longo dos anos, como apresenta a Figura 94. Podemos observar que essas massas de ar apresentam o mesmo comportamento ao longo do ano com origem geralmente em $-25^{\circ}$ de latitude e $-^{\circ}$ de longitude. Também podemos notar que entre os meses de novembro a março 
as massas de ar apresentam trajetórias praticamente com o mesmo aspecto, entretanto, entre os meses de abril a outubro, as trajetórias se mostram com uma leve dispersão, o que não foi observado nos outros meses.

Como visto anteriormente no estudo da ZCIT, observa-se que esta região onde se encontra NAT recebe influência de ventos apenas do OAS, e a simulação das trajetórias em NAT estão em concordância com estes estudos.

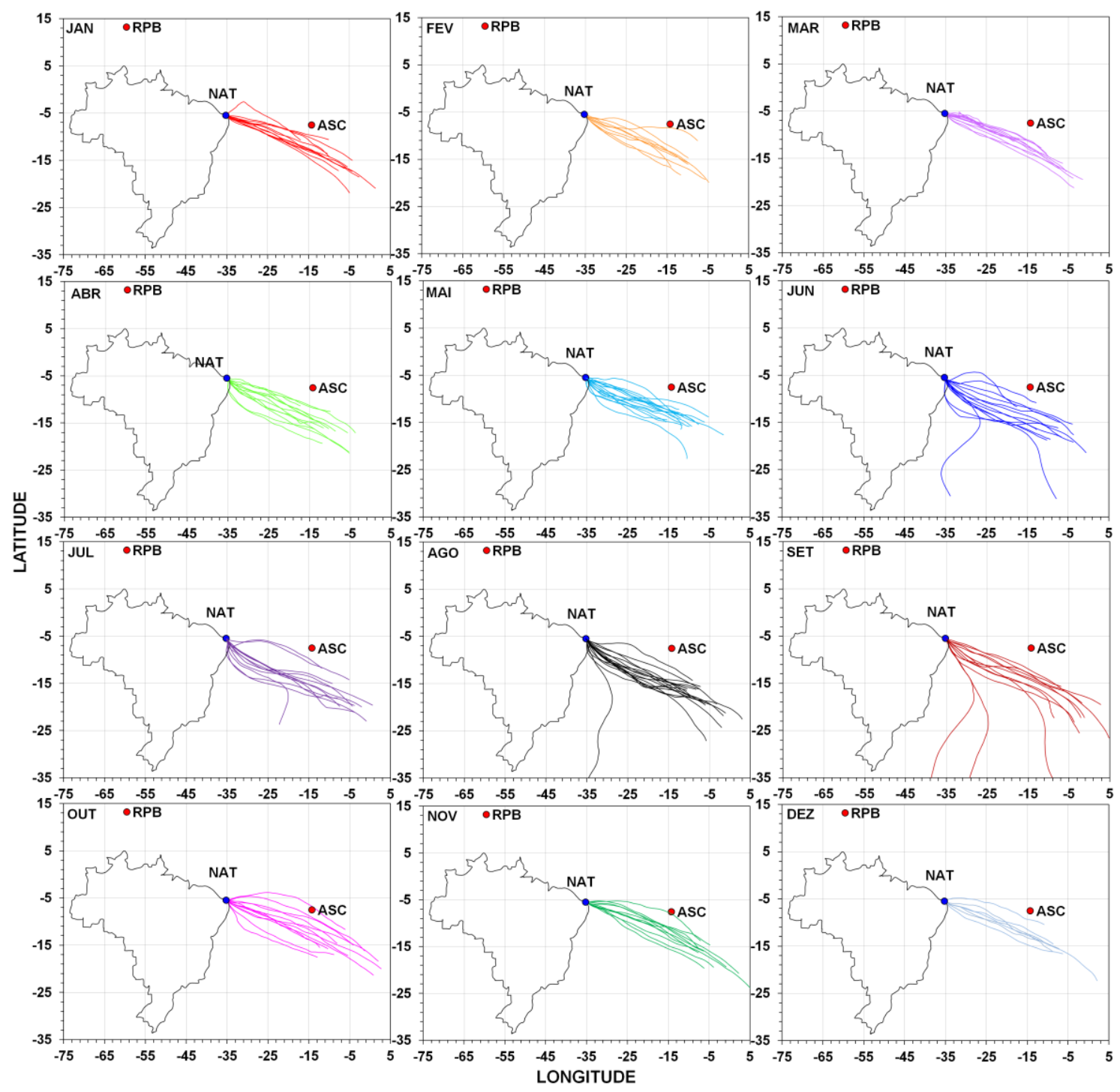

Figura 94: Trajetórias retrocedentes das massas de ar que chegaram a NAT, separadas para cada mês referentes a todos os anos de estudos.

Foi realizado em NAT um estudo da direção e velocidade do vento para se avaliar a sazonalidade do local de coleta. Os dados utilizados neste estudo foram os registrados no momento da coleta na estação meteorológica de Maxaranguape. 
Podemos observar que a direção do vento em NAT apresenta-se entre $90^{\circ}$ a $180^{\circ}$, como mostra a Figura 95, indicando ventos vindos do sudeste e sul deste ponto de coleta. E a velocidade do vento em NAT mostra uma variabilidade entre 2 a $15 \mathrm{~m} \mathrm{~s}^{-1}$, sendo que entre os meses de maio a setembro foram observadas velocidades de vento superior à $12 \mathrm{~m} \mathrm{~s}^{-1}$.

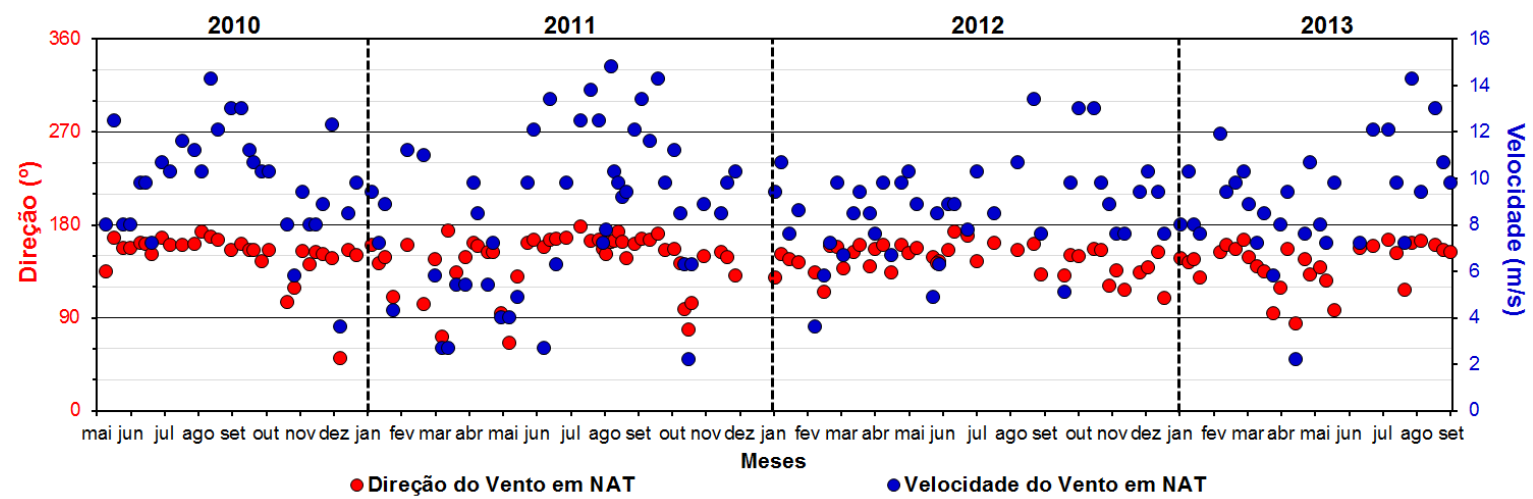

Figura 95: Direção e velocidade do vento em NAT, com base nas observações do dia da coleta na estação de Maxaranguape - RN.

Utilizando os dados de direção e velocidade do vento obtido no portal do INMET ${ }^{[56]}$ para a estação de Natal, foi observado que as trajetórias das massas de ar apresentam similaridades com esses dados. Podemos observar na Figura 96, entre abril a outubro direções do vento acima de 150ㅜ, entretanto de novembro a março a direção esteve entre 90 a 150․ Assim, a dispersão apresentada nas trajetórias das massas de ar que chegaram a NAT, podem ser relacionadas com a direção do vento.

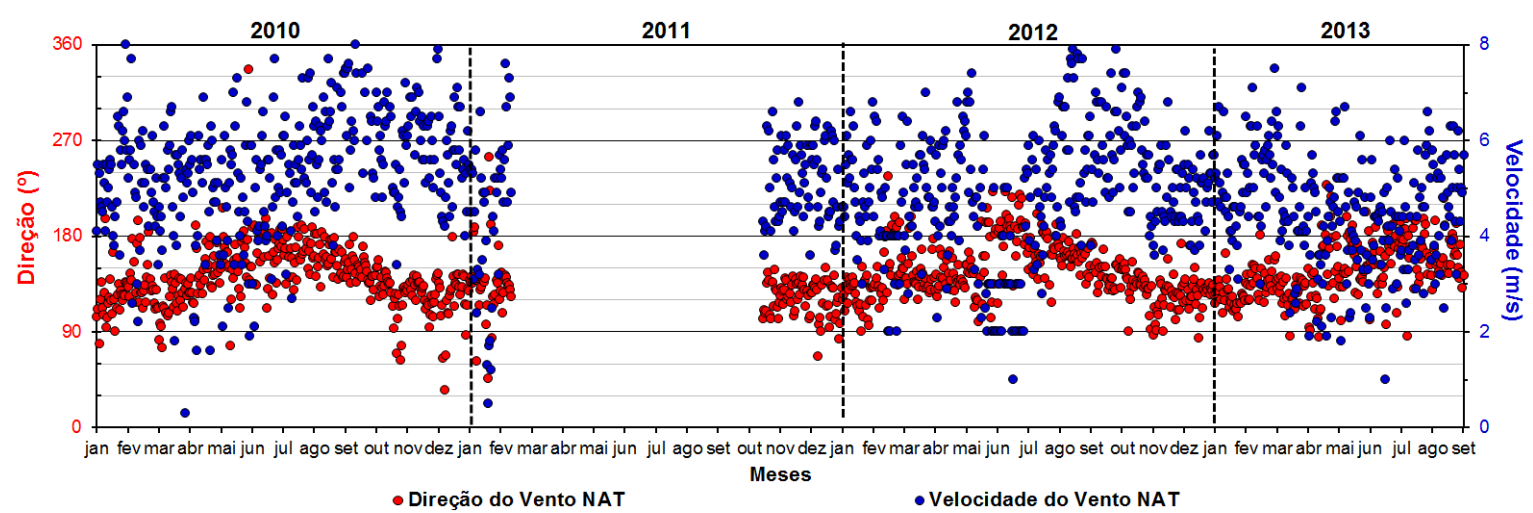

Figura 96: Direção e velocidade do vento às 12 horas em Natal, utilizando a base de dados do INMET ${ }^{[56]}$. Entre fevereiro a outubro de 2011 não houve dados. 


\subsubsection{Avaliação das concentrações de $\mathrm{CO}_{2}$}

As concentrações obtidas em NAT são apresentadas na Figura 97, assim como as concentrações medidas pelo laboratório da NOAA para NAT e para as estações globais. As concentrações de $\mathrm{CO}_{2}$ em NAT, para ambos os laboratórios (LQA/IPEN e NOAA), apresentaram comportamento semelhante ao observado em ASC, praticamente durante todo o período estudado.

Foi observado entre agosto a novembro, nos três anos de estudo, que concentrações de $\mathrm{CO}_{2}$ estiveram mais elevadas quando comparadas com as estações globais, porém neste mesmo período RPB apresenta um decréscimo em suas concentrações devido ao ciclo sazonal de $\mathrm{CO}_{2}$ que ocorre no $\mathrm{HN}$, devido a mudança de estação.

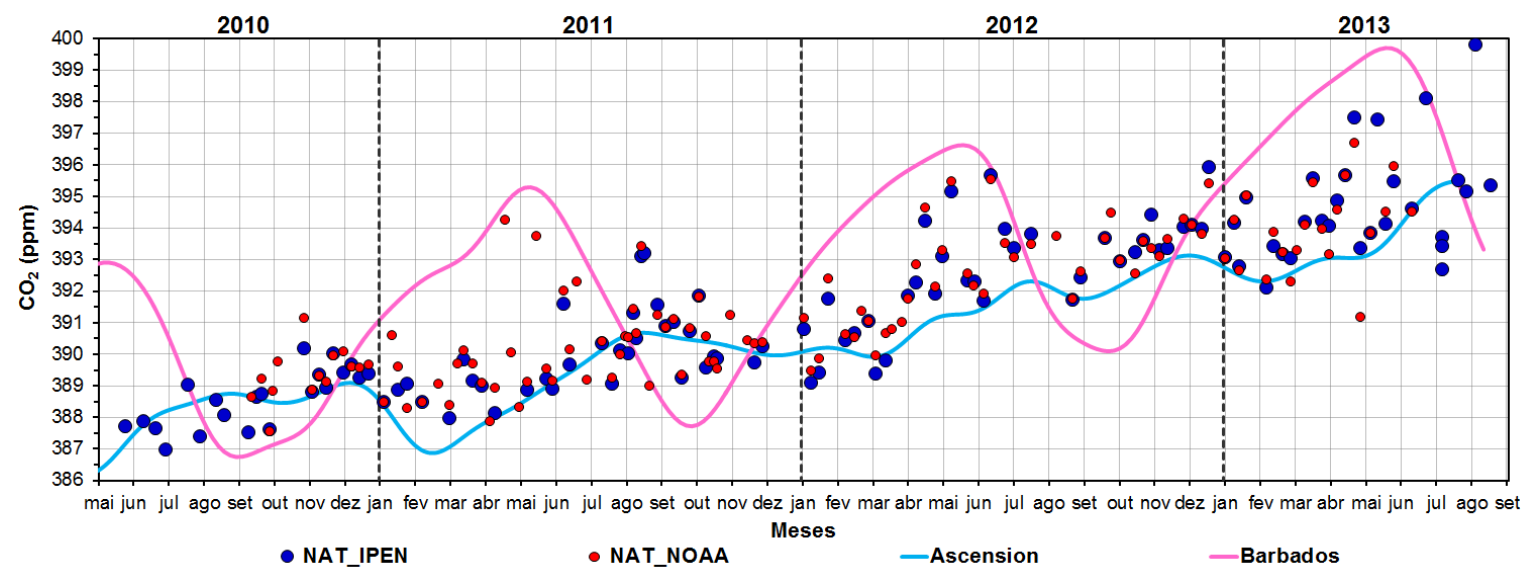

Figura 97: Série temporal de $\mathrm{CO}_{2}$ em NAT, estação de Maxaranguape - RN. Símbolos azuis - LQA/IPEN e símbolos vermelhos - NOAA.

As concentrações médias obtidas em NAT, para todos os anos de estudo, são apresentados na Tabela 18, onde se observa que os resultados em NAT, para ambos os laboratórios, mostram a ocorrência de aumento nas concentrações com o passar dos anos, e a diferença entre os laboratórios não ultrapassou a 0,5 ppm. Podemos notar 1,25 ppm e 0,51 ppm de diferença entre as concentrações medidas em NAT pelo LQA com a média global para os anos de 2011 e 2012, respectivamente.

A concentração média anual em NAT, foi comparada com a concentração média global por latitude a cada ano através dos dados fornecidos pela NOAA, e disponibilizados no sistema LAGEE. Esta comparação pode ser vista na Figura 98, onde podemos observar que a concentração média para cada 
ano em NAT, esteve muito próxima da média global, para a latitude onde se localiza este ponto de coleta.

Em 2010, a diferença entre a concentração média global, na latitude onde se localiza NAT, e a média de NAT, foi de 0,3 ppm acima, lembrando que neste ano a média de NAT foi referente ao intervalo de maio a dezembro. Em 2011 a diferença foi de 0,4 ppm abaixo e, em 2012 foi de 0,5 ppm acima. Considerando a variação que pode existir na medida, as concentrações em NAT apresentam o mesmo comportamento da média global para essa latitude.

Tabela 18: Concentração média anual de $\mathrm{CO}_{2}$ em NAT

\begin{tabular}{ccccc}
\hline \multicolumn{5}{c}{ Concentração média de $\mathbf{C O}_{\mathbf{2}}(\mathbf{p p m})$} \\
\hline Local & $\mathbf{2 0 1 0}$ & $\mathbf{2 0 1 1}$ & $\mathbf{2 0 1 2}$ & $\mathbf{2 0 1 3}$ \\
\hline NAT - LQA & $388,59^{1} \pm 0,93$ & $389,65 \pm 1,07$ & $392,59 \pm 1,60$ & $394,94^{2} \pm 1,48$ \\
NAT - NOAA & $389,35^{3} \pm 0,64$ & $390,07 \pm 0,71$ & $392,77 \pm 1,32$ & $394,03^{4} \pm 0,59$ \\
Média global & $389,00 \pm 1,43$ & $390,90 \pm 1,49$ & $393,10 \pm 1,54$ & - \\
\hline \multicolumn{5}{c}{ Variação entre os laboratórios $\mathbf{L Q A}$ e NOAA } \\
\hline \multirow{5}{*}{ Variação NAT - LQA } & $\mathbf{2 0 1 0 - 2 0 1 1}$ & $\mathbf{2 0 1 1 - 2 0 1 2}$ & $\mathbf{2 0 1 2 - 2 0 1 3}$ \\
\cline { 3 - 5 } & \multirow{2}{*}{ - } & - & 2,94 & - \\
\hline
\end{tabular}

Média entre os meses: ${ }^{1}$ maio a dezembro; ${ }^{2}$ janeiro a agosto; ${ }^{3}$ setembro a dezembro $e^{4}$ janeiro a junho. - Sem dados.
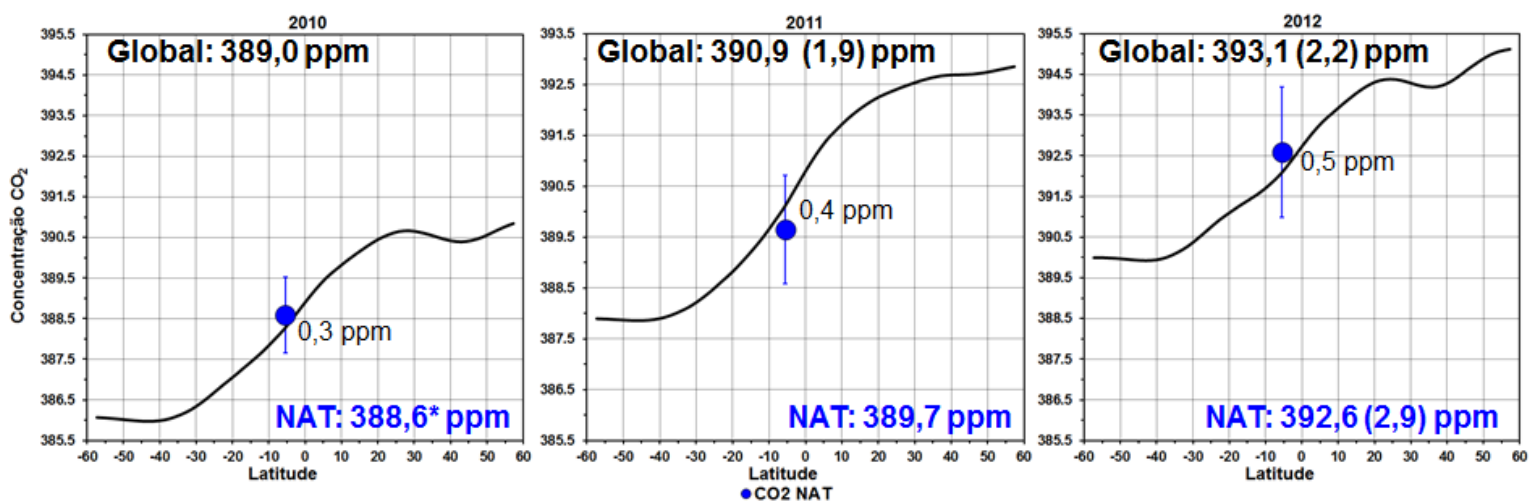

Figura 98: Comparação da concentração média anual do $\mathrm{CO}_{2}$ em NAT (símbolo azul) com a concentração média anual global por latitude (linha preta).

Para verificar a sazonalidade das concentrações de $\mathrm{CO}_{2}$ em NAT foi efetuada a separação dessas concentrações por mês, para cada ano de estudo como representado na Figura 99. Podemos observar que NAT não apresentou sazonalidade bem definida em todo período, porém é possível notar que as concentrações apresentam crescimento ao longo do ano para cada ano estudado. 
O diagrama de dispersão entre as concentrações de NAT com as de ASC e RPB, são apresentadas na Figura 100, onde para todo o período estudado foi encontrada uma correlação de 0,88 entre NAT e ASC e, 0,66 entre NAT e RPB, evidenciando assim que NAT possui maior correlação com ASC devido as concentrações destes locais apresentarem valores muito próximos.

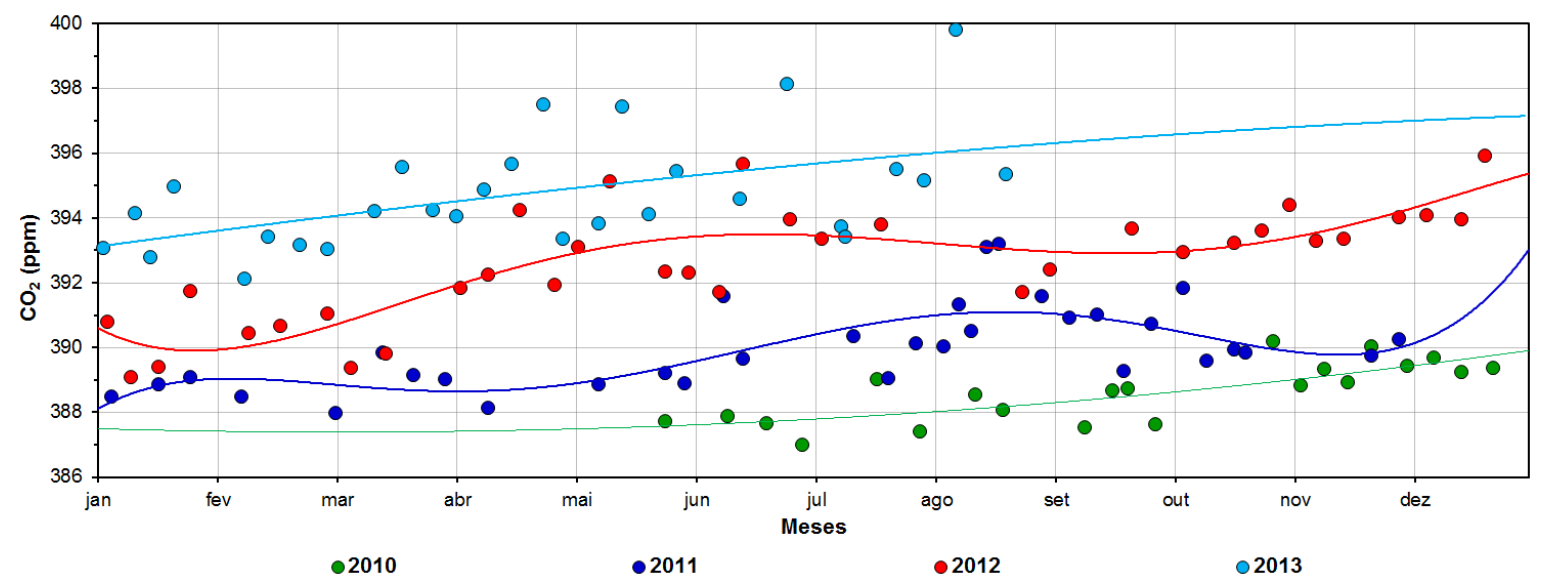

Figura 99: Concentrações de $\mathrm{CO}_{2}$ mensais e polinomiais para cada ano de estudo em NAT.
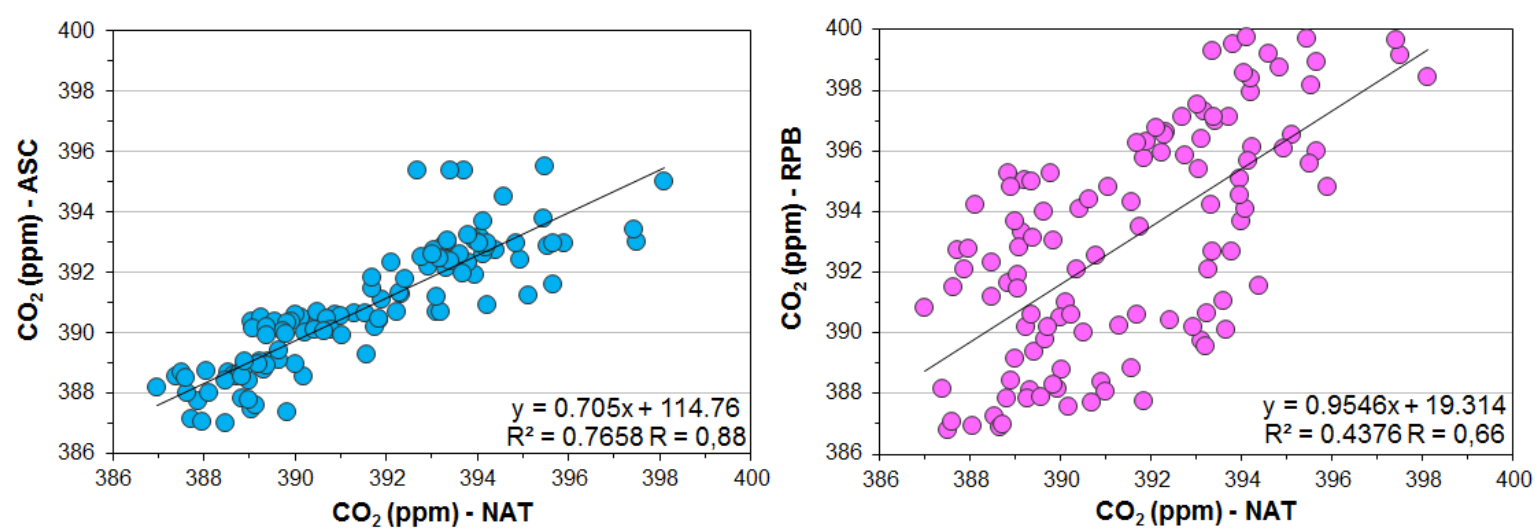

Figura 100: Diagrama de dispersão entre as concentrações de $\mathrm{CO}_{2}$ em NAT com as estações de ASC e RPB para todo o período.

\subsubsection{Avaliação das concentrações de $\mathrm{CH}_{4}$}

As concentrações de $\mathrm{CH}_{4}$ em NAT para ambos os laboratórios, apresentaram comportamento semelhante ao da estação global de ASC, durante todo o período como mostra a Figura 101. Este padrão homogêneo nas concentrações se deve ao fato deste local receber massas de ar apenas do OAS.

As concentrações médias obtidas em NAT para todos os anos de estudo e para ambos os laboratórios são apresentados na Tabela 19, onde se observa a ocorrência de um aumento com o passar dos anos, e a diferença entre os laboratórios ficou em torno de 1,64 ppb, levando em consideração os anos 
completos de medidas como 2011 e 2012. A diferença entre estes dois anos é um indicativo de desaceleração do crescimento das concentrações de $\mathrm{CH}_{4}$. Observou-se que a concentração média do LQA está abaixo da concentração média global, apresentando as diferenças de 33,31 ppb e 36,28 ppb para os anos de 2011 e 2012, respectivamente.

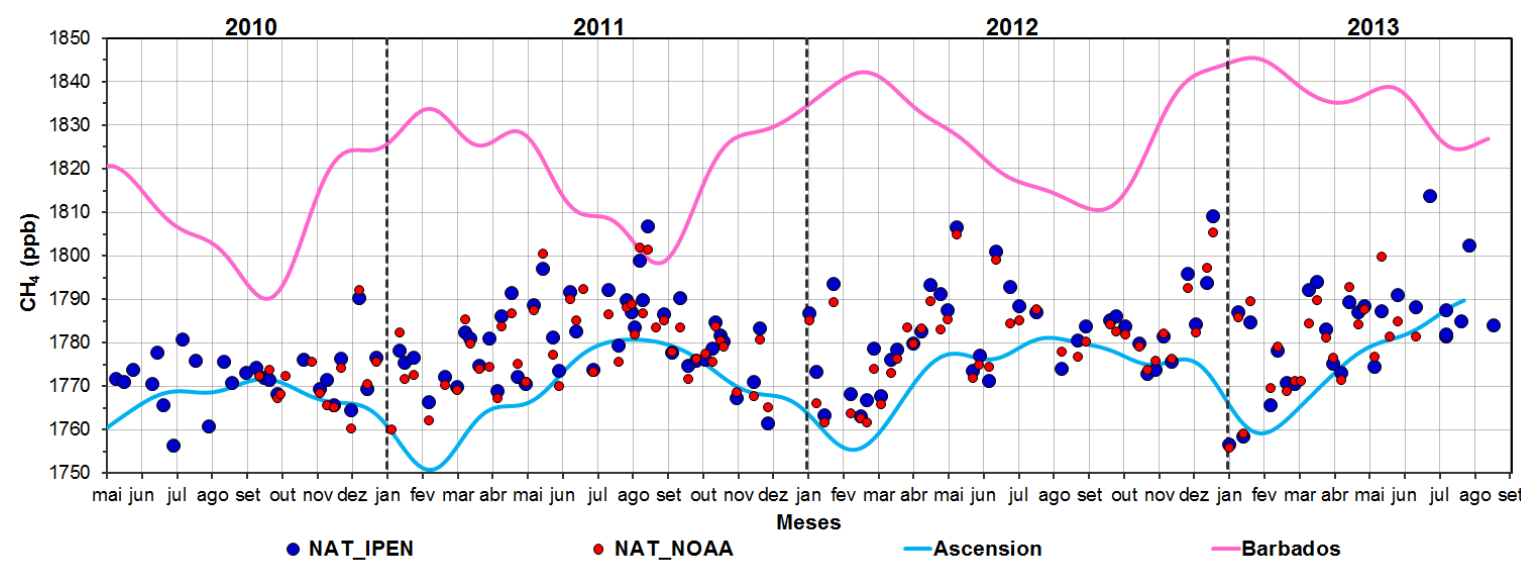

Figura 101: Série temporal de $\mathrm{CH}_{4}$ em NAT, estação de Maxaranguape - RN. Símbolos azuis - LQA/IPEN e símbolos vermelhos - NOAA.

Tabela 19: Concentração média anual de $\mathrm{CH}_{4}$ em NAT

\begin{tabular}{|c|c|c|c|c|}
\hline \multicolumn{5}{|c|}{ Concentração média de $\mathrm{CH}_{4}(p p b)$} \\
\hline Local & 2010 & 2011 & 2012 & 2013 \\
\hline$N A T-L Q A$ & $1771,82^{1} \pm 3,64$ & $1779,69 \pm 6,50$ & $1782,72 \pm 7,23$ & $1783,28^{2} \pm 9,35$ \\
\hline$N A T-N O A A$ & $1771,41^{3} \pm 2,60$ & $1778,06 \pm 6,87$ & $1781,08 \pm 7,44$ & $1778,95^{4} \pm 5,43$ \\
\hline Média global & $1808 \pm 6,63$ & $1813 \pm 6,93$ & $1819 \pm 7,42$ & - \\
\hline
\end{tabular}

\begin{tabular}{ccccc}
\hline \multicolumn{4}{c}{ Variação entre os laboratórios LQA e NOAA } \\
\hline - & 1,63 & 1,64 & - \\
\hline Variação NAT - LQA & $\mathbf{2 0 1 0 - 2 0 1 1}$ & $\mathbf{2 0 1 1 - 2 0 1 2}$ & $\mathbf{2 0 1 2 - 2 0 1 3}$ \\
\cline { 2 - 4 } & - & 3,03 & - \\
\hline Média entre os meses: & maio a dezembro; ${ }^{2}$ janeiro a agosto; ${ }^{3}$ & setembro a \\
dezembro e & 4 janeiro a junho. - Sem dados.
\end{tabular}

A concentração média anual em NAT, foi comparada com a concentração média global por latitude para cada ano de estudo. Esta comparação pode ser vista na Figura 102, onde podemos observar que a concentração média para os três anos de estudo em NAT, esteve acima, porém muito próxima da média global, para a latitude onde se localiza NAT.

Em 2010, a diferença entre a concentração média global, na latitude onde se localiza NAT, e a média de NAT, foi de 6,4 ppb, lembrando que neste 
ano, a média de NAT foi referente ao intervalo de maio a dezembro. Em 2011, a diferença foi de 10,6 ppb e, em 2012 foi de 7,1 ppb. Considerando a variação mínima da medida, as concentrações em NAT apresentam praticamente o mesmo valor da média global para essa latitude.

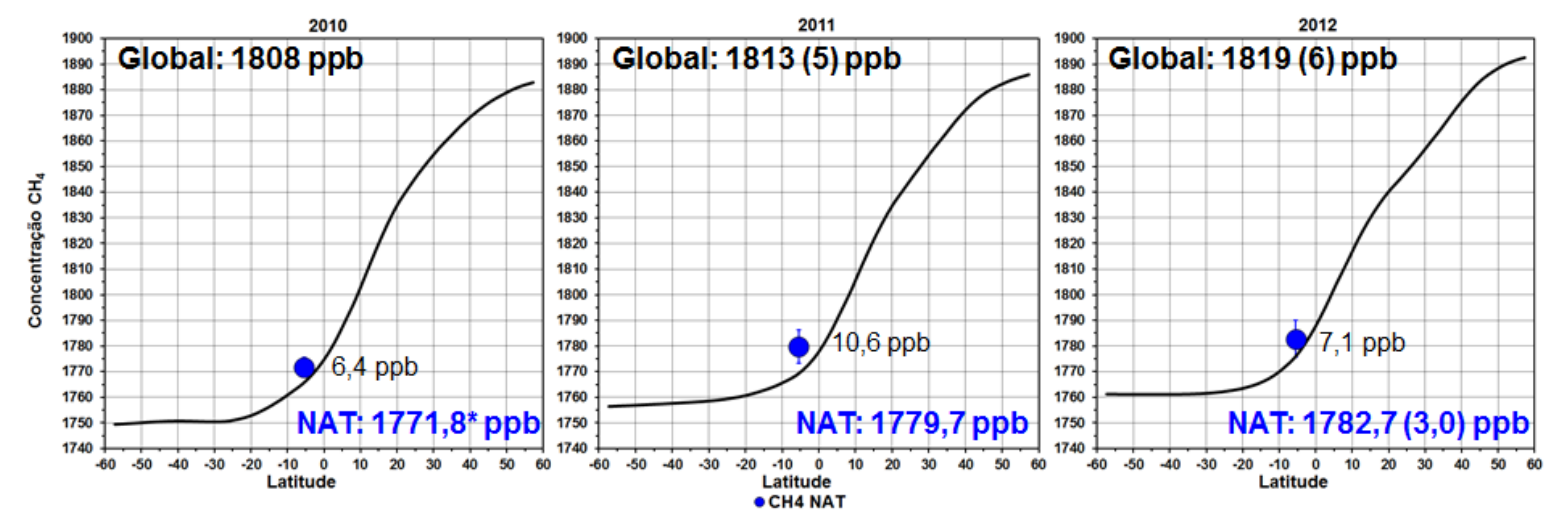

Figura 102: Comparação da concentração média anual do $\mathrm{CH}_{4}$ em NAT (símbolo azul) com a concentração média anual global por latitude (linha preta).

$\mathrm{Na}$ Figura 103, podemos observar que as concentrações de $\mathrm{CH}_{4}$ em NAT apresentaram um aumento contínuo porém discreto de janeiro a junho, e após este período voltam a diminuir de julho a dezembro, como pode ser visto na série temporal.

A diferença entre os períodos é apresentada na Tabela 20, onde de janeiro a junho, as concentrações foram menores em relação ao período de julho a dezembro, sendo a diferença média observada de 3,80 ppb.

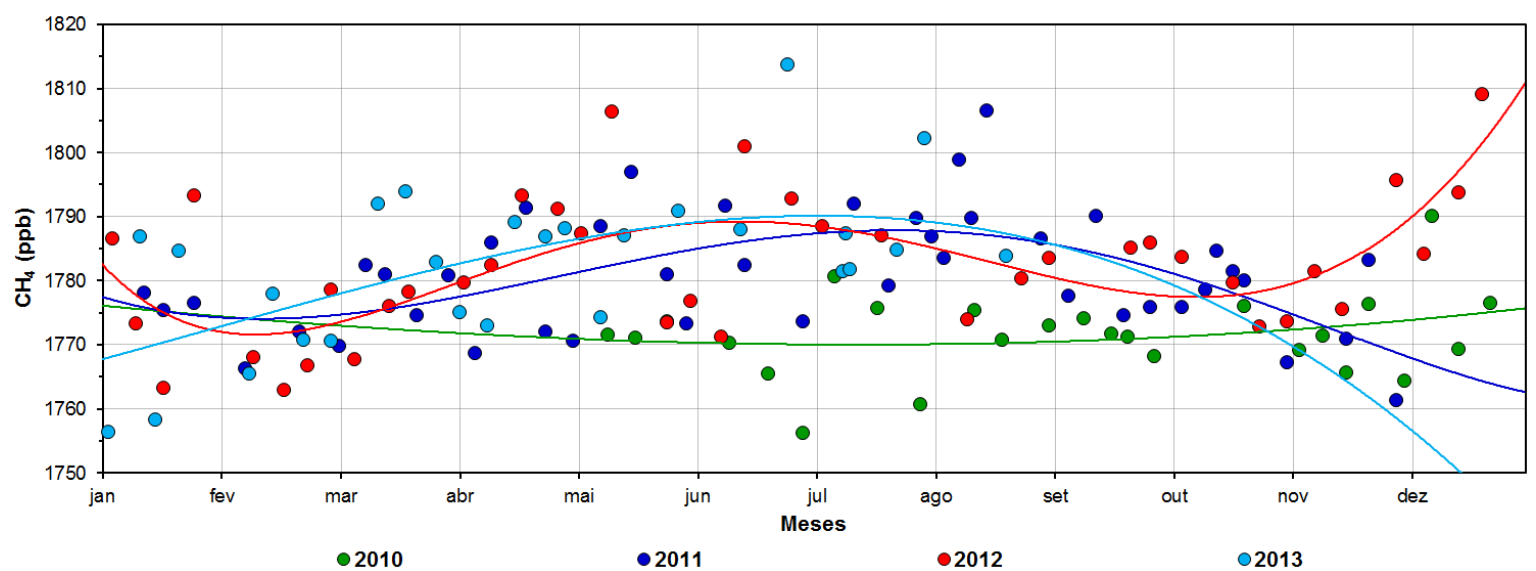

Figura 103: Concentrações de $\mathrm{CH}_{4}$ mensais e polinomiais para cada ano de estudo em NAT. 
Tabela 20: Concentração média de $\mathrm{CH}_{4}$ por período em NAT

Concentração média de $\mathrm{CH}_{4}$ (ppb) por período de cada ano

\begin{tabular}{ccccc}
\hline Períodos & 2010 & 2011 & 2012 & 2013 \\
\hline Jan-Jun & - & $1778,72 \pm 8,24$ & $1780,43 \pm 12,16$ & $1781,20 \pm 13,18$ \\
Jul-Dez & $1772,61 \pm 6,42$ & $1782,44 \pm 10,00$ & $1784,31 \pm 9,00$ & -
\end{tabular}

\begin{tabular}{lllll}
\hline Variação & - & 3,72 & 3,88 & - \\
\hline \multicolumn{4}{c}{ - Sem dados. }
\end{tabular}

O diagrama de dispersão entre as concentrações de NAT com ASC e RPB são apresentadas na Figura 104. Para todo o período foi encontrada uma correlação de 0,47 entre NAT e ASC, e de 0,01 entre NAT e RPB, assim confirmamos que as concentrações em NAT tem correlação apenas com ASC em função das concentrações de ambos os locais apresentarem o mesmo comportamento.
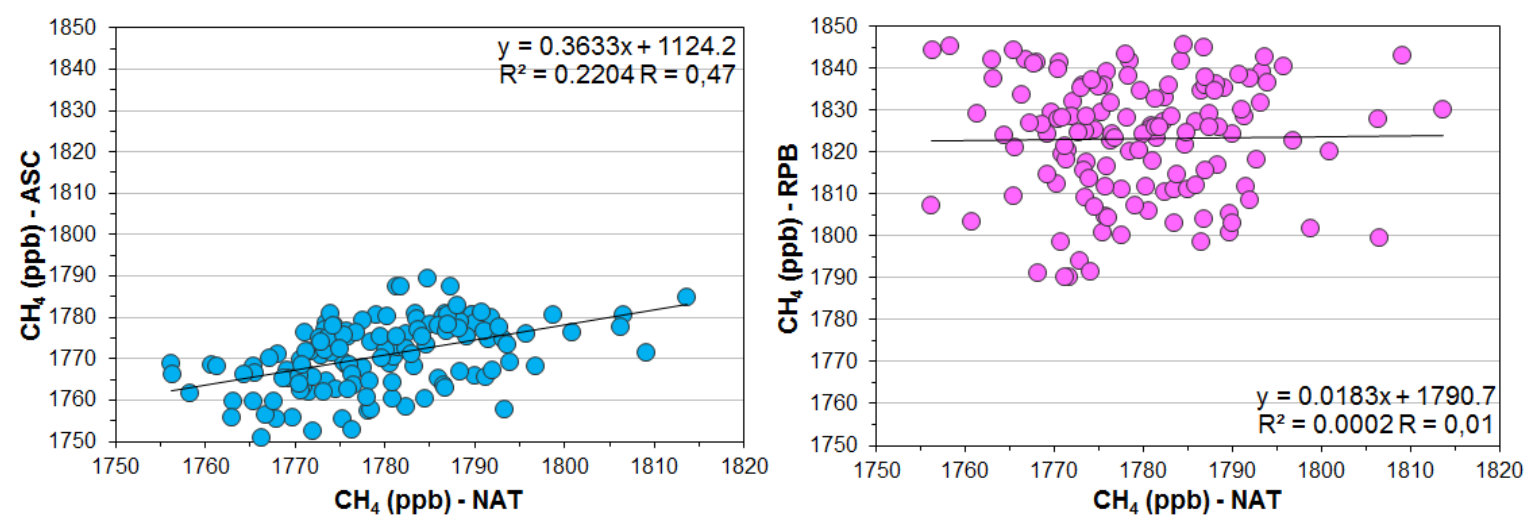

Figura 104: Diagrama de dispersão entre as concentrações de $\mathrm{CH}_{4}$ em NAT com as estações de ASC e RPB para todo o período.

\subsubsection{Avaliação das concentrações de $\mathrm{N}_{2} \mathrm{O}$}

As concentrações de $\mathrm{N}_{2} \mathrm{O}$ medidas em NAT para ambos os laboratórios mostraram que de maneira geral os resultados do LQA/IPEN estavam acima de ambas as estações globais de RPB e ASC e eventualmente observa-se valores menores, ficando abaixo dos medidos em ASC, como mostrado na Figura 105.

As concentrações médias em NAT são apresentadas na Tabela 21, onde se observa a ocorrência de um aumento com o passar dos anos, sendo a maior diferença entre as concentrações médias dos laboratórios de 0,52 ppb em 2012. Também observa-se que a concentração média do LQA, para o ano de 2011, apresentou uma diferença de apenas 0,08 ppb em relação a média global, e no ano de 2012 esta diferença foi de 0,61 ppb. 


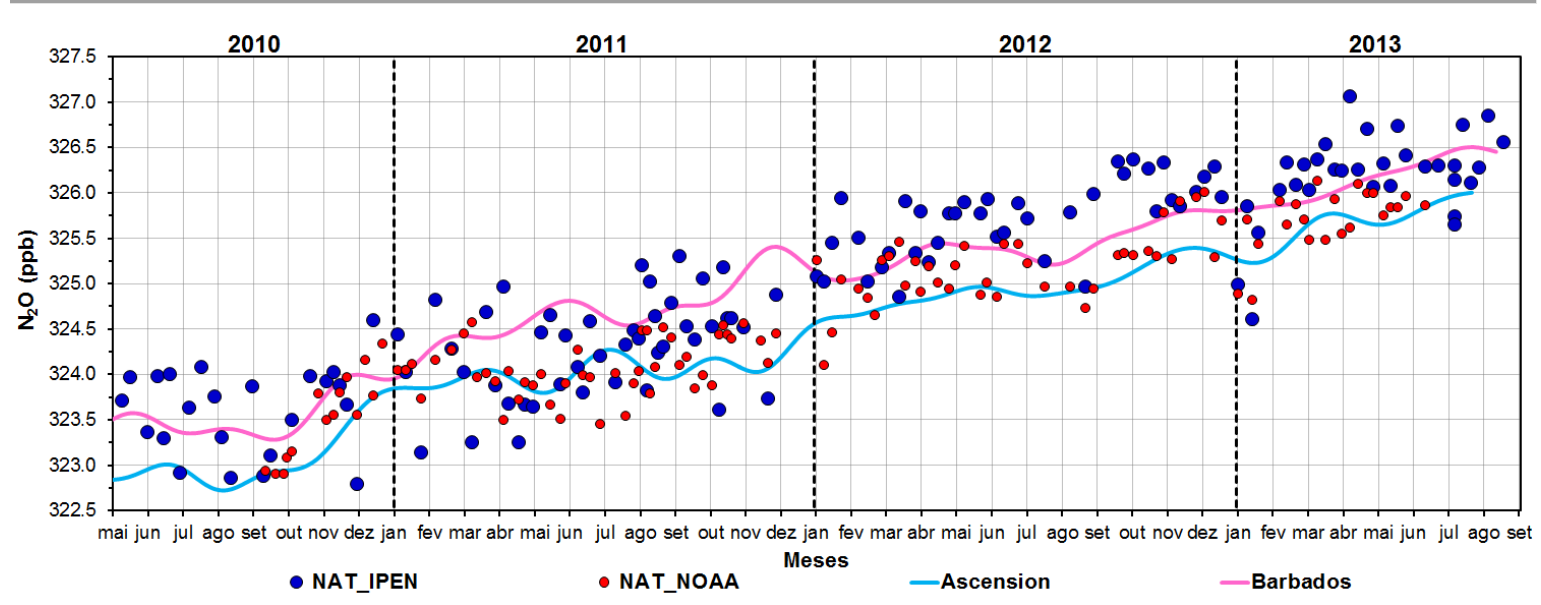

Figura 105: Série temporal de $\mathrm{N}_{2} \mathrm{O}$ em NAT, estação de Maxaranguape - RN. Símbolos azuis - LQA/IPEN e símbolos vermelhos - NOAA.

Tabela 21: Concentração média anual de $\mathrm{N}_{2} \mathrm{O}$ em NAT

\begin{tabular}{|c|c|c|c|c|}
\hline \multicolumn{5}{|c|}{ Concentração média de $\mathrm{N}_{2} \mathrm{O}$ (ppb) } \\
\hline Local & 2010 & 2011 & 2012 & 2013 \\
\hline$N A T-L Q A$ & $323,60^{1} \pm 0,29$ & $324,28 \pm 0,31$ & $325,71 \pm 0,35$ & $326,21^{2} \pm 0,43$ \\
\hline$N A T-N O A A$ & $323,47^{3} \pm 0,45$ & $324,06 \pm 0,22$ & $325,19 \pm 0,30$ & $325,72^{4} \pm 0,25$ \\
\hline Média global & $323,2 \pm 0,37$ & $324,2 \pm 0,33$ & $325,1 \pm 0,27$ & - \\
\hline \multicolumn{5}{|c|}{ Variação entre os laboratórios LQA e NOAA } \\
\hline & - & 0,22 & 0,52 & - \\
\hline \multirow{2}{*}{\multicolumn{2}{|c|}{ Variação NAT - LQA }} & 2010-2011 & 2011-2012 & 2012-2013 \\
\hline & & - & 1,43 & - \\
\hline
\end{tabular}

Média entre os meses: ${ }^{1}$ maio a dezembro; ${ }^{2}$ janeiro a agosto; ${ }^{3}$ setembro a dezembro e ${ }^{4}$ janeiro a junho. - Sem dados.

A concentração média anual em NAT para o $\mathrm{N}_{2} \mathrm{O}$, foi comparada com a concentração média global por latitude para os anos de 2010 e 2011 apenas, pois os dados de 2012 não estavam disponíveis. Esta comparação apresentada na Figura 106, mostra-nos em 2010, que a média em NAT, foi maior que a média global sendo esta diferença de 0,3 ppb, ressaltando que a média neste ano em NAT foi de maio a dezembro. Em 2011, a média em NAT ficou abaixo da média global por latitude em apenas $0,1 \mathrm{ppb}$, levando em consideração para ambos os anos as concentrações médias para a latitude onde se localiza NAT.

$\mathrm{Na}$ Figura 107, podemos observar que as concentrações de $\mathrm{N}_{2} \mathrm{O}$ em NAT não apresentaram sazonalidade durante todo período, porém, é possível notar que as concentrações apresentam um crescimento ao longo do ano, de cada ano estudado. 

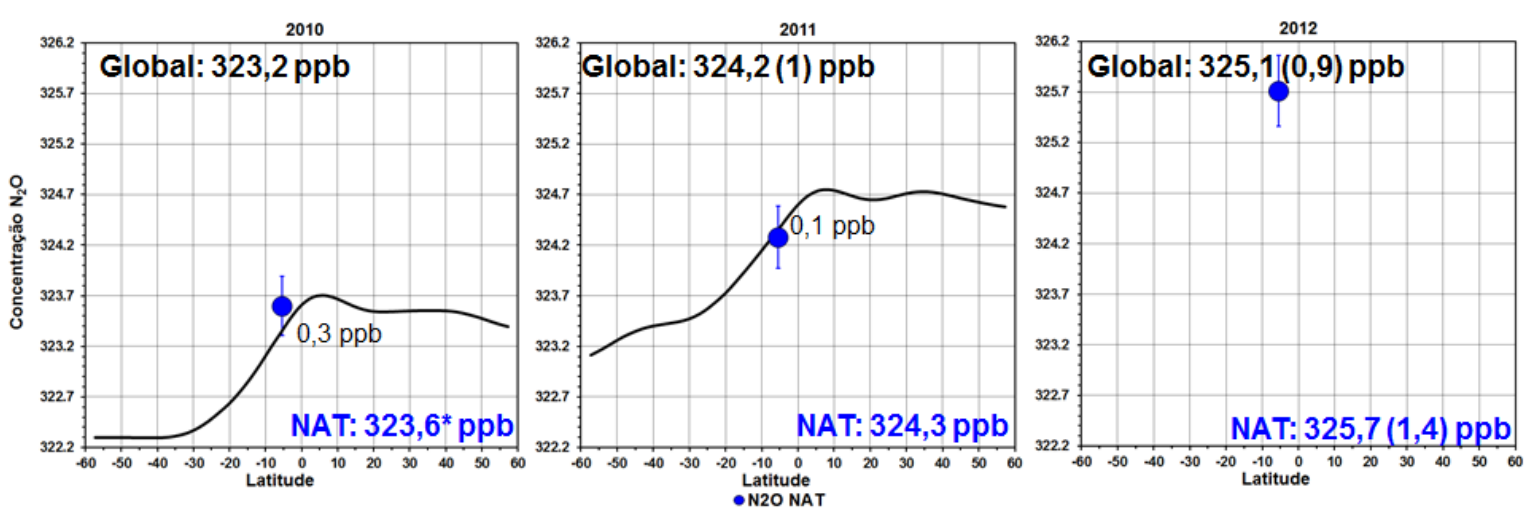

Figura 106: Comparação da concentração média anual do $\mathrm{N}_{2} \mathrm{O}$ em NAT (símbolo azul) com a concentração média anual global por latitude (linha preta).

O diagrama de dispersão entre as concentrações de NAT com as concentrações de ASC e RPB são apresentadas na Figura 108, e para todo o período estudado foi encontrada uma correlação de 0,90 entre NAT e ASC, e de 0,87 entre NAT e RPB, mostrando assim, que NAT possui correlação com ambas as estações, devido a todas apresentarem um crescimento relativamente homogêneo, sem uma clara sazonalidade.

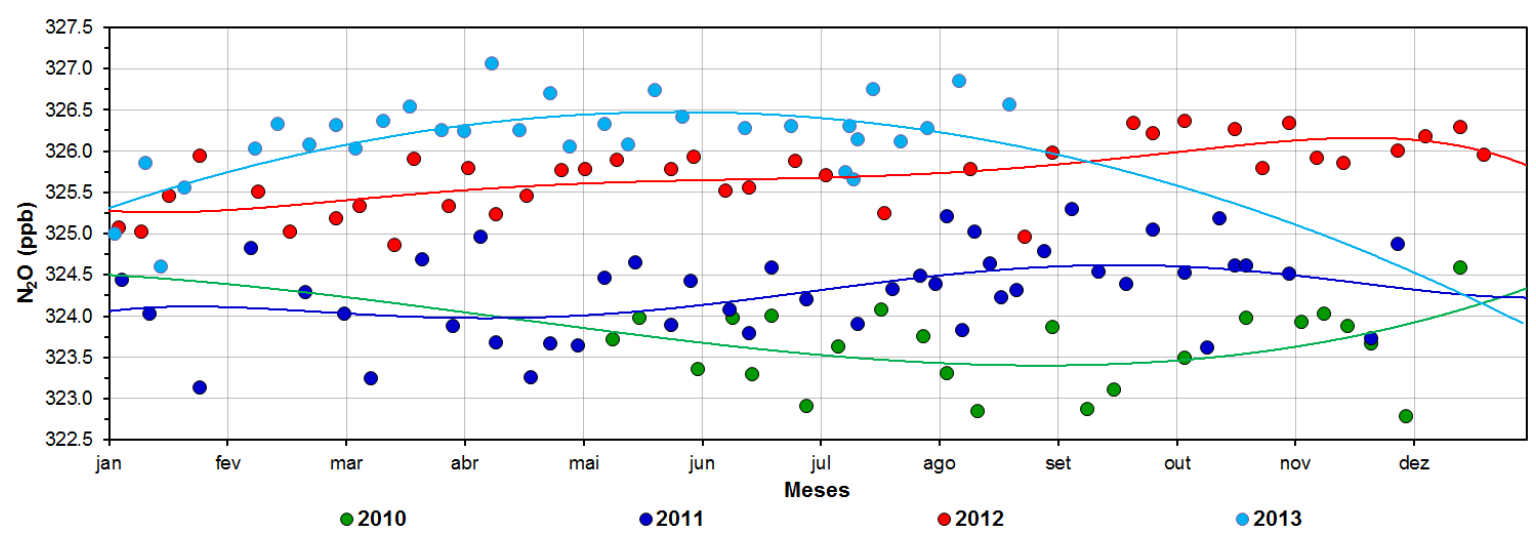

Figura 107: Concentrações de $\mathrm{N}_{2} \mathrm{O}$ mensais e polinomiais para cada ano de estudo em NAT.
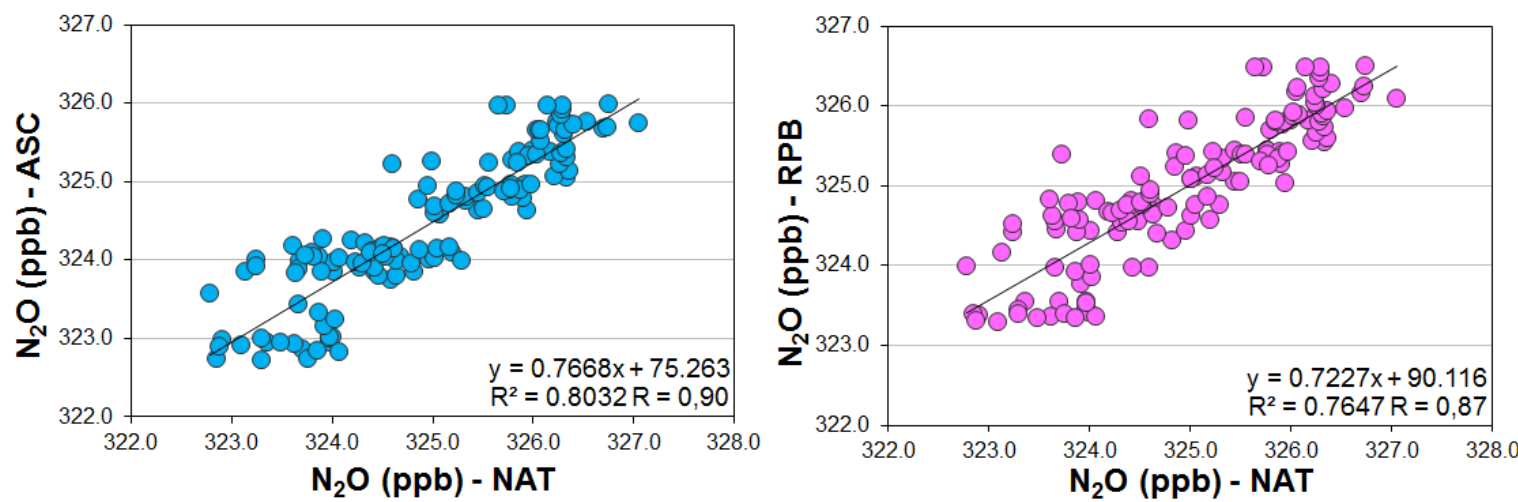

Figura 108: Diagrama de dispersão entre as concentrações de $\mathrm{N}_{2} \mathrm{O}$ em NAT com as estações de ASC e RPB para todo o período. 


\subsubsection{Avaliação das concentrações de $\mathrm{SF}_{6}$}

As concentrações de $\mathrm{SF}_{6}$ medidas em NAT para ambos os laboratórios, apresentaram comportamento semelhante ao das concentrações medidas em ASC, como mostra a Figura 109, onde podemos notar o aumento de aproximadamente 1 ppt entre o início do estudo até o mês de agosto.

As concentrações médias em NAT são apresentadas na Tabela 22, onde podemos observar para ambos os laboratórios, que está ocorrendo um aumento com o passar dos anos. A diferença máxima observada entre os laboratórios foi de 0,01 ppt. E o aumento da concentração média do LQA de 2011 para 2012 foi de 0,32 ppt. Podemos observar que as medidas do LQA estão abaixo da concentração média global, sendo a diferença em 2011 de 0,13 ppt, e em 2012 de 0,10 ppt.

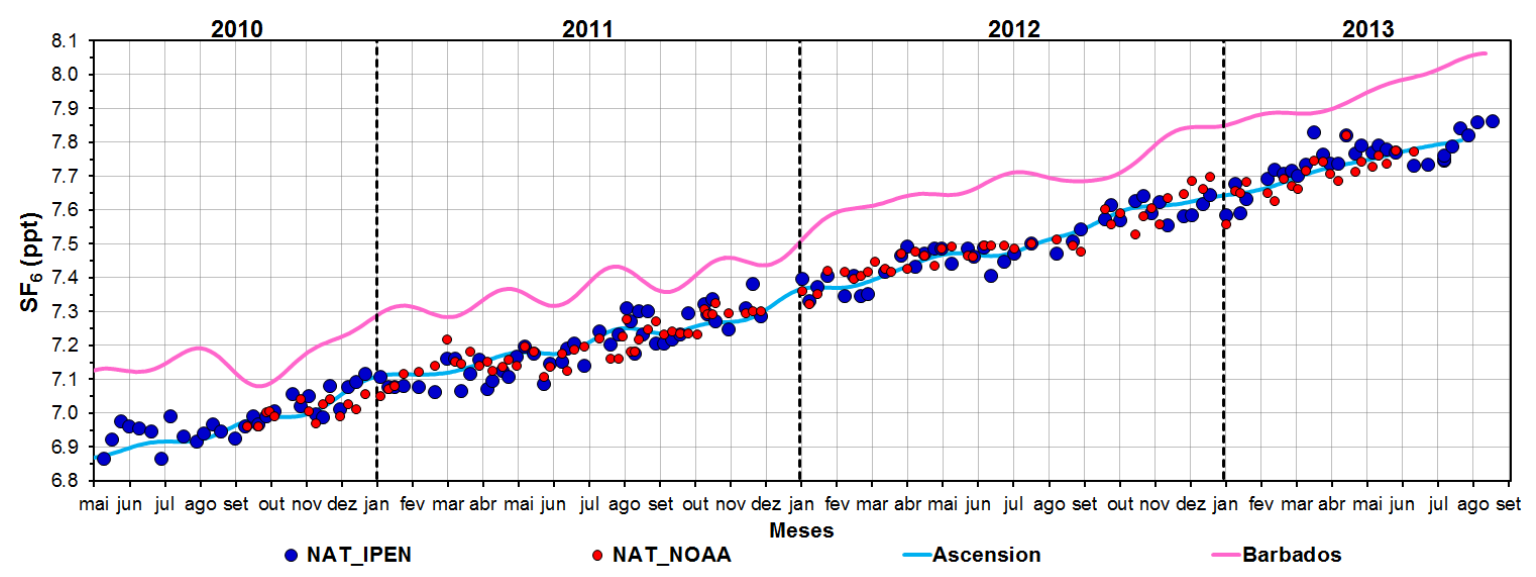

Figura 109: Série temporal de $S_{6}$ em NAT, estação de Maxaranguape - RN. Símbolos azuis - LQA/IPEN e símbolos vermelhos - NOAA.

Tabela 22: Concentração média anual de $S_{6}$ em NAT

\begin{tabular}{|c|c|c|c|c|}
\hline \multicolumn{5}{|c|}{ Concentração média de $S F_{6}(p p t)$} \\
\hline Local & 2010 & 2011 & 2012 & 2013 \\
\hline$N A T-L Q A$ & $6,98^{1} \pm 0,06$ & $7,18 \pm 0,09$ & $7,50 \pm 0,09$ & $7,75^{2} \pm 0,07$ \\
\hline$N A T-N O A A$ & $7,00^{3} \pm 0,02$ & $7,19 \pm 0,07$ & $7,50 \pm 0,09$ & $7,71^{4} \pm 0,05$ \\
\hline Média global & $7,02 \pm 0,09$ & $7,31 \pm 0,09$ & $7,60 \pm 0,08$ & - \\
\hline \multicolumn{5}{|c|}{ Variação entre os laboratórios LQA e NOAA } \\
\hline & - & 0,01 & 0,00 & - \\
\hline \multirow{2}{*}{\multicolumn{2}{|c|}{ Variação NAT - LQA }} & $2010-2011$ & 2011-2012 & 2012-2013 \\
\hline & & - & 0,32 & - \\
\hline
\end{tabular}

Média entre os meses: ${ }^{1}$ maio a dezembro; ${ }^{2}$ janeiro a agosto; ${ }^{3}$ setembro a dezembro $e^{4}$ janeiro a junho. - Sem dados. 
A concentração média anual em NAT, foi comparada com a concentração média global por latitude para os anos de 2010 e 2011. Esta comparação pode ser vista na Figura 110, onde observa-se, em 2010, que a concentração média em NAT, esteve maior que a média global por latitude, sendo esta diferença de 0,05 ppt, vale ressaltar que neste ano, a média de NAT foi entre os meses de maio a dezembro. Em 2011, a concentração média em NAT ficou abaixo da média global por latitude em apenas 0,02 ppt, levando em consideração para ambos os anos, concentrações médias para a latitude onde se localiza NAT.
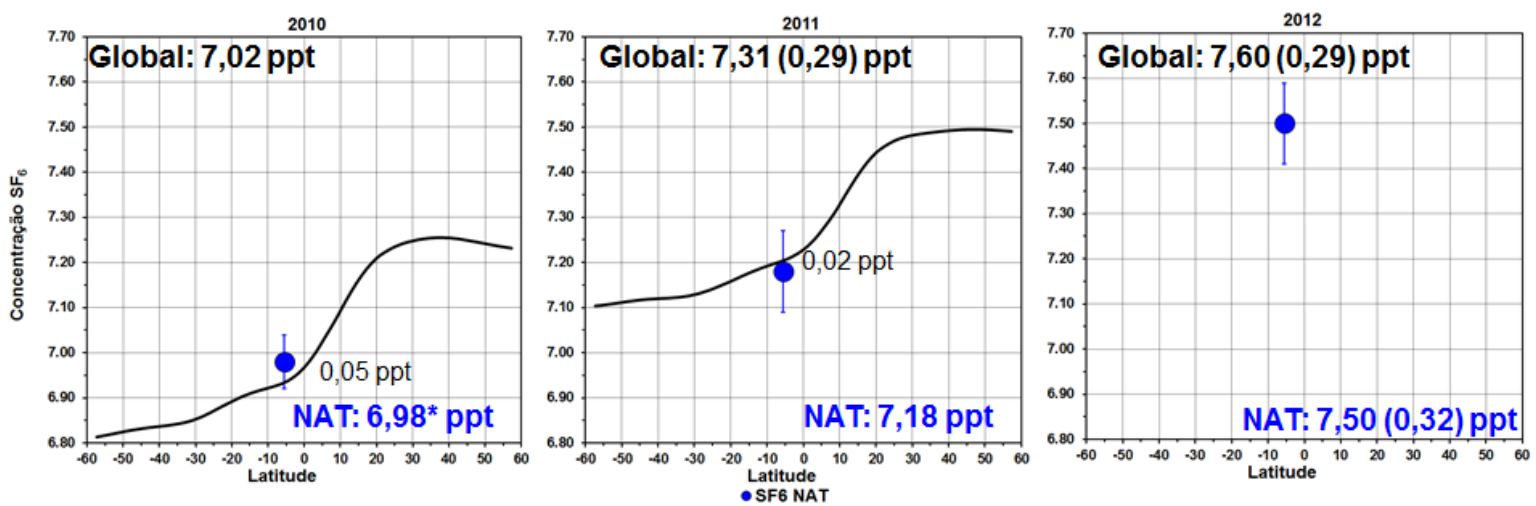

Figura 110: Comparação da concentração média anual do $\mathrm{SF}_{6}$ em NAT (símbolo azul) com a concentração média anual global por latitude (linha preta).

Podemos observar que as concentrações de $\mathrm{SF}_{6}$ em NAT não apresentaram sazonalidade como representado na Figura 111, no entanto ocorre um contínuo crescimento dessas concentrações ao longo do ano, assim como observado nos relatórios que divulgam as concentrações globais deste gás.

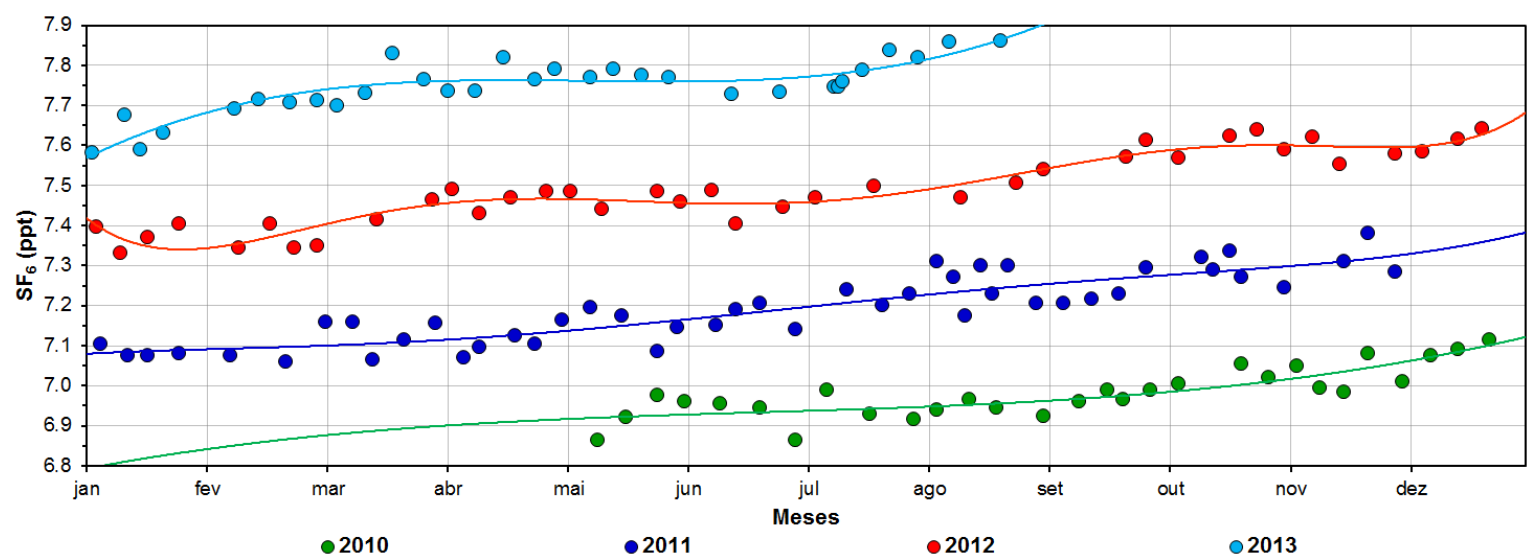

Figura 111: Concentrações de $\mathrm{SF}_{6}$ mensais e polinomiais para cada ano de estudo em NAT. 
O diagrama de dispersão entre as concentrações de NAT com ASC e RPB é apresentada na Figura 112. Para todo o período foi encontrada uma correlação de 0,99 entre NAT e ASC e, de 0,98 entre NAT e RPB. Isso nos mostra que esta correlação alta se deve as concentrações tanto de NAT como as das estações globais, apresentarem o mesmo comportamento de contínuo crescimento sem clara sazonalidade.
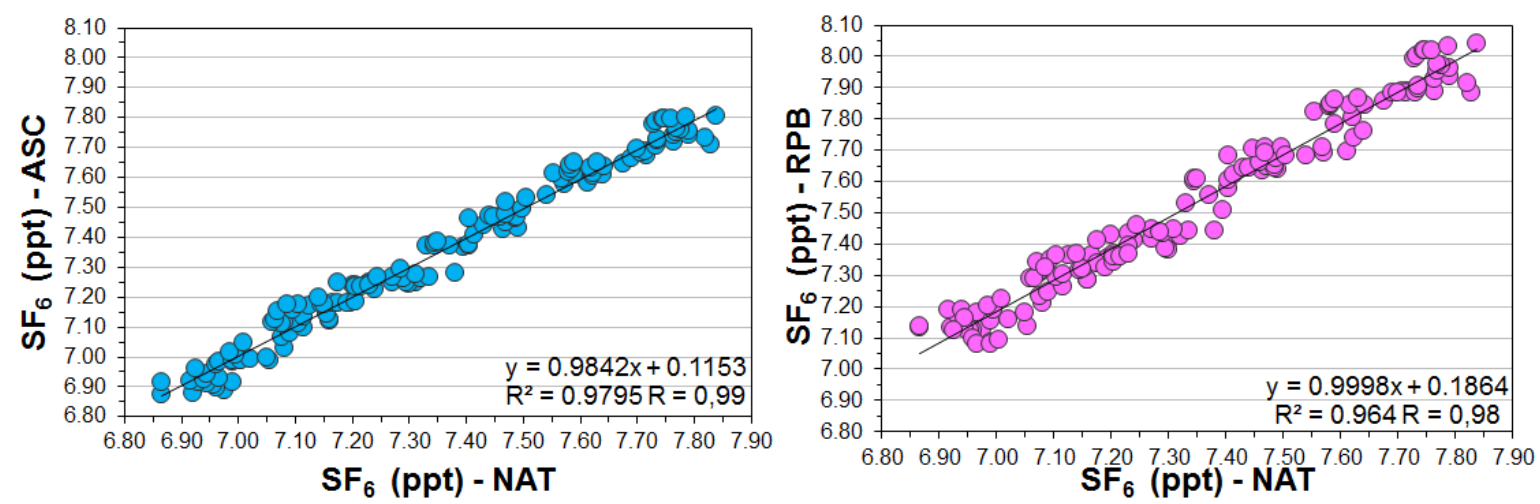

Figura 112: Diagrama de dispersão entre as concentrações de $\mathrm{SF}_{6}$ em NAT com as estações de ASC e RPB para todo o período.

\subsubsection{Avaliação das concentrações de CO}

As concentrações de CO medidas em NAT para ambos os laboratórios apresentaram comportamento semelhante ao das concentrações medidas na estação global de ASC realizados pela NOAA como mostrado na Figura 113. As concentrações de CO apresentaram-se mais elevadas do que ASC e RPB entre os meses de agosto a outubro em todo o período estudado. Este período é caracterizado por queima de biomassa, tanto no Brasil como na África, como pode ser observado na Figura 114, que mostra um exemplo de trajetória retrocedente com origem no continente africano em um período de grande incidência de queimada, podendo dessa forma ocorrer o transporte de $\mathrm{CO}$, através das massas de ar, influenciando as concentrações em NAT, e mesmo foi observado em SAL e SAH, devido a massas de ar oriundas da África.

As concentrações médias obtidas em NAT, para ambos os laboratórios são apresentadas na Tabela 23. Observa-se nas medidas do LQA um aumento de 0,22 ppb de CO entre 2011 a 2012. A maior diferença entre os laboratórios foi de 1,79 ppb em 2011, sendo que tanto em 2010 como em 2011, as medidas do LQA foram inferiores as da NOAA. A concentração média do LQA em 2011 foi 12,39 ppb inferior à média global. 


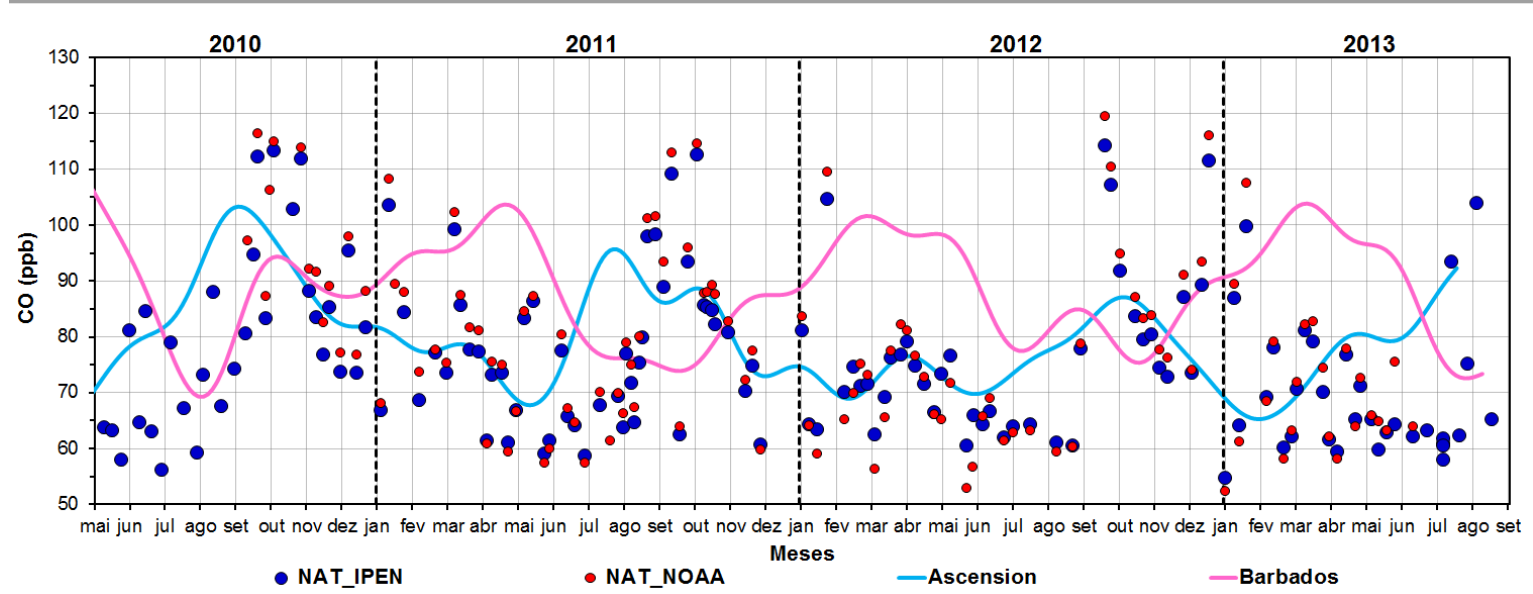

Figura 113: Série temporal de CO em NAT, estação de Maxaranguape - RN. Símbolos azuis - LQA/IPEN e símbolos vermelhos - NOAA.
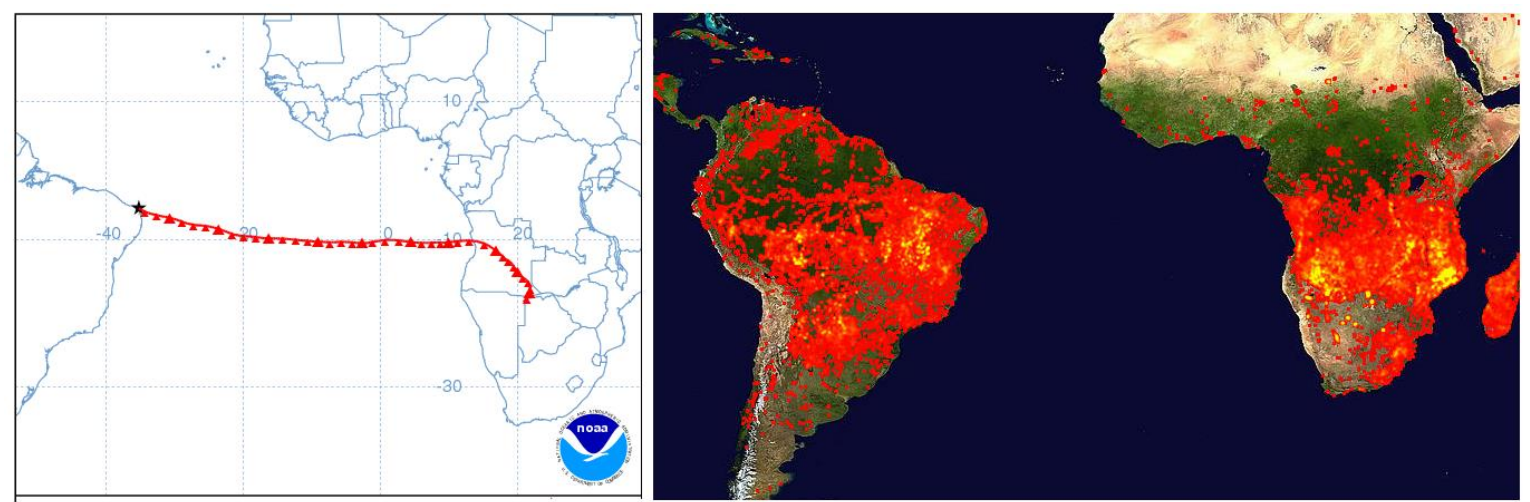

Figura 114: Trajetória retrocedente de 240 horas para o dia 21/09/12 e focos de queimadas entre o período de $17 / 09$ a 26/09/12 ${ }^{[55,69]}$.

Tabela 23: Concentração média anual de CO em NAT

\begin{tabular}{ccccc}
\hline \multicolumn{5}{c}{ Concentração média de CO (ppb) } \\
\hline Local & $\mathbf{2 0 1 0}$ & $\mathbf{2 0 1 1}$ & $\mathbf{2 0 1 2}$ & $\mathbf{2 0 1 3}$ \\
\hline NAT - LQA & $79,85^{1} \pm 14,83$ & $76,61 \pm 8,68$ & $76,83 \pm 13,39$ & $70,29^{2} \pm 7,34$ \\
NAT - NOAA & $96,42 \pm 12,03^{3}$ & $78,40 \pm 10,05$ & $77,86 \pm 15,81$ & $69,88^{4} \pm 5,26$ \\
Média global & 93 & 89 & - & - \\
\hline \multicolumn{5}{c}{ Variação entre os laboratórios LQA e NOAA } \\
\hline- & 1,79 & 1,03 & - \\
\hline Variação NAT - LQA & $\mathbf{2 0 1 0 - 2 0 1 1}$ & $\mathbf{2 0 1 1 - 2 0 1 2}$ & $\mathbf{2 0 1 2 - 2 0 1 3}$ \\
\cline { 2 - 5 } & & - & 0,22 & - \\
\hline
\end{tabular}

Média entre os meses: ${ }^{1}$ maio a dezembro; ${ }^{2}$ janeiro a agosto; ${ }^{3}$ setembro a dezembro $e^{4}$ janeiro a junho. - Sem dados.

A comparação da concentração média anual em NAT com a concentração média global por latitude pode ser vista na Figura 115, entre os anos de 2010 a 2013. Podemos observar que na latitude onde se encontra NAT, as concentrações médias de CO estiveram acima da média global, sendo que 
estas diferenças foram de 8,2 ppb em 2010 (lembrando que neste ano a média de NAT foi referente ao intervalo de maio a dezembro), 8,5 ppb em 2011, e de 1,8 ppb em 2012. Se considerássemos a variação mínima da medida, as concentrações em NAT seriam menores que a média global para essa latitude.
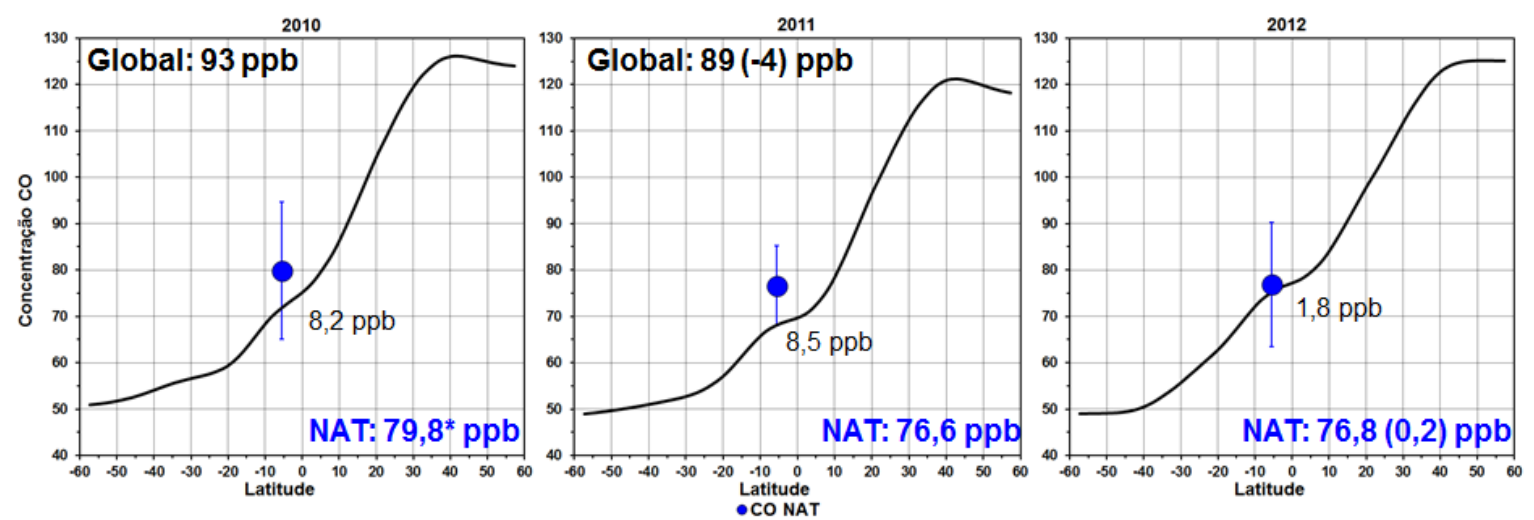

Figura 115: Comparação da concentração média anual do CO em NAT (símbolo azul) com a concentração média anual global por latitude (linha preta).

As concentrações de CO em NAT apresentaram sazonalidade como pode ser vista na Figura 116, onde as concentrações estiveram um pouco mais elevadas entre janeiro a março, apresentando uma ligeira queda que estabiliza até o fim de julho, e a partir de agosto as concentrações iniciam um aumento que volta a diminuir em outubro e aumenta novamente em dezembro.

A concentração média entre os períodos de janeiro a julho e de agosto a dezembro são apresentadas na Tabela 24. Podemos observar que as concentrações foram menores para o primeiro período em relação ao segundo, devido ao primeiro apresentar concentrações homogêneas e o segundo apresentar períodos de concentrações elevadas.

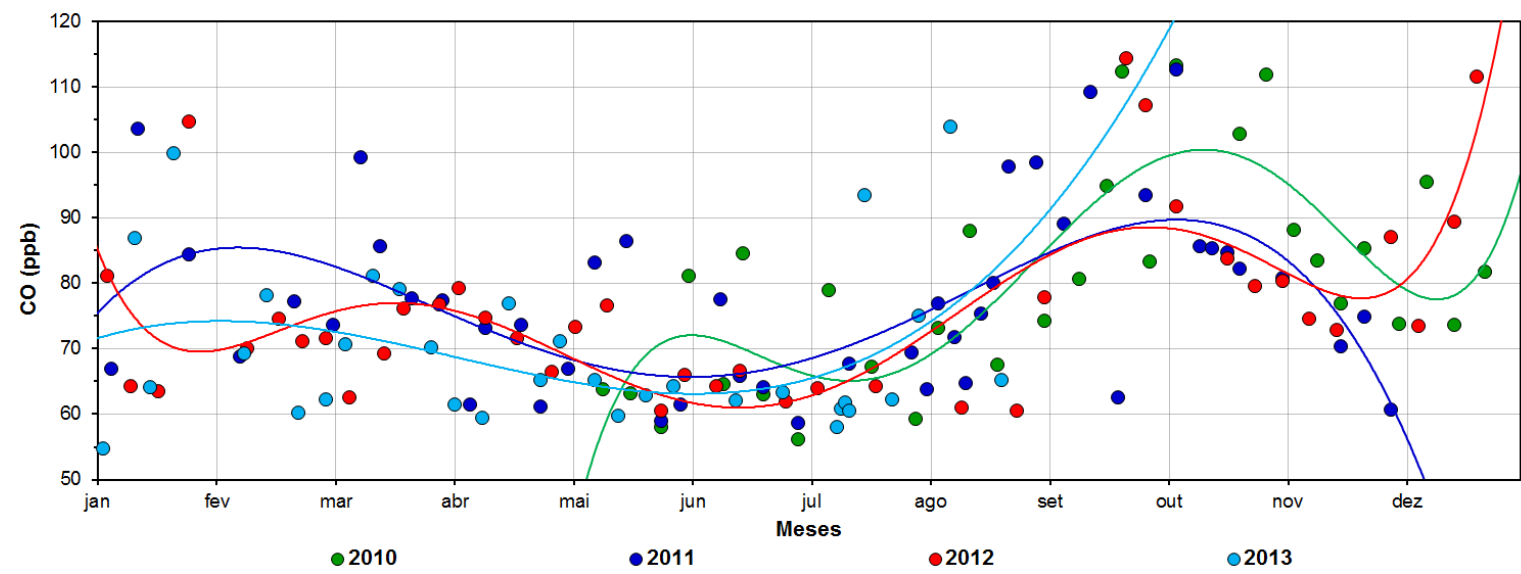

Figura 116: Concentrações de CO mensais e polinomiais para cada ano de estudo em NAT. 
Tabela 24: Concentração média de CO por período em NAT

\begin{tabular}{ccccc}
\hline \multicolumn{5}{c}{ Concentração média de CO (ppb) por período de cada ano } \\
\hline Períodos & 2010 & 2011 & 2012 & 2013 \\
\hline Jan-Jul & $67,21^{1} \pm 9,76$ & $73,70 \pm 11,79$ & $70,96 \pm 9,13$ & $68,61 \pm 10,84$ \\
Ago-Dez & $87,33 \pm 14,17$ & $81,85 \pm 14,56$ & $84,29 \pm 16,43$ & $84,48^{2} \pm 27,40$ \\
\hline Variação & 20,12 & 8,15 & 13,33 & 15,86 \\
\hline \multicolumn{5}{c}{ Valor referente: ' ${ }^{\prime}$ maio-julho; ${ }^{2}$ agosto. }
\end{tabular}

As concentrações de NAT apresentaram 0,30 de correlação com ASC, e $-0,13$ com RPB, para todo o período como apresenta a Figura 117. Esta correlação com ASC só não foi mais elevada pois as concentrações em NAT, apesar de apresentar o mesmo comportamento desta estação, apresentou também valores elevados a partir de agosto, influenciando assim esta comparação.
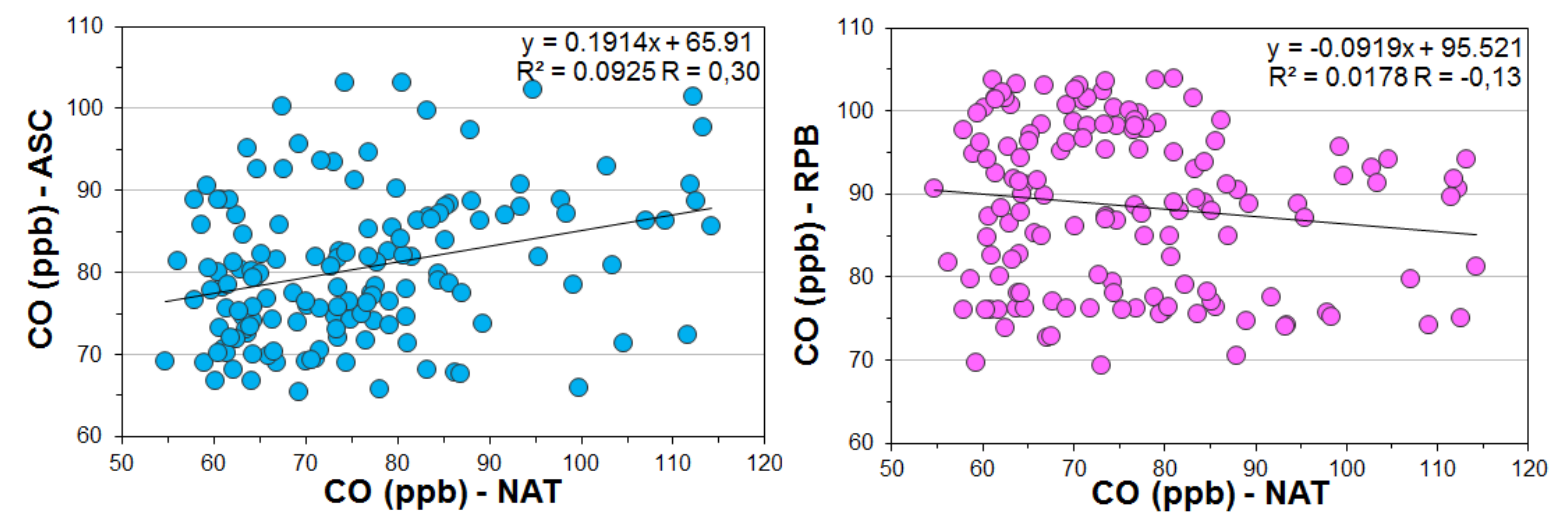

Figura 117: Diagrama de dispersão entre as concentrações de CO em NAT com as estações de ASC e RPB para todo o período.

\subsubsection{Intercomparação das concentrações entre NAT/IPEN e NAT/NOAA}

A intercomparação semanal ocorrida em NAT, foi realizada coletando 2 pares de frascos de amostra, um para ser analisado no LQA/IPEN e o outro na NOAA. Estas amostragens foram coletadas subsequentemente, com um intervalo médio de 20 minutos entre os pares. Este procedimento pode trazer alguma variação não desejável na intercomparação.

Para realizar a intercomparação entre o LQA/IPEN e a NOAA, foi realizada a diferença entre as concentrações médias obtidas para todos os gases amostrados em NAT, para 111 amostras. A frequência dessa diferença assim como, a média e o desvio padrão são apresentadas na Tabela 25. 
Tabela 25: Frequência observada entre a diferença das concentrações médias entre NAT/IPEN e NAT/NOAA, para todos os anos de estudos

\begin{tabular}{|c|c|}
\hline \multicolumn{2}{|c|}{ Diferenças entre as concentrações médias de 111 amostra } \\
\hline 0,00 & $1 \%$ \\
\hline 0,25 & $49 \%$ \\
\hline 0,50 & $28 \%$ \\
\hline 0,75 & $12 \%$ \\
\hline 1,00 & $7 \%$ \\
\hline 2,00 & $2 \%$ \\
\hline Média & $0,32 \pm 0,32$ \\
\hline \multicolumn{2}{|c|}{$\mathrm{CH}_{4}(\mathrm{ppb})$} \\
\hline 0,00 & $0 \%$ \\
\hline 1,00 & $22 \%$ \\
\hline 2,00 & $25 \%$ \\
\hline 3,00 & $13 \%$ \\
\hline 4,00 & $20 \%$ \\
\hline 5,00 & $9 \%$ \\
\hline 6,00 & $4 \%$ \\
\hline Acima de 6,00 & $7 \%$ \\
\hline Média & $2,74 \pm 2,09$ \\
\hline \multicolumn{2}{|c|}{$\mathrm{N}_{2} \mathrm{O}(p p b)$} \\
\hline 0,00 & $0 \%$ \\
\hline 0,25 & $31 \%$ \\
\hline 0,50 & $23 \%$ \\
\hline 0,75 & $23 \%$ \\
\hline 1,00 & $15 \%$ \\
\hline 1,25 & $6 \%$ \\
\hline 1,50 & $3 \%$ \\
\hline Média & $0,52 \pm 0,35$ \\
\hline \multicolumn{2}{|c|}{$S F_{6}(p p t)$} \\
\hline 0,000 & $3 \%$ \\
\hline 0,025 & $35 \%$ \\
\hline 0,050 & $30 \%$ \\
\hline 0,075 & $22 \%$ \\
\hline 0,100 & $11 \%$ \\
\hline Média & $0,04 \pm 0,03$ \\
\hline \multicolumn{2}{|c|}{$C O(p p b)$} \\
\hline 0,00 & $0 \%$ \\
\hline 2,00 & $44 \%$ \\
\hline 4,00 & $32 \%$ \\
\hline 6,00 & $18 \%$ \\
\hline 8,00 & $3 \%$ \\
\hline 10,00 & $3 \%$ \\
\hline Média & $2,83 \pm 1,95$ \\
\hline
\end{tabular}


Os resultados para o $\mathrm{CO}_{2}$ mostram que das 111 amostras, $49 \%$ estão com uma diferença de até 0,25 ppm, e $89 \%$ se encontram até 0,75 ppm, sendo a média das diferenças de todos os anos de estudo de 0,32 ppm. Para o $\mathrm{CH}_{4}, 47 \%$ das amostras apresentaram diferenças até 2,00 ppb, e $80 \%$ apresentou diferença até $4 \mathrm{ppb}$, sendo que a média das diferenças para todo o período foi de 2,74 ppb. Os resultados para o $\mathrm{N}_{2} \mathrm{O}$ mostram que $54 \%$ das amostras estão até $0,50 \mathrm{ppb}$ e $92 \%$ até $1 \mathrm{ppb}$ de diferença. $\mathrm{O}^{\mathrm{SF}} 6$ apresentou $68 \%$ das diferenças em até 0,050 ppt, e $90 \%$ até 0,075 ppt. O CO apresentou $44 \%$ das amostras com diferenças até 2,00 ppb e 94\% até 6,00 ppb.

Para avaliar as medidas realizadas pelo LQA e pela NOAA, foi realizada a correlação entre as concentrações médias destes laboratórios. O diagrama de dispersão para todos os gases estudados é mostrado na Figura 118. Para $\circ \mathrm{CO}_{2}$ foi encontrada uma correlação de 0,98 , para $\circ \mathrm{CH}_{4}$ de 0,95 , para o $\mathrm{N}_{2} \mathrm{O}$ de 0,86 , para o $\mathrm{SF}_{6}$ de 0,98 e para o $\mathrm{CO}$ de 0,99. Esses resultados mostram que os resultados obtidos no LQA/IPEN tem uma alta correlação com 0 laboratório da NOAA, para os dados observados na estação de NAT, garantindo a qualidade das medidas no Brasil.
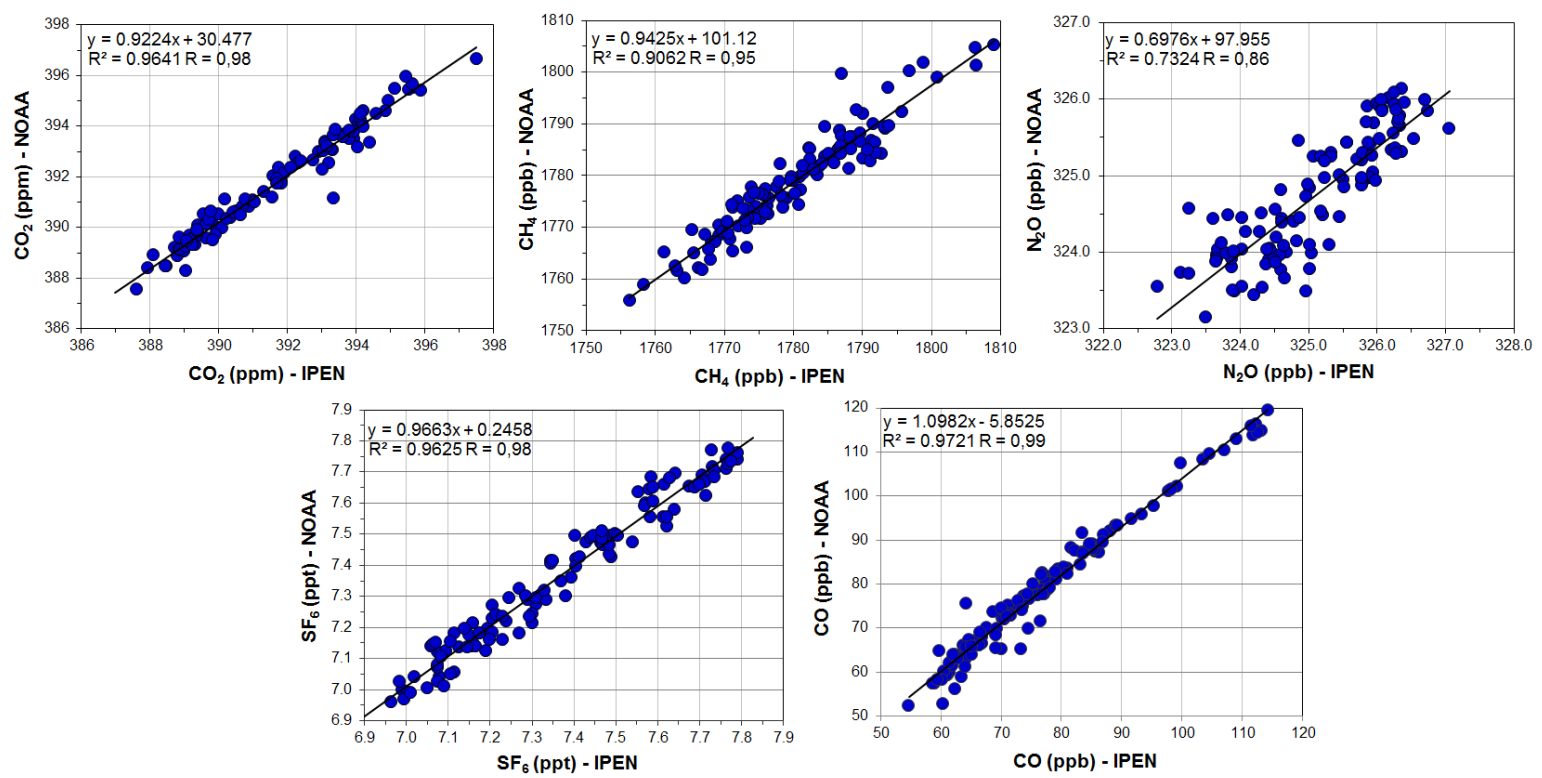

Figura 118: Diagrama de dispersão entre as concentrações médias obtidas em NAT realizadas pelo LQA/IPEN e pela NOAA para $\mathrm{CO}_{2}, \mathrm{CH}_{4}, \mathrm{~N}_{2} \mathrm{O}, \mathrm{SF}_{6}$ e $\mathrm{CO}$.

\subsection{Comparação das concentrações dos GEE entre SAL e NAT}

A média das concentrações obtidas em cada ano, para cada local de estudo, é apresentada na Tabela 26. Em NAT, foram iniciadas medidas em maio de 2010, assim a média é referente ao período de maio a dezembro e, em 2013 a 
média foi realizada entre janeiro a agosto. Em SAL, para o ano de 2013, a média é referente ao período de janeiro a setembro. Porém, para se fazer a comparação entre SAL e NAT para os anos onde esta foi parcial, foi realizada a média das concentrações de SAL para os períodos de maio a dezembro de 2010 e de janeiro a agosto de 2013.

Tabela 26: Concentrações médias dos GEE em SAL e NAT

\begin{tabular}{|c|c|c|c|c|c|c|}
\hline \multicolumn{7}{|c|}{ Concentração dos Gases de Efeito Estufa } \\
\hline Local & Ano & $\mathrm{CO}_{2}(\mathrm{ppm})$ & $\mathrm{CH}_{4}(\mathrm{ppb})$ & $\mathrm{N}_{2} \mathrm{O}(p p b)$ & $S F_{6}(p p t)$ & $C O(p p b)$ \\
\hline \multirow{6}{*}{ SAL } & 2010 & $388,01 \pm 1,19$ & $1784,92 \pm 9,42$ & $323,96 \pm 0,42$ & $6,98 \pm 0,07$ & $97,10 \pm 12,56$ \\
\hline & 2011 & $390,39 \pm 1,29$ & $1795,78 \pm 14,65$ & $324,79 \pm 0,35$ & $7,25 \pm 0,06$ & $94,15 \pm 10,66$ \\
\hline & 2012 & $392,14 \pm 0,82$ & $1794,36 \pm 12,84$ & $325,97 \pm 0,31$ & $7,54 \pm 0,07$ & $96,05 \pm 19,29$ \\
\hline & $2013^{1}$ & $394,75 \pm 0,77$ & $1800,94 \pm 13,54$ & $326,65 \pm 0,20$ & $7,83 \pm 0,05$ & $90,95 \pm 17,14$ \\
\hline & $2010^{2}$ & $387,73 \pm 1,19$ & $1781,09 \pm 7,32$ & $323,84 \pm 0,44$ & $7,02 \pm 0,07$ & $92,11 \pm 7,20$ \\
\hline & $2013^{3}$ & $394,83 \pm 0,85$ & $1803,73 \pm 13,83$ & $326,62 \pm 0,13$ & $7,81 \pm 0,04$ & $92,54 \pm 18,95$ \\
\hline \multirow{4}{*}{ NAT } & $2010^{2}$ & $388,59 \pm 0,93$ & $1771,82 \pm 3,64$ & $323,60 \pm 0,29$ & $6,98 \pm 0,06$ & $79,85 \pm 14,83$ \\
\hline & 2011 & $389,65 \pm 1,07$ & $1779,69 \pm 6,50$ & $324,28 \pm 0,31$ & $7,18 \pm 0,09$ & $76,61 \pm 8,68$ \\
\hline & 2012 & $392,59 \pm 1,60$ & $1782,72 \pm 7,23$ & $325,71 \pm 0,35$ & $7,50 \pm 0,09$ & $76,83 \pm 13,39$ \\
\hline & $2013^{3}$ & $394,94 \pm 1,48$ & $1783,28 \pm 9,35$ & $326,21 \pm 0,43$ & $7,75 \pm 0,07$ & $70,29 \pm 7,34$ \\
\hline \multirow{3}{*}{$\begin{array}{l}\text { Média } \\
\text { global }\end{array}$} & 2010 & $389,0 \pm 1,43$ & $1808 \pm 6,63$ & $323,2 \pm 0,37$ & $7,02 \pm 0,09$ & 93 \\
\hline & 2011 & $390,9 \pm 1,49$ & $1813 \pm 6,93$ & $324,2 \pm 0,33$ & $7,31 \pm 0,09$ & 89 \\
\hline & 2012 & $393,1 \pm 1,54$ & $1819 \pm 7,42$ & $325,1 \pm 0,27$ & $7,60 \pm 0,08$ & - \\
\hline \multicolumn{7}{|c|}{ Variações entre os anos de estudo / aumento Global } \\
\hline \multirow{2}{*}{ SAL } & $2010-2011$ & $2,38 / 1,9$ & $10,86 / 5$ & $0,83 / 1,0$ & $0,27 / 0,29$ & $2,96 /-4$ \\
\hline & 2011-2012 & $1,75 / 2,2$ & $1,42 / 6$ & $1,18 / 0,9$ & $0,28 / 0,29$ & 1,90 \\
\hline NAT & 2011-2012 & 2,94 & 3,03 & 1,43 & 0,31 & 0,22 \\
\hline \multicolumn{7}{|c|}{ Variações entre locais de estudos (SAL - NAT) } \\
\hline & $2010^{2}$ & $-0,86$ & 9,27 & 0,24 & 0,04 & 12,26 \\
\hline & 2011 & 0,74 & 16,09 & 0,51 & 0,07 & 17,54 \\
\hline & 2012 & $-0,45$ & 11,64 & 0,26 & 0,04 & 19,22 \\
\hline & $2013^{3}$ & $-0,11$ & 20,45 & 0,41 & 0,06 & 22,25 \\
\hline
\end{tabular}

Média entre: ${ }^{1}$ janeiro a setembro; ${ }^{2}$ maio a dezembro; ${ }^{3}$ janeiro a agosto. - Sem dados.

Esses resultados mostram que tanto em SAL como em NAT, de maneira geral, ocorreu aumento nas concentrações dos GEE. Observa-se em SAL, para $\circ \mathrm{CH}_{4}$, de 2010-2011, que a diferença entre os anos de estudo foi maior que o aumento global. No entanto, este local foi alterado por ter sido constatado a influência da praia a leste com forte movimento turístico. Para os outros gases a diferença entre os anos estiveram próximos do aumento global. A diferença entre as concentrações médias, em cada ano de estudo, mostram que SAL apresenta valores maiores do que NAT, isso se deve a localização de SAL 
que recebe influências tanto do OAN, como do OAS, além das possíveis contribuições locais, e NAT recebe influências apenas do OAS.

\subsection{Comparação das concentrações de SAL e NAT com a concentração de entrada calculada pelo método do $\mathrm{SF}_{6}$}

As concentrações medidas em SAL e NAT foram comparadas com as concentrações calculadas pelo método do $\mathrm{SF}_{6}$, como sendo os valores da concentração de entrada no continente (CEC), para cada voo realizado na Bacia Amazônica, pelos projetos do LQA no período de 2010 e 2011. Este método consiste em supor que não existe contribuição de emissão dentro do continente desde a costa brasileira até os locais de coleta dentro da Bacia Amazônica. Sendo assim, sua concentração durante o perfil vertical é a mesma do momento em que cruza a costa brasileira. Esta concentração é relacionada às medidas em ASC e RPB, e assim é calculada uma fração destas relações, sendo esta fração utilizada para encontrar as concentrações de entrada para todos os gases estudados ${ }^{[21,27,28]}$.

Podemos observar para o gás $\mathrm{CO}_{2}$, que as CEC para ALF, RBA, SAN e TAB, apresentaram em grande parte do ano o mesmo comportamento das concentrações medidas em NAT, porém observa-se uma elevação das concentrações em NAT, que não é observada nas CEC calculadas, como mostra a Figura 119. Esta elevação acontece justamente no pico da estação das queimadas na Amazônia. Este aumento pode ser uma contaminação pela emissão das queimadas no Brasil, que sairiam do continente pela circulação de corrente ascendente e descendente, primeiramente indo para o oceano e posteriormente retornando para o continente em nível mais baixo (Fonte: Bernard Rappenglück, comunicação pessoal). Pode ainda ser uma contaminação oriunda de queimadas na África, com mostrado anteriormente na Figura 114. Observa-se ainda que para $T A B$ e RBA, quando as massas de ar tem maior influência do $H N$, as CEC mostram valores entre NAT e SAL, portanto, assumir um dos locais da Costa levaria a um erro de subestimação ou superestimação da CEC.

Analisando os resultados do gás $\mathrm{CH}_{4}$ na Figura 120, as CEC de SAN e ALF apresentaram o mesmo comportamento de NAT de janeiro a agosto. As CEC de RBA e TAB apresentaram o mesmo comportamento apenas de abril/maio. Porém de julho a setembro NAT apresenta o mesmo pico já observado para $\mathrm{CO}_{2}$ 
e não representado nas $\mathrm{CEC}$ calculadas para $\mathrm{CH}_{4}$. A partir de setembro/outubro, observa-se um aumento das CEC para RBA e TAB, mostrando uma influência que pode ser oriunda de queimadas na África, da mesma maneira explicada para o $\mathrm{CO}_{2}$.

Podemos observar na Figura 121, que as CEC para ALF, RBA, SAN e $T A B$, para o gás $\mathrm{N}_{2} \mathrm{O}$, apresentaram o mesmo comportamento das concentrações de NAT, principalmente em 2011, exceto entre agosto e outubro. E para o gás $\mathrm{CO}$, as CEC, de uma maneira geral apresentaram o mesmo comportamento das concentrações em NAT no primeiro semestre, porém a partir de junho/julho apresentam um aumento das concentrações até novembro, exceto para a CEC em TAB, que estiveram mais próximas de SAL, como mostra a Figura 122. 

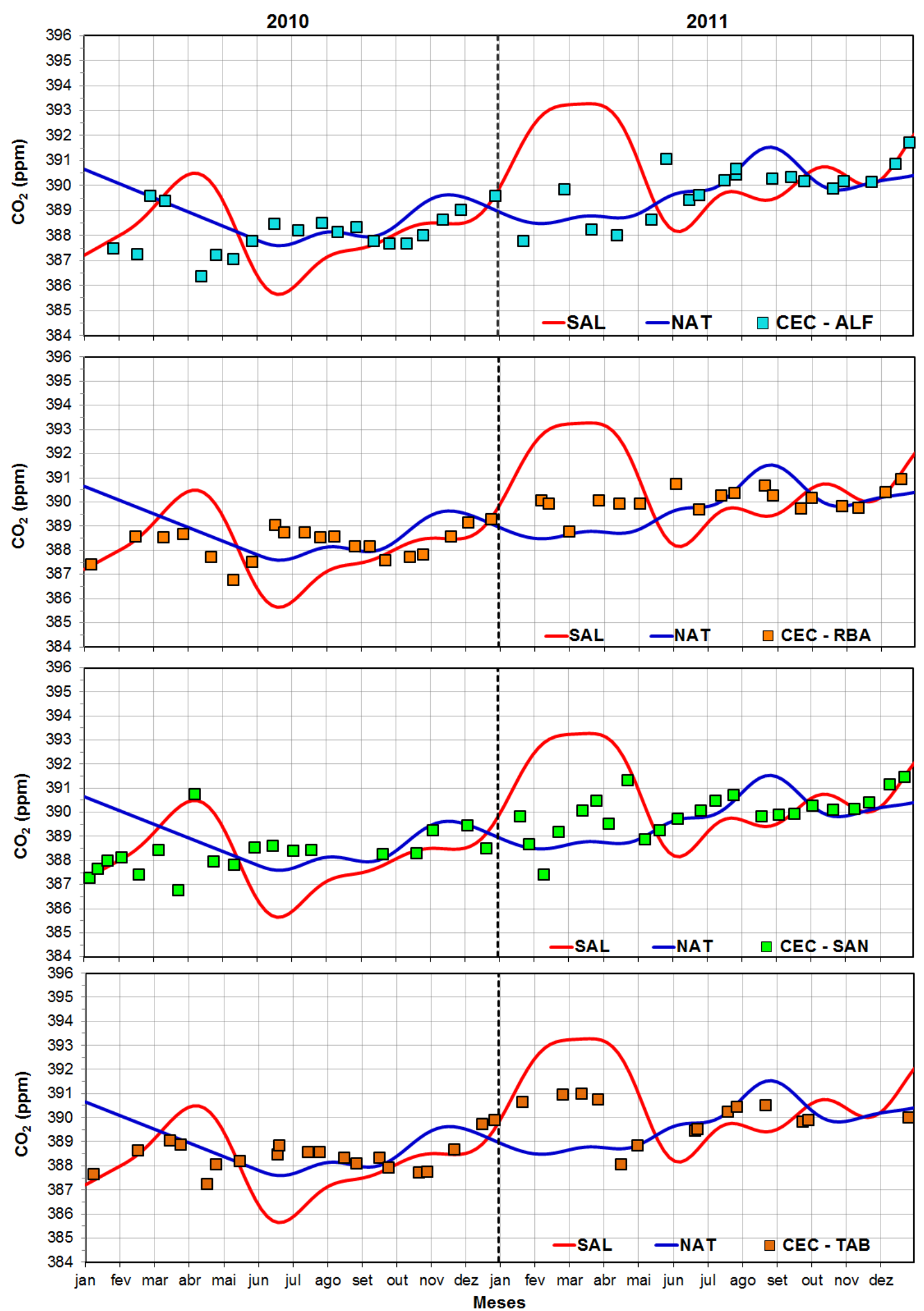

Figura 119: Comparação das concentrações de $\mathrm{CO}_{2}$ em SAL e NAT, com as concentrações de entrada no continente (CEC), para ALF, RBA, SAN e TAB. 

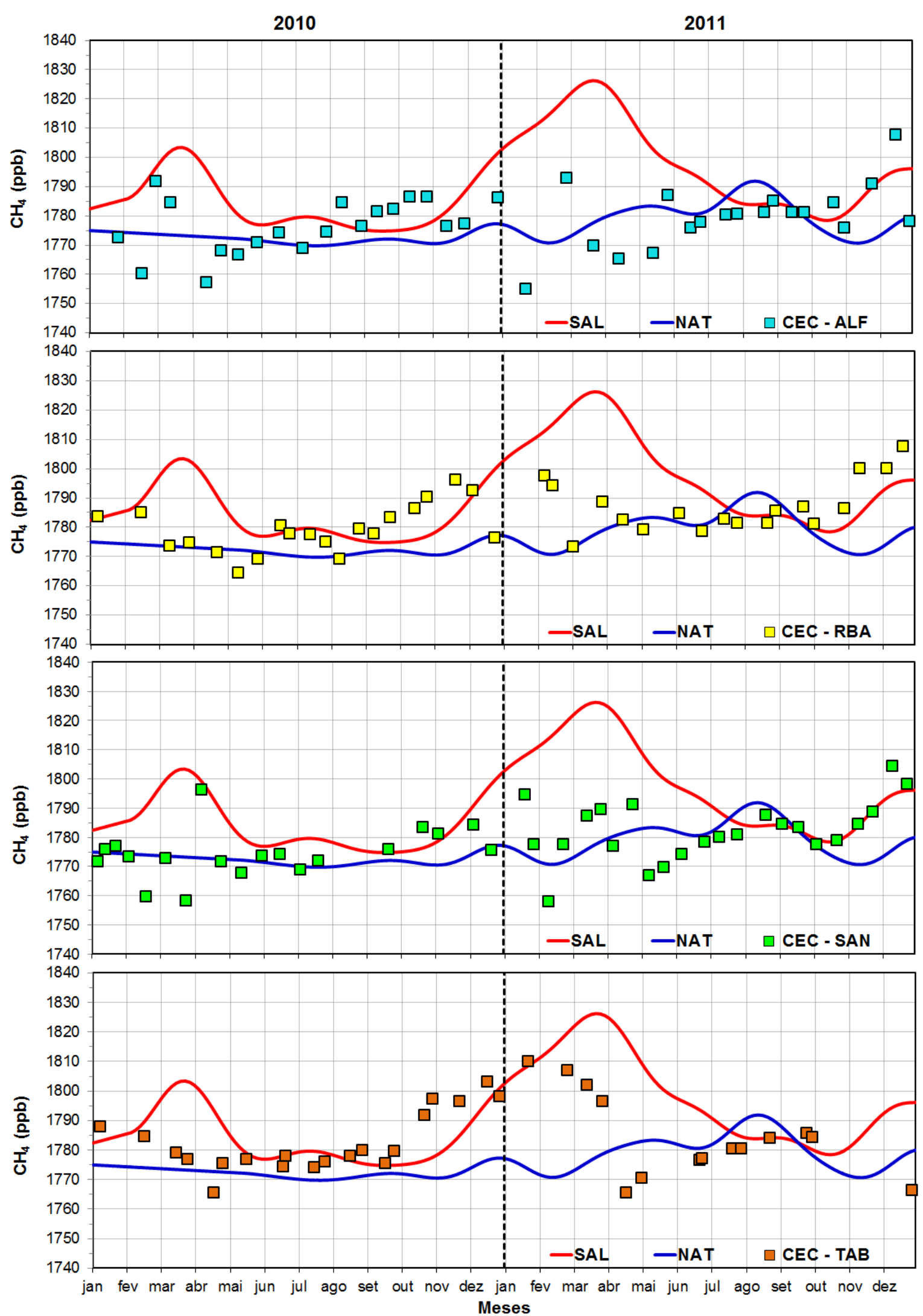

Figura 120: Comparação das concentrações de $\mathrm{CH}_{4}$ em SAL e NAT, com as concentrações de entrada no continente (CEC), para ALF, RBA, SAN e TAB. 

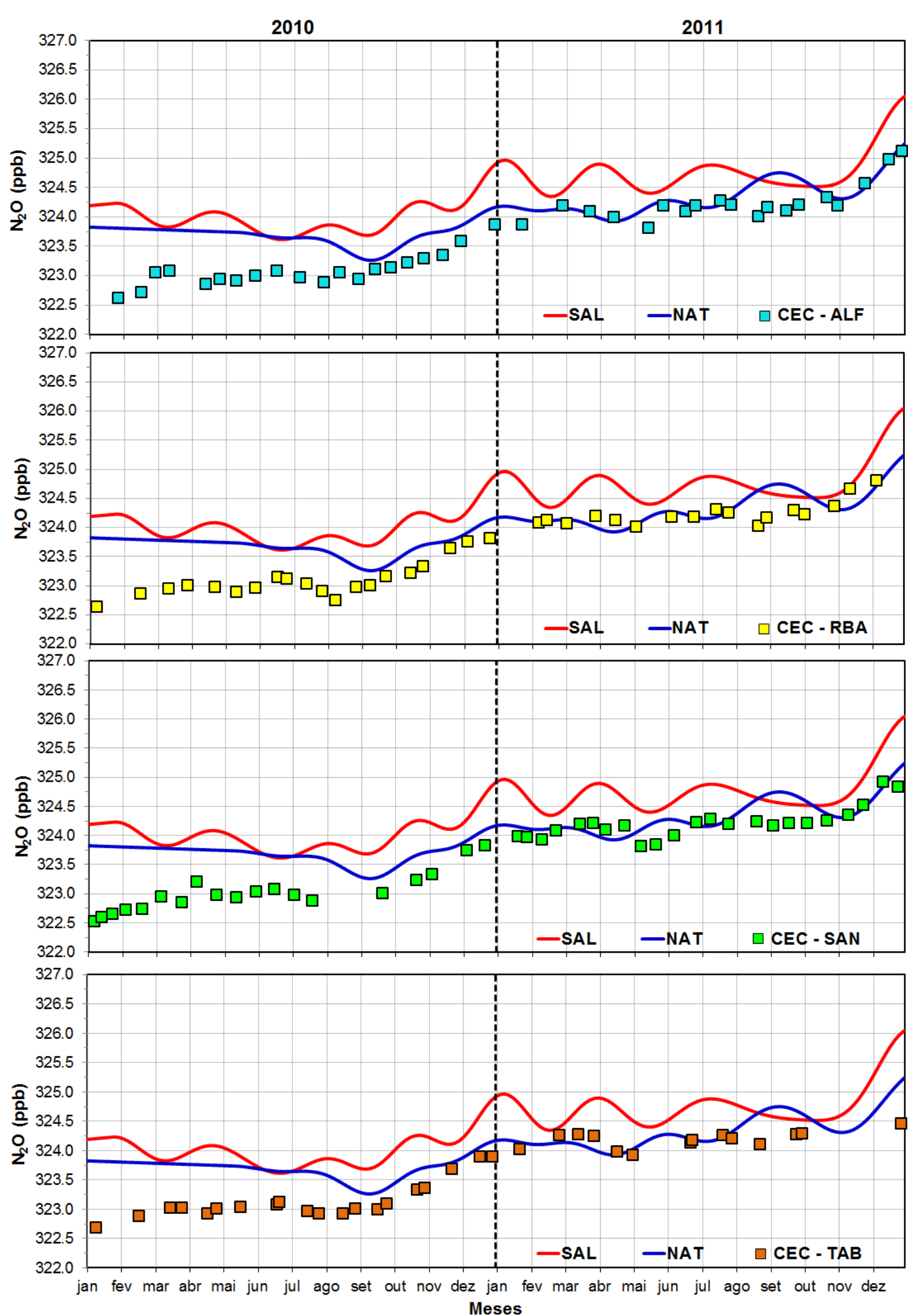

Figura 121: Comparação das concentrações de $\mathrm{N}_{2} \mathrm{O}$ em SAL e NAT, com as concentrações de entrada no continente (CEC), para ALF, RBA, SAN e TAB. 

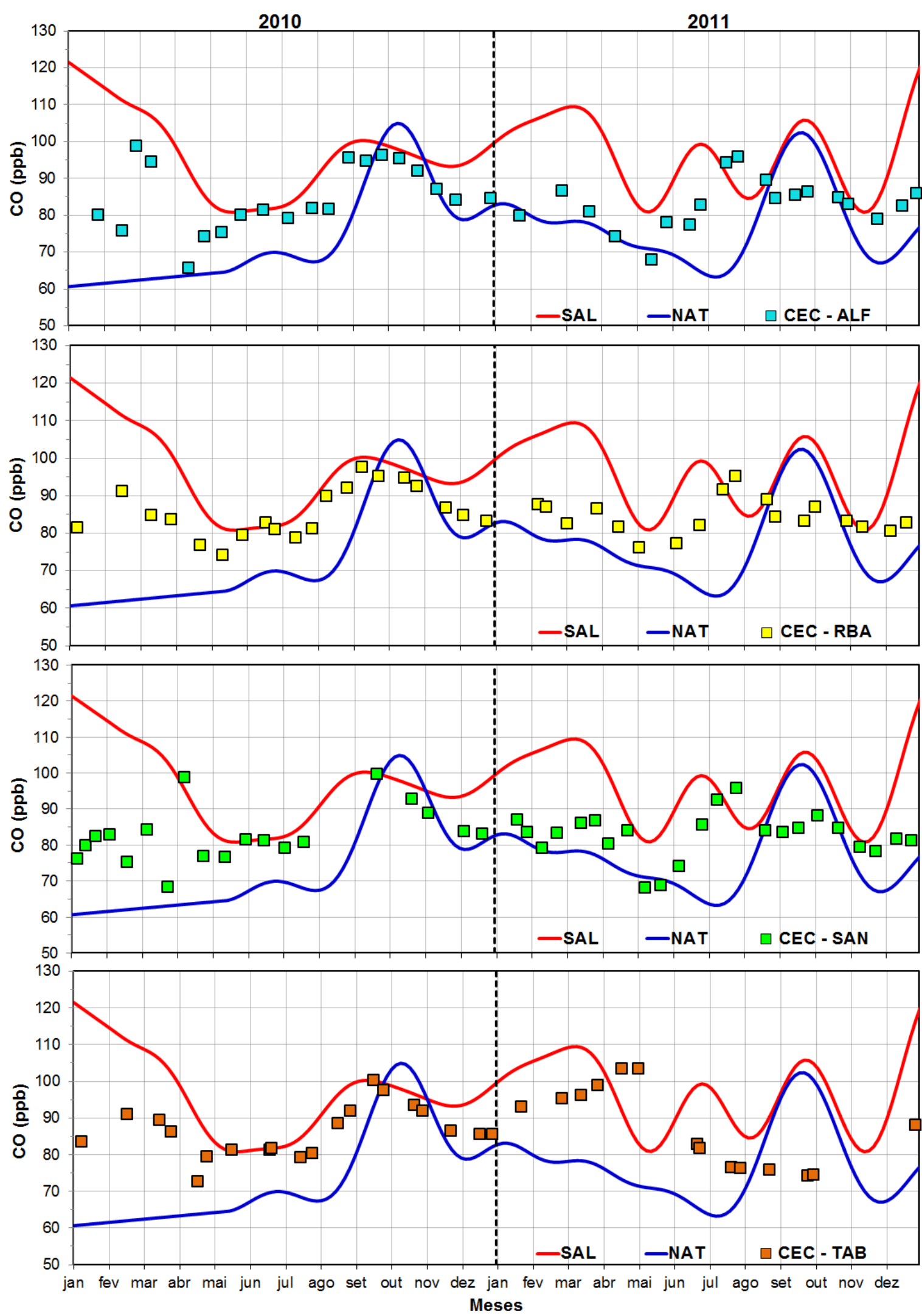

Figura 122: Comparação das concentrações de CO em SAL e NAT, com as concentrações de entrada no continente (CEC), para ALF, RBA, SAN e TAB. 
As concentrações medidas $(\mathrm{CM})$ de $\mathrm{SF}_{6}$, nos locais de coleta dentro da Bacia Amazônica, apresentaram o mesmo comportamento das concentrações medidas na Costa brasileira, como mostra a Figura 123. Porém entre janeiro a abril, as CM em RBA, SAN e TAB, estão mais próximas de SAL, devido aos locais da Bacia também receberem massas de ar do OAN neste período.

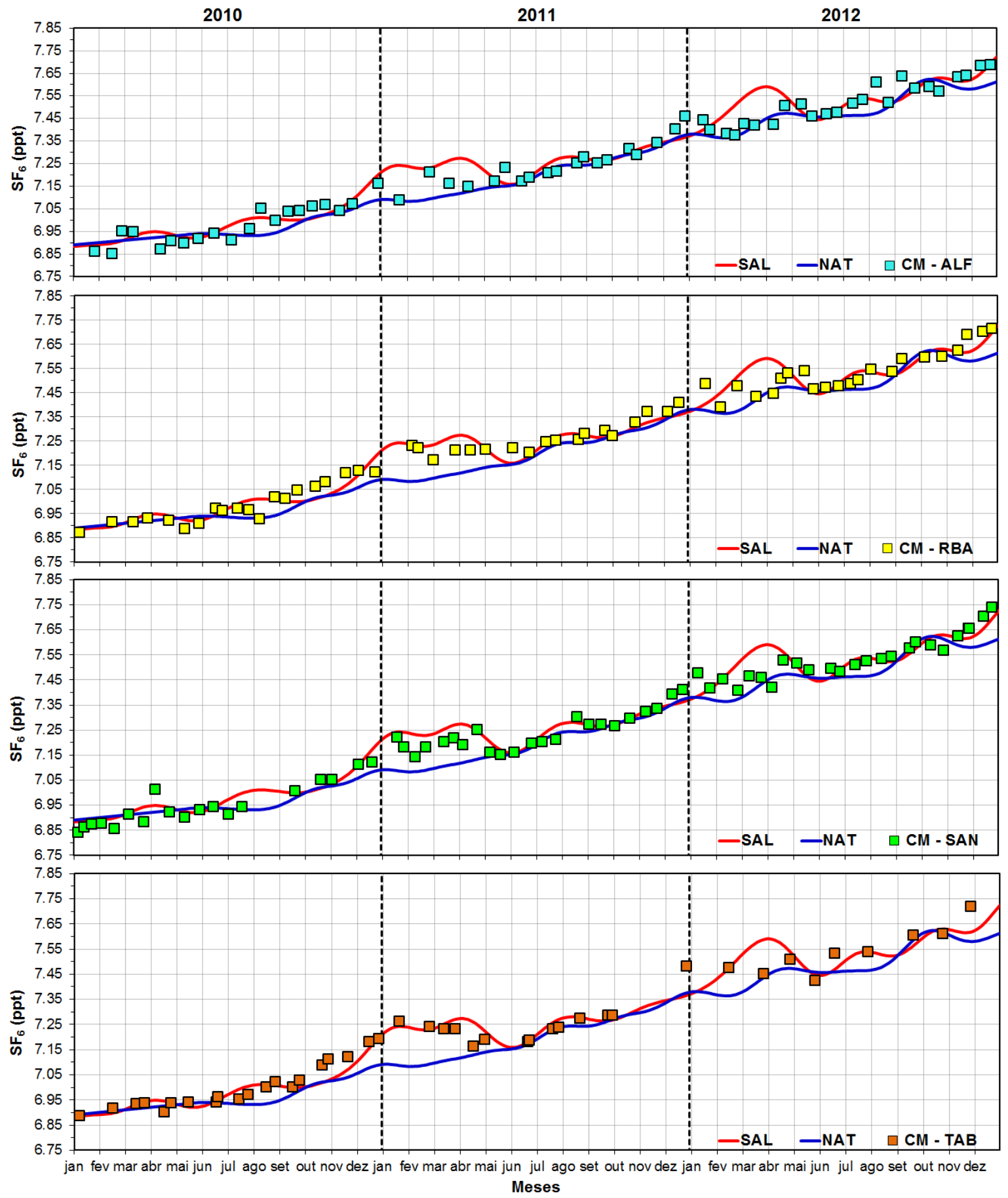

Figura 123: Comparação das concentrações de $\mathrm{SF}_{6}$ em $\mathrm{SAL}$ e NAT com as concentrações medidas em SAN, RBA, ALF e TAB. 


\section{$6 \quad$ CONCLUSÕES}

De uma maneira geral, os GEE em SAL apresentaram uma forte influência do $\mathrm{HN}$, mostrando similaridade nas concentrações observadas em uma parte significativa do ano com RPB. Isso se deve a localização de SAL, por estar próxima da linha do Equador, e desta forma, em parte do ano, as massas de ar são oriundas do HN. Já em NAT os GEE estudados apresentaram similaridade com as concentrações medidas na estação global de ASC, devido a este local receber influências apenas do HS, onde as concentrações são menores.

As simulações das trajetórias retrocedentes, possibilitaram observar como cada local de estudo é influenciado pelas massas de ar que neles chegam. Assim em SAL foi observado massas de ar provenientes tanto do OAN como do OAS, dependendo do período do ano, e em NAT foi observado apenas massas de ar do OAS, sendo este comportamento relacionado com a posição da ZCIT que sofre alterações ao longo do ano. Essas massas de ar que chegam do OAN, podem elevar as concentrações dos GEE em SAL, já que o HN possui maiores concentrações de GEE, quando comparadas ao HS.

Durante o estudo realizado na costa, vale ressaltar duas importantes observações. A primeira é que em SAL, houve processos de absorção de $\mathrm{CO}_{2}$ pelo oceano. A diminuição das concentrações deste gás coincidem com o aumento da vazão do Rio Amazonas, e portanto, ocorre um maior aporte de matéria orgânica no oceano, resultando em maior produtividade primária e, desta forma, acarretando no aumento de absorção de $\mathrm{CO}_{2}$ pelo oceano. A segunda observação é a elevação da concentração de $\mathrm{CO}$ no período da seca, sendo esta relacionada com a queima de biomassa tanto no Brasil como no continente africano, devido ao transporte realizado pelas massas de ar.

Em ambos os locais de estudo, SAL e NAT, foi observado o aumento das concentrações dos GEE a cada ano. E este aumento acompanha a mesma taxa de crescimento das concentrações globais.

As concentrações dos GEE em SAL e NAT, quando comparadas com as concentrações de entrada no continente (CEC), para os locais de coleta na Bacia Amazônica, ALF, RBA, SAN e TAB, mostraram que nenhum dos dois locais 
estudados NAT e SAL representariam bem o ano todo a CEC para estes locais, mas sim, apenas parcialmente.

A comparação dos resultados da Costa brasileira com as concentrações globais por latitude nos mostra a necessidade de se efetuar mais medidas em áreas tropicais, pois as variações observadas estão relacionadas com a insuficiência de dados nestas áreas. 


\section{REFERÊNCIAS BIBLIOGRÁFICAS}

1 MALHI Y.; MEIR P.; BROWN S., Forests, carbon and global climate, Philosophical Transactions Royal Society Lond. A, v.360, p.1567-1591, 2002

2 SEINFELD, J.H.; PANDIS, S.N., Atmospheric Chemistry and Physics: from air pollution to climate change, Ed. Wiley, $2^{\mathrm{a}}$ edição, New York, 2006.

3 BRASSEUR, G.P.; ORLANDO, J.J.; TYNDALL, G.S., Atmospheric Chemistry and Global Change, Ed. Oxford University Press, 1를 edição, New York, 1999.

4 LE QUÉRÉ, C.; ANDRES, R.J.; BODEN, T.; CONWAY, T.; HOUGHTON, R.A.; HOUSE, J.I.; MARLAND, G.; PETERS, G.P.; van der WERF, G.R.; AHLSTRÖM, A.; ANDREW, R.M.; BOPP, L.; CANADELL, J.G.; CIAIS, P.; DONEY, S.C.; ENRIGHT, C.; FRIEDLINGSTEIN, P.; HUNTINGFORD, C.; JAIN, A.K.; JOURDAIN, C.; KATO, E.; KEELING, R.F.; KLEIN GOLDEWIJK, K.; LEVIS, S.; LEVY, P.; LOMAS, M.; POULTER, B.; RAUPACH, M.R.; SCHWINGER, J.; SITCH, S.; STOCKER, B.D.; VIOVY, N.; ZAEHLE, S.; ZENG, N., The global carbon budget 1959-2011, Earth Syst. Sci., 5, 165-185, 2013.

5 LE TREUT, H.; SOMERVILLE, R.; CUBASCH, U.; DING, Y.; MAURITZEN, C.; MOKSSIT, A.; PETERSON, T.; PRATHER, M., Historical Overview of Climate Change, In: Climate Change 2007: The Physical Science Basis. Contribution of Working Group I to the Fourth Assessment Report of the Intergovernmental Panel on Climate Change. Cambridge University Press, Cambridge, United Kingdom and New York, NY, USA, 2007.

6 VENKATARAMAN, S.V.; INIYANB, S.; GOIC R., A review of climate change, mitigation and adaptation, Renew. \& Sust. Energ. Rev.,n.16,p.878-897,2012.

7 MARENGO, J.A., Mudanças climáticas globais e seus efeitos sobre a biodiversidade: caracterização do clima atual e definição das alterações climáticas para o território brasileiro ao longo do século XXI, Ed. MMA, 2 ${ }^{\mathrm{a}}$ edição, Brasília, 2007.

8 JACOBSON, M.Z., Atmospheric Pollution: history, science and regulation, Ed. Cambridge, 1a edição, United Kington, 2002.

9 SOARES, T.J.; HIGUCHI, N., A convenção do clima e a legislação brasileira pertinente, com ênfase para a legislação ambiental no amazonas, Acta Amazonica, vol. 36(4), p. 573-580, 2006.

${ }^{10}$ AHRENS, C.D., Essentials of Meteorology: an invitation to the atmosphere, Ed. Brooks/Cole Thomson Learning, 3를 edição, Canadá, 2000.

${ }^{11}$ BAIRD, C.; RECIO, M.A.L.; CARRERA, L.C.M., Química Ambiental, Ed. Bookman, 2 ${ }^{\mathrm{a}}$ edição, São Paulo, 2002.

12 STEPHENS, G.L.; LI, J.; WILD, M.; CLAYSON, C.A.; LOEB, N.; KATO, S.; L'ECUYER, T.; STACKHOUSE JR, P.W.; LEBSOCK, M.; ANDREWS, T., An update on Earth's energy balance in light of the latest global observations, Nat. Geosci., v.5, p.691-696, 2012. 
${ }^{13}$ FORSTER, P.; RAMASWAMY, V.; ARTAXO, P.; BERNTSEN, T.; BETTS, R.; FAHEY, D.W.; HAYWOOD, J.; LEAN, J.; LOWE, D.C.; MYHRE, G.; NGANGA, J.; PRINN, R.; RAGA, G.; SCHULZ, M.; VAN DORLAND, R., Changes in Atmospheric Constituents and in Radiative Forcing, In: Climate Change 2007: The Physical Science Basis. Contribution of Working Group I to the Fourth Assessment Report of the Intergovernmental Panel on Climate Change. Cambridge University Press, Cambridge, United Kingdom and New York, NY, USA, 2007.

14 SOLOMON, S.; QIN, D.; MANNING, M.; ALLEY, R.B.; BERNTSEN, T.; BINDOFF, N.L.; CHEN, Z.; CHIDTHAISONG, A.; GREGORY, J.M.; HEGERL, G.C.; HEIMANN, M.; HEWITSON, B.; HOSKINS, B.J.; JOOS, F.; JOUZEL, J.; KATTSOV, V.; LOHMANN, U.; MATSUNO, T.; MOLINA, M.; NICHOLLS, N.; OVERPECK, J.; RAGA, G.; RAMASWAMY, V.; REN, J.; RUSTICUCCI, M.; SOMERVILLE, R.; STOCKER, T.F.; WHETTON, P.; WOOD, R.A.; WRATT, D., Technical Summary, In: Climate Change 2007: The Physical Science Basis. Contribution of Working Group I to the Fourth Assessment Report of the Intergovernmental Panel on Climate Change. Cambridge University Press, Cambridge, United Kingdom and New York, NY, USA.

15 WALLACE, J.M., HOBBS, P.V., Atmospheric Science: an introductory survey, Ed. Academic Press, 2ª edição, United States, 2006.

${ }^{16}$ WMO. Greenhouse Gas Bulletins. The State of Greenhouse Gases in the Atmosphere Using Global Observations through 2008. n.5, 2009. Disponível em: $\quad<$ http://www.wmo.int/pages/prog/arep/gaw/ghg/documents/ghg-bulletin 2008 en.pdf>. Acesso: 14 set. 2010.

17 WMO. Greenhouse Gas Bulletins. The State of Greenhouse Gases in the Atmosphere Based on Global Observations through 2009. n.6, 2010. Disponível em: <http://www.wmo.int/pages/prog/arep/gaw/ghg/documents/ GHG bull 6en.pdf>. Acesso: 28 fev. 2011.

18 WMO. Greenhouse Gas Bulletins. The State of Greenhouse Gases in the Atmosphere Based on Global Observations through 2010. n.7, 2011. Disponível em: <http://www.wmo.int/pages/prog/arep/gaw/ghg/documents/ GHGbulletin 7 en.pdf $>$. Acesso: 12 abr. 2012.

19 WMO. Greenhouse Gas Bulletins. The State of Greenhouse Gases in the Atmosphere Based on Global Observations through 2011. n.8, 2012. Disponível em: <http://www.wmo.int/pages/prog/arep/gaw/ghg/documents/ GHG Bulletin No.8 en.pdf>. Acesso: 11 mar. 2013.

20 WMO. Greenhouse Gas Bulletins. The State of Greenhouse Gases in the Atmosphere Based on Global Observations through 2012. n.9, 2013. Disponível em: <http://www.wmo.int/pages/prog/arep/gaw/ghg/documents/GHG Bulletin No.9 en.pdf>. Acesso: 10 nov. 2013.

${ }^{21}$ GATTI, L.V.; Miller, J.B.; D’AMELIO, M.T.S.; MARTINEWSKI, A.; BASSO, L.S.; GLOOR, M.E.; WOFSY, S.; TANS, P., Vertical profiles of $\mathrm{CO}_{2}$ above eastern Amazonia suggest a net carbon flux to the atmosphere and balanced biosphere between 2000 and 2009, Tellus B, v.62, p.581-594, 2010.

22 MALHI, Y.E.; WRIGHT, J., Spatial patterns and recent trends in the climate of tropical rainforest regions, Philos. T. Roy. Soc. B, v.359, p.311-329, 2004. 
${ }^{23}$ CRAMER, W.; BONDEAU, A.; SCHAPHOFF, S.; LUCHT, W.; SMITH, B.; SITCH, S., Tropical forests and the global carbon cycle: impacts of atmospheric carbon dioxide, climate change and rate of deforestation, Philos. T. Roy. Soc. B, v.359, n.1443, p.331-343, 2004.

${ }^{24}$ MALHI, Y.; GRACE, J., Tropical forests and atmospheric carbon dioxide, Trends Ecol. Evol., v.15, n.8, p.332-337, 2000.

${ }^{25}$ GLOOR, M.; GATTI, L.; BRIENEN, R.; FELDPAUSCH, T.R.; PHILLIPS, O. L.; MILLER, J.; OMETTO, J.P.; ROCHA, H., BAKER, T.; JONG, B. de; HOUGHTON, R.A.; MALHI, Y.; ARAGÃO, L.E.O.C.; GUYOT, J.-L.; ZHAO, K.; JACKSON, R.; PEYLIN, P.; SITCH, S.; POULTER, B.; LOMAS, M.; ZAEHLE, S.; HUNTINGFORD, C.; LEVY, P.; LLOYD, J., The carbon balance of South America: a review of the status, decadal trends and main determinants, Biogeosciences, v.9, p.5407-5430, 2012.

${ }^{26}$ WMO. Global Atmosphere Watch. World Data Centre for Greenhouse Gases. Disponível em: <http://ds.data.jma.go.jp/gmd/wdcgg/cgi-bin/wdcgg/map_ search.cgi>. Acesso: 23 jul. 2013.

27 D'AMELIO, M.T.S.; Gatti, L.V.; MILLER, J.; TANS, P., Regional $\mathrm{N}_{2} \mathrm{O}$ fluxes in Amazonia derived from aircraft vertical profiles, Atmos. Chem. Phys., v.9, p.8785-8797, 2009.

${ }^{28}$ MILLER, J.B.; GATTI, L.V.; D’AMELIO, M.T.S.; CROTWELL, A.M.; DLUGOKENCKY, E.J.; BAKWIN, P.; ARTAXO, P.; TANS, P.P., Airborne measurements indicate large methane emissions from the eastern Amazon basin, Geophys. Res. Lett., v.34, L10809, 2007.

${ }^{29}$ WMO - World Meteorological Organization - Global Atmosphere Watch - World Data Centre for Greenhouse Gases. WMO WDCGG Data Summary, n.36. Japan Meteorological Agency em cooperação com WMO, 2012.

${ }^{30}$ WMO - World Meteorological Organization - Global Atmosphere Watch - World Data Centre for Greenhouse Gases. WMO WDCGG Data Summary, n.37. Japan Meteorological Agency em cooperação com WMO, 2013.

31 HOBBS, P.V., Introduction to atmospheric chemistry, Ed. Cambribge University Press, $1^{\text {a }}$ edição, United States of America, 2000.

32 CANADELL, J.G.; QUÉRÉ, C.L.; RAUPACH, M.R.; FIELD, C.B.; BUITENHUIS, E.T.; CIAIS, P.; CONWAY, T.J.; GILLETT, N.P.; HOUGHTON, R.A.; MARLAND, G., Contributions to accelerating atmospheric $\mathrm{CO}_{2}$ growth from economic activity, carbon intensity, and efficiency of natural sinks, PNAS, v.104, n-47, p.18866-18870, 2007.

${ }^{33}$ WMO - World Meteorological Organization. Greenhouse Gas Bulletin - The state of Greenhouse gases in the atmosphere using global observation throught 2008. Disponível em: <http://www.wmo.int/pages/prog/arep/gaw/ghg/ ghg5-online.html>. Acesso: 30 mai. 2013.

${ }^{34}$ WMO. Global Atmosphere Watch. World Data Centre for Greenhouse Gases. Disponível em: <http://ds.data.jma.go.jp/gmd/wdcgg/pub/global/globalmean. html>. Acesso: 12 dez. 2013.

35 ANDRES, R.J.; BODEN, T.A.; BRÉON, F.-M.; CIAIS, P.; DAVIS S.; ERICKSON, D.; GREGG, J.S.; JACOBSON, A.; MARLAND, G.; MILLER, J.; 
ODA, T.; OLIVIER J.G.J.; RAUPACH, M.R.; RAYNER, P.; TREANTON, K., A synthesis of carbon dioxide emissions from fossil-fuel combustion, Biogeosciences Discuss., v.9, p.1299-1376, 2012.

${ }^{36}$ UNITED STATES CENSUS BUREAU. Internacional Programs. Disponível em: $<$ http://www.census.gov/population/international/data/worldpop/table_populatio n.php> e <http://www.worldometers.info/world-population/>. Acesso: 01 ago. 2013.

37 UNITED NATIONS. Department of Economic and Social Affairs. Population Division, Population Estimates and Projections Sections (2013). Disponível em: <http://esa.un.org/wpp/unpp/panel_population.htm>. Acesso: 01 ago.2013.

${ }^{38}$ MCT, Ministério da Ciência e Tecnologia. Segunda Comunicação Nacional à Convenção-Quadro das Nações Unidas sobre Mudança do Clima, Brasília, 2010.

${ }^{39} \mathrm{MCTI}$, Ministério da Ciência, Tecnologia e Inovação. Estimativas anuais de emissões de gases de efeito estufa no Brasil, Brasília, 2013.

40 PRODES. Coordenação Geral de Observação da Terra - OBT. Monitoramento da Floresta Amazônica Brasileira por Satélite. Disponível em: <http://www.obt. inpe.br/prodes/index.php>. Acesso em: 23 out. 2013.

41 European Commission, Joint Research Centre (JRC)/PBL Netherlands Environmental Assessment Agency. Emissions Database for Global Atmospheric Research (EDGAR), release version 4.2. (2010) Disponível em: <http://edgar.jrc.ec.europa.eu/index.php>. Acesso em: 13 jun. 2012.

42 KIRSCHKE, S.; BOUSQUET, P.; CIAIS, P.; SAUNOIS, M.; CANADELL, J.G.; DLUGOKENCKY, E.J.; BERGAMASCHI, P.; BERGMANN, D.; BLAKE, D.R.; BRUHWILER, L.; CAMERON-SMITH, P.; CASTALDI, S.; CHEVALLIER, F.; FENG, L.; FRASER, A.; HEIMANN, M.; HODSON, E.L.; HOUWELING, S.; JOSSE, B.; FRASER, P.J.; KRUMMEL, P.B.; LAMARQUE, J.-F.; LANGENFELDS, R.L.; LE QUÉRÉ, C.; NAIK, V.; O'DOHERTY, S.; PALMER, P.I.; PISON, I.; PLUMMER, D.; POULTER, B.; PRINN, R.G.; RIGBY, M.; RINGEVAL, B.; SANTINI, M.; SCHMIDT, M.; SHINDELL, D.T.; SIMPSON, I.J.; SPAHNI, R.; STEELE, L.P.; STRODE, S.A.; SUDO, K.; SZOPA, S.; VAN DER WERF, G.R.; VOULGARAKIS, A.; VAN WEELE, M.; WEISS, R.F.; WILLIAMS, J.E.; ZENG, G., Three decades of global methane sources and sinks, Nat. Geosci., p.1-11, 2013.

43 SCHEUTZ, C.; KJELDSEN, P.; GENTIL E., Greenhouse gases, radiative forcing, global warming potential and waste management an introduction, Waste Manage. Res., v.27, p.716-723, 2009.

44 DENMAN, K.L.; BRASSEUR, G.; CHIDTHAISONG, A.; CIAIS, P.; COX, P.M.; DICKINSON, R.E.; HAUGLUSTAINE, D.; HEINZE, C.; HOLLAND, E.; JACOB, D.; LOHMANN, U.; RAMACHANDRAN, S.; SILVA DIAS, P.L. da; WOFSY, S.C.; ZHANG, X., Couplings Between Changes in the Climate System and Biogeochemistry, In: Climate Change 2007: The Physical Science Basis. Contribution of Working Group I to the Fourth Assessment Report of the Intergovernmental Panel on Climate Change. Cambridge University Press, Cambridge, United Kingdom and New York, NY, USA, 2007.

${ }^{45}$ BASSO, L.S., Estudo da Emissão de Metano da Bacia Amazônica 
utilizando Perfis Verticais com Avião, 2011. Dissertação (Mestrado) Instituto de Pesquisas Energéticas e Nucleares, São Paulo.

${ }^{46}$ DLUGOKENCKY, E.J.; Bruhwiler, L.; White, J.W.C.; Emmons, L.K.; Novelli, P.C.; Montzka, S.A.; Masarie, K.A.; Lang, P.M.; Crotwell, A.M.; Miller, J.B.; GATTI, L.V., Observational constraints on recent increases in the atmospheric $\mathrm{CH}_{4}$ burden, Geophys. Res. Lett., v.36, p. L18803, 2009.

47 D'AMELIO, M.T.S., Estudo de Fluxo de Óxido Nitroso $\left(\mathrm{N}_{2} \mathrm{O}\right)$ regional na Bacia Amazônica, 2010. Tese (Doutorado) - Instituto de Pesquisas Energéticas e Nucleares, São Paulo.

48 KROEZE, C.; DUMONT, E.; SEITZINGER, S.P., New estimates of global emissions of $\mathrm{N}_{2} \mathrm{O}$ from rivers and estuaries, Environmental Sciences, v.2(23), p.159-165, 2005.

49 GLOOR, M.; DLUGOKENCKY, E.; BRENNINKMEIJER, C.; HOROWITZ, L.; HURST, D.F.; DUTTON, G.; CREVOISIER, C.; MACHIDA, T.; TANS, P., Three-dimensional $\mathrm{SF}_{6}$ data and tropospheric transport simulations: Signals, modeling accuracy, and implications for inverse modeling, J. Geophys. Res. vol.112, D15112, doi:10.1029/2006JD007973. 2007.

50 RIGBY, M.; MUHLE, J.; MILLER, B.R.; PRINN, R.G.; KRUMMEL, P.B.; STEELE, L.P.; FRASER, P.J.; SALAMEH, P.K.; HARTH, C.M.; WEISS, R.F.; GREALLY, B.R.; O'DOHERTY, S.; SIMMONDS, P.G.; VOLLMER, M.K.; REIMANN, S.; KIM, J.; KIM R.K.; WANG, H.J.; OLIVIER, J.G.J.; DLUGOKENCKY, E.J.; DUTTON, G.S.; HALL, B.D.; ELKINS, J.W., History of atmospheric $\mathrm{SF}_{6}$ from 1973 to 2008, Atmos. Chem. Phys, v.10, p.1030510320, 2010.

51 PATRA, P.K.; TAKIGAWA, M.; DUTTON, G.S.; UHSE, K.; ISHIJIMA, K.; LINTNER, B.R.; MIYAZAKI, K.; ELKINS, J.W., Transport mechanisms for synoptic, seasonal and interannual $\mathrm{SF}_{6}$ variations in troposphere, Atmos. Chem. Phys. Discuss., v.8, p.12737-12767, 2008.

52 IBGE (Instituto Brasileiro de Geografia e Estatística). Cidades@. Disponível em: $\quad<$ http://www.ibge.gov.br/cidadesat/xtras/perfil.php?codmun=150620\& search=para|salinopolis> \& <http://www.ibge.gov.br/cidadesat/xtras/perfil.php? codmun=240810 $>$. Acesso em: 11 jul. 2013.

53 D'AMÉLIO, M.T.S.. Estudo de gases de efeito estufa na Amazônia. 2006. Dissertação (Mestrado) - Instituto de Pesquisas Energéticas e Nucleares, São Paulo.

54 DOMINGUES, L.G.. Estudo do papel da Bacia Amazônica na emissão/absorção de dióxido de carbono durante o ano de 2010. 2012. Dissertação (Mestrado) - Instituto de Pesquisas Energéticas e Nucleares, São Paulo.

55 DRAXLER, R.R. AND ROLPH, G.D., 2013. HYSPLIT (HYbrid Single-Particle Lagrangian Integrated Trajectory) Model access via NOAA ARL READY. Disponível em: <http://www.arl.noaa.gov/HYSPLIT.php>. NOAA Air Resources Laboratory, College Park, MD.

56 INMET - Instituto Nacional de Meteorologia. Disponível em: <http://www.inmet.gov.br/portal/index.php?r=estacoes/estacoesAutomaticas> 
57 CAVALCANTI, I.F.A.; FERREIRA, N.J.; SILVA, M.G.A.J.; DIAS, M.A.F.S., Tempo e Clima no Brasil. Oficina de Textos, São Paulo - SP, 2009.

58 BARRY, R.G.; CHORLEY, R.J., Atmosfera, tempo e clima. Bookman, Porto Alegre - RS, 9ª ed, p.512, 2013.

59 NASA's Earth Observatory, using data provided by the MODIS Atmosphere Science Team, NASA Goddard Space Flight Center. Imagery by Reto Stockli. Disponível em: <http://neo.sci.gsfc.nasa.gov/view.php?datasetld=MODAL2_M_ CLD_FR\&year=2013>. Acesso em: 12 ago. 2013.

60 TERNON, J.F.; OUDOT, C.; DESSIER, A.; DIVERRES, D., A seasonal tropical sink for atmospheric $\mathrm{CO}_{2}$ in the Atlantic ocean: the role of the Amazon River discharge, Marine Chemistry v.68, p.183-201. 2000

61 SUBRAMANIAM, A.; YAGER, P.L.; CARPENTER, E.J.; MAHAFFEY, C.; BJORKMAN, K.; COOLEY, S.; KUSTKA, A.B.; MONTOYA, J.P.; SANUDOWILHELMY, S.A.; SHIPE, R.; CAPONE, D.G., Amazon River enhances diazotrophy and carbon sequestration in the tropical North Atlantic Ocean, PNAS, v.105, n.30, p.10460-10465, 2008.

62 FRATANTONI, D.M.; GLICKSON, D.A., North Brazil Current Ring Generation and Evolution Observed with SeaWiFS, J. Phys. Oceanogr., v.32, p.10581074, 2002.

63 GLOOR,M.; BRIENEN, R.J.W.; GALBRAITH, D.; FELDPAUSCH, T.R.; SCHÖNGART, J.; GUYOT, J.-L.; ESPINOZA, J.C.; LLOYD, J.; PHILLIPS, O.L., Intensification of the Amazon hydrological cycle over the last two decades, Geophys. Res. Lett., v.40, p.1-5, doi:10.1002/grl.50377, 2013.

64 NIKIEMA, O.; DEVENON, J.-L.; BAKLOUTI, M., Numerical modeling of the Amazon River plume. Cont. Shelf Res., v.27, p.873-899, doi:10.1016/j.csr.2006.12.004, 2007.

${ }^{65}$ ACKER, J.G.; LEPTOUKH, G., "Online Analysis Enhances Use of NASA Earth Science Data", Eos, Trans. AGU, v.88, n. 2, p.14,17, 2007. Disponível em: < http://gdata1.sci.gsfc.nasa.gov/daac-bin/G3/gui.cgi?instance_id=ocean_month\& selectedMap=Blue\%20Marble\& >. Acesso em: 22 out. 2013.

66 SEKARAN, U. Research methods for business: a skill-building approach, Ed. John Wiley \& Sons, Inc, 4a edição, EUA, 2003.

67 ODUM, E. P., Ecologia, Ed. Guanabara, 1aㅡ edição, Rio de Janeiro, 1988.

68 EKAU, W.; KNOPPERS, B., An introduction to the pelagic system of the Northeast and East Brazilian shelf, Arch. Fish. Mar. Res., 47(2/3), p.5-24. 1999.

69 NASA's Earth Observing System Data and Information System (EODIS), Fire Information for Resource Management System (FIRMS), Global Fire Maps. Disponível em: <https://earthdata.nasa.gov/data/near-real-time-data/firms/active -fire-data\#tab-content-7>. Acesso em: 02 nov. 2013. 